D LIPE

JDWARI SIEI? FLSS
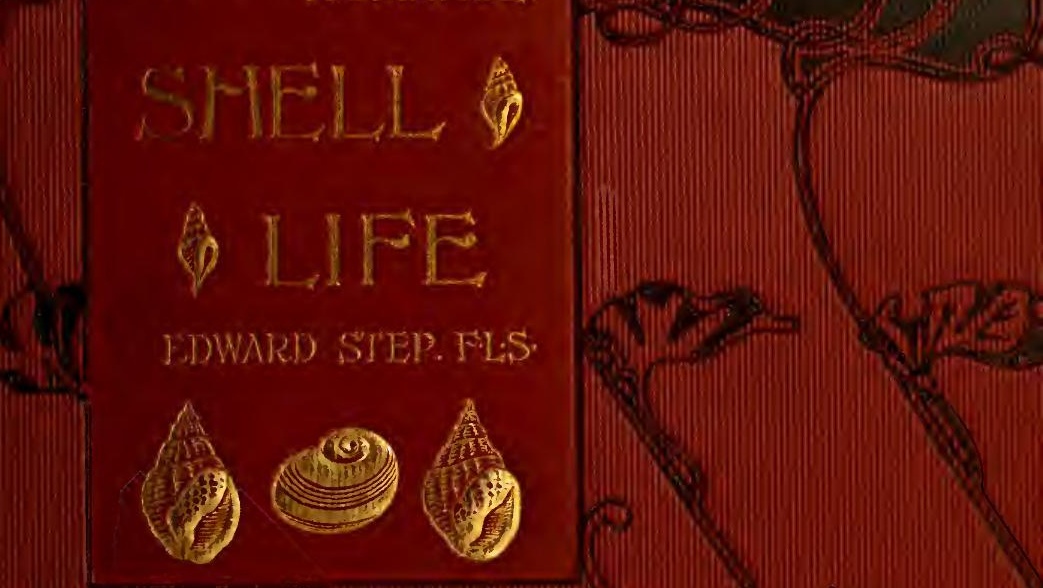

(1)
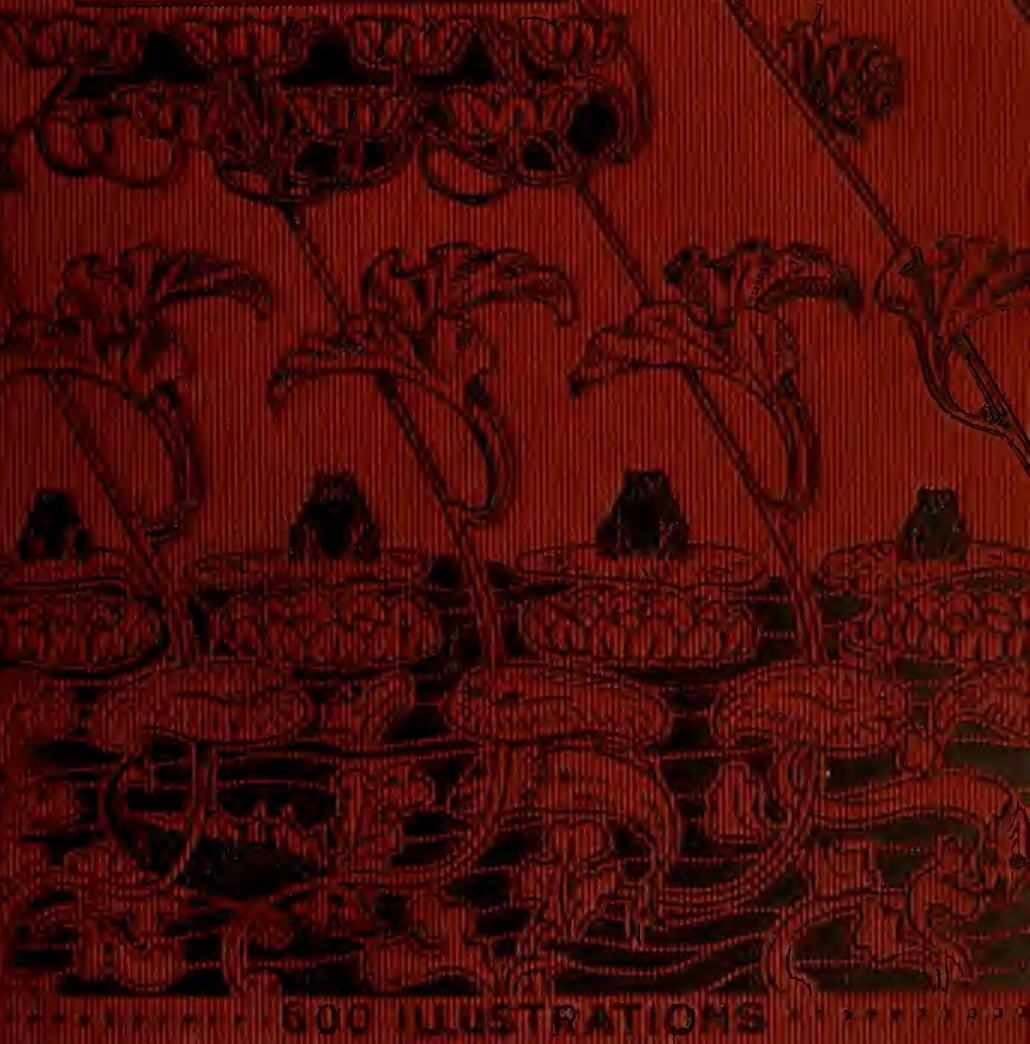


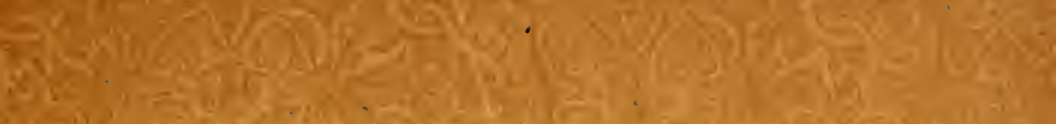

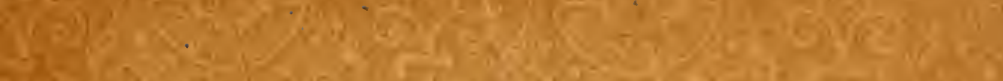

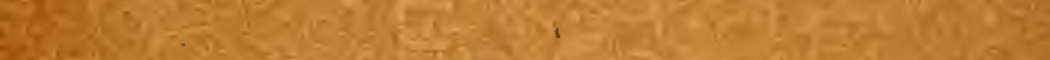

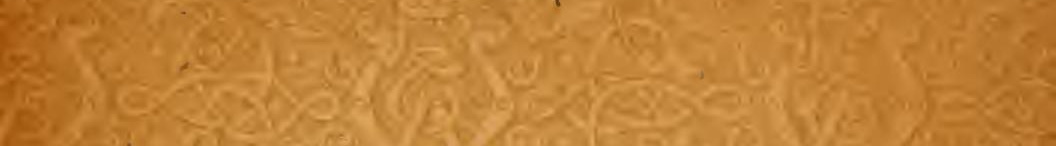

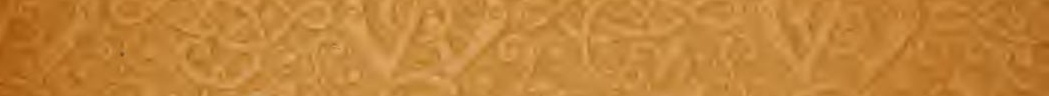

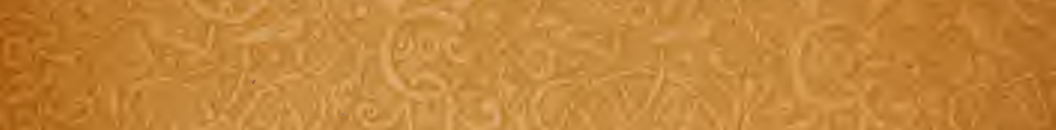

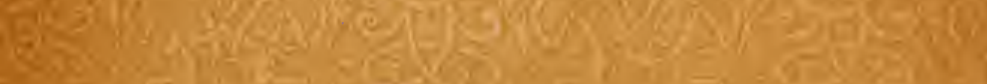
18.

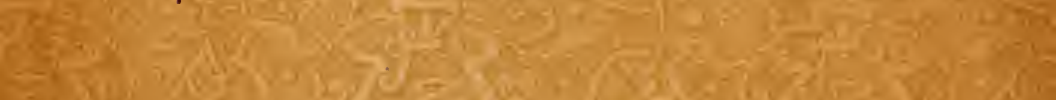

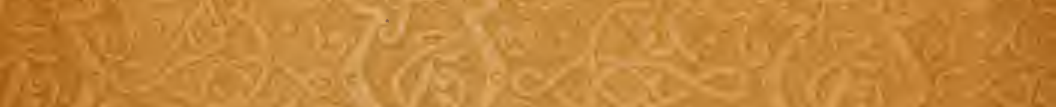

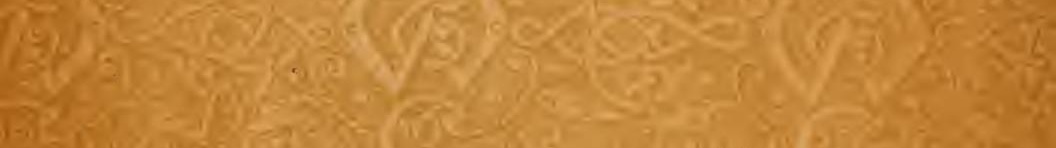

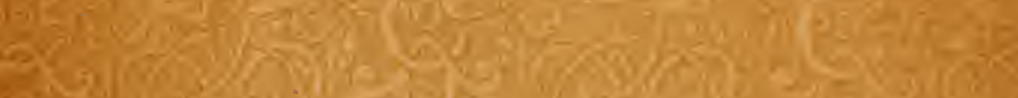
3.5. ST:

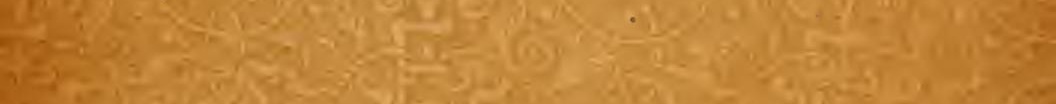

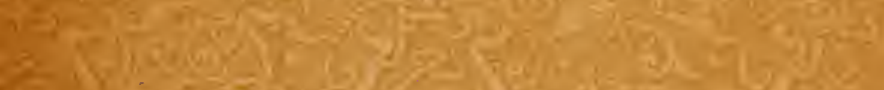
1.2. 1. ,

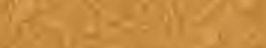




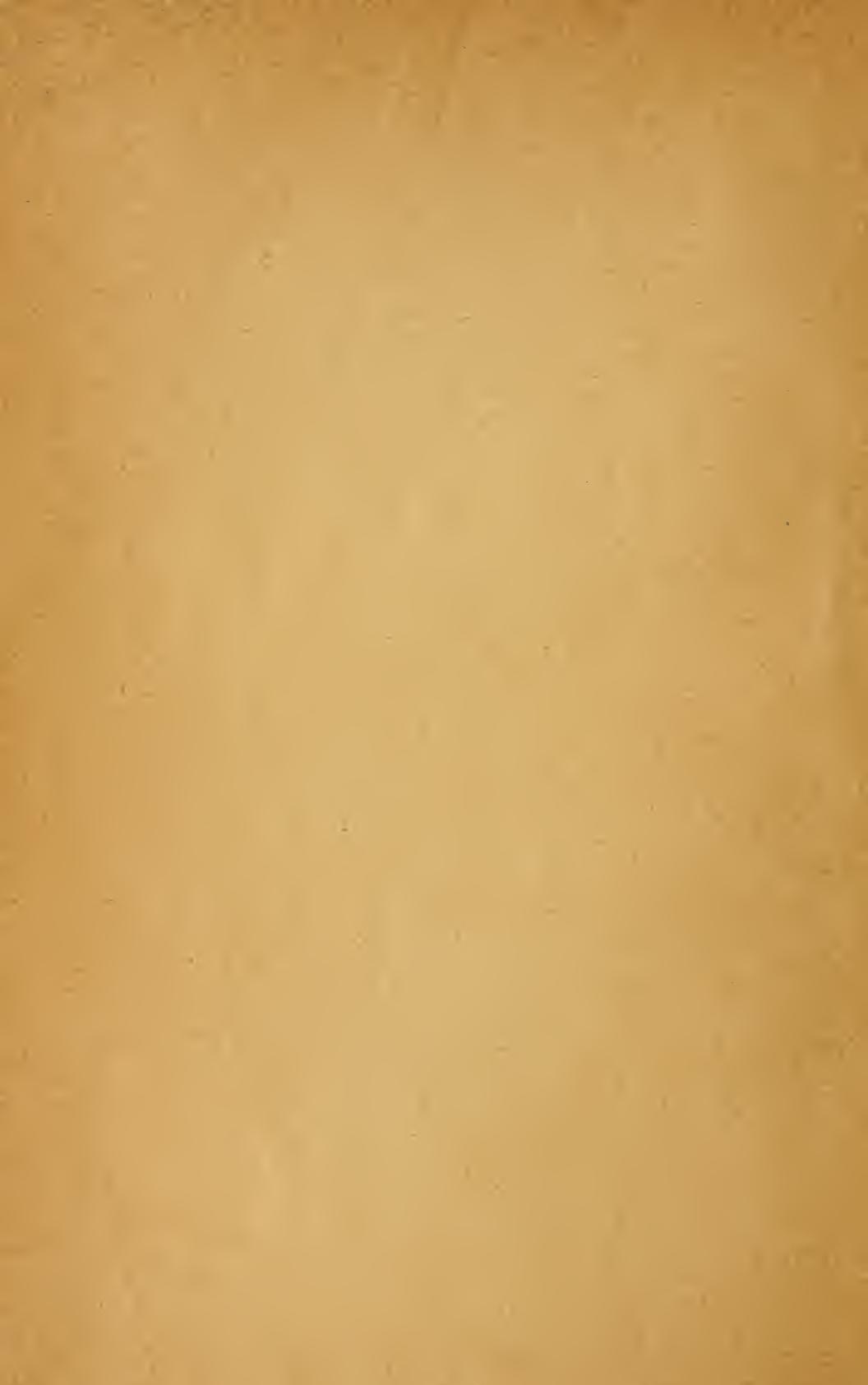




\section{THE LIBRARY OF NATURAL HISTORY ROMANCE.}

\section{The Romance of Wild Flowers. A}

Companion to the British Flora. By Edward Step, F.L.S., author of "Favourite Flowers of Garden and Greenhouse," "Wayside and Woodland Blossoms," \&c. In crown $8 \mathrm{vo}$, cloth gilt, gilt top, price 6s.

This volume (No. 1) contains upwards of 200 Original Illustrations by M. E. Step, T. Carreras, and the Author, of which 32 are full-page plates, finely printed in tints from photographs taken from Nature expressly for the work.

Love of the country, which steadily grows upon our ever-increasing town populations since they have taken to cycling, is largely mixed up with an interest in the animal and vegetable life of moorland, wood, and seashore. To aid in the identification of these creatures there are numerous admirable Floras and Text-books, which give the structural details with brevity and technical precision. Unfortunately, such literature only encourages the enthusiast, whilst it repels all others.

The Library of Natural History Romance is projected, not for the enthusiastic specialist, but for the others-the readers who do not want to be told that a certain organ or creature is of such a shape, but why it is so formed. Structure will be indicated plainly, but the reason for that structure and its relation to the creature's habits and mode of life will be brought out strongly. The volumes will really aim at imparting the most interesting facts of Natural History in the most interesting manner, to which end the pencil and the camera will be freely used to assist the pen. "No one is better qualified to write a popular book on the British flora than Mr. Edward Step. He is the guide, counsellor, and friend of every field club, and his knowledge, gained as it is from Nature herself rather than from the library or the class-room, is placed before the unscientific reader in just such a form as he or she can easily comprehend. Print, illustrations, and text are alike excellent, and this library should appeal to every lover of the country."-Pall Mall Gazette.

Chandos House, Bedford Street, Strand, London 


\section{Frederick Warne Eे Co.'s Publications}

\section{HOW TO KNOW AND WHERE TO FIND THE WILD FLOWERS.}

\section{Wayside and Woodland Blossoms.}

First and Second Series. Pocket Guides to the British Wild Flowers for the Country Rambler. By Edward Step, author of "Favourite Flowers of Garden and Greenhouse," \&c. In pocket-book form, size $6 \frac{1}{2}$ by $4 \frac{1}{2}$ ins., in neat art linen gilt, limp binding, round corners, price $7 \mathrm{~s} .6 \mathrm{~d}$. each; or in best French morocco tuck, gilt edges, with expanding Pocket for Notes, Specimens, \&c., price Ios. 6d. each.

The purpose of these volumes is to assist a very large and increasing class of persons who possess a strong love of flowers, but to whom the ordinary "Floras" are as books written in an unknown tongue. 'The author's aim has been to write a work that, whilst it satisfied the rambler who merely wishes to identify the flowers of his path, might also serve as a stepping-stone to the "Floras" of Hooker, Bentham, and Boswell-Syme.

Each volume contains over 120 coloured plates, portraying about 156 species, drawn direct from nature; among them representatives of all the best-known genera will be found. There are also several black and white plates, and upwards of 400 species are clearly described in the text.

Mr. Britten, writing of the First Series in Nature Notes, said- "Mr. Step has condensed the best observations into a small compass, and his little volume is greatly in advance of every previous undertaking. It will add very slightly to the bulk of the most restricted arrangement of luggage, and forms an admirable pocket companion for the lover of wild flowers. . . . In it the reader will find much to learn and very little to unlearn, and we know of no other that can be so unreservedly recommended to the tyro in British Botany."

"This is just the little book which every true lover of that particular phase of natural beauty-namely, wild flowers-delights to find in his pocket when rambling along country lanes. The delicately-tinted illustrations are absolutely true to their growing counterparts."-Liverpool Mercury.

"It is an excellent book, which will be welcomed alike by the more learned in flower lore and by the beginner who would be more fully versed in the evolutions of woodland and wayside life."-Sheffield Daily Telegraph.

\section{Ghandos House, Bedford Street, Strand, London}


.... The Library

of Natural History

..... Romance

\section{SHELL LIFE}

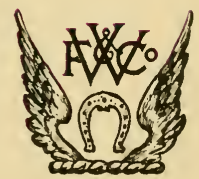





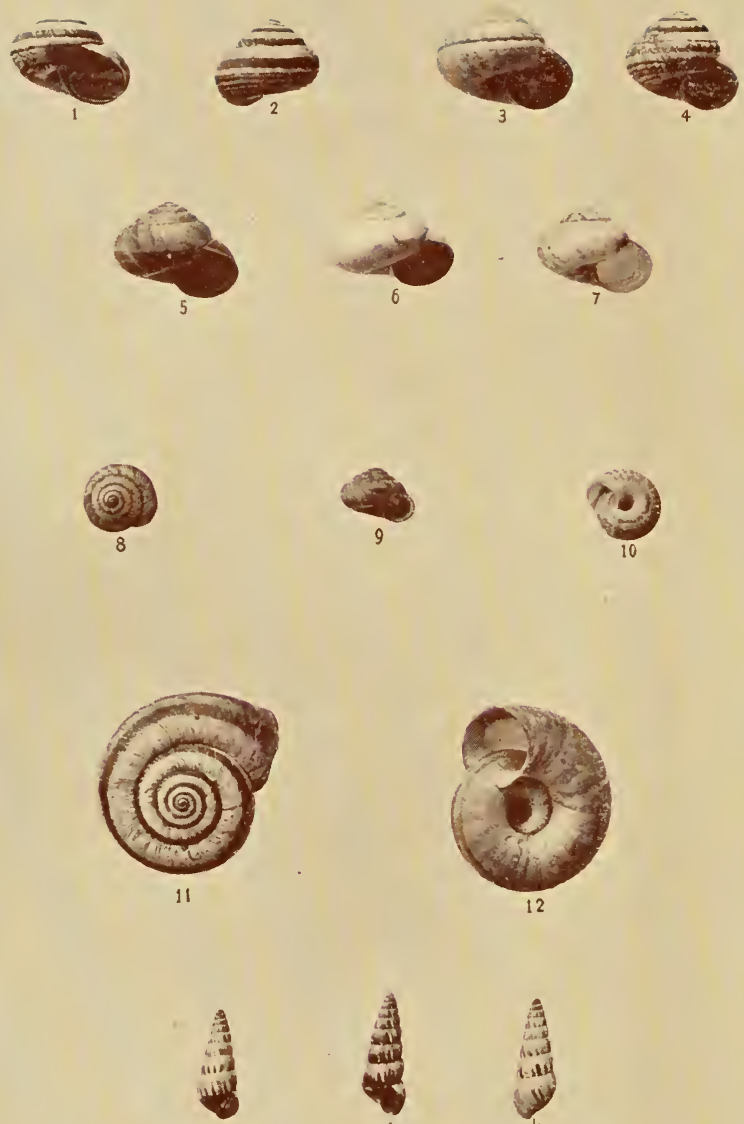

13
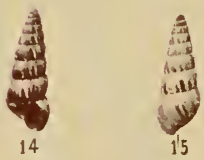

I TO 7 B.nded Snail; 8 to io Wrinkled Snall, it, i2 Heath Snail.; I3 TO I5 Polnted SNaII.. 


\title{
BRITISH MOLLUSCA
}

\author{
BY \\ EDWARD STEP, F.L.S. \\ AUTHOR OF \\ "FAVOURITE flowers of GaRden AND GREenhouse" \\ "WAYSIDE AND WOODLAND BLOSSOMS" \\ "THE ROMANCE OF WILD FLOWERS" ETC. ETC.
}

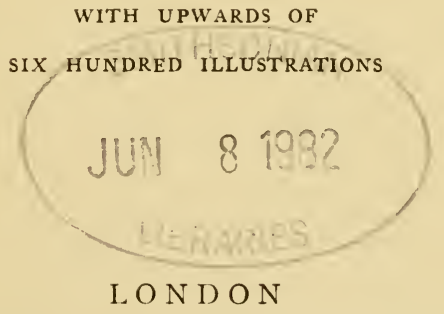

FREDERICK WARNE \& CO.

A N D NE IV YORK

I 90 I 
Smar.Int 


\section{P R E F A C E}

THE object of this work is much the same as that 1 which led to the writing of its companion volume The Romance of Wild Flowers - to awaken an interest in, and lead to a closer study of, the creatures described. Shells and their makers, of course, necessitated a different kind of treatment from that accorded to the wild flowers; but the author's plan of making his readers first acquainted with the outstanding characteristics of the prevailing types of structure as emborlied in such familiar forms as the snail, the mussel, and the cuttle, will enable them to follow him throughout the further chapters.

It is not pretended that this volume will enable the reader to determine the exact species of all the native mollusks that may come under his notice; but it is hoped he may get from it an intelligent idea of the sub-kingdom so far as it is represented in these islands, and may be assisted in discriminating between most of those commonly encountered in the woods and lanes, by the pond and stream, or along the seashore. Of the seven hundred and fifty species of Mollusca indigenous in the British Islands and the adjacent seas, no less than six hundred and fifty species have been briefly described in these pages. Butitid not as at 
shell - collector's handbook that the volume is sent forth; rather to suggest the consideration of these creatures as living organisms, whose diversity of form and structure has intimate relation to their mode of life, the persecution of enemies, and other factors in the struggle for existence-though some of us are at times too apt to regard such differences as being dictated by the needs of the classifying naturalist. In accordance with this intention, so far as was compatible with the necessity for producing a volume of handy size, attention has been directed to those habits and external influences that may reasonably be considered to have brought about modifications of form and colour, protective resemblances, and so forth.

A few words may be added as to the system upon which the Genera, Families, and Orders have been grouped (see Appendix). In this matter I have mainly followed the plan adopted by the Rev. A. H. Cooke, M.A., in his admirable "Molluses" (Cumbridge Nutural History, vol. iii.), which is likely to long remain the standard text-book. The reader who desires to enter upon the wider and deeper study of this branch of Nature will thus experience no difficulty in expanding his elementary acquaintance with our local fauna into a fuller knowledge of the Mollusca of the world. 


\section{O N T E N T S}

\section{INTRODUCTORY}

Materials for the study of Mollusks elose at handGarden Snail and its shell-Swan Mussel and Common Mussel-Common Sepia or Cuttle-Types of three principal classes of Shell-life . . . . . .

\section{THE SHELL AND ITS FORMATION}

Shellfish a misnomer-Some Mollusks without shellsThe primitive shell-Importance of the conical form to shore-dwellers-Form of shell determined by habit of Mollusk-Comparisons between the shells of shallow and deep water, rock and sand--The door of the shell-The Oyster a degenerate-Thin shells of pelagic species-Thinness of fresh-water shells-Land-snails-Shells of Shing and Cuttles undereloped or absent . . . .

\section{FEEDING AND BREATHING}

Oyster, though headless, has a mouth-Bivalves all tongueless-Cuttles' bird-like beak-The Snail's wonderful tooth-ribbon, and thousands of teeth-Powerful gizzardsLungs and gills-Air-breathers and water-breatlers-The molluscan heart and circulation-Blood mostly colourless .

\section{SEEING, HEARING AND SMELLING}

Sense organs of Mollusks differ from those of higher animals - Decentralisation of sense impressions-Local brains-Nerve-threads, commissures, and ganglia-Eyes and eye-spots-Stalked-eyes, internal eyes, and vanished eyes --Evolution of the molluscan eye-The Argus-eyed Scallops -The Saddle-oyster's sense of hearing-Otocysts and Otoliths--Sense of smell more important than sight or hearing - Whelk's keen scent-Slug's sense of locality-A strange form of nose-Sense of touch acute . . . 


\section{NUT-SHELLS AND MUSSELS}

Bivalve shells-Nut-shells-The "foot" of a burrower in gravel-How the valves are kept closed-Hinges, lockingteeth, and bands of muscle-Leda-shells-Long siphons denote a deep burrower-Microscopic food of bivalvesSaddle-oysters and their attachment-plug-Noah's ArkDog-Cockle-Eared Limopsis-Common Mussel-Its value for food and bait-Gregarious-Its byssus, or mooringropes-Mussels as foreshore conservators-The legend of Bideford Bridge-Horse Mussels and their crab companion -Crenellas

\section{OYSTERS AND SCALLOPS}

Fan Mussels and Pea-crab-The Oyster : its personality - The parent of millions-Their infantile activity and later laziness_-" Natives" and " (rreen Oysters"-Enemies of the Oyster-Scallops-Their flight through the seaPurpose of the ribs and "ears"-The Quin as butterfly of the sea-File-shells . . . . . . .

\section{HEART-COCKLE AND FRESH-WATER COCKLES}

Astarte-shells-Hinge-teeth and their relation to habit of Mollnsk-Another reason for rils-Burrowing feetIceland Cyprina-Heart-Cockle-Lucina and Hatchetshells-Double-tooth-Urchin-shell-A strange attachment -Kelly-shells-Shell-collecting from fish stomachs : a big hanl-Coin-shells and Crustaceans-A bivalve scavenger -The Weasel's-eye : its strange use of shell-Fresli-water Cockles and their climbing ropes-Pea-shells-Fresh-water Mussels: their probalble origin-British pearls and pearl fishery-Swan Mussels-The Zebra Mussel and its strange history .

\section{WEDGE-SHELLS, VENUS-SHELLS, AND COCKLES}

Tellins-Mud burrowers-Furrow-shells-Wedge-shells with milled edges-Trongh-shells-Circe and ArtemisSmooth Venus, our most massive native-Toothed edges 
not requisite-The Clam-Food and money-Carpet-shells PAGE -The Pullet-Rock Venus-liock-borers-Red Nose-A nolluscan lieigehog-Various Cockles-Common Cockle .

\section{GAPERS, PIDDOCKS, AND SHIPWORMS}

Shells that will not shut-Sunset-shells-Old Maid, a mud dweller-Its remarkable siphons, always extendedBasket-shells-Otter-shells or "Clumps"-Eaten in Herm -Razors of sorts-Why the hinge is not central-Razors not so sharp as mussels-Saxicava-Flask-shell-Piddocks -How rocks are broken up-Multivalve shells-Paper Piddocks-Wood Piddock-Ship-worms-How wreckage is disposed of-Pandora-Lantern-shells-skye Gaper

\section{TUSK-SHELLS, MAII-SHELLS, AND LIMPETS}

Elephant's - tusk-A connecting link-Mail-shells-A shell of plates-Tortoiseshell Limpets-Other LimpetsCommon Limpet and its stronghold-How it adheres-Its excavating powers-Its homing habit-Blue-rayed Limpet: its two forms-slit-linpets and Keyhole-limpets-Ormer or Sea Ear-Its perforated shell

\section{TOP-SHELLS AND PHEASANT-SHELL}

Dolphin-shells-Umbilicus and operculum-Top-shells -Pheasant-shell-A tiny gem-Fresh-water Nerite-Probable origin from a marine form

\section{NECKLACE-SHELLS AND WINKLES}

Violet Sea-snail and its egrg-raft-Eyeless derelictsWentletraps or Staircase-shells-A forty-guinea shellAclis-shells-Necklace-shells and their strange egg-bancls -How shells are rednced-Marsenia : a snail that is seen through-Protective resemblance-Velvet-shell - Bonnet Limpets-Hungarian Cap-Cup-and-Saucer LimpetA quaint interior-Winkles-Dwarf Winkle and its resemblance to bladders of Fucus-Rough Winkle-Is it becoming a land-snail ?-An object-lesson in erolutionPeriwinkle-Chink-shells 


\section{SPIRE-SHELLS AND MARSH-SNAIIS}

Round-monthed Snail-A sea-snail that has left the sea -Evidenees of its origin-Its shell door-Its enemy, Drilus -Point-shell-Spire-shells-Rissoas and Hydrobias-Small and numerous - Fresh-water Winkles - Sentinel-shellsBelted shell-Marsh Snails or River Snails-ViviparousValve-shells

\section{COWRY AND PYRAMID-SHELLS}

Small Needle-whelk-"Shillifillies "-Horn-shells-_The Reversed Horn-Obelisk-shell-Serew-shell or Auger-A snail that deliberately breaks its shell-Strange history of the Blind-shell-Pelican's-foot-Cowries-Another objectlesson in s':ell-evolution-Margin - shell-Poached EggProtective ornamentation-European Cowry-Atlanta

\section{WHELKS AND CONELETS}

Some toothless sea-snails-Polished Eulima-Of parasitic descent-Urchin Snail-A strange habitat-Pyramidshells by the score-The teeth of the Whelk familySpindle-shells-Why a siphon is needed-Sting-winklesVarices or growth lines: what they indicate-Why oysters are scarce-The Purple and its dye-How it clings to wavewashed rocks-Its stony shell-How the Star-fish eats it out of house and home-Its singular egg-capsules-Dogwhelks-Despoilers of bait-Spindle-shells-Red Whelk or Buckie-White Whelk-Common Whelk-Varieties and monsters-Egg capsules-Keen scent-Money value of a Whelk "fishery"-Least Whelk-Conelets .

\section{SEA-SLUGS}

Darwin's mistake about Sea-slugs-How shells have been discarded-Actreon and Bubble-shells-Snail crushers -Canoe - shells - Blind burrowers - Shells hidden and thinned-Lobe-shell-Sea Hare-A reputed depilatoryIts colour changes-Its purple clouds-The true Sea-slugs -Pleurobranchus - How enemies are discouraged - The origin of foot-lobes-Crowned Runcina-Cerata and their functions-Sea Lemons-Resemblance to sponges-Sense- 
organs and gill-leaves-Venus Slug mimics anemonePAGE Crested Slug-Declined by fishes-Homberg's TritonDeveted to Deadman's Fingers-Gulf-weed Slug-Carrying one's liver outside - Bushy - backed Slug-Disguise a necessity-Crowned Sea-nymph-Marbled Slug-Plumed Eolis-Mimies Sagartia-Alder's Eolis-Green EolisDespised Eolis: a spectral slug-Embleton's Eolis-A variety that has taken to fresh water-Other EolidsCrowned Eolis : an anemone eater-Hermeas, Crimson and Green-Food and shelter combined-Alder's Slug-Green Elysia-Falmouth Slug-Pteropods .

\section{POND-SNAILS}

Lung breathers-Stalked-eyes and sessile eyes-Hermaphrodites-Herald-shell-Mouse-eared Alexia-Little Earshell-Fresl-water Limpets-Great Pond-snail-A general feeder-Its development affected by size of pond-Marsh Limnaca-Dwarfed Limniea: a wet-nurse for the Liver Fluke-The evolution of Sheep Rot-Tennyson and Nature -Smooth Pond-snail-Ear P'ond-snail-Wandering Pondsnail-Glutinous Snail - Involute Snail-Flat-coils or Trumpet-snails-The Ram's-horn-A small snail in a large house-Twisted Trumpet-snail-Other Trumpet-snailsAn American visitor-Bladder-snails-MIoss Bladder-snail .

\section{LAND-SLUGS AND GLASS-SNAILS}

Unpopular suljects-Not all Slugs are harmful-Slugs with shells and without-Carnivorous Slug-A foe to earthworms-Great Grey Slug-Its liking for sculleries and dairies-A taste for cream and lamb-A taster of booksTree Slug-Yellow Slug-Field Slug-A destroyer of seedlings and (reputed) consumption cure - Smooth SlugKeeled Slug-Small Black Slug-Glass-snail-Simroth's theory of Slug origins-Draparnaud's Snail-Cellar Snail -Garlic Snail-Other Glass-snails-Love darts

\section{LAND-SNAILS}

More Slugs-Large Black Shug-Fondness for fruit-A very mixed feeder-Dusky Slug - Garden Slug-Spotted Kerry Slug - Twenty-five Helices - Dwarf Snail - The 
reward of patient seeking-Rock Snail-liounded SnailStone-turning and leaf-sifting-Beautiful Snail-Prickly Snail-A climber of trees and a parachutist-Plated SnailCheese Snail-A relic of the ancient forests-Lapilary Snail - Bristly Snail - Ruddy Snail-A weakness for strawberries -Silky Snail-Green Hairy Snail-Dusky Snail-Kentish Snail-Carthusian Snail-Copse Snail-Knew the way to the tap-Sandlhill Snail-A probable alien-Banded Snail -Snail-showers-'The flavour of Down mutton-Sheepsnails-Heath Snail- Wrinkled Snail - Theorising on a false basis - Pointed Snail-Brown-lipped Snail - Its wonderful variation - White-lipped Snail_-Common Garden Snail_Comes home to roost-Apple Snail or Roman SnailA reputed alien, but more probable antochthon-Apples or pot-licls-Its winter sleep-Its egg-laying-A chalky eggshell-The Apple-snail's first meal-The Good Samaritan of Shell-life-Bulins-Molluscan Dirty Dicks-Chrysalisshells-Numerous but minute-Barred doors-Tree Snail -Door-shells-Mimicry of beech-buds-How the ridges are worn away-Slippery Moss-snail-Agate Snail-A blind, subterrranean ghoul-Amber Snails and more flukes-A remarkable seashore slug

\section{CUTTLES}

The most highly-organised mollusks-Suckers and Inkbags - How colour-changes are effected - The Common Octopus-The Curled Octopus-Eight-armed Cuttles and ten-armed Cuttles-Spirula-Fragile shells that cross the Atlantic-Common Cuttle-"Cuttle-bone"-Hectocotylusarm-Derivation of word Cuttle-Eggs in bunches-Penand-ink mollusks-Little Cuttle-Ross' Cuttle-Conmon Squic-First-class bait-How to catch a Squid-Absence of Squid "pens" on shore-Egg"-mops-Marbled SquidFlying Scluids-Architenthis, a monstrous Squid-Oceanic Cuttles-Evolution of the Cuttles' shells . .

383

\section{APPENDIX}

A Classified List of British Mollusks Index to Popular Names 


\section{LIST OF ILLUSTRATIONS}

\section{PAGE PLATES}

Land Snails (Hclix) Frontispice Dog Cockle,

Green Crenella, Fucing proge 63
etc.

Great Scallop and Quin,

Scallops,

Astarte-shells, etc. $\}$,, 84

Iceland (yprina and)

Heart-Cockle $j$,

Zebra Mussel, ? ,

Montagu-shells, etc. $j$, 99

Orb-shells and?

Pea-shells j . , 106

Tellins and )

Furrow-shells;

Wedge-shells and)

Trough-shells $j \cdot, \quad 127$

Venus-shells ant)

Carpet-shells f ., , 130

Cockles . . . ., 139

Sunset-shells and
Piddock

Mail-shells and)

Limpets f . . 182

$\left.\begin{array}{ll}\text { Ormer and } & \text { Blue-rayed Limpet }\end{array}\right\} \quad, \quad 193$

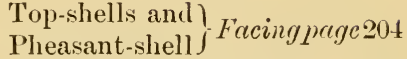

Necklace-shells and)

Winkles

Periwinḳle and)

Chink-shells $\} \quad$, ", 226

Conelets and)

Dog-whelks f • . , 238

Sea-slugs . . . , , 287

Sea-slugs . . . , , 294

Sea-slugs . . . , , 302

Fresh-water Snails . , 319

Land-slugs (Limex) . , , 334

$\left.\begin{array}{l}\text { Slug-shells and } \\ \text { Glass-snails }\end{array}\right\} \quad$. , , 340

Land-slugs (Arion) . , , 345

Land-snails (Helix) . , , 351

Brown-lipped Snail . . , 363

White-lipped Snail . ,, $36 t$

Common Garden Snail ) , , 366 and Apple Snail $f,, \quad 36$

Chrysalis Snails and ) , $\quad 374$

$\begin{array}{lll}\text { Door-shells } \quad " \quad 374 & \\ \text { Cittles } & & 383\end{array}$

Cuttles . . . . . 398

** The above full-page plates depict about 300 figures of Mollusks, the individual names of which will be found at the foot of each plate. 


\section{TEXT ENGRAVINGS}

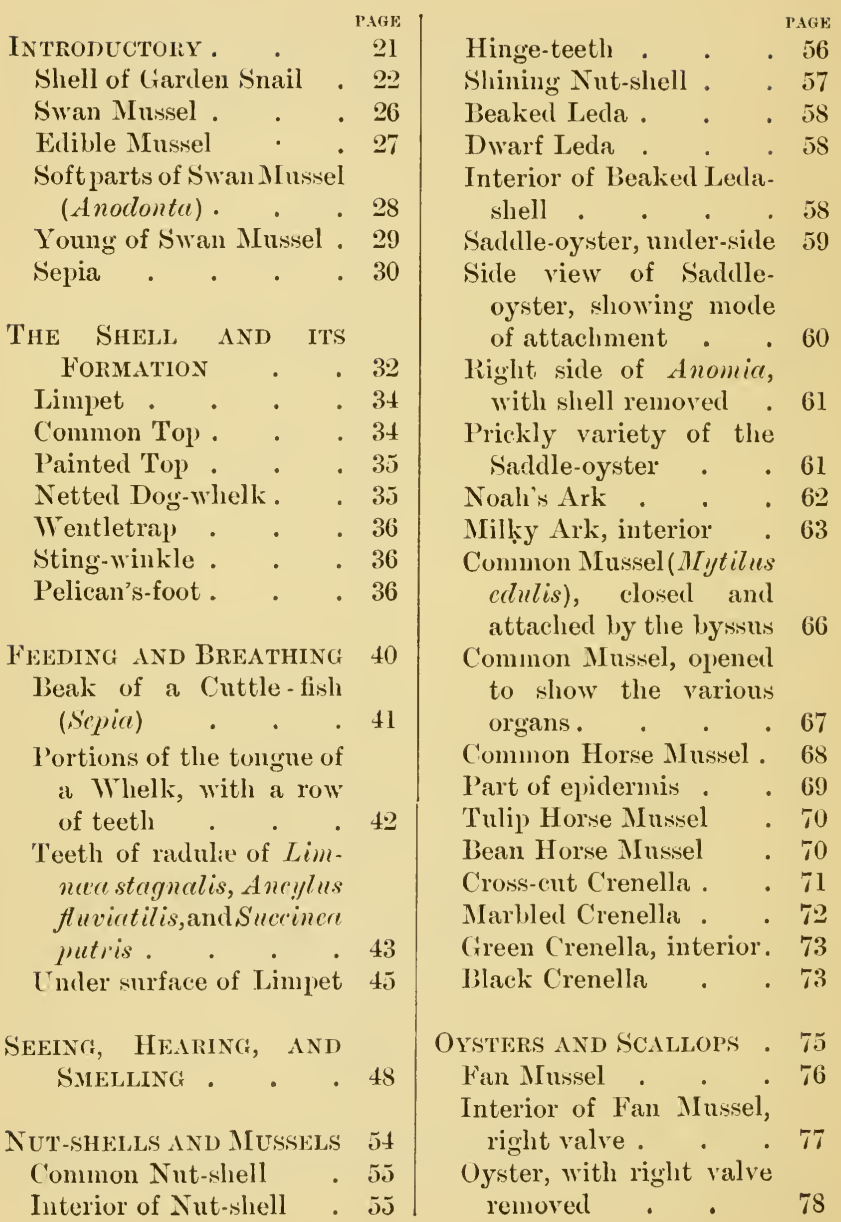




\begin{tabular}{|c|c|c|c|}
\hline & PAGE & & \\
\hline unchback Scallop & . 82 & River Pea-shell & \\
\hline & 83 & Painter's Mussel . . & \\
\hline Quin or Qneen & 84 & Pearl IInssels, showing & \\
\hline Seven-rayed Scallop & 85 & the shell, & \\
\hline Tiger Scallop . & & & \\
\hline Mottled Scallop, shell & & Swan Mussel, end view. & \\
\hline and animal . & 86 & Duck Mussel . . . & \\
\hline raping File-shell & 88 & Zebra Mussel . & \\
\hline file-shell & & & \\
\hline Fragile File-shell & 89 & WEDGE-SHELLs, VENUS- & \\
\hline Gaping File-shell & & IND COCKLES & \\
\hline File-shell in its nest & 90 & h foot and & \\
\hline Gaping File-shell, & & xtended . & \\
\hline & 91 & & \\
\hline & & & \\
\hline ART - COCKLE & & & \\
\hline R COCKLF & 92 & nterior & \\
\hline Furrowed Astarte. & 93 & & \\
\hline Furrowed Astarte, in- & & & \\
\hline & & & \\
\hline Flat & 9 & & \\
\hline & 9 & & \\
\hline & 9 & & \\
\hline & 9 & & \\
\hline rockle. & $s$ & & \\
\hline Cockle & 9 & & \\
\hline Nor & 97 & & \\
\hline $\begin{array}{l}\text {-shell, sus- } \\
\text { yssus }\end{array}$ & & $\begin{array}{c}\text { Little Circe-shell, ex- } \\
\text { terior. }\end{array}$ & \\
\hline rof Globose Kelly & & $\begin{array}{l}\text { Little Circe-shell, in- } \\
\text { terior . }\end{array}$ & \\
\hline shell & & in of hinge & \\
\hline & & shell & \\
\hline Shining Coin-shell and & & & \\
\hline & & & \\
\hline Coin-shell . & 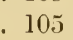 & & \\
\hline s Weasel-eye, & & & \\
\hline & & of Smooth Venus & \\
\hline herium. & & & \\
\hline & & & \\
\hline & & interior & \\
\hline Lake Orb-shell & & Striped Venus & \\
\hline
\end{tabular}


Wavy Venus, exterior and interior

Golden Carpet-shell . 135

Banded Carpet-shell . 135

Banded Carpet-shell, interior . . . 136

Pullet Carpet-shell . $\quad 136$

Cross-cut Carpet-shell . 137

Tiock Venus . . . 137

Rock-borer (Petricule lithophaga) . . . 138

Rough Cockle . . 140

Little Cockle . . . 140

Banded Cockle . . 141

Common Cockle, interior 141

\section{GAPERS, PIDDOCKS, AND} SHIP-WORMS

. 144

Blunt Gaper . . . 145

Hinge-teeth of Psammobic .

Tellin-like Sunset-shell . 146

Faroe Sunset-shell .

147

Hinge and cartilage process of Gapers

Old Maid . . . . 149

Blunt Gaper . . . 150

Basket-shell . . . 151

Interior of Basket-sliell, showing hinge-teeth . 151

Pointed Basket-shell . 151

Siphons of Necra . . 151

Oblong Otter-shell. . 153

Common Otter-shell . 154

Short Razor . . . 155

Smooth Short Razor . 155

Egg-shell Razor . . . 156

Pod Razor . . . 157

Pod Razor, interior of left valve . . . 158

Sword Razor . . . 160

Wrinkled Rock-borer . 161
Wrinkled Rock-borer . 161

Arctic Rock-borer . . 162

Flask-shell, front view . 162

Flask-shell, side view . 162

Flask-shell . . . 163

Case of Flask-shell. . 163

Pholas in its burrow . 164

Right valve of Common

Piddock . . . 165

Portion of hinge-plate . 165

Dorsal shields. . . 166

Common Piddock in its cell . . . . 166

White Piddock . . 167

Little Piddock $\quad . \quad 167$

Paper Piddock . . 168

Wood Piddock $\quad . \quad 169$

Ship-worm . . . 170

Norwegian Ship-worm . 172

Pandora-shell . . . 173

Left valve of Pandora . 173

Thin Lantern-shell. . 175

Papery Lantern-shell $\quad .176$

\section{TUSK-SHELLS, MAIL-SHELLS,}

AND LIMPETS . . 178

Elephant's Tusk-shell $\quad 179$

Grooved Tusk-shell . 180

Mail-shells . . . 181

Under-side of Chiton and

profile of head . . 182

Bristly Mail-shell . . 183

Bordered Mail-shell . 185

Smooth Mail-shell . . 185

Marbled Mail-shell . 186

Tortoiseshell Limpet . 186

Common Limpet . . 188

Blne-rayed Limpet . 193

Blne-rayed Limpet, older

specimen . . . 193

Keyhole Limpet . 194

Punctured Limpet. 194 
Punctured Limpet, from above. . 195

Common Slit-limpet $\quad 195$ Rosy Slit-limpet . . 195 Ormer . . . . 196

TOP-SHELLS AND PHEASANT-SHELL . . 199 Head of Grey-top . . 201 Operculum . . . 201 Common Top-shell. . 201 Grey Top-shell . . 205 Painted Top . . . 205 Plieasant-shell . . 207 Head of Phasicmella . 208 Fresh-water Nerite . 208

Necklace-Shells AND

WinkLes . . . 210

Violet Sea-snail with its float . . . . 211

Violet-snail and float, side view . . . 212

Head of Wentletrap . 213

Common Wentletrap . 213

Glossy Aclis-shell . . 214

Egg-band of Natica alderi. . . . 215

Large Necklace-shell . 216 Life aspect of $N$. catena . 216 Common Necklace-shell . 217 Velvet-shell . . . 219 Hungarian Cap . . 221 Cup-and-Saucer Limpet, interior . 221

Single row of teeth from the radula of Periwinkle 222 Animal of male Periwinkle, with the shell removed

Periwinkle . . . 224 Eggs of Periwinkle . 225
Banded Chink-shell, . 226

Banded Chink-shell, enlarged . . . . 226

Pallid Chink-shell . . 227

Eggs and young of Pallid Chink-shell . . . 227

SPIRE-Shells AND MARSHSNAILS . . 228 Round-mouthed Snail . 229 Latticerl Spire-shell . 231 Thick-lipped Spire-shell . 231 Laver Spire-shell . . 232 Common Bitlynia. . 233 Dun Sentinel . . . 233 Dun Sentinel . . . 234 White Belted-shell. . 234 River Snails . . . 235

Common River Snail . 236

Lister's River Snail . 236 Common Valve-shell . 237

\section{Cowry AND Pyramid-} SHELLS. • . . 238 Small Needle-whelk . 239 Auger-shell . . . 240 Blind-shell . . . 240 Pelican's foot . . . 241 Pelican's foot, from below 242 Margin-shell, from above and below . . . 243 Margin-shell and animal 243 Poached Egg . . . . 244 Poached Egg-shell . . 244 Young shell of Cowry . 245 European Cowry, from above and below . . 245 European Cowry . . 245 Atlanta peroni . . 246

Whelks AND CONELETS . 248 Polished Eulima . 249 


\begin{tabular}{|c|c|}
\hline \multirow{2}{*}{ Conicol Pyramis_shell } & PA \\
\hline & . 2 \\
\hline Staircase Pyramid . & . 251 \\
\hline Sting-winkle . . & 252 \\
\hline Ribled Spindle-shell & 252 \\
\hline Purple or Dog-winkle & 255 \\
\hline Egg-capsules of the & \\
\hline Purple. . . & \\
\hline Netted Dog-whelk. & \\
\hline Netted Dog-whelk. & \\
\hline Slender Spindle-shell & \\
\hline Common Whelk & 262 \\
\hline
\end{tabular}

Whelk

. 263

Opercula of Whelk, nor-

mal form and double . 263

Cluster of Egg-capsules . 263

Least Whelk. . . 265

Seven-ribbed Conelet . 265

Teeth of Bela. . . 265

Red Conelet . . . 266

Turreted Conelet . . 266

\begin{tabular}{|c|c|c|}
\hline & & 267 \\
\hline Actreon-shell . & & 271 \\
\hline Blunt Bubble-slıel & & 271 \\
\hline Canoe-shell . & & \\
\hline Cylindrical Bubbl & e-shell & \\
\hline Cylindrical Bubbl & e-shell & \\
\hline Southern Bubble-s & shell & \\
\hline ble-shell & & \\
\hline Gizz & Acera & \\
\hline ubble-shell & & \\
\hline Lobe-shell & & \\
\hline Lobe-shell & & \\
\hline Sea Hare. & & \\
\hline of Sea Hare & & \\
\hline Spawn of Doris & & \\
\hline $\begin{array}{r}\text { Young of Doris, } \\
\text { shell }\end{array}$ & & \\
\hline Red Doris & & \\
\hline Hairy Sea Lemon & & \\
\hline Crested Slug . & & \\
\hline
\end{tabular}

Gulf-weed Slug PAGE

Bushy-backel Slug. . 288

Plumed Eolis . . 291

Dotted Eolis . . . 297

Green Elysia . . . 301

Black Limapontia . . 302

Clione . . . 303

Shell of Limacina . $\quad 304$

Clio pyramidate . . 305

POND-SNAILS . . . 306

Least Herald-shell . . 307

Mouse-eared Alexia . 308

Fresh-water Limpet . 309

Part of a row of teeth

from the radula of

Fresh-water Limpet . 310

Portion of row of teeth

from radula of Great

Pond-snail . . . 311

Great Pond-snail . . 312

Great Pond-snail . . 313

Marsh Limnæa . 314

Dwarfed Limnea . . 314

Smooth Pond-snail . . 316

Ear Pond-snail . . 317

Wandering Pond-snail . 317

Ram's-horn Snail . . 320

Ram's-horn . . . 321

Whirlpool Trumpet . 322

Margined Trumpet . 323

Shining Trumpet . . 325

Fountain Bladder-snail . 325

Shell of Fountain

Bladder-snail . . 325

Moss Bladder-snail . 326

LAND-SLUGS AND GLASS-

SHELLS . . . 323

Shell-bearing Slug(T'estc-

cella haliotidea). $\quad .330$

Great Slug . . . 332 


\begin{tabular}{|c|c|c|c|}
\hline & PAGE & & PAGE \\
\hline Shell of Great Slug & 333 & Two-lipped Door-shell & 376 \\
\hline Pellueid Glass-snail & & Slippery Moss-snail & 378 \\
\hline shell . . . & 338 & Three - toothed Moss- & \\
\hline Cellar-snail . . & . 340 & snail . . & 379 \\
\hline Tawny Glass-snail . & . 342 & Agate Snail . & 379 \\
\hline & & Amber Snail . . . & 380 \\
\hline LAND-SNAILS & 343 & Row of teeth of radula & \\
\hline Black Slug . & . 344 & of Succinece putris & 380 \\
\hline Lapidary Snail & .353 & Large Amber Snail & 381 \\
\hline Kentish Snail & .356 & Graceful Amler Snail & 381 \\
\hline Carthusian Snail & .357 & & \\
\hline Sandhill Snail & .358 & Cuttles $\cdot$ & 383 \\
\hline Pointed Snail. . & 362 & Suckers of Cuttle & 385 \\
\hline Brown-lipped Snail & . 363 & Spirula peronii & 389 \\
\hline Mountain Bulin . & 370 & Common Cuttle & 389 \\
\hline Lesser Bulin . & 370 & Shell of Sepia. & 390 \\
\hline Large Chrysalis-snai & 371 & Pen of Little Cuttle & 391 \\
\hline Pupa antivertigo . & 373 & Little Cuttle, upper-side & 392 \\
\hline Tree Snail . & 373 & Common Squid . . & 394 \\
\hline Plaited Door-shell . & 374 & Pen of Common Squid & 394 \\
\hline
\end{tabular}





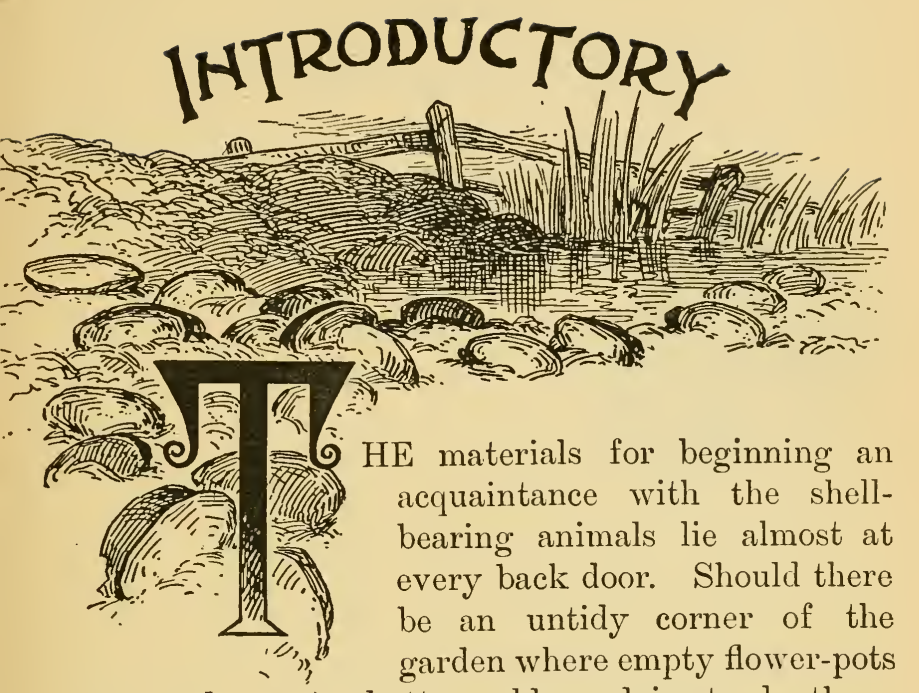
are stored, a water-butt, or old wood is stood-there, without search, you may surely find a few examples of the dingy and too common Garden Snail. Much as we may object to the presence of this Snail where there are choice or tender plants, we shall find it a very handy example if we desire to obtain knowledge respecting the class to which it belongs. All the Mollusca, it is true, do not agree in structure with the Snail, any more than they agree in external appearance, but we may well adopt it as one of the few general types of structure under which all the species may be classed. A description of a species that is accessible to all, and at least familiar by sight, should prove more generally acceptable than an illustration drawn from 
the sea, which to the mass of Britons is not always get-at-able: therefore we search slightly among the trailing ivy in the back-garden and pick up a rather shabby-looking shell.

This is the portable house wherein is lodged the common Garden Snail, and when the shell has been

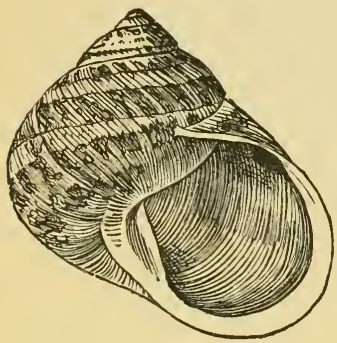

Shell of Garden Snail washed by contact with the dripping leaves after a heavy summer shower, one may get an iclea of its true colours. It has a yellowish ground, thickly overlaid with spots and bands of dark warm brown broken by irregular lines of lighter tint. The shell is packed with a solid jelly of greenish huethe living creature that formed the hard shell by excretion from its outer surfaces, but at present it is without form, a mere jelly in a jelly-mould.

Let us put this specimen into a saucer with a little tepid water, and see what effect it will have upon him. Here are just those conditions he likes best,warmth and moisture,-and he immediately begins to emerge from his shell and assume a definite shape. His body is elongated, with a flat base and a rounded upper side, the front ending in a sort of head distinguished by two pairs of what children designate "horns." These tentacles, instead of having the character of horns, are exceedingly soft and mobile, readily shortened to escape injury, or even completely withdrawn into the head. The lower of these appendages are short, and curved towards the ground; the upper ones are much longer and carry the eyes 
at their extremities-they take an upward direction and are waved backwards and forwards for the purpose of receiving impressions.

The shell is supported near the middle of this elongated body, and appears to be rather small for the accommodation of so large an inmate, though we have not yet seen the whole of the Snail. What we can now see extended is generally known as the foot - the locomotive organ of the Snail. Within the shell is a good deal more-the "visceral hump" containing most of the internal organs. By a series of muscular contractions the Snail glicles along upon the sole of its foot, slime being poured out for the necessary lubrication of its path - the glistening silvery trail that often enables the irate gardener swiftly to avenge the loss of his choicest seedlings.

The mouth of the creature, as will have been seen, is situated just below the smaller pair of tentacles, and is bounded by lips. Behind the upper lip is the horny, arched, and ribbed jaw which bites off and breaks down the food, which is then passed over a ribbon-like tongue, set in regular order with thousands of hook-like teeth, which rasp it into minute fragments. It then, of course, finds its way to the crop and the stomach by way of the gullet, for, in spite of the Snail's jelly-like, structureless appearance, it can boast of heart, liver, kidney, reproductive organs, and both nervous and muscular systems. With these items we have no immediate concern, for in this volume I do not propose to enter deeply into the anatomy of my subjects; but there is one point to which I must call attention. If we look at the mouth of the shell when the Snail is extended, we shall see 
that it is closely lined with a very soft material called the mantle. The name suggests that this organ invests the whole borly of the Snail when it is withdrawn into the shell; it does this and more-the inantle is the immediate producer of the shell.

The porcelain of our Snail's shell is composed mainly of carbonate of lime, and a microscopical section reveals the fact that it is made up of three distinct layers, each formed separately by different portions of the mantle. The material is obtained from the tissues of the plants upon which the Snail feeds, and has been absorbed from the soil by the roots. It appears to be separated from the Snail's blood as this circulates through the mantle, which has the power to pour it in a fluid state upon its outer surface. By exposure to the atmosphere the fluid lime mixed with animal matter hardens into shell. This animal matter is conchiolin, a substance not differing greatly from chitin, of which the hard parts of insects are constructed. The calcareous particles appear to be held together by the animal matter, and the whole sets into a hard stony formation. When a portion of shell is soaked in a weak acid, the carbonate of lime is dissolved and a very delicate gelatinous film is left. A similar result is obtained in the case of Whelk and Top-shells to which certain sea-anemones attach themselves. The base of the anemone appears to pour out some acid which dissolves the lime and leaves only a soft papery shell-form behind. When the mollusk is dead and the empty shell is left exposed to the atmosphere, the animal matter soon perishes and leaves the shell without gloss and exceedingly brittle.

All parts of the mantle have power to excrete one 
or other layers of this shell, as is proved by the repair of breakages. Many an adult shell bears signs of earlier accidents, the fractures being always evident from the fact that the colour patterns of the original are not reproduced. It is only the edge of the mantle that can produce the colour and pattern, and this is the part that first makes all the additions to a growing shell to allow room for the growth of the animal, whilst the other parts of the mantle merely strengthen this first layer by backing and thickening it. The upper layer therefore carries the pattern and colour, whilst the lowest layer is usually white and highly polished. Outside all there is a kind of animal varnish, protecting the shell from many injuries, and this is known sometimes as the epidermis, but more correctly as the periostracum. Sometimes the shelly matter assumes the crystalline condition, the carbonate of lime having taken the form of calcite or aragonite. The statement made above that the fluid shell-matter is poured out and moulded upon the external surface of the mantle is the modern view generally held, but some authorities agree with the late Dr. W. B. Carpenter, who held that it was secreted in the cells and interstices of the outer membrane of the mantle, which was afterwards separated.

The Snail breathes air, but its "lung" is merely a eavity opening directly on the surface of the animal and closed at will, in a manner corresponding to the opening and closing of our lips. Its inner walls are lined with a fine network of vessels through which the blood courses, absorbing oxygen from the moist air and giving off carbon. This simple form of lung is referred to as the Pulmonary Sac, and its external 
opening may be watched for just below the lip of the shell on the right-hand side.

Each individual Garden Snail combines the functions of both sexes. When one reflects that every one of those Snails clustering under the ivy will probably produce numerous eggs, he ceases to wonder at the enormous number that contrives to survive in spite of the clepredations of birds and gardeners. One hundred may be taken as the average number of its eggs, and these are deposited in cup-shaped hollows among herbage, and covered with a little loose earth. The young come forth with the same shape as their parents, carrying a tiny, glassy shell on their backs, and differing only in size. They become adult in about a year, and live until about five years old. Late in autumn they retire in companies to dry nooks and corners, there to spend the winter, many of them attaching their shells to those of their neighbours, all closed by tough films which keep in some degree of warmth.

The Snail is not the stupid senseless creature he

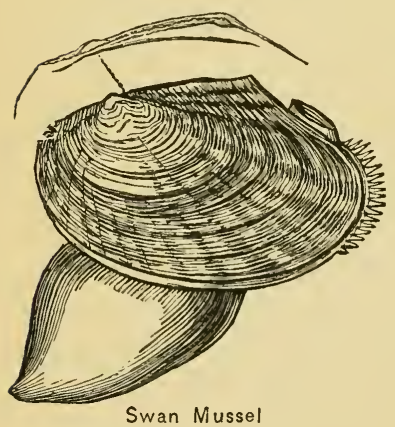

Swan Mussel is commonly thought to be. His entire body is very sensitive, and even when deprived of his eyes he can distinguish between light and darkness. His sense of locality is of a high order, for he has his favourite roosting place and invariably returns to it for his day's rest after a night's wanderings in search of food. As an example of a second class of shells and shellmakers, let us take either of the large Swan Mussels 
that live in fresh-water ponds and lakes, or the Edible Mussel of our seashores. These are so much alike in general structure, that either will serve our present purpose. Here the shell is a bivalve - that is, it is formed in two pieces (valves) which are hinged together by their upper edges. Having seen that the shell of the

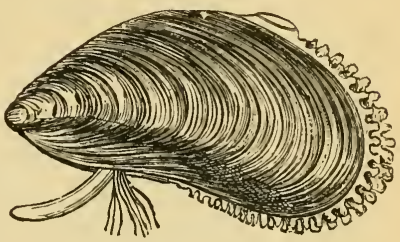

Edible Mussel Snail was produced by the mantle, we shall not be surprised to find that the Swan Mussel's mantle is in two parts corresponding with the valves of the shell. Within the two lobes of the mantle there are four plates or leaves of very delicate tissuethe gills-in two pairs. Between these again lie the foot, the visceral mass, and the lips of the mouth. This creature, though it has a mouth, has no head, and it does not wander about in search of food, but lies partly embedded in the mud with the shell gaping slightly, and waits for its food to come to it.

The gill-plates are covered with delicate filaments (cilia) like the gossamer of small spiders, and, apparently by the constant rhythmical movement of these, currents of water are drawn in, passed over and between the gills, where the blood circulating through their tissues absorbs the oxygen, whilst the microscopic forms of animal and plant life with which the waters abound are filtered out and passed to the lips. This being the method of their feeding, the bivalves lack the horny jaws and the tooth-studded ribbon such as we found in the Garden Snail. Occasionally examples of the Swan Mussel are found combining the functions 
of both sexes, but as a rule in bivalves the sexes are in separate individuals.

We have here several points of difference in struc-

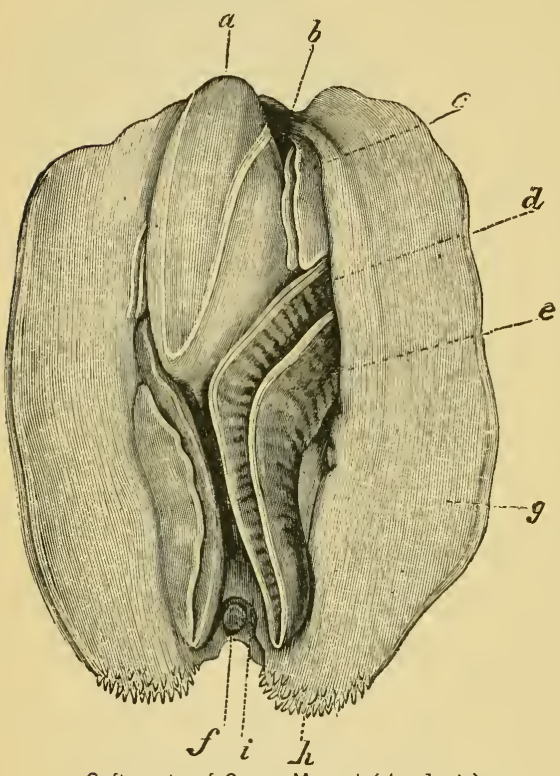

Soft parts of Swan Mussel (Anodonta)

(t foot; $b$, mouth; $c$, lips; $d, e$, gills; $f$, vent; $g$, mantle; $h$, siphon ture and habit between the Garden Snail and theSwan Mussel; there is also a want of uniformity in the length of their lives, for our present subject attains a respectable old age varying from twenty to thirty years, and does not begin to produce young until it is five years old. This difference of age may be at least partly accounted for by the quiet sedentary life lived by the Swan Mussel, which has also probably brought about a condition of degeneration from a primitive form; whilst the active Snail has no doubt advanced from that primitive condition. The evidences of this degeneration are to be found in the loss of head, eyes, masticatory apparatus, and reduced means of locomotion.

One other dissimilarity between these two types 
must be noted. We have seen that the Snail lays eggs, and that when the young escape from these they resemble their parents in all respects other than size. The Swan Mussel retains its eggs until they hatch, but the little creatures that emerge in no wise resemble the parent. They appear to represent an early ancestral condition of

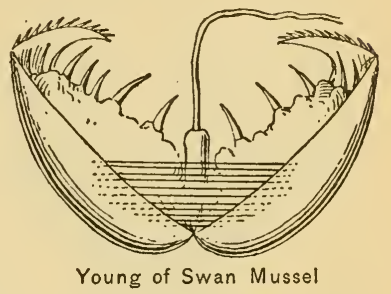
the species. They have a temporary two-valved shell with hooked tips, with which they cling to the fins and tails of fishes, leading a kind of parasitical existence for a time; and then they drop to the mud where a new and permanent shell grows within the valves of their cradle. This part of the Swan Mussel's history may be dealt with more fully later.

Our third type of structure must be sought in the sea, for it has neither land nor fresh-water representative. It is the Common Sepia, one of the Cuttles. Here there is no sign of an external shell, and the shape is altogether different from either of those we have already considered. The Sepia is quite symmetrical in form, with a distinct head surmounted by a crown of eight arms and two long clubbed tentacles. In the centre of this crown is the mouth, armed with a pair of horny jaws not greatly unlike the beak of a parrot, which they resemble in their action. Within the mouth there is a toothribbon like that of the Snail, but it is comparatively small, because the principal work of disintegration of food is done by the jaws, and the Sepia's digestive powers are of a superior order. The eyes are large 
and prominent, placed on the sides of the head below the arms. There is no external shell, but in the

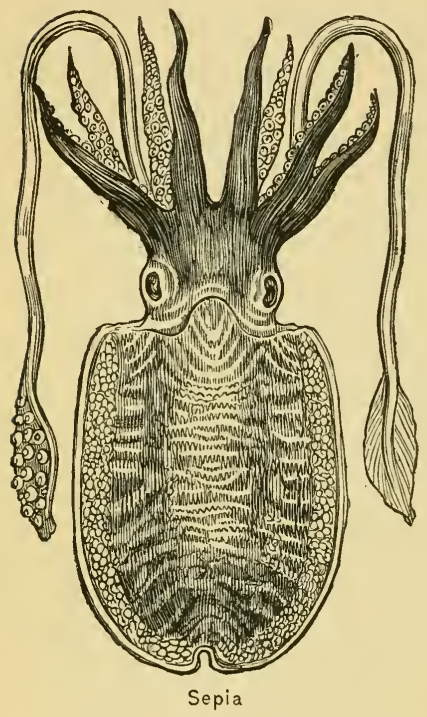
mantle there is the one familiarly known as "Cuttle - bo ne," more especially to bird fanciers. This consists of a thin hard shield, filled with thin soft plates of porous lime.

The Sepia can walk head downwards by the aid of its arms, whose inner surfaces are covered with powerful suckers; it can also swim rapidly backwards by violently ejecting water from the gill-chamber through a tube called the funnel. The opening by which water is admitted to the pair of gills is in front below the arms. The sexes are distinct, and the young are produced from eggs attached in great clusters to seaweeds.

These three creatures - the Garden Snail, the Swan Mussel, and the Sepia-stand as types of the three principal classes of mollusks with which we have to deal in the following pages; and we have so introduced them on the principle of proceeding from the most generally known to the less known. Regarded from the point of view of the systematic naturalist, the Sepia, as the highest 
type, should stand first, the Snail next, and the Swan Mussel last,-its structure being more primitive than that of the others, - but reversing this order we propose to deal first with the more simple forms. For the natural sequence of the British species, proceeding from the most highly organised to the lowest groups, the reader is referred to the Appendix. 


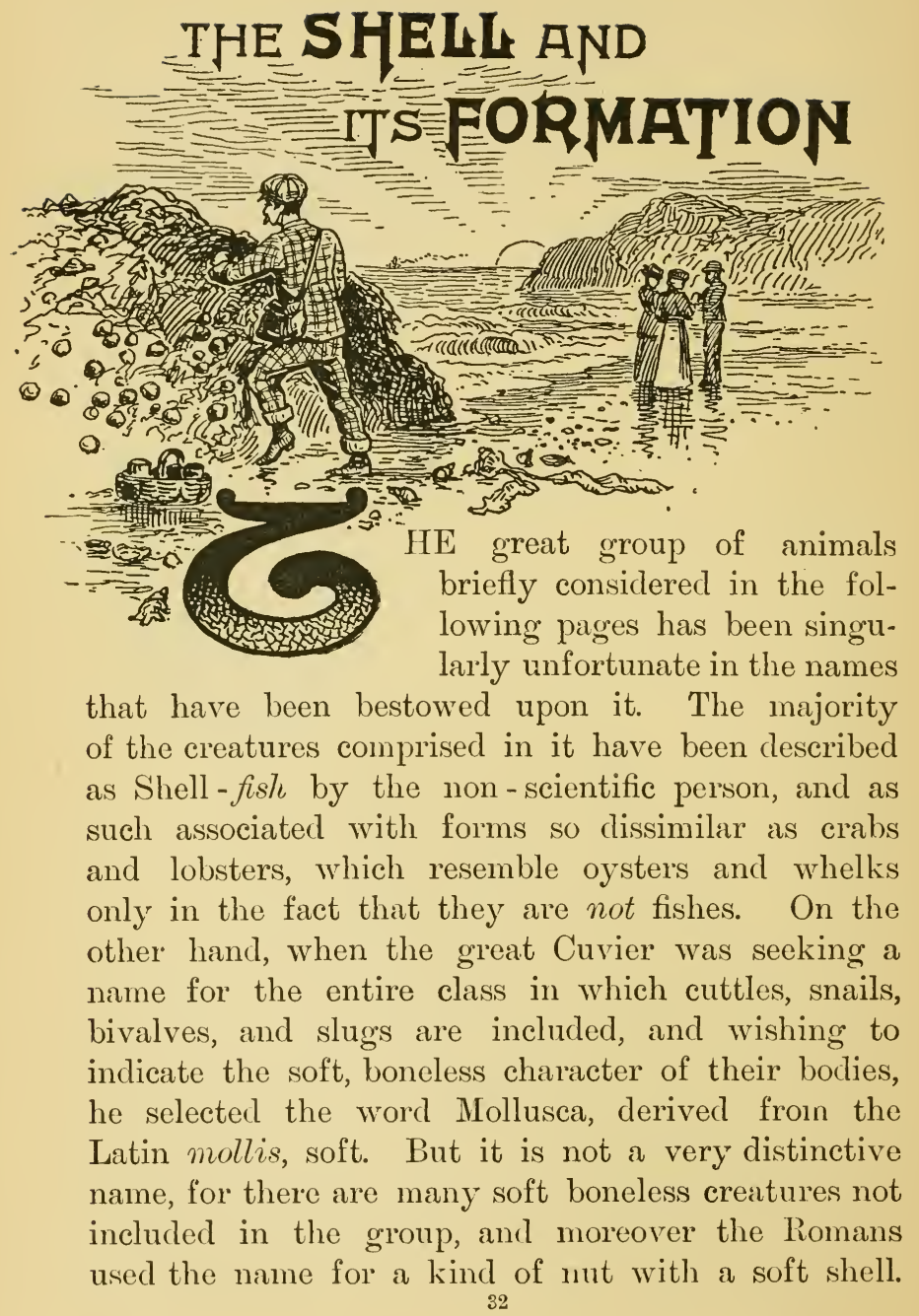


We are, therefore, in the position of having no wellknown name that will apply with anything approaching accuracy or distinctness, in the way, for example, that we denote beasts, birds, reptiles, and fishes; and there does not appear to be any prospect of getting what we want. The naturalist is so used to the term mollusk that he is not likely to seek or adopt another, and the layman is too conservative to give up so well-known and so inaccurate a name as Shellfish. The reader will understand why the word "Shells" occupies a more important position in the title of this volume than the makers and wearers of those shells, and will not regard it as being due to sympathy with the early collectors and writers who regarded the shell as of chief importance, and the animal that secreted and lived in it as quite a secondary matter.

In such a case accuracy is out of the question, for many of the creatures described in these pages have no apparent shell; a greater number have absolutely none when full-grown, though some of them begin life with a rudimentary shell which does not develop. But though the shell is not everything, it is so characteristic of the Mollusca as a class, that we are justified in giving some consideration to it at the start.

There is every reason for supposing that the primitive molluscan shell was not much unlike that which covers the Limpets to-day. Such a form gives great strength with but a small expenditure of material, and it is susceptible of modification in many directions. A number of species whose anatomy shows they are not intimately related, have retained this form of shell to the present day. In proof of this 
we need only refer to the native species of Acmcea, Haliotis, Calyptrcea, and Ancylus. For creatures

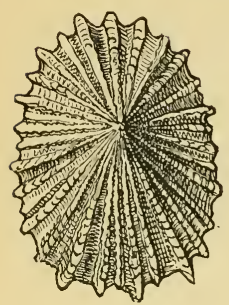

Limpet living in shallow water along the seashores, exposed to frequent hammering by the waves, such a form would be highly protective, as may be proved by watching the Limpets (Patella) on the rocks. Arlhering tightly with the base of their bodies to the rock, and drawing down the edges of the shell by muscular contraction, the wave breaks upon the shell without harming or shifting it. In the case of the Limpet the shell is enlarged equally all round its edge, so that it fits accurately to the spot of rock the Limpet has chosen for a permanent resting-place.

Even where the simple uncoiled form of shell has been departed from, there has in innumerable instances been a retention of the general external shape, that the minimum of resistance shall be offered to the waves. Take either of the common species of Top-shells that frequent the same situations as the Limpets: although the cone is here coiled several times upon an axis, the external shape is still that of a cone with an almost flat base.

All our univalve shells will be found to be modifications of this type, in some making a low pyramid, in others drawn out to a proportionately great length. This diversity of form

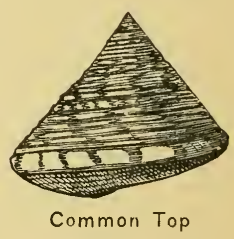
is, no doubt, determined by the habit of the mollusk and the situation it inhabits. For example, those 
species that adhere to rocks in shallow water (Top, Purple, Winkle, Limpet), and are therefore subject to the rushing of water and the heary beating of breakers, have their shells broad, smooth, and free from sculpturing that might eatch the water and so result in the mollusk being swept from its hold. Closely relater species that live on sandy or gravelly bottoms appear in many cases to find an advantage in angles and knobs; probably because, their foothold being precarious, when they are detached by waves their irregular surface prevents their being swept far from the spot. This difference is well illustrated by comparing the Common Top

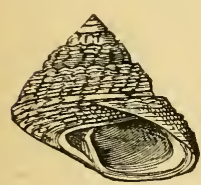

Painted Top with a closely allied species, the Painted Top, which occurs on sand, and has the surface of

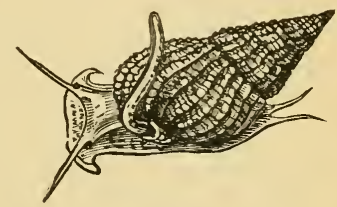

Netted Dog-whelk the shell broken up into a series of little knobs. The Netted Dog-whelk lives on sandy shores, and its shell has a similar surface, whilst the upper surface of the animal is dotted with dark spots that closely resemble grains of sand. The Common Wentletrap has a great number of flat plates standing out edgewise from each coil of the long shell. The very rugged character of the Sting Winkle's house is obviously determiner by similar reasons for utility; and, though much less rugged, the strong sculpturing of the Pelican's-foot is clearly of the same order.

How the character of the shell is modified by 
changed habits in the creature that makes it, may be seen clearly in the case of the Blue-rayed Limpet

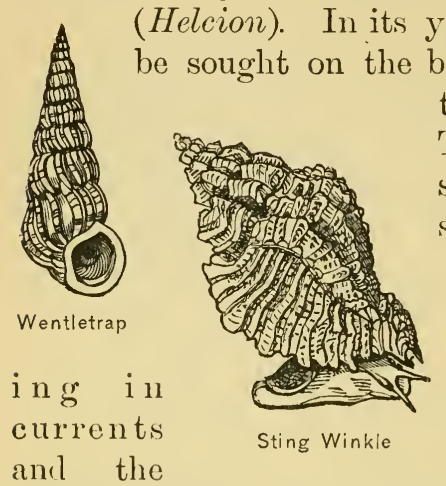

shell offering little opposition to the flow of the water. As

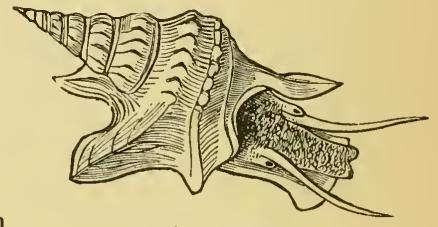

Pelican's-foot

the frond waves iridescent gleams play upon its purple-brown, and in order that the Blue-rayed Limpet may not be readily seen it bears upon its clear brown shell from three to six fine lines of bright blue radiating from the apex and giving an effect similar to that seen on the tangles. As it gets older this Limpet climbs down the stalk, where there is no iriclescence, and finally is to be found among the root-like suckers by which the weed is attached to the rock. In such a situation there is more risk to the shell from the rush of stones, etc., at the lower level. The shell, in consequence, becomes much thickened, the edges are modified to fit it for adhering to the cylindrical stem instead of the plane surface of the frond, and as the blue lines would be an attraction rather than a disguise they are gradually obscured. The shell 
has assumed the form known as the Smooth Limpet. Exotic species of Patella that live entirely upon floating seaweeds have their transparent shells like those of Helcion, but those that live upon rocks require thick shells to withstand the breakers.

All the species to which we have just referredwith the exception of the Limpets-have the mouth of the shell accurately closed by a thin plate of shell or chitin. It is seen closing the orifice of the Wentletrap figured opposite, and on the end of the foot of the Sting Winkle beside it. It is known as the operculum, or cover, and at one time was considered to be the other valve, bringing the univalves into close agreement with the bivalves. But a little consideration serves to show that the operculum is not part of the true shell, for it is not a product of the mantle, but of the foot.

And this brings us to the consideration of the enormous difference between the shells of, say, the Oyster and the Whelk. In spite of the very high value, commercial and epicurean, that is set upon the Oyster, present-day knowledge all seems to point to the probability that he is a degenerate from the form of the ancestral mollusk, which almost certainly had a head and something approaching a masticatory apparatus. Whilst some of its descendants in successive generations went on improving the simple tent-like form of their shells, by twisting them into spirals, and developing their organs to fit them for lives of varied activity; others, finding that the sea was well provided with food, appeared to think that activity involved an unnecessary strain upon the organism. These simply 
attached themselves to rocks or weeds, or burrowed slightly in sand or mud, and lay with their mouths open to receive such good things as might chance to fall in. They lay over on one side, the mantle became divided into two lobes, and consequently the shell moulded upon its surface was in two valves hinged together, the head was lost, though the toothless, tongueless mouth remained, hidden by the lobes of the mantle.

That the general tendency of development was in the direction of improving upon the simple ancestral form is indicated by the fact that of the enormous number of distinct species known in a fossil or recent condition, only one-fifth are bivalves, whilst three-fourths have a single shell.

To get back to the adaptation of the shell to the conditions of life: pelagic or floating species have the shell reduced to a thin glassy consistency, serving the double purpose of rendering them light and transparent, the transparency preventing their easy detection by enemies who are likely to regard them instead as part of the jelly-fishes upon which such pelagic mollusks largely subsist. Some species that dwell in deep water out of the reach of surface convulsions have very thin shells also. At the other extreme some deep-water forms that have evidently been much sought after by the larger fishes for their food secrete very thick and solid shells that may be proof against the equally hard and stony palate-teeth of the fishes. In all the fresh-water forms it is evident there can be little need for thick and heavy shells, and as a matter of fact they are light and thin. Especially is this 
the case with the pond-snails, who probably find carbonate of lime not very plentiful in their little world, neither is it greatly needed as a protection. A strong shell is required by those land-snails whose habitat exposes them to the attacks of birds like the thrush, but it is essential that the shell should not be heavy. The carbonate of lime is in this case obtained from the plants upon which the snails feed, and it is therefore only to be expected that on chalky soils the snails should be exceeringly abundant, whilst in sandy districts they are rare or entirely absent. But it does not follow that on chalky soil the shells will be necessarily thick, Clausilia laminata, for example, plentiful in beech woods on the chalk, having a thin semi-transparent shell, apparently with little chalk in it.

In the slugs of our gardens and hedgerows the shell has been reduced to a little shield covering the breathing organ, or to a few granules of lime beneath the mantle; whilst many of the Sea-slugs have found it an advantage not to develop the shell at all, though they are born with the nucleus of a shell like all other mollusks. A somewhat similar case to that of the terrestrial slugs, so far that is as the shell is concerned, will be found among the Cephalopods: the Sepia produces beneath its mantle the familiar "cuttle-bone," in the Squid this is reduced to the long transparent "pen" of animal matter only, whilst in the Octopus the shell is represented by two little stylets in the substance of the mantle. 


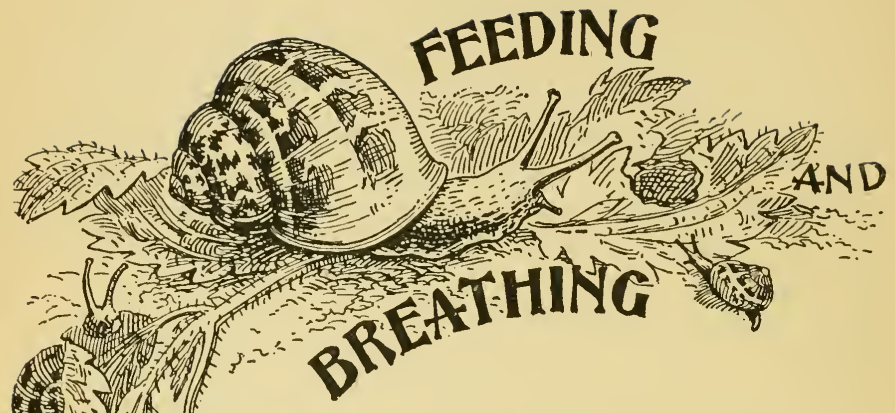

4. 4. If $\mathrm{N}$.

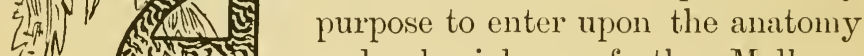
i.) forment and physiology of the Mollusca $2 \int \begin{aligned} & \text { beyond what is necessary for an } \\ & \text { understanding of the differences in }\end{aligned}$ groups, there are certain points which are so characteristic of the class, or which distinguish the several orders, that some elementary reference to them is essential. But the reader whose interest at present extends only to external forms and coverings may, an it please him, for the present skip this chapter and return to it later.

Though, as we have seen, the bivalves have probably retrograded so far from the prevailing type as to have lost their heads, these presumed degenerates have retained a mouth and a digestive system as being necessary to their continued existence. But though the mouth remains in these bivalves, it is little more than an opening to the 
gullet and the stomach; there are neither jaws, teeth, nor tongue. The absence or presence of a tongue has been found to be an important item in classification, and we find that some authors have divided the Mollusea into two unequal groups, the Tongue-bearers (Glossopliora) and the Tongueless (Aglossa), the Tongue-bearers including the Cuttles and the Univalves, the Bivalves constituting the Tongueless.

It is in the Cuttles that we find the highest development of jaws for the purpose of biting off portions of food. These are composed of chitin, formed much like the beak of a parrot, and working much in the same fashion except that in the case of the Cuttle the upper jaw works

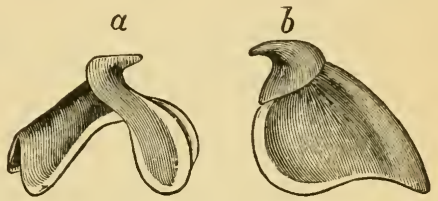

Upper $(a)$ and lower $(b)$ portions of the beak of a Cuttle-fish (Sepia)

within the lower. The more ordinary type of jaws may be observed by watching any of our common snails feeting. The Land-snails (Helix) have the jaw only in one portion, and this is placed behind the upper lip; but in the Pond-snails (Limncea) there is an accessory plate on either side of the mouth, and these act with the upper plate. If a pondsnail be watched as it glides up the glass of an aquarium and cleans off the minute vegetation, the mechanism of the jaws will be understood better than from a description.

The food having been cut off by the jaws is not yet in a condition to be readily digested; it has first to be masticated. This work is performed 
by a very remarkable organ peculiar to the Mollusca. It is an almost transparent ribbon of chitin, whose upper surface bears a large number of minute teeth, of varying forms, number, and arrangement, set in transverse rows, and each row symmetrically divided into central, lateral, and marginal teeth. The organ is variously known as the tongue, the radula, the lingual ribbon, or the odontophore. Only a small portion

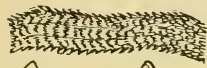
$\widehat{A P} \mathrm{sm}$ Wi

Portions of the tongue of a Whelk, with a row of teeth (greatly enlarged) is brought into action, the remainder being coiled away at the back of the mouth, ready for use when the teeth on the forepart shall have been worn out. These teeth as a rule are few and large in those species of carnivorous habit, whilst those of herbivorous tendency have them small and numerous. Many of the carnivorous mollusks make their tongues serve a double office, for they have no jaws, and the whole of the cutting and breaking up of their food has to be done by the teeth; this, no doubt, explains their larger size.

The number of these teeth to one tongue or raduli varies to a remarkable extent: thus, one of the Seaslugs (Eolis coroncta) of our own coasts has only about 17, whilst the large brown Sprinkled-snail (Helix aspersa) of our gardens and hedges has 105 teeth in each transverse row, and no less than 135 rows-that is, a total of 14,175 teeth in one mouth. There are, of course, many species with numbers intermediate between Eolis and Helix; the large Pond-snail (Limnoe stugnalis), whose teeth are shown in the figure $a$ below, has 111 such teeth in 
a row and about 110 rows $=12,210$; the little Freshwater Limpet (Ancylus fluviatilis) $b$ has 120 rows of $75=9000$; and the Amber Shell (Succinea putris) $c$ of our watersides has 50 rows of 65 teeth $=3250$. A Mexican species of Helix is said to have 40,000 teeth, whilst Umbrella, a Mediterranean mollusk, has so many it is impossible to count them, but they have been estimated to number somewhere about 750,000 ! Every one of these minute teeth has
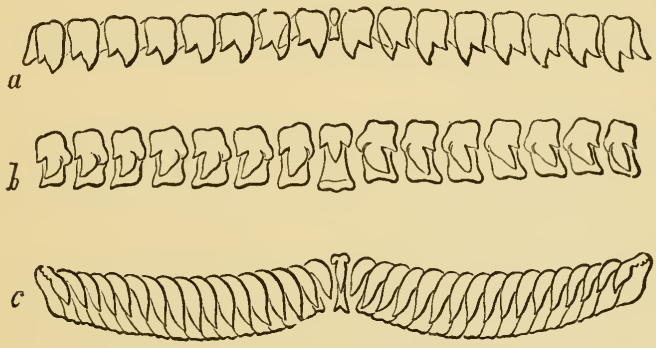

Teeth of radula of-a, Limncea stagnalis; $b$, Ancylus fluviatilis; $c$, Succinea putris (greatly magnified)

muscular attachment to the radula, and can be erected or depressed at the will of the mollusk.

These remarkable organs extracted from the mouth of any of the common mollusks of our hedges or seashores, make beautiful objects for the microscope; but their preparation requires a good deal of care and nice manipulation. They are first boiled in caustic potash to get rid of the animal matter, and after washing in clean water are mounted in glycerine jelly.

Most of the mollusks that bear these radulæ are also provided with salivary glands, and in some of the species that habitually bore through the shells 
of others in order to feed upon the occupant, the saliva is found to contain an appreciable proportion of free sulphuric acid, which evidently softens the spot of shell upon which the ralula is then brought to bear.

The molluscan stomach, with which we have not space to deal, varies with the habit and food of the mollusk. Some species have it lined with knife-like plates, or with knobs and teeth. The Canoe-shell (Scaplander lignarius) has a gizzard in which the Tusk-shell (Dentalium), its favourite food, is crushed up prior to digestion.

Having glanced at the mechanism by which the mollusks prepare their food for assimilation, let us take a similarly brief and superficial view of the means whereby the blood is aërated in the principal groups. It is evident that one system of respiration will not serve for the whole of the Mollusca, seeing that whilst some spend their lives submerged in fresh or salt water, others live as constantly surrounded by the atmosphere. Many of the fresh-water species, however, breathe air only, and cannot therefore venture far from the surface, their air-chamber requiring to be frequently recharged. On the other hand, marine species like the Limpet and Periwinkle, provicled with gills for breathing water, have to spend hours on the dry rocks, and can only do so by storing sufficient moisture to keep their gills damp.

It is probable that the ancestral mollusk had no special organs for respiration, but simply absorbed oxygen through his surface tissues, beneath which the blood flowed and took up the vital gas. Then 
probably the production of a shell closely covered so much of the surface that a simple comb-like organ was developed to carry on this function constantly. Such an organ exists in what we may regard as little different from the primitive form in certain species of Mail-shells (Chiton). Into this comb-like organ (ctenidium) the blood flows, and through the tissues of the branches absorbs the oxygen from the surrounding waters. In other species these simple ctenidia have degenerated until no longer functional, and their place is taken more efficiently by a series of plate-like gills encircling the body Such a form of respiratory apparatus may be seen in the Limpet, of which a figure is here given. Here the letters $c c c$ show the position of the encircling series of gill-plates, whilst the true but aborted ctenidia must be sought in a pair of very small yellow bodies situated on the sides of the neck.

External branchiæ are also developed in

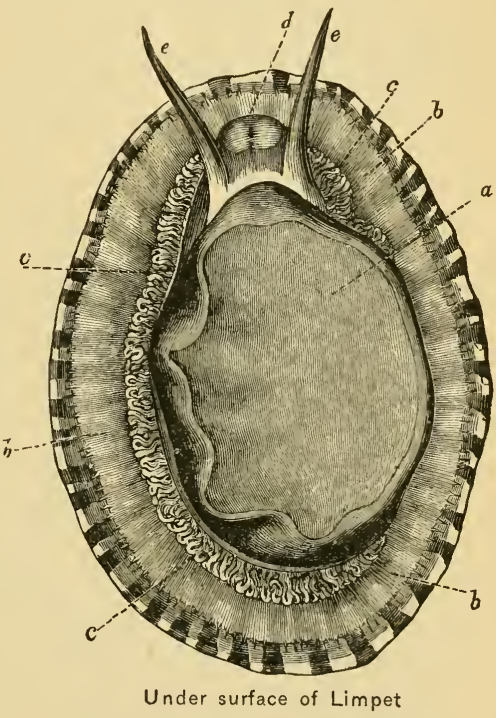

$a$, foot; $b$, mantle; $c$, gills; $c l$, mouth; $e$, tentacles many of the Sea-slugs, taking the form of cerata, whiplike, plume-like, or foliage-like proeesses from the back, 
through which the blood flows and takes up oxygen through their tissues. In the bivalves, as will be more fully described later, the gills vary greatly in the degree of complexity. They are usually placed on either side of the body between it and the mantle which thus form the branchial cavity. In most cases a couple of tubes or siphons lead to this chamber from the exterior, one admitting fresh supplies of water, the other carrying off that which has passed over the gills and been robbed of its oxygen.

In the land and fresh-water snails (excepting the few whose shells are closed by an operculum) respiration is effected in a "lung-chamber," though there is no lung in the sense of a spongy mass of tubes as we know it in the higher animals. The chamber, which opens on the right side of the snail, more or less towards the front part, is lined with a network of branching vessels through which the blood circulates. Air is taken into this cavity frequently when the mollusk is active, and then the opening is closed until all the oxygen has been taken up by the blood, when the chamber is refilled and again closed. The Pond-snails (Limnoes) when living in shallow water frequently come to the surface to recharge this cavity with fresh air, but when living at considerable depths they appear to absorb the oxygen from the water, whether by filling this lung-chamber or through the general skin-surface is not quite clear.

In intimate relation with the varied forms of gills or lungs there is, of course, a heart; and where there is only a single gill there will only be one auricle and one ventricle to the heart, but there may be two or four auricles if there are as many gills. From the 
gills the oxygenated blood flows to the heart, whence by way of the aorta it is distributed throughout the body, and returning by veins it is again passed through the gills. It must not be supposed, however, that the circulation is as rigidly confined in definite tubular vessels as in the higher animals. Much of the blood appears to flow indefinitely in irregular spaces of the body called lacunce and sinuses, getting reinforced by that which has passed through the gills and heart, but perhaps not all of it finding its way back to these organs. The vital fluid is in most mollusks colourless, but a few of the more active species possess the red colouring matter (hcemoglobin) which distinguishes the blood of vertebrates. 

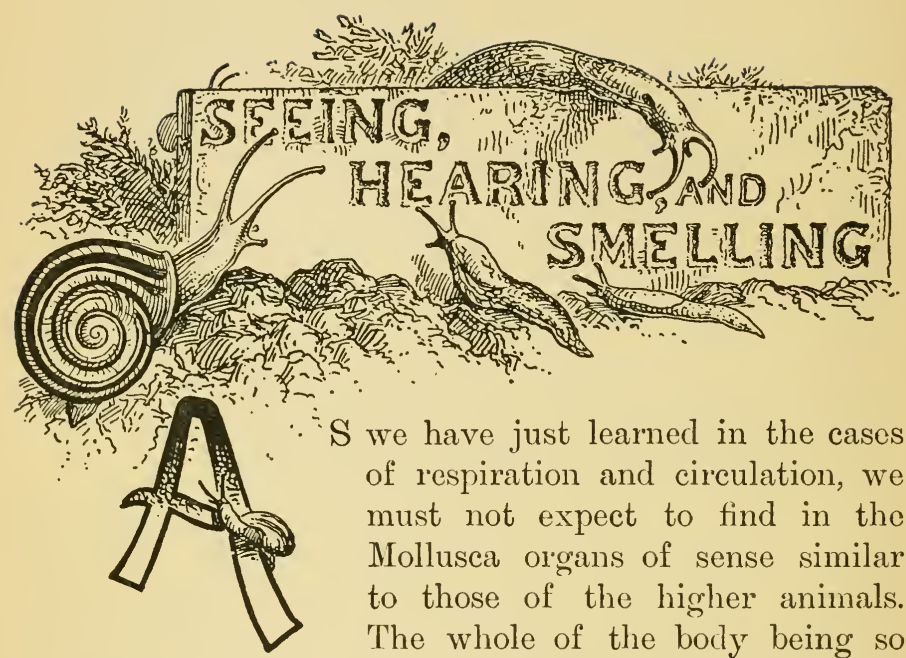

$\mathrm{S}$ we have just learned in the cases of respiration and circulation, we must not expect to find in the Mollusea organs of sense similar to those of the higher animals. The whole of the body being so soft is no doubt highly sensitive; nevertheless there are special organs for special senses, and these organs are well furnished with nerves to convey their impressions to the local brain. For there is no grand centre of the nervous system as furnished by our. brain. Instead of one great trunk-line of nerves and nerve-bundles, as in the vertebrates, we find in the mollusks a system of large and small nerve-threads traversing the length and breadth of the animal, connected here and there by loops (commissures), and from certain knots (local brains or ganglia) sending off a number of short branches. All these local brains are connected by other nerves, and the chief of them are known as the cerebral, the pedal, and 
the risceral ganglia. In those mollusks that possess a distinct head nerves go off from the cerebral ganglion to the tentacles, the eyes, and are connected with a pair of small ganglia (the buccal ganglia) that command all the mouth parts, the pedal ganglia supplies the foot, the visceral or pleural ganglia send nerves to the mantle, the heart, the gills, the stomach, and the other internal organs.

The eyes of the Mollusca are alike different from those of higher animals, and from one another. The highest development of the molluscan eye is found among the Cuttle-fishes and their allies, but a pair of well-developed eyes is the possession of nearly all the mollusks that are furnished with heads. Yet the presence of a hear is not absolutely essential for the acquirement of eyes, for some of the bivalves, such as the Scallops and Ark-shells, have eyes on the fringes of the mantle, and some foreign species of Mail-shells (Chiton) have been found to have certain parts of their shell-plates closely studded with minute pigmented dots which serve the office of eyes. In the land-snails the eyes are carried at the top of the longer pair of tentacles, a position which allows the snail to see in all directions; in the water-snails the eyes are at the base of the tentacles. Species that live underground have the eyes more or less aborted. Our own little Needle-shell (Crecilianella acicula), which lives an entirely subterranean life, has lost them altogether; so also have several of our marinesnails that are always seeking their food under the sand. Others of similar habit have eyes, but they are covered by thick skin that can allow very little impression of light to reach them. 
From a consideration of a series of molluscan eyes it is not difficult to surmise the developmental history of the inost perfect among them. Thus, in the Limpet-to which we have already referred as being probably much like the ancestral mollusk-there is little more than a fold of the skin forming a depression lined with rod-shaped cells containing pigment and forming a retina, which is connected with the optic nerve. In the Tops (Trochus) the depression of the epidermis is greater, so that it encloses a spherical space lined with retinal cells and filled with fluid (vitreous humour), but open in front so that the face of the eye is bathed in water. In the Sting Winkles (Ifurex) there is an advance upon this form, for the opening of the eye has become quite closed and there is a lens before the vitreous humour. Now the eyes of these three species present a very close resemblance to three stages in the development of the eye in the embryo of the Squid (Loligo), which shows an advance upon Murex by producing an iris round the fore-part of the lens, an optical chamber in front of the lens, and a transparent cornea before that again.

It must be apparent that eyes are of the greatest value to the most active species of Mollusca-the Cuttles. These have, consequently, developed their eyes to a greater degree of efficiency than other orders. The inactive, often fixed, bivalves have been found in many cases to have a pair of eyes on what may be regarded as the head during their larval condition, thus indicating that in the early history of the Pelecypoda they had eyes in the adult state. Those bivalves that lead a more active life, such as 
the Scallops (Pecten), have a considerable development of eyes upon the fringes of the mantle, and it has been reasonably surmised that these eyes enable them to guide themselves in their vigorous zigzag flights through the waters. But it may be regarded as tolerably certain that these eye-substitutes, or pigment spots, that are crowded upon certain parts of the mantle in many bivalves are merely sensitive to varying qualities of light and are useless for observation. The casting of a shadow upon such species affects these pigment spots, and from them the intelligence is conveyed along the nerves to the various ganglia, with the result that as a precautionary measure, the foot and siphons are withdrawn and the valves are shut with a snap. The Landsnails (Helix) being crepuscular or nocturnal in their habits can see farther in twilight than at midday, but their visual powers are very limited at the best, and extend only to a distance of about six millimetres. The Round-mouthed Snail (Cyclostoma elegans), however, whose eyes are not mounted on tentacles, can see to a distance of about a foot.

The sense of hearing has not been very extensively investigated, at least little but negative results have been obtained from experiments made with a view to testing its extent. One experiment of the kind made by Mr. W. Bateson in the Plymouth Laboratory of the Marine Biological Association, a few years ago, showed that a Saddle-oyster (Anomic) suspencled in the water to be free from any chance of jarring of the solidly-framerl tank, closed its valves on Mr. Bateson making a creaking sound 
of a particular pitch by rubbing his finger along the glass.

The seat of hearing resides in a pair of closed cells called otocysts filled with a clear fluid in which are suspended one or more grains of chalky material called otoliths, and lined with cilia. These otoliths may be very numerous, and they are agitated by sounds in the immediate neighbourhood of the animal. These vibrations act upon the cilia which convey impressions by the acoustic nerve to the cerebral or the pedal ganglia.

The most important of the senses to the Mollusca is apparently that of smell. It is quite certain that it is much farther-reaching than either vision or hearing, and more constantly in use. Great numbers of carnivorous mollusks, such as whelks, dog-whelks, and naticas, are found in lobster-pots baited with "high" fish which they have smelled through the waters. Slugs appear to be highly endowed with this sense. Apples and bean-pods dropped in the centre of a road will draw slugs from the hedges on either side. As soon as certain species of Agaric come up in the woods slugs bear down upon them and commence feeding upon them. They are also able to locate a dish of milk in a dairy and proceed to drink from it. Of course, this sense is more highly developed in the active univalves than in the more or less sedentary bivalves, but the agile Pea-shells (Pisidium) are not deficient in it, as shown by the numbers that swarm over any dead animal that has been thrown into a ditch or pond inhabited by them. Some of the Sea-slugs have a special pair of antennæ furnished with projecting plates which are believed 
to collect sensations of smell from the surrounding waters. They are therefore known as rlinophores or nose-bearers.

The sense of touch is acute, as must be obvious to anyone who has handled almost any species of mollusk. Creatures of such soft substance must necessarily be very sensitive in this direction or they would meet with many injuries. To touch a snail, however lightly, is to cause it to shrink into its shell at once. A slug has no shell that it can crawl into on being molested, but it instantly draws in its eyes and antennæ and hunches the body up into a thick, short heap that exposes the minimum of surface to attack. In many of the shelled species the margin of the mantle is cut up into lobes and filaments which are all very sensitive to touch, and in some there is in addition a pair of protruding palps near the mouth that serve as tactile organs. These palps are also present in the bivalves but there, except in special cases, most of the tactile work is performed by the foot and the siphons. 


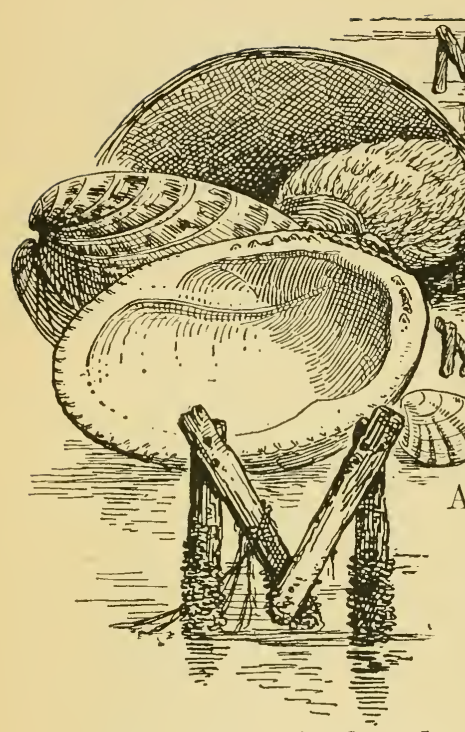

ANY different systems have been adopted at various times for the intelligent and orderly arrangement of the bivalve mollusks (Pelecypoda). That followed in these pages is based upon the character of the breathing organs, and, all things considered, this appears to afford the most natural basis. In the sketch of the Swan Mussel in the opening chapter the position and structure of these organs were briefly indicated, but in that species the gills have reached a high stage of development. Starting from the simplest form of such organs we find examples in the little Nut-shells that burrow in the mud and sand of our seashores.

The most plentiful of these is the Common Nutshell (Nucula nucleus), whose empty shells may be found along our beaches washed in from deeper 
water, its living range being between 3 and 145 fathoms of water. The shell, as shown in the figure, is bluntly triangular in shape, coloured outside with yellowish green marked with darker growth-lines running parallel with the lower margin, whilst many very fine grooves radiate from the rather prominent beak to the lower margin. The little creature

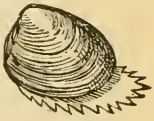

Common Nut-shell that produces this shell is cream coloured; its mantle has plain margins, and its oval foot is toothed all round the edge. The mouth and lips are small, but the lips have long appendages which are protruded from the shell at the same time as the foot, and used as sense-organs in the search for food. The small brown gills are simple and plume-like.

The maker of the Nut-shell burrows among sand and gravel, the "foot" being extended to its utmost length and worked between the fragments; each tip of the tooth-like edges then catches hold of a particle of gravel, the foot as a whole is shortened, and so the shell is hauled along by the contraction of the foot. At the same time the appendages of the lips feel about for food. When the dredge has scraped up one of these little mollusks from the bottom there is no foot visible; it has been withdrawn into the shell, and the valves now fit closely together.

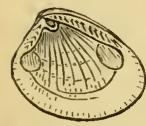

Interior of Nut-shell Only the insertion of a knife to sever the muscles, or to break them by leverage, can effect the opening of the shell. The examination of an odd empty valve, picked up on the shore, or of the accompanying figure, will help us to understand how this firm closure is maintained. It is a left-hand valve, 
so that the figure shows it in its natural position, with the concave side towards us. In the complete shell the upper margin of this valve is connected with its fellow by a kind of hinge (ligament), resembling those primitive leather hinges by which boys attach lids to boxes and doors to rabbit-hutches. This shell hinge, however, is more horny than leathery, and is, so to speak, fixed on the stretch, and this explains why when a bivalve mollusk dies its shell gapes open : the hinge-ligament exerts a pulling action which tends to separate the lower edges.

Just beneath the beak inside each valve there is a little spoon-shaped projection containing a bulging bit of elastic cartilage, which also serves the

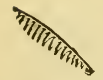
purpose of forcing the valves apart. On either side of this cartilage is a row of low Hinge-teath
(enlarged) ridges like the teeth of a comb, and into the spaces between similar teeth on the right valve fit; the lower margin of each valve is also faintly marked in a like manner. The number of the hinge-teeth varies in different species; in the present one there are about 15 teeth in front of the beak and about 25 behind it. The object of all these interlocking teeth is to ensure the accurate closing of the valves when they are brought together, and to prevent any lateral movement that would enable an enemy to destroy the hinge. But the mechanism by which the two valves are closed and held tightly together, in spite of the opening action of the hingeligament, consists of a couple of bands of muscle, one towards each end of the shell. On the pearly inner surface of the valve we can see slight oval impres- 
sions of the ends of these muscles; these are the points to which they were attached. The hinge-teeth on the valves of the Nut-shells are simple in character, but we shall find in other species that they gradually became more complex.

There are three other native species of Nut-shells whose peculiarities may be briefly noted in contrast with those of the common species. The Furrowed Nut-shell $(N$. sulcata) has a larger, more triangular shell, with five ridges parallel with the lower margin; dull olive. Found locally in from 3 to 50 fathoms where the bottom is of sandy mud or clay. The Shining Nut-shell ( $N$. nitida) is more acutely triangular, yellowish brown, and very glossy; mantle fringed. Sand and gravel from extreme low water to 86 fathoms, but not very common. The Thin Nut-shell (N. tenuis), though still triangular; has a tendency to roundness of outline, but flattened

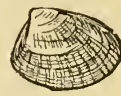

Shining Nut-shell from side to side; brownish yellow, thin, and glossy. Found locally, in sand and mud from 25 to 100 fathoms, chiefly along the Scottish coasts, the northeast of England, and east and south of Ireland. The external colours given above are those of the living epidermis or periostracum, which invests and protects the shell from the action of gases dissolved in the water. Beneath this covering the actual surface of the shell may be entirely different in hue, but where the epidermis is permanent it will be more convenient to indicate its colour rather than that of the shell.

Closely allied to the Nut-shells are the four native species of Lecla, but they are readily distinguished by several differences in form and structure. One 
important advance in development consists in the production of the hinder part of the mantle into two long tubes or siphons, which are

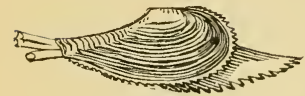

Beaked Leda

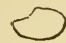

Dwarf Leda thrust out beyond the shell and reach up to the water above the mud and sand in which the creature burrows. The purpose of these siphons is to enable the Leda to remain safely buried whilst it gets a constant fresh current of water over its gills, and to bring microscopic food to its mouth. Through the lower of these tubes the fresh supplies pour in, whilst the vitiated current carrying off waste passes out through the upper tube. With a view to the better protection of these siphons the shell has been elongated backwards. In the Dwarf Leda (L. pygmaca) the siphons are not very long, and they are united throughout their length, showing that though the mollusk affects deep water (20 to 86 fathoms) it does not burrow much below the surface of the mud, or indeed remain entirely covered by it. Its tubes may be entirely withdrawn into the shell, which closes all round as do the Nut-shells. The shell is scarcely a quarter of an inch long. The Beaked Leda ( $L$. minuta) is a much larger species, and the great change in the shape of the shell shows that the creature is given to burrowing more deeply and to remain buried. The siphons, which are united only for half their length, have become much longer in order to reach the water

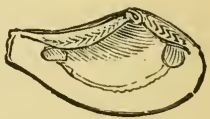

Interior of Beaked Leda-shell above, and the shell has become greatly lengthened behind for their partial protection, there being 
insufficient room in a shell shaped like that of L. pygmeece to withdraw the whole of the long siphons. The valves at this point do not fit closely. There is a slight gape, and this indicates that owing to the constant protrusion of the siphons the mantle is never able to extend the edges of the shell so that they will meet. In some other bivalves we shall see that the foot also is kept so constantly distended that the shell gapes at the front end also. The hinge-teeth are in this species less simple in their. shapes, as will be seen in the figure of the interior of a left valve. It is found in muddy gravel and sand between 20 and 100 fathoms deep, on our northern coasts.

The two genera Nucula and Lede constitute the sole British representatives of the order Protobranchiata, the bivalves in which the branchiæ or respiratory organs have the simplest character. They consist of parallel, unbranched, independent filaments arranged in two rows on each side of the central body-mass. In the next lowest group, the order Filibranchiata, the filaments have become so long that they are folded back upon themselves and show signs of lateral adhesion. The order includes the Saddleoysters (Anomia), the Ark-shells $(A r c a)$, and the Mussels (Mytilus).

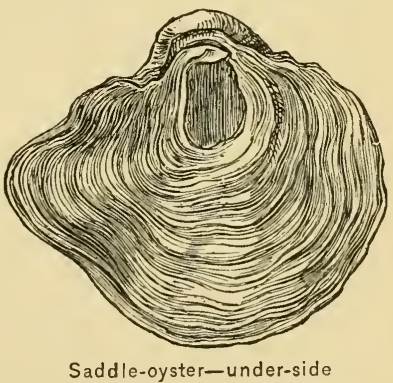

The Saddle-oyster (Anomia epllippium) is a thin, flat, little pearly shell found on old oyster-shells, crabs, 
rocks, and other submerged objects, and is not unreasonably - though quite inaccurately-regarded by the 'long-shore folk as the young of the true Oyster (Ostrea). It is not even closely related to the true Oyster, nor is it edible. It is by no means an easy task to persuade fishermen that these are not young oysters, but the quickest method of convincing them is to prise off the Saddle-oyster and exhibit its underside as shown in our figure. It is then seen that there is a pear-shaped orifice in the lower valve through which an attachment plug passes and fixes the Sacldle-oyster to its chosen support. No genuine Oyster is attached in this way, nor has it a hole in

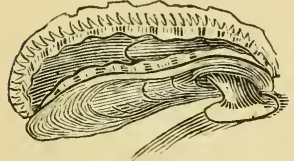

Side view of Saddle-oyster, showing mode of attachment its shell. The Common Saddleoyster is about 2 inches across when full-grown, variable in outline, but more or less circular. It is never very thick, but varies in this respect according to age. Outside it is dull white in colour, or tinged with yellow, pink, or brown; within it is polished and opalescent. The lower valve in its growth follows the modelling of the surface to which it is attached, whether that be the smooth rounded stem of a huge seaweed, the rough surface of the rock, or the ribbed shell of a scallop. The upper valve, of course to a less degree, follows the shape of the lower. Normally the lower valve is flat and the upper one convex. There are no hinge-teeth as in the Nut-shells, though there is a half-moon shaped par of cartilage to keep the valves apart when the single muscle is relaxed. The plug by which the shell is fixed to its support is 
attached to the upper valve and passes through the lower one. It appears to represent the byssus-threarls of the Mussel and Scallop united into a solid mass. The expanded end evidently corrodes the living surfaces to which it attaches, for it is frequently found to be lodged in a little pit.

The animal varies in colour from yellow to red and brown. Its mouth

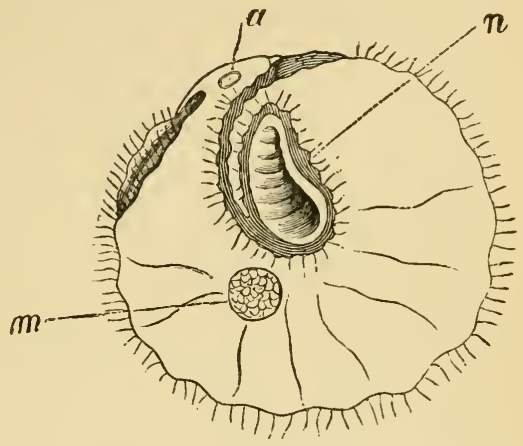

Right side of Anomia, with shell removed a, opening for hinge; $m$, adductor muscle; $n$, calcified byssus is large, and furnished with a pair of long slender lips. As the animal does not burrow, and is usually found solitary, it can develop its shell pretty equally in all directions; the mantle is therefore more or less circular like the shell, its margin fringed with two or three rows of yellowish filaments. Again,

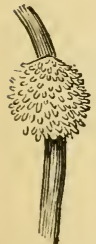

Prickly variety of the Saddle-oyster because it is not a burrowing or otherwise active animal, the white cylindrical foot is very small. There is a variety (aculeata) in which prickly scales are developed on the upper valve.

The only other British species is the Ribbed Saddle-oyster (A. patelliformis), smaller than the last, and attaining to little more than half its dimensions. From 20 to 30 waved ribs radiate from the beak to the margin, and the shell is often ornamented with 
streaks or spots of red-brown, and by a number of fine overlapping scales. It is a common but littleknown species, its range being only between the depths of 10 and 86 fathoms. Both these species appear to owe their security alike from storm and enemy to the thin flat form that sits so tightly on its chosen base, and affords little opening to the predatory fish or bird that might consider its thin body worth prising off.

The Ark-shells (Arca) present an appearance very different from the exceedingly thin Saddle-oysters. The Common Noah's Ark (A. tetragona) is a quaint little yellow and brown box-like shell of distorted aspect that loves to spend its time in the

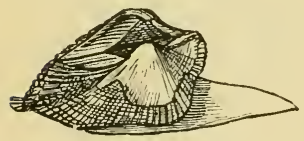

Noah's Ark crevices of rocks, or attached by its byssus to the empty shells of other bivalves. A perfect specimen is covered all over with ridges which radiate from the beaks to the lower margins, whilst other but less prominent ridges cross these at right angles; but owing to its habit of grubbing in crannies and among rubbish, the greater portion of this ornamentation gets rubbed off, as shown in the illustration, and consequently it is not easy to obtain a good example. The beaks are wide apart, and the 40 to 50 hinge-teeth are of simple form. Towards the hinder margin of the whitish mantle there is a number of closely grouped ocellidark spots that are not true eyes but which are so sensitive to changes in the intensity of light that they serve the same purpose. They consist of cells filled with a dark pigment and covered with a cuticle of ligh refractive power. Real eyes are 


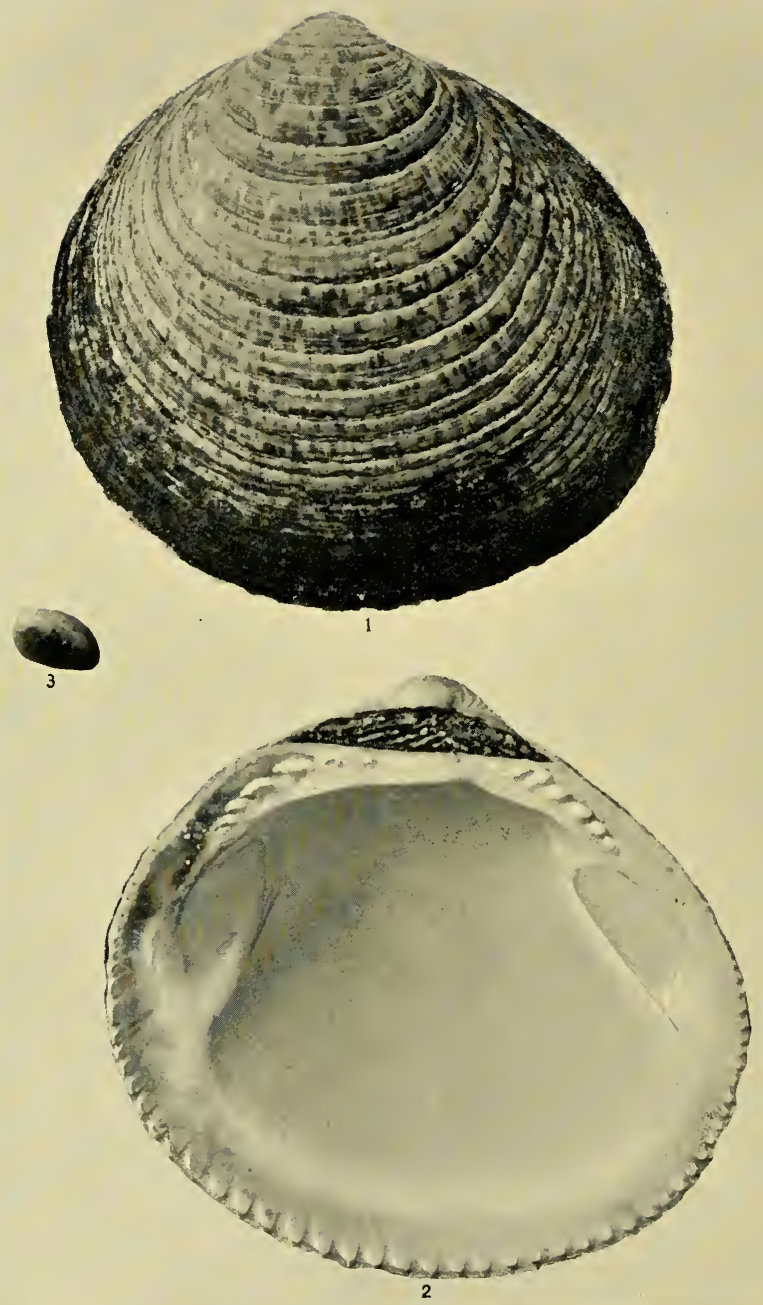

I Dog Cockle exterior; 2 Ditto, interior; 3 Grien Crenella. 
seen in the larval condition of many species, and this is part of the evidence that the bivalves have degenerated from a higher primitive type. The conical white foot has a deep central groove, through which a dark green byssus is spun. The porcelainlined interior of the shell bears large oval impressions of the muscles, and the inner margin is marked with a series of indentations, those of one valve fitting into those of its companion. The Noah's Ark occurs on all our coasts, at all depths.

There are four other native species: one, the Hebridean Ark (A. pectunculoides), with thinner shell, finer sculpture, and the left valve larger than the right, is found chiefly in deep water (35 to 100 fathoms) round Shetland and the Hebrides. Another, the Milky Ark (A. lactea), has valves of equal size, their white colour partially hidden by the brown velvety epidermis. The animal is not much given

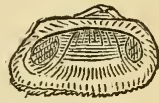

Milky Arkinterior to burrowing, but chiefly attaches its short horny byssus-threads to the inside of old shells and to rock-crevices between 15 and 25 fathoms, on all our shores.

The Dog - Cockle or Comb-shell (Pectunculus glycimeris) has an appearance quite distinct from any other native species, and requires very little description to enable one to identify it. The shell is nearly circular, of a dull yellowish - white colour, irregularly marked with zigzag lines and conical patches of dark red. The epidermis forms a thick dark brown velvet, but from most specimens that are washed up the beach this is all rubbed off. On specimens dredged up from the deeper water it 
affects (7 to 90 fathoms), a band of epidermis will usually be found bordering the lower margin. Large examples measure $2 \frac{1}{2}$ inches across. It would appear that many fishes not strong enough to crush this solid shell yet make attempts to wrest its valves apart, for great preparations have been made to keep off such enemies. The valves are united by a number of bundles of ligament, attached to long triangular cavities sunk in the shell between the beak and the broad hinge-plate. The hinge-teeth are thick, and in adults number about six on each end of this plate, which is plain in the centre, though young individuals exhibit a few minute teeth here. The impressions of the mantle and muscles are very deep on the interior, and the flat, lower margin is impressed with about 50 teeth, in appearance like the edge of a coarse comb. Those of the two valves interlock, and so prevent the slightest shifting by the most powerful assailant when the shell is closed. In spite of this, it has one enemy that it cannot defy. This is the Cat-fish, which cracks the stony shells with its long powerful teeth as though they were nuts. The animal is of sluggish habit, and lives on the surface of gravel and among "nullipore," all round our coasts. It does not burrow, and therefore has no siphons, but the edge of the mantle is somewhat contracted and protruded at the hinder side of the shell; at this part, too, it is studded with a great number of black eye-spots.

The Eared Limopsis (Limopsis auritu) somewhat resembles the Dog-Cockle internally, though the shell is less round and owes its name to a fancied likeness to Lima, the File-shell. Although common 
as a 'Tertiary fossil, in a living or recent state it is rare. A few specimens have been taken in deep water ( 85 fathoms) off the Shetlands. It is a very small, glossy white shell, marked with fine lines radiating from the beak, and crossed by irregular ridges. The yellow-brown epidermis takes the form of a fringe of long hairs. The margins of the shell are rounded except behind the hinge, where its straightness gives the eared appearance to the shell. Like those of the Dog-Cockle, the strong teeth of this species are in a continuous line, but confined to the hinge-plate. The lower margins are devoid of teeth. It has a long thin foot, by means of which it creeps and climbs, and spins an almost transparent thread.

The Common Mussel (Mytilus edulis) is one of the most useful of the Mollusca to mankind, for in addition to its wide use as a food, it is of great value as a bait in the long-line fishing. Strongly gregarious in its habits, it attaches itself to rocks, timbers, and masonry by its tough byssus spun by the short darkbrown foot. This habit of associating in closely packed masses has doubtless led to the contracted wedgelike form of the shell, and to the absence of - in this case - unnecessary hinge or marginal teeth. Occasionally a few small hinge-teeth are developed, but as the species indulges in very little locomotion after early life these are not much needed. The mantle has a double margin, the outer one plain, whilst the inner is at different parts fringed or toothed, and on the hinder part formed into an inperfect siphon.

Though the Mussel is always found hung up by its 
byssus, it is by no means a prisoner. It possesses the

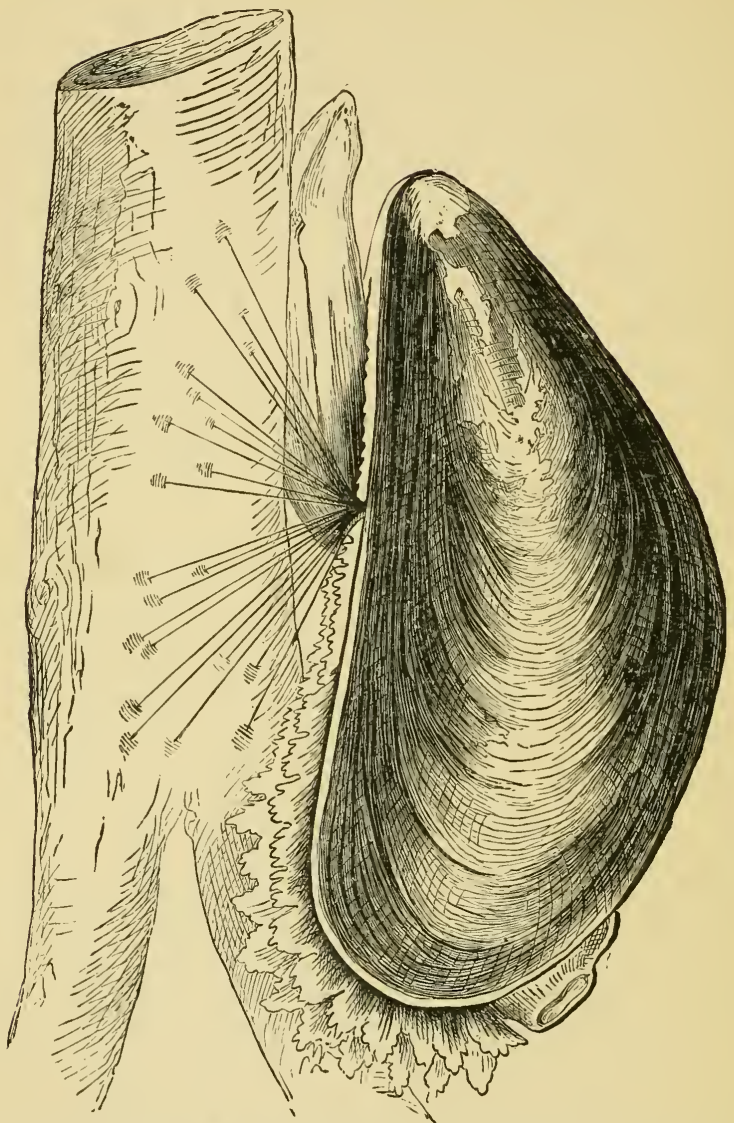

Common Mussel (Mytilus edulis), closed and attached by the byssus (nat. size)

power of separating itself from these threads. In an aquarium when a Mussel has attached itself and then 
grown dissatisfied with its position, you will see the broken and discarded byssus-ends in patches all over the tank. Mussel-beds on some parts of our coasts have been jealously watched because of their power to hold the mud and sand, and prevent the foreshore shifting away with the tides and currents. The story of Bideford Bridge is founded upon the knowledge of the binding power of the bysius. Most books mentioning Mussels repeat the legend that Mussels instead of mortar bind the stones of the bridge together, and that, therefore, the town authorities forbid the removal of

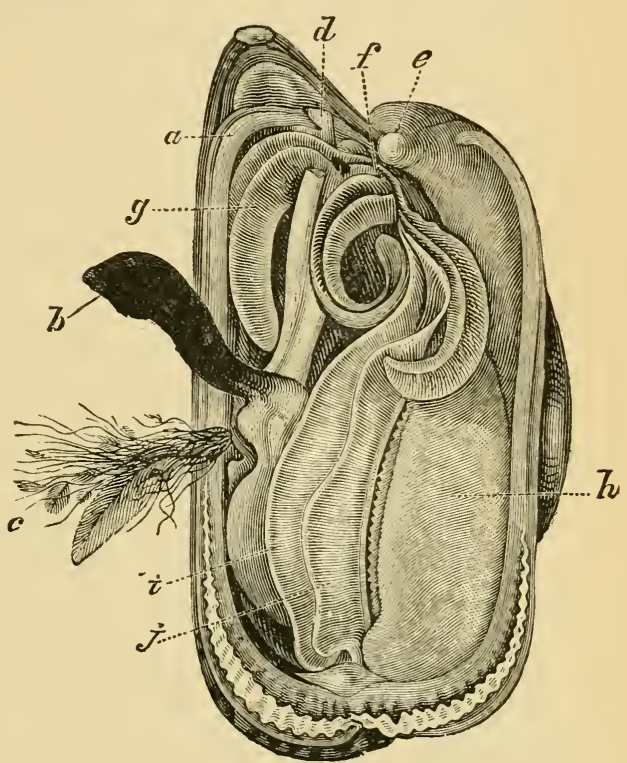

Common Mussel, opened to show the various organs (nat. size)

the mollusks that $a$, mantle edge $; b$, foot; $c$, byssus; $d, e$, muscles of the foot; throng its piers $f$, mouth $; g$, lips; $h$, lobe of mantle $i, j$, gill plates

It is true that a prohibition of this sort exists, but it is due to a conviction that the Mussels keep off the wear and tear of the tide. Mussels at times give rise to very unpleasant symptoms in those who have eaten them, occasionally even causing death. All kinds of theories have been invented 
to account for this unwholesome condition, but it would appear to be due to their growth in the comparatively stagnant waters of harbours, or to their being laden with spawn. In various parts of the coasts of Europe, Mussels are in a sense cultivated by placing boughs of trees on the mud, which become covered thickly with Mussels. The boughs are taken up after a few years and sold by weight. The accompanying woodcut showing the various parts of the animal will help to make clear further descriptions of the bivalves.

The large Horse Mussels are by most authors separated from the genus Mytilus and known by the name of Mocliolu. Of these we have several distinct species. Their shells are more oblong than wedgeshaped, quite without teeth, and the byssus though much finer is also more ample. Instead of hanging themselves up, they burrow, and some spin a kind of byssal nest around themselves in which gravel and other marine rubbish is mixed up. The affix "Horse" signifies that these Mussels are coarse and

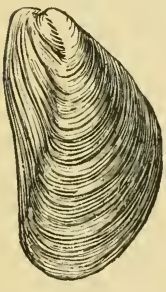

Common Horse Mussel (reduced) unfit for food.

The Common Horse Mussel (M. modiolus) may be distinguished readily from the Mussel by the fact that the beaks instead of being at the extreme pointed end of the shell are at a slight distance from it. The thick solid shell is purplish yellow in hue, but its true colour is disguised by the dark brown epidermis which, in young specimens, becomes drawn out into long fringing processes. As in the Mussel, the impressions of the mantle and muscles are 
well marked. The animal, too, may be at once identified by its difference in colour from the true Mussel. The latter has a creamy white tint, but this is dark orange; the foot red, whitish towards the thick and wrinkled base. Both margins of the mantle are without fringe or toothing, though covered with delicate cilia.

Its habitat is a muddy gravel at various depths between low water and 80 fathoms, most plentifully on our northern coasts. Its usual size is about 5 inches long, but it has been found over 9 inches in length. Its roomy interior is a favourite resort of the Pea-crab, which appears to live on the most friendly terms with it, and to avoid all risk of injuring its host has got rid of every one of those angles and sharp edges that characterise most crabs, and is now as smooth and glossy as glass, with every edge rounded.

There are several other British species described, of which one or two are possibly only juvenile forms. The Bearded Horse Mussel (M. barbatus) is little more than 1 inch long, with an orange or scarlet shell, mostly hidden by a thick yellow-brown epidermis, which on the back and front of the shell is so split up as to form a fringe of thorns. Each of these thorns is bearded along one side only, as shown in the figure of a small portion. It occurs on the south and west coasts of England and Wales; rarely on the east; also on the south and west of Ireland. Its habitat is on rough ground from low water

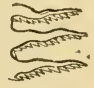

Part of epidermis to 18 fathoms. The Tulip Horse Mussel (M. adriatica) has a broad convex shell, slightly smaller than 
the last, thin and glossy, of a yellowish hue, the hinder portion being also usually marked with rosy

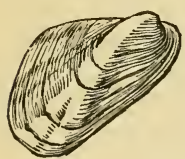

Tulip Horse Mussel or purple streaks after the manner of a tulip. The thin polished epidermis is almost transparent. It occurs very locally in Scotland, more frequently in the south of England, around Ireland, and along the Welsh coast, preferring a bottom of gravel or sandy mud, at depths ranging from 7 to 40 fathoms; but it cannot be reckoned as at all a common shell in British waters. The general aspect of the Bean Horse Mussel (M. phaseolinus) is similar to that of the Bearded Horse Mussel, owing to the manner in which the epidermis is split up into slender processes. But the difference may be seen at once if one of these filaments be examined, for neither of its edges is bearded as in $M I$. barbatus. Stripped of this shaggy coating the shell would be seen to be very much the shape of a kidney-bean, as indicated by the name phaseolinus, and of a yellow colour tinged with purple. The hinge-plate is sculptured into a series of round teeth. It is about threefourths of an inch in length. It is common on all our rocky coasts from low water to a depth of 86 fathoms.

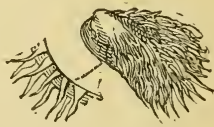

Bean Horse Mussel It often disguises itself by spinning up fragments of shell and gravel with byssus into an outer envelope.

The "crenulated" or notched hinge and upper margin of the last species constitutes a connecting link with the genus Crenella, which has obtained its name from such ornamentation. The shell resembles that of Nucula in the fact that it is entirely 
composed of "mother-o'-pearl." The mantle forms only one siphon,-that for getting rid of waste, and this is very short,-fresh supplies being taken in by the open front. 'The foot is of peculiar' construction, consisting of a cylindrical stalk and a tongue-shaped expansion which is used for crawling. Instead of spinning an extensive byssus, these content themselves with a single thread by means of which they suspend themselves. The genus is now restricted to two species, though formerly those now forming the genus Moctiolaria were included in C'renella.

The Glossy Crenella (C! rhombea) has a solidlooking, glossy white shell, marked by delicate radiating ribs, and covered by a slight pale yellow epidermis. The broad hinge-plate is notched or crenulated as already noted, and bears a wedgeshaped tooth with notched edges. The interior edges are also crenulated, so that the valves securely interlock all round. It is less than one-quarter of an inch in length, and occurs on rocky coasts in the south-west of England and round the Channel Islands from low water to about 20 fathoms. The Crosscut Crenella ( $C$. decussutu) is more oval than the last, of the dimensions shown in the figure. It is also glossy, but the number of ribs is smaller, and they are crossed by fine hair- crenella like lines. At the points of contact these lines are slightly raised into minute rounded points. The epidermis is thicker and of a darker hue, so that the general appearance of the shell's colour is pale olive. It affects gravelly sand on our northern coasts, from Yorkshire and Northumberland to the Shetlands, and ranging from 3 to 70 fathoms in depth; it 
also occurs off the coast of Antrim, Ireland. It is very active, and likes to climb and hang suspended by its thread.

The Moctiolarias, though formerly regarded as Crenellas,-which we retain as a popular name,differ from these in several small but sufficiently important points. The mantle forms a distinct incurrent tube in front and an excurrent one behind. The foot is strap-shaped, and may be extended until it is a mere thread two or three times the length of the shell. The shell is rhomb-shaped, but instead of the ribs on the surface extending equally all over the shell they are in two series, which leave the centre of the valves plain. The hinge-plate is notched as in Crenella, but as a rule the central or cardinal tooth is wanting. There are four British species. The Marbled Crenella (M. marmorata) though

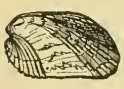

Marbled

Crenella somewhat angular is roughly oval in shape, thin and glossy, pale green marbled with red-brown. Its byssus is almost transparent, but tolerably strong. It lives among the root-like suckers of the larger seaweeds, in the crevices of rocks, the interior of empty shells, and very commonly embedded in the tough coat of the simple ascidians. An average specimen of Ascidic mentule may yield as many as twenty of these mollusks, which do not appear to cause any inconvenience to the host. It occurs on all our coasts, but must be sought below the lowest tide-mark, in what are known as the Laminarian and Coralline zones. If not satisfied with its present quarters, it displays considerable activity in seeking others, stretching its foot to its greatest extent, and having 
taken hold by its tip, pulling itself rapidly along by contracting its foot again. Having secured a corner to its taste, it spins its byssus and becomes fixed for the time. The Ribbed Crenella ( $I I$. costuluta) is a much smaller and brighter species, the shell proportionately narrower, cream coloured marked with purple-brown streaks, which are often zigzag, and which show through the pale green epidermis. Occasionally it attains the length of half an inch. It is local on the coasts of Devon, Cornwall, Wales, Donegal, and the Island of Herm, where it may be found spun up under stones, or on small seaweeds, in the lowest range of rock-pools, often with shell fragments and gravel mixed up with its byssus. The Green Crenella ( $I$. cliscors) is slightly longer and much broader than the last, yellowish brown, with a rather thick green epidermis; less angular than the others. The animal sews together branches of the common coralline and other small seaweeds that it may dwell in safety within the nest. It is very generally distributed, and may be found

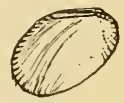

Green Crenella -interior abundantly in rock-pools at half-tide and below. The Black Crenella (M. nigra) is so-called because in aged specimens the epidermis assumes a black tint; more frequently it is something between a purplish brown and dark olive when looked at closely. The colour and the sculpture at once distinguish it from the Black Crenella others. The two sets of ribs from the beaks are crossed by a third and coarser transverse set, which form a network, often with minute knobs at the 
intersections. It is a purely northern species, being found round the coasts of Scotland and Shetland, extending south only as far as Yorkshire and Durham; occurring in muddy gravel at depths ranging from 7 to 90 fathoms. Large specimens may measure as much as $2 \frac{1}{2}$ inches. It is known to northern fishermen as the "Corduroy Mussel."

These are the only genera of Filibranchiata represented on our coasts. 
varying from 10 to 15 inches in length, with a greatest breadth of more than half that measureinent. The shell is wedge-shaped, the beaks at the extreme front, the broad end gaping and closure impossible. For two-thirds of their upper margins the valves are connected by a narrow, horny, elastic ligament, set in a fold of the toothless hinge-plate. The glossy, horn-coloured, thin shell is marked by lines radiating

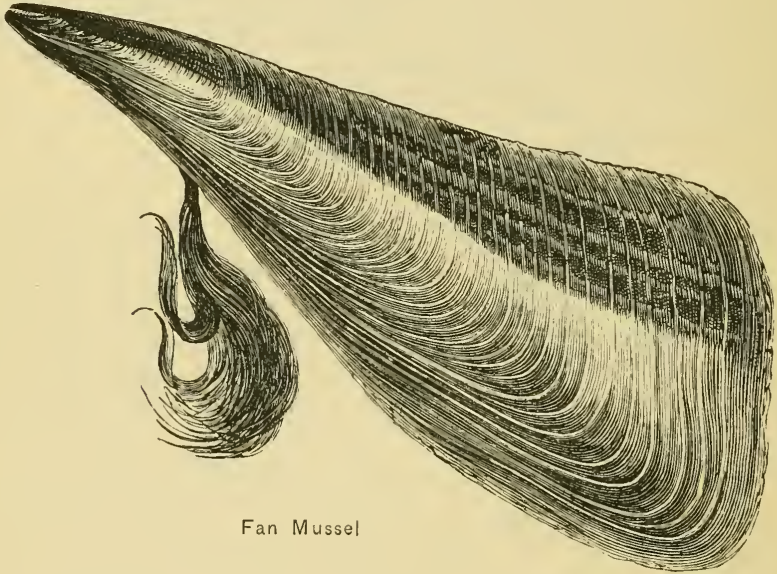

from the beaks to the hinder margin, and lines of growth crossing these. The animal, which varies in colour from yellow to rerl-brown, uses its foot chiefly for spinning the strong and abundant byssus by which it moors itself to the bottom. The connection between form and habit is at once seen in all the members of this order: they are inactive creatures, so the foot, which is primarily a locomotive organ, has dwindled to small proportions. The byssus-shown 
in the figure-has been worked up, as an object of curiosity chiefly, into muffis and other articles, and when mixed with silk has been woven into gloves.

Although the Fan Mussel occurs all round our islands, in mudily gravel or sand, from low water to a depth of 80 fathoms, it cannot be regarded as a common species. Where it does occur it will be found in some numbers, for it is gregarious in habit, like all the species mentioned in this chapter. The pointed forepart of the shell is inserted in the ground, so that the broad open end is uppermost. The fishermen avoid the ground where the Fan Mussels are

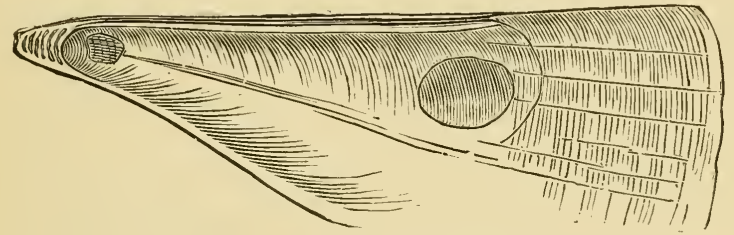

Interior of Fan Mussel-right valve

from fear of having their nets destroyed by the sharp knife-like edges of these broad ends. I have already referred briefly to the little Pea-crab (Pinnoteres) as lodging permanently in the shell of the Mussels and Horse Mussels; still more does it affect the Fan Mussel, in which retreat it came under the notice of Pliny and other ancient writers, who called it Pinna's Friend, and invented many marvellous fables of the loings of these strange partners. Except on the supposition that the crab acts as a housemaid or scavenger it is not easy to understand what advantage the mollusk derives from the partnership. Crab 
architecture is rich in angles, sharp edges, and spines, to serve various purposes in their lives; but the Peacrab has given itself up so whole-heartedly to the comfort of its friend that it has got rid of every angle, every sharp edge, every spine and stiff hair. All its parts are rounded, and polished with a surface like glass, so that the movements of this strange little crustacean between the gills of the Pinna camnot cause injury to the very delicate tissues of the mollusk.

The Oysters are represented in our fauna by the solitary species which has from the earliest human period been regarded as a luxury, because the demand appears always to have exceeded the supply; and concerning whose structure, growth, artificial cultivation, and commercial value very much has been written.

The Common Oyster (Ostrea edulis) needs little description, its shell being at least as familiar in the

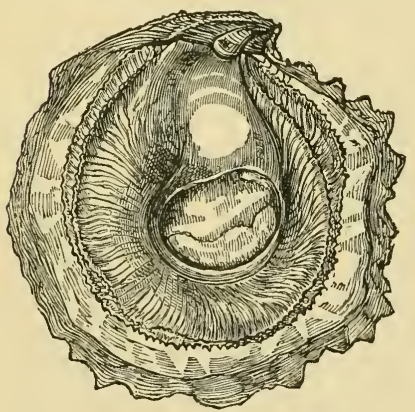

Oyster, with right valve removed streets of inland cities as it is on the seashore. Attention may be called to the fact, however, that the valves are not equal in size or form, the lower (left) being larger and convex, and the upper (right) is flat or slightly concave. Whilst the left is frequently marked by overlapping plaits, folds, and flat spines, the right is usually plain. The shell of the very young Oyster is round in outline, but 

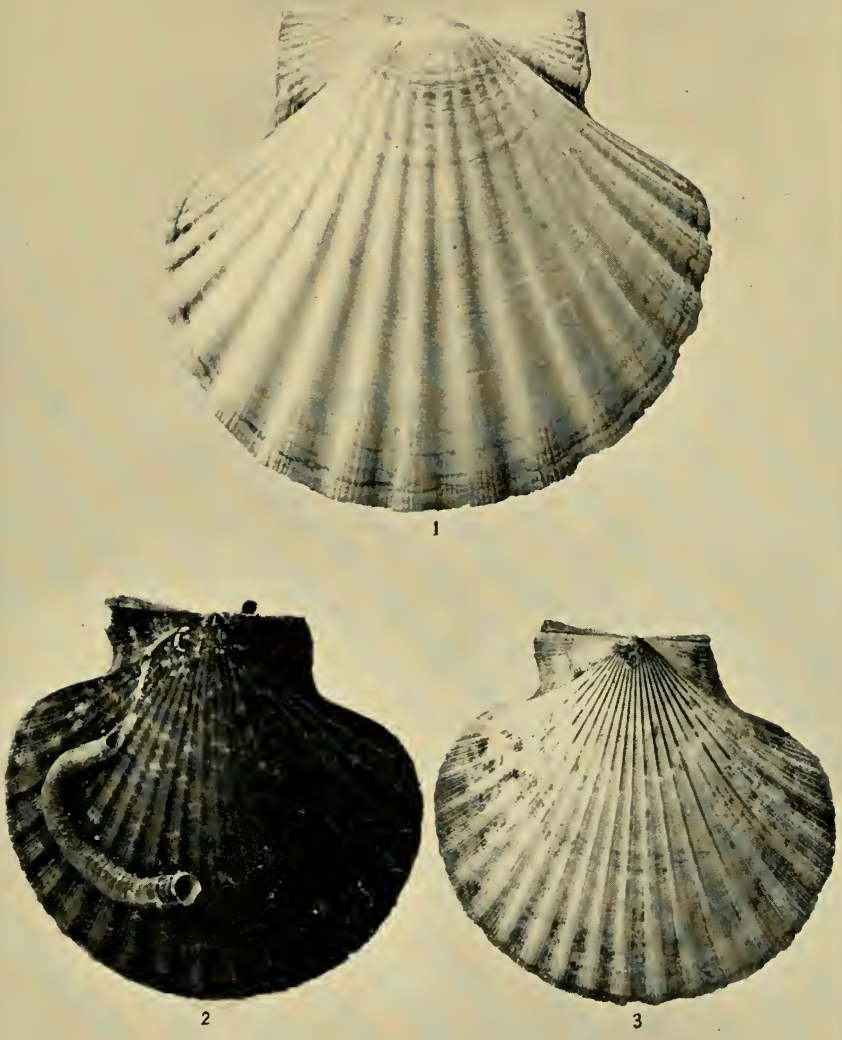

2.

I Great Scallop; 2 Quin (With tubes of Seríla); 3 Quin, white variety. 

its succeeding growth will in all probability greatly modify this form. At an early stage of existence the left valve becomes cemented to a stone, an older shell, or to some other object on the bottom, and thenceforward remains a fixture. It has, therefore, no need of a foot either for locomotion or for spinning a byssus, and the foot is absent. The mantle has a double margin with a fine fringe; the lips are large and nearly triangular. In the adjoining figure it will be seen that the solitary muscle for closing the valves is placed nearly in the centre of the shell. In the species considered in the previous chapter there were two such muscles, one at each end of the shell but away from the beaks. In Pinna, though these muscles appear to have changed their positions, it is really the beaks that have moved to the extreme front of the shell. In Ostrea, one muscle has entirely gone, but the remaining one is much enlarged. There is a thick, strong, curved pad of cartilage between the beaks to keep the valves open, and a short ligament on either side of it. The hinge-plate is thick, but not furnished with teeth.

Having regard to the number of natural foes,apart from man, the most rapacious of them all,-it is not surprising to learn that the progeny-"spat"of one Oyster may be anything from a few hundred thousands to sixty millions. When discharged by the parent these are furnished with delicate cilia, and by lashing these they float through the water during the first two days. They then settle on some suitable foundation, to which they become permanentlyattached -or they perish. The character of the weather at this period is of the utmost importance to the future 6 
Oyster supply; and the Oysters have selected the summer months as affording the greatest chance of success. A warm day and a quiet sea are the favourable conditions required; with a low temperature and troubled waters there is every probability of the spat being destroyed, or, what is almost as bad, carried far out to sea.

Left on their natural banks Oysters are full-grown in about four years, but when dredged and laid down again in the culture beds they take several years longer. "Natives" are those supposed to have passed the whole of their lives in the beds about the mouth of the Thames and Medway, but many of them no doubt are those that have been dredged in distant parts of the coast, purchased by the Kent and Essex merchants, and relaid for a year or so. Oysterdredging is regulated by local fishery bylaws, which fix the minimum limit of size at which dredging is legal; $2 \frac{1}{4}$ inches, for instance, being the minimum at Falmouth, the Oyster then being about $2 \frac{1}{2}$ years old. They are considered to live about ten years, but to be at their best at five years, when the shell measures as many inches across. The "Green Oysters," or huitres de Murennes, of Normandy have been specially fattened on a green diatom (Navicula ostrearic) in ponds rich in this particular form of microscopic plant-life. In the course of several years of this diet the Oyster in turn becomes green, and acquires a special flavour.

Both on the natural sea-banks and the estuarine beds to which they are transplanted, Oysters have a number of enemies to contend with. Starfishes and crabs are the best known of these, and they can be 
captured and destroyed; but a more insidious foe is not evident until its mischief is done. This is a small orange sponge (Cliona) that bores a network of tumnels ramifying completely throughout the shell, rendering it rotten, and compelling the Oyster constantly to deposit new layers of shelly matter within to keep the intruder out. Whelks and other mollusks with drilling power bore through the shells and eat out the Oyster; whilst the octopus with his parrotlike beak, and the skate with its powerful teeth, also ardd to the destruction. The Oyster occurs naturally on all our coasts ranging in depth from low water to about 45 fathoms.

The Scallops (Pecten) are not only the near allies of the Oyster, but some of them share the same beds with their more valuable relatives. Though the Oyster is more highly esteemed on account of its commercial and gastronomic importance, the Scallops must be pronounced at once more beautiful and more interesting. The shell is more nearly symmetrical, though the valves are usually unequal, and the strong even ribs with which the surfaces are ornamented has made the shell familiar in decoration of many kinds. This shell though strong is thin, though hard is light. The strength is largely due to the hollow ribs, which make possible the lightness necessary for submarine flight, small Scallops and Quins being remarkable for their power of rapidly flitting with a zigzag course through the water by the opening and rapid closing of their valves. A glance at the interior even of an empty shell will show that the muscle for closing the valves is very large, and must conse- 
quently be very powerful. The ribs of the Scallop shell serve another important purpose besides that of combining strength with lightness: at the lower margin the ribs and intervening spaces of the two valves so accurately fit together that with the almost central muscle holding the valves together any shifting of them to right or left is impossible. The development of the "ears" at each side of the beak gives similar strength to the upper margin, and allows of the employment of a long though narrow ligament. The foot is developed as a fingerlike organ, occupied in the spinning of byssal threads, and space is left between the ears for the passage of these, the two valves being kept slightly apart at this place by a little boss. Ordinarily the shell is kept slightly open by the pad of elastic cartilage between the beaks, and then the mantle is seen to great advantage. Its margin is double, the inner finely fringed and the outer edged with long tentacles, and at their base gleam a row of large and brilliant opalescent "eyes," whose optical powers appear to be of a relatively high order. All the British species are unattached

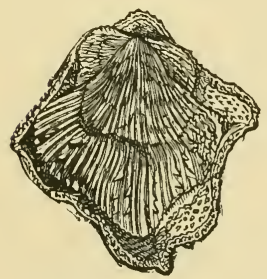

Hunchback Scallop with the exception of-

The Hunchback Scallop ( $P$. pusio), which in the adult state becomes attached like an Oyster by its lower valve. Though it begins life with as symmetrical a shell as the others, it has a liking for contracted quarters, such as the interior of vacated shells, clusters of certain corallines (Eschara), etc. After attaching the newest portion 
of its right valve to its support, its further growth proceeds unequally; so that the distorted appearance ensues which has suggested the title of Hunchback as a fitting one, though Linnæus called it pusio (a youngster), from what he evidently regarded as its immature or unexpanded appearance. In its early and regular condition the shell is longer from back to front, like the other species, but as maturity comes to it the distance from beaks to lower margin becomes greater than the length. The valves, too, that had formerly been equal in size, now become unequal, the upper often larger and more convex than the lower. The sculpture consists of larger and smaller sharp ribs, which alternate, and in an adult number about 70, here and there rising into prickly scales. It ranges through all shades of colour, from white through yellow and red to brown, streaked and blotched with other tints of the same series. The posterior ear is larger than the other; and the ocelli are few in number. It may be found where the coast is rocky, ranging from 5 to 85 fathoms.

The Variegated Scallop (P. varius) has only from 25 to 30 ribs of equal thickness, often bearing blunt thornlike plates on their upper sides. The ears are unequal, the hinder one being the larger. Its colour and markings are much like those of the Hunchback, but its ocelli-of which there are about 30-are smaller than

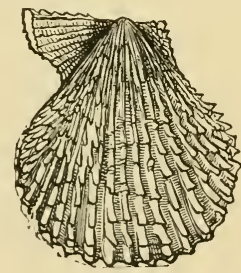

Dariegated Scallop in that species. It is well distributed all along our coasts, from extreme low water to a depth of 40 fathoms. 
The Quin or Queen (P. opercularis) is more nearly circular in shape, thin and smooth, marked by 18 or 20 broad, rounded ribs, sometimes with scales upon them. The ears are almost equal. The colour varies from white to yellow, orange, pink, red, brown, or purple, often marked with streaks or spots of other colours. The animal is as varied in colour as its shell. The 35 to 40 black ocelli have a pupil-like spot of greenish grey. Full-grown specimens measure from $2 \frac{1}{2}$ to 3 inches across. The Quin is more partial to sandy than to rocky shores, and that is probably the reason why it is less given to fixing itself, and more addicted to flitting like a submarine butterfly. It is strange that this power of flight should be so little known to fishermen: I have caused the most profound astonishment in some experienced members of this class by showing them Quins in full activity in an aquarium-tank. This species is much used for food on some of our coasts, the oyster-dredgers obtaining great numbers from the oyster-banks and selling them for a few pence per hundred.

The Seven-rayed Scallop (P. pes-lutrce) is also almost circular in outline, but at once distinguished from the others by the very different sculpture, the seven ribs being widely distant from each other. Between these strong ribs the somewhat glossy shell is very finely grooved. In the upper valve the ears are almost equal, but in the lower 

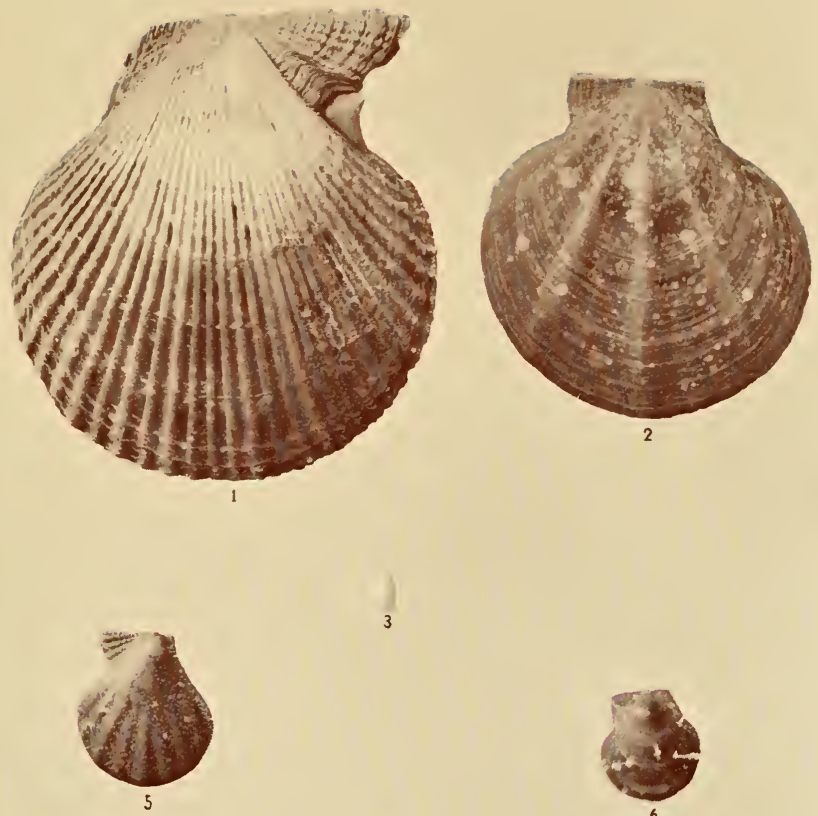

3
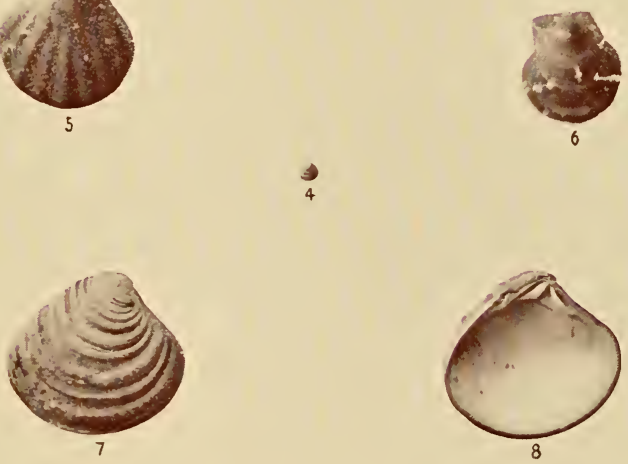

I Variegated Scallop; 2 Seven-rayed Scallop; 5 Tilier Scallop; 6 Mottlen Scallor; 3 Heart File-shelt ; + Triangular Astarte-shell; 7, 8 Furrowed Astarte-shei.l.. 

one the right ear is distinctly larger. The shell is ruddy brown in colour, marked with white, and measures $1 \frac{1}{2}$ inch across. It is entirely a northern form, Northumberland marking its most southern range on our coasts; it has a preference for rough ground and deep water, what is termed its bathymetrical range lying between 20 and 90 fathoms.

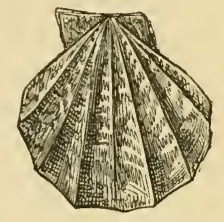

Seven-rayed Scallop (one-fourth nat. size)

The Tiger Scallop (P. tigrinus) has a smaller and proportionately thicker shell, covered with fine even corrugations but with only a few distinct ribs. The ears are very unequal, that to the left of the beak being three or four times larger than its fellow. It ranges from yellow (occasionally white) to purple, with the streaks and spots of other hues that have suggested its names. The animal varies from creamy white to red, and its 10 brown ocelli have pupils of gold. It is fairly plentiful wherever the bottom is sandy or gravelly, and is fond of hiding in the interstices of masses of coral or clinker, whence it Tiger flits at pleasure. Almost any stony mass from the bottom will be found to harbour a number of living examples of this species, providing its surface is at all broken up into minute caverns, where the little Porcelain-crab and many another marine animal will also be found. Testa's Scallop ( $P$. incomparabilis) is very similar, but with a broader, flatter, and thinner shell, less prominent beaks, and more equal ears. Its colouring is brighter, and as a rule the inside of the shell is without the crenu- 
lations which enable the valves to interlock. It is recorded from deep water (18 to 80 fathoms) at Shetland, Skye, Antrim, Galway, Exmouth, and Guernsey

The Mottled Scallop (P. striatus) differs but slightly at first sight from Testa's Scallop, but it is "larger, thinner, and more fragile," the ribs are

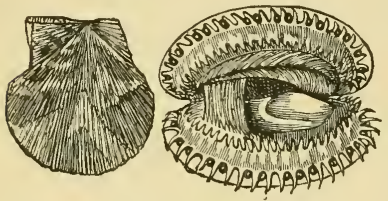

Mottled Scallop, shell and animal thickly covered along their ridges with projecting scales, and crossed by minute and irregular raised lines. The colouring, though similar, is less bright. The whitish animal has 25 crimson pupilled, blue-black ocelli, of unequal size and irregular disposition. It is found on hard ground in from 12 to 90 fathoms of water round Shetland, Scotland, north-east England, Ireland, Man, and Scilly.

The Pygmy Scallop ( $P$. similis) is a minute and exceedingly fragile species, of almost circular form. The lower valve is much smaller than the upper, and looked at from above the right ear is larger than the left. The sculpturing takes the form of fine concentric lines instead of the usual radiating ribs; the colour white or yellowish, streaked or mottled with brown or white. The animal has about 20 unequal ocelli in two series, black with a pearly centre. It prefers sandy bottoms of a muddy quality, and ranges from 2 to 80 fathoms, all round our islands, but is nowhere very plentiful.

The Great Scallop or Clam (P. maximus) differs 
from all the other species in the inequality of its valves, the lower being very convex outside, whilst the upper is flat with a slight concavity towards the beak. This upper valve is also smaller than the lower, so that the lower margins do not meet. The shell is thick and solid, ornamented and strengthened by about 15 broad ribs, which are themselves corrugated. The lower valve is white suffused with pink and pale yellow, but the upper valve has the ribs dark red, and the intervening channels brown, the whole colour paling away to the beak. The animal is pink or red, the mantle marbled with brown and white. There are from 30 to 35 large unequal ocelli in two series, greenish or dark blue. The young ones spin a byssus and suspend themselves by it, but before they have become adult they appear to have lost this power, or to have learned that their shells have acquired sufficient weight and solidity to resist movements of the lower waters. It occurs generally around our islands in water of from 7 to 80 fathoms. The saucer-like lower valve has long done duty as a drinking vessel.

Closely related to the Scallops are the File-shells ( $L \mathrm{im} \iota$ ), so-called on account of the rasp-like character of the shell sculpture. The valves of the shell are uniform and always white, and the mantle is not ornamented with prominent ocelli at the margins. But though not well developed and conspicuous they are there, and to make up for their deficiency the tentacles which fringe the mantle are exceedingly long and numerous, and wave about like the tentacles of the sea-anemones. During early life the Fileshells flit through the water like the Scallops. The 
foot of the animal is finger-shaped and grooved; and its lips are furnished with tentacles like those of the mantle. Like the Scallops the File-

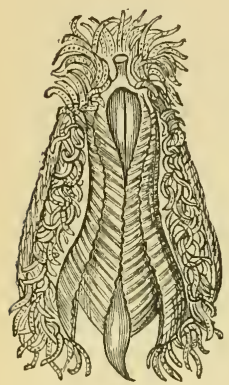

Gaping File-shell shells spin a byssus, which may be an casily detachable cord whereby they temporarily attach themselves, or may be an enveloping tissue like that of the Horse Mussel, only in this case it would be plastered over with excrement, gravel, shell fragments, and seaweeds, forming a nest in which are several youngsters or one adult. The native species are four in number. The Elliptical File-shell (L. elliptica) is a small species confined to the waters of the west coast of Scotland and Shetland. Its shell is oval or elliptical, thin and glossy in spite of the 30 or 40 fine ribs with toothed crests which radiate from the prominent beaks. The valves have small triangular ears, and are connected by a slight ligament. The body and foot of the animal are pale orange, whilst the tentacles are more pink in hue. It inhabits sandy mud in water from 15 to 85 fathoms deep.

The Heart File-shell (L. subauriculata) is smaller than the last, more oblong, more convex, and with only 24 ribs, of which the middle one is the largest. The beaks projecting beyond the hinge are very prominent. The animal agrees in colour with the white shell, and uses its white foot for crawling. It is generally distributed round our coasts where there is a

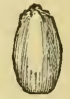

Heart Fileshell sandy or gravelly bottom at a depth from 18 to 90 fathoms, 
The Fragile File-shell (L. loscombii) differs from the preceding in the fact that the ralves of the shell are not equal sided. The ribs number from 40 to 60 , and are very fine and sharp. The upper side of the shell gapes slightly. The animal is coloured bright orange, and the tentacles of the same hue curling back over the white shell present a

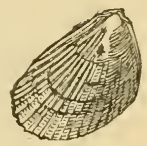

Fragile File-shell striking contrast. It is generally distributed where there is mud or gravel between 5 and 100 fathoms. It is one of the species that weare nests, though not invariably. If the bottom is soft it sinks chambers in it, but where the ground is hard some protection is needed against members of the Cod-family who have a weakness for Lima-flesh; then it spins a nest, and decorates the exterior with shells or fragments of shell of other mollusks and of crustaceans.

The Gaping File-shell (L. lians), our largest species, is more solid and less glossy than the others; its ribs stronger and rougher. The triangular ears are unequal, and the pure white colour which distinguishes it in early life afterwards becomes more or less

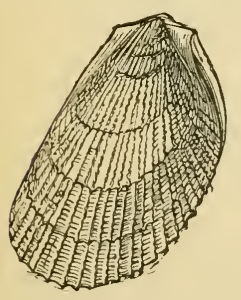

Gaping File-shell discoloured. The ralves gape along the front margin, and discover the red animal. The orange mantle is fringed with a thousand or more filaments which, curling over the shell, are in constant movement. Like the tentacles of the anemones, these have the power of taking hold; and by placing one's finger among this living fringe the Lima may be drawn to a considerable distance. It affects harder ground than its con- 
geners, in water from 12 to 40 fathoms. Here it builds its nest under large stones, mingling with the byssus-threads bits of nullipore and

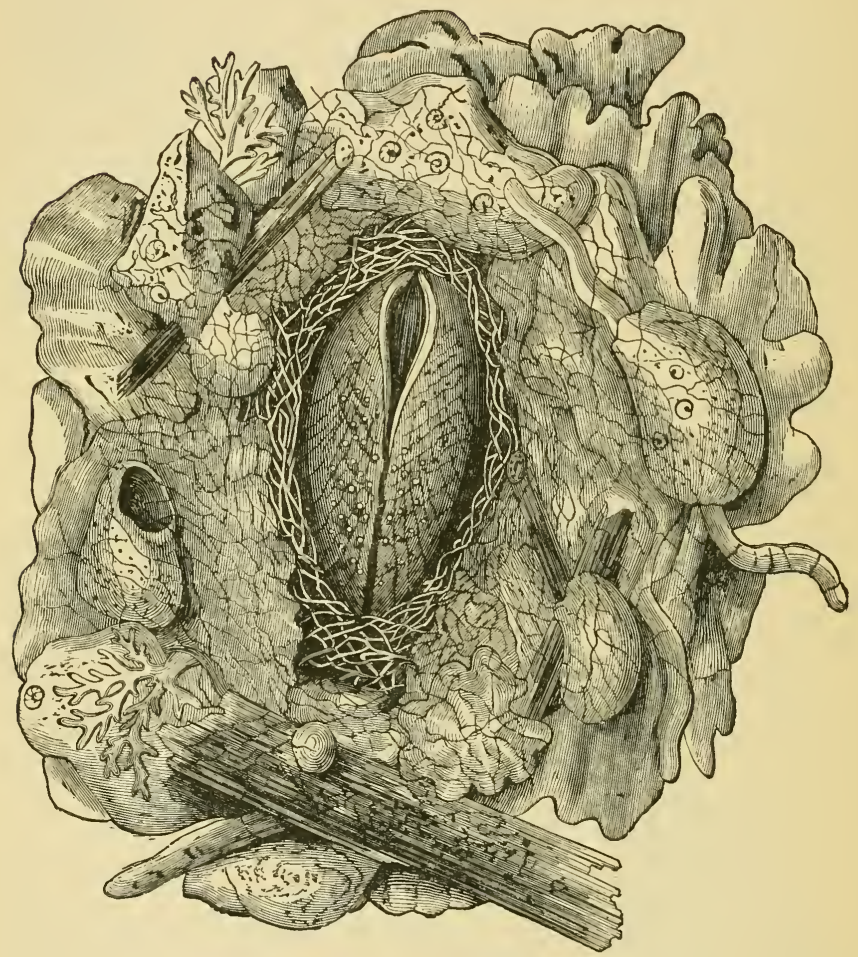

File-shell in its nest (nat. size)

fragments of shell, lined within with excrement. The young ones often associate, several in one nest, but the adults are quite solitary. They frequently, however, accommodate guests, who in all probability 
act as scavengers. Among these are the little Porcelain-crab (Porcellance longicornis) and a marine worm (Polynoe). The Hermit-crab who lives in cast-off whelk-shells has similar messmates who do their best to keep the house clean for their host.

This family also contains the Wingshell (Avicula lirundo), one of the Pearl-oysters, and closely allied to Pinna. It is like a small Pecten whose hinder "ear" has grown to an

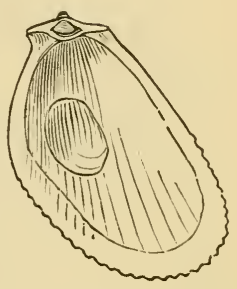

Gaping File-shell interior inordinate length, so that it resembles a wing rather than an ear. Its home is in the Mediterranean, but it is occasionally taken on our southern shores, perhaps being brought hither by currents in its earlier stages. Several fishes, crabs, and jelly-fishes also make their way from the Mediterranean to the coasts of Cornwall and Devon. 


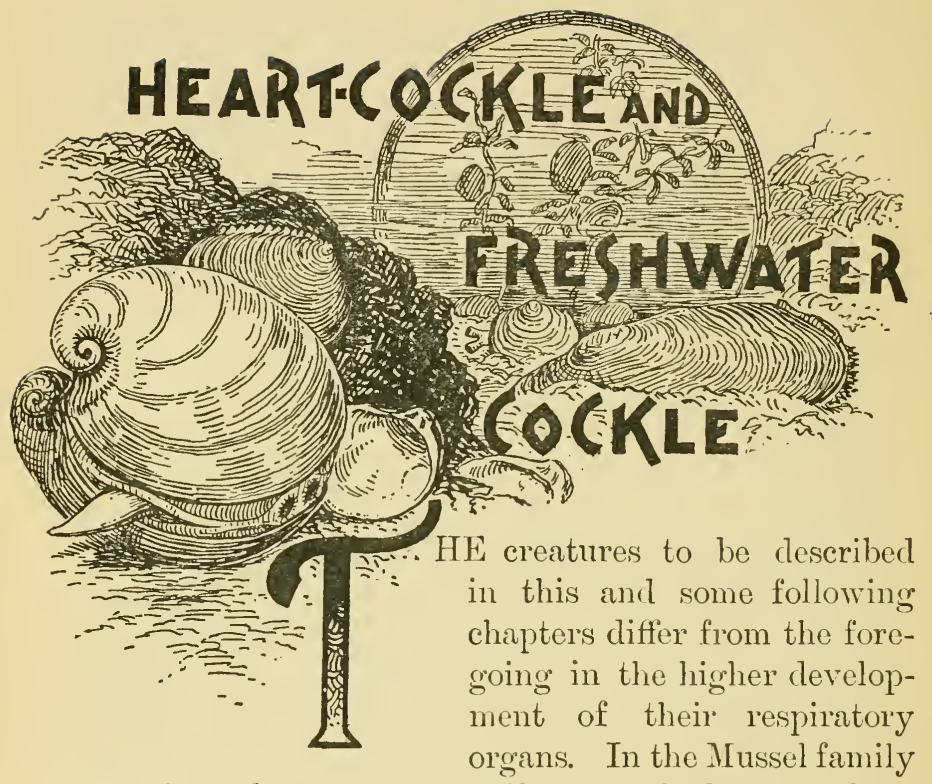

we showed that the gill-filaments had got so long that they had to be folded over so that the gills appeared to be fourfold on each side of the visceral mass. In the Oyster and Scallop family advance had been made upon this development by the ends of the turned-over gills uniting with the foot and the mantle respectively. The present chapter deals with mollusks in which the two folds of each gillplate have been partially united by trusses which leave internal spaces and increase the respiratory eapacity. There are usually two muscles for closing the shell, and the mantle-edges are united at one or more points. The group includes both marine and 


\section{Heart-Cockle and Fresh-water Cockle 93}

fresh-water species, so we must at times turn from the seashore to the river and pond.

The animal in the first genus-Astarte-has an almost round body, flattened from the sides. The lips are large; the mantle thick, not fringed with tentacles, but part of it forms a short excretory siphon behind. The foot is conical and small, though tolerably powerful. The shell is more or less triangular and thick, somewhat flattened, with concentric furrows. It is covered by a thick yellow or brown epidermis, and has prominent beaks. In front of the beaks will be found a dark depression called the lunule, found in many other genera of bivalves, and here heart-shaped or lance-shaped. Internally the valves are furnished with three central teeth (cardinals) below the beak, and a ridge-like tooth (lateral) on either side. There are three native species.

The Furrowed Astarte-shell (A. sulcata) has from 24 to 40 thick ridges, and is white beneath the brown epidermis. The broad hinge-plate bears

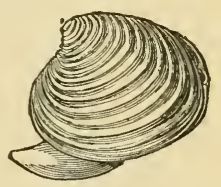

Furrowed Astarte three cardinal teeth, one small and indistinct, two large; laterals indistinct. The margin is thick and

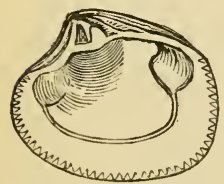

Furrowed Astarteinterior notched within. It partially embeds itself in sand and mud all round our islands in water from 7 to 145 fathoms deep. It is by no means active, getting its microscopic food in plenty without the necessity for pursuing it. The Flat Astarte-shell ( $A$. compressa) is only about one-half the length and breadth of the last named, and may be distinguished 
from younger examples of that species by its flatter, more equilateral valves, and the slight depressions between the ridges. The interior margin has a plain bevelled edge, not notched. This is a local species of northern range. It has been found in sand and mud off the coasts Flat Astarte of Yorkshire, Mull, and Antrim, in from 20 to 40 fathoms of water. The Triangular Astarteshell (A. triangularis) is the smallest of the trio, and, as its names indicate, has three almost equal sides. It is thick in proportion to its size, and the valves are almost without the thick ridges of the two foregoing species. Where these are present they are few and not very prominent. The yellow or brown epidermis, which is streaked with darker tints, disguises the white of the shell. The margin may be either tootherl, or plain and bevelled. It occurs locally in from 3 to 60 fathoms of water. A fourth species (A. crencta) has been dredged between the Hebrides and Faröes, but can scarcely be regarded as British.

Attention should be called in connection with the Astartes to the development of the hinge-teeth. We shall gradually come upon species that are more or less advanced in this respect, and we wish our readers to consider these teeth in relation to the habits of the animal. A deep-burrowing species that is provided with long siphons, rendering frequent visits to clean water unnecessary, is also in little need of very powerful hinge-teeth. As a matter of fact the shell will be rarely closed; and powerful locks would be thrown away on an open house. But the Astartes only partially embed themselves in the 

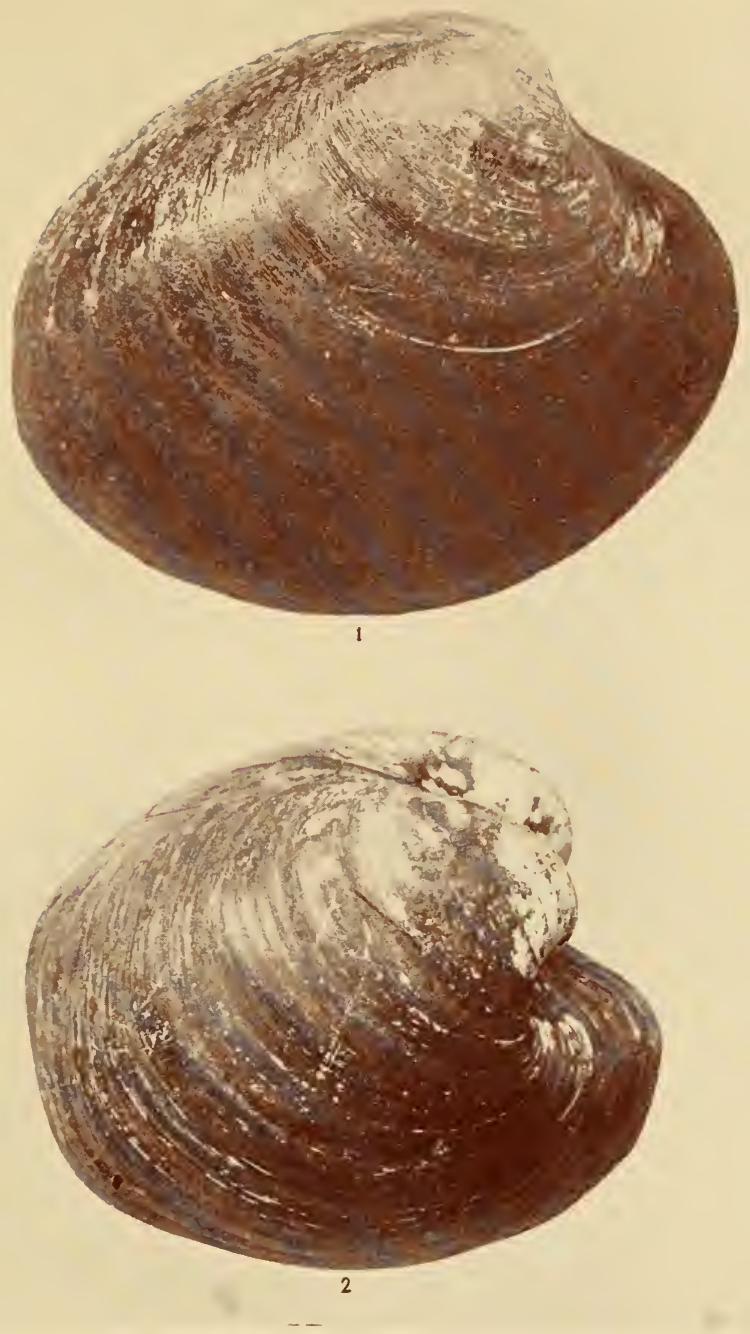

I Iceland Cyfrixa; 2 Heart Cockle. 

mud-so little that they need no long siphons; sufficiently, however, to make the presence of ribs upon the shell an advantage-these helping to keep them firmly in place when they have withdrawn the foot and closed the valves.

In the Iceland Cyprina (Cyprina islandica) we have an example of a single species constituting the sole living representative of its genus, though of the fossil species of that genus we know nearly a hundred. The shape of the valves is shown in the figure, but if the complete shell be looked at from behind it will be seen that -in that aspect-it is heart-shaped. It is a

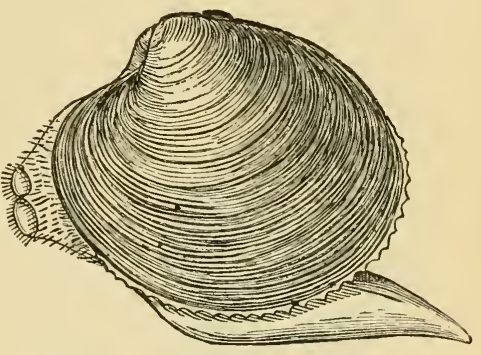

Iceland Cyprina thick and slightly glossy shell, with numerous irregular concentric raised lines, which are stronger towards the margins than in the middle. The colour is white tinged with yellow and pink, but the brown epidermis hides this. The beaks are prominent and

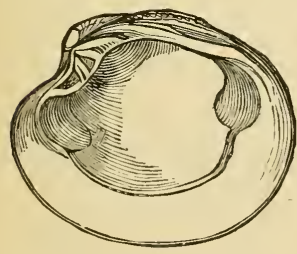

Interior of Cyprina considerably curved. Along the upper edge of each valve there is a groove which holds one side of the ligament. The hinge-plate is broad and bears three strong cardinal teeth. The laterals are also strong in the left valve, but in the right they are very slight. It measures between 4 and 5 inches in length, and almost as much from the beak to the lower 
margin. The animal is of a creamy tint, and the mantle forms two short tubes behind, whose mouths are fringed with delicate tentacles. The long foot is broad at the base, but runs to a sharp point. By the aid of this powerful instrument the Cyprina burrows in the muddy sand, but not deeply, as may be gathered from the shortness of the tubes and the sculpture of the shell, slight as that is. It is found on all our coasts, at all depths from low water to 100 fathoms.

The Heart-Cockle (Isocardir cor) when viewed from the side appears almost round, but from either

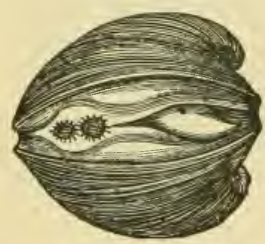

Heart-Cockle end it is seen to be more completely heart-shaped than Cyprina. The beaks are curved spirally towards the front, and from this point they present the appearance of the illustration. The thick shell is yellowish white in colour, but this is quite hidden beneath the red-brown epidernis, which bears stiff short hairs set in numerous lines radiating from the beaks. The thick, broad hinge-plate bears two cardinal teeth and two laterals. All these interlock and form a powerful safeguard against the shifting of the valves. The animal is whitish, the borders of the mantle orange, and the strong triangular foot of the same colour. The siphons are very short, with broad, fringed openings which are at the

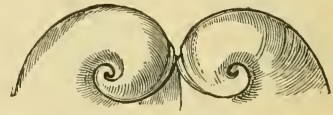

Beaks of Heart-Cockle centre of the lower margin. Full-grown specimens average 4 inches across the longer axis of the shell, and almost as much at right angles to it. The 
strange situation of the siphons is explained by the habit of the Heart-Cockle: by means of the foot the shell is embedded, beaks first, in the slope of a muddy bank, so that only the lower margin of the shell with siphons is exposed. It is a local shell, and its distribution is almost confined to Devon, Cornwall, the west coast of Scotland, and the south and east coasts of Ireland.

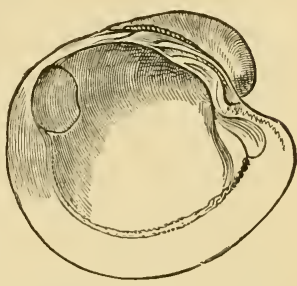

Interior of Heart-Cockle

The Northern Lucina (Lucince borealis) is also an almost round shell viewed from the side, but from

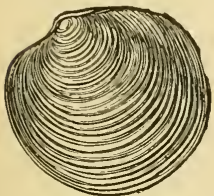

Northern Lucina either end it is seen to be a much flatter shell than the preceding. Its whiteness is hidden by a yellow-brown epidermis, and its surface is relieved by a series of low but sharply cut concentric ridges. The pointed beaks, in spite of their small size, are tolerably distinct. The hinge-teeth are two strong cardinals with a long lateral on each side of the beak. The interior margins are sinooth and bevelled. The animal is white, with short thick lips and extremely short siphons. The long slender foot emerges from the shell at about the centre of the lower margin, and serves chiefly as an anchor to moor it to the gravel and sand upon which it lies all round these islands, from extreme low water to upwards of 100 fathoms. There is a second species - the Prickly Lucina ( $L$. spinifera)-which is of more local occurrence. The shell is more triangular than the last named, the epiclermis of a much paler tint, the beaks less 
prominent, and the ridges somewhat overlapping, their terminations giving a spiny character to the upper margin. There is but one cardinal tooth in the right valve, but in the left there is a small additional one. It is more plentiful on our northern shores than in the south, and especially on the west coast of Scotland.

In the next genus, the Hatchet-shells (Axinus), the smooth shell is more globular, though with a triangular outline, the hinder portion furrowed. The beaks are considerably recurved, but the hinge-teeth are entirely wanting, though an excavation in the right valve and a corresponding eminence in the left have somewhat the appearance of teeth. The margins of the shell are not toothed. The thickened margin of the mantle is open all round and not prolonged into siphons. The long slender foot is almost cylindrical. There are five British species, all small and all living on muddy-sandy shores. The Rusty Hatchet-shell (A. ferruginosus) is the most plentiful of these, and gets its name from a rust-like deposit over the epidermis which protects the thin, white, almost globular, shell. It occurs between 30 and 100 fathoms, chiefly off Skye, Shetland, and the west of Ireland. The Wavy Hatchet-shell (A. flexuosus) has a more oval and less glossy shell. The terms "wavy" and "flexuosus" apply to the upper margin behind the beaks. The hinder margin of the mantle is contracted so as to form some approach to a siphon or the aperture of one. This species is widely distributed, and ranges between 3 and 90 fathoms. The Skye Hatchet-shell (A. croulinensis) is obliquely oval, swollen, more solid, and longer than the last 

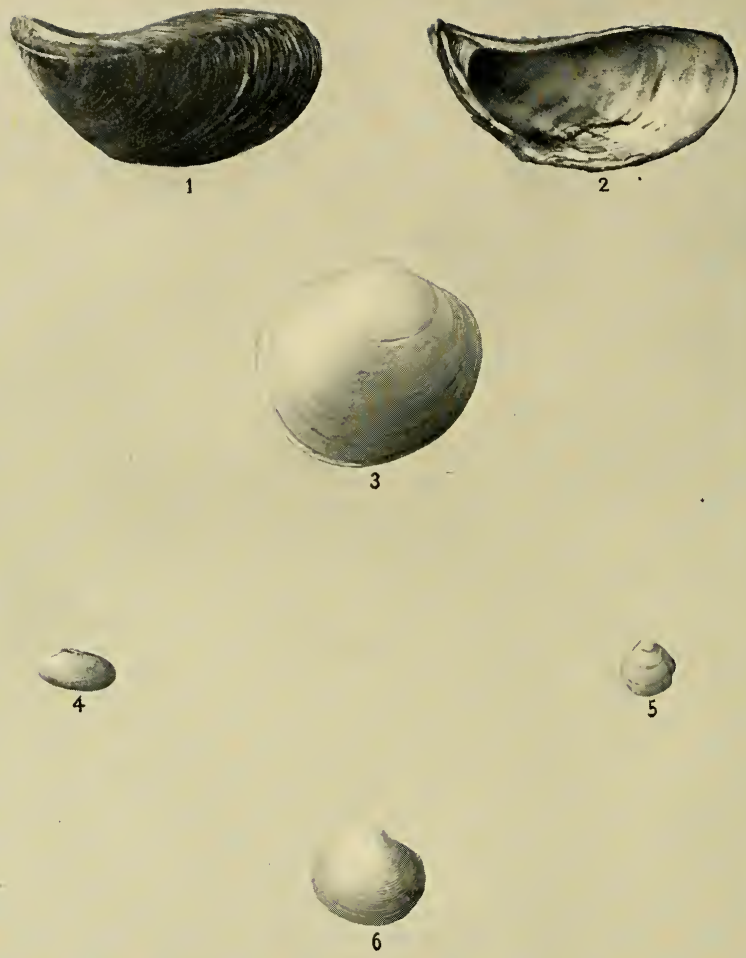

3

$\overrightarrow{8}$

I, 2 Zebra Mussel; 3 Round Double-tooth ; 4 Rusty Montagu-shell;

5 Wavy Hatchet-shell; 6 Prickly Lucina; 7 Montagu's

URCHIN-SHELL ; 8 TWO-TOUTHED URCHIN-SHELI. 
named. The white shell shows through the thin epiclermis. The tooth-like folds of the hinge-plate are stronger than in either of the other species. It is a rare species, and appears to be restricted (in Britain) to Skye and Shetland, where it occurs in deep water, between 45 and 85 fathoms.

The Round Double-tooth (Diplodonta rotundata) is almost round in outline, somewhat glossy, with irregular concentric ridges; white, but covered in front by the yellowish epidermis. There are two cardinals and two laterals in each valve, one of the cardinals in each being cleft in order to receive the undivided one of the opposite valve. The animal is white, with large free lips, and the mantle edges are united, save for the large aperture on the lower margin where the foot emerges, and for the incurrent and excurrent orifices on the lower margin. The shell is about 1 inch long, and almost as deep from the beak to the lower margin. It is found on the surface of sandy mud in from 12 to 20 fathoms, chiefly on our southern shores, but also locally on the west, as at Lundy, Anglesea, and Fishguard.

There are six little bivalves of local occurrence that have been named after Colonel Montagu, who first discovered and described them. His name in the Latinised form of Montacuta stands for that of the genus. As they have no popular name, we think it fitting to call them Montagu-shells. Montagu's Urchin-shell (M. substriate) is a small, yellowish, oval, semi-transparent shell, about a quarter of an inch in length. Its valves are marked by about a dozen faint ribs radiating from the beaks, but not reaching to the front margin. The animal spins a 
byssus, and on the lower margin there is an indentation whence this issues. There is a long tooth on each side of the hinge-line, those of one valve interlocking with those of the other. The animal agrees with its shell in being almost transparent. The rear portion of the fringed mantle forms a brief tube for the outward current of water, and the foot is large and powerful. From 8 to 100 fathoms deep is the range of this species on all our shores, but not on the sand or mud affected by its allies. It has a more remarkable habitat, being found only on living Sea Urchins, and chiefly on the spines of the Heart-Urchins, such as Spotangus purpureus, Echinocardium cordatum, and Bryssus lyrifer. To these spines it is attached by the coarse byssus-threads, and no doubt it selects this strange position in order to share the food of the Urchin. The Heart-Urchins, it may be inentioned, bury themselves in the sand, and appear to exist by continually swallowing it and digesting out the organic matter mixed with it. The Urchin's mouth is a shovel-shaped aperture on the lower surface, and Montagu's-shell is attached to a spine in front of it where the indraught of sand is likely to bring' minute food-particles to the mollusk. The two-toothed Montagu-shell (M. billentat $\iota$ ) is less oval than the last, approaching nearer to square; flatter, and much less transparent; whiter in colour. The teeth in the right valve are shorter and broader than those in the left. The mantle has its margin fringed with bright silvery teeth, and forms a very brief tube behind. The large broad foot is somewhat triangular in outline. It may commonly be found on all our coasts, in water from 10 to 70 fathoms, nestling in 
the crevices of old bivalves, sometimes in the burrows of the Boring-sponge (Cliona) in old oyster-valves. Its greatest length is only a couple of lines. The rusty Montagu-shell (M. ferruginosa) is more oblong, greyish white in hue, but this is hidden by a rusty-looking incrustation that covers the epidermis, and is no doubt due to the peculiar habitat of the creature. The front teeth differ from the back, and the opposite front pair differ somewhat from each other in order that they may interlock. It affects the burrows of the Heart-Urchin (Echinocardium cordutum), and often is attached by its byssus to the bristle-like spines of the Urchin, and is dragged about with every movement of the Urchin.

We have now to briefly describe four small genera, two of them each represented by a solitary species. They are all small, and consequently little known to the average seaside visitor, and have no popular names. We must therefore utilise their scientific names as far as possible. The Globose Kelly-shell (Kellia suborbicularis) is more or less globular, equal-sided, thin, glossy, with faint lines running across from the beaks, and others parallel with the lower margin. The thin and iridescent epidermis gives a greenish hue to the white of the shell. In the right valve the two strong teeth are

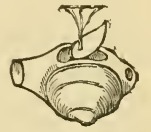
Globose Kellyshell, suspended by byssus laterals; they are repeated in the left valve with the addition of a cardinal. Both shell and animal are nearly transparent. As shown in the first figure, the mantle extends considerably beyond the shell margin, and its edges are united all round. There is a large opening on the lower margin to allow passage for 
the strap-shaped foot; it is greatly extended in front to form an incurrent tube, and a small opening behind serves as an excurrent siphon. The

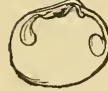

Interior of Globose Kelly-shell longer diameter of the shell is from onethird to a half-inch. The small creature moves freely by means of its foot, and attaches itself by an almost invisible thread, hanging in the position shown in the figure. It is fond of taking refuge in muddy discarded shells in rock-crevices, and about the tangled suckers of the larger seaweeds. Its vertical range is from extreme low water downwards. The Minute Kellyshell (K. minuta) is much smaller, its longest measurement being only one-twelfth of an inch. It has a thin, semi-transparent, glossy shell of a purple-brown tint, darker at the beaks and paler in front. Its principal markings are the irregular lines of growth. There is but one siphon in this species. The foot is comparatively large, very flexible, and much used by the

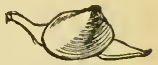

Minute Kelly-shell (enlarged) animal for climbing seaweeds. It is found in great abundance all round our coasts at low water and a little beyond. It has sometimes been called the Mullet-shell because of the fondness of that fish for it. Mr. Hyndman took about 35,000 of these shells from the stomach of a single mullet. This certainly showed praiseworthy industry on the part of the fish in the collection of food, as well as testifying to the good qualities of the mollusk as a fish-food and to its astonishing fecundity.

In the matter of size the Ruddy Lasæa (Lascea rubra) comes between the two Kelly-shells, being about the tenth of an inch in length. The shell is 
oval, unequal-sided, white, deeply tinged with red towards the upper margin, and covered by a yellowish epidermis. There are two lateral teeth in each valve, but in the left valve there is in addition a small cardinal. The mantle does not extend so much beyond the shell as in Kellia, but in front it forms a protuberant incurrent tube. The excurrent orifice is not seen beyond the shell margin. The long, tongueshaped foot is used for similar purposes as in the last-named species, and a byssus of less simple character moors it to rock-crevices, to corallines and other seaweeds, chiefly between tide-marks, all round our coasts. It is a species that retains its eggs until they are hatched. These are produced in batches of from 12 to 20, and when sufficiently developed the fry are shot into the world of waters through what ordinarily serves as the incurrent siphon.

The Coin-shells (Lepton), so-called from their resemblance to a small coin (lepton), are represented by five native species. They differ in several respects from the creatures just described. The shell is more liberally provided with hinge-teeth, there being a cardinal and two laterals in each valve. The mantle, which is fringed with long tentacles, protrudes nearly all round, and the foot can be flattened in such manner that it resembles the foot of a snail, and is used in similar fashion. The Scaly Coinshell (L. squamosum) is almost square and flat, its substance thin almost to transparency, glossy, and white. It is finely ribbed in two directions, the spaces left between

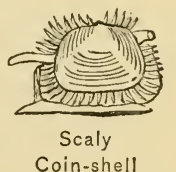
the network thus formed giving the surface the appearance of being minutely pitted. Inside the shell is 
iridescent, marked with fine irregular groores which run from the beak to the lower margin. The cardinal tooth is small and erect, whilst the laterals are long and plate-like. The white animal has a short excurrent siphon, and a bluish foot streaked with white. The fringe of tentacles around the mantle is shown in the figure, where will also be seen one tentacle above the foot developed abnormally as compared with the others. When the creature crawls along it waves this tentacle about, apparently using it as a sense-organ, feeling its way and ascertaining the presence of food. It is a southern species, its distribution here being restricted to Dorset, Devon, Cornwall, the Channel Islands, and the south and west of Ireland. Like the Montagushells previously described, it has a preference for the company of a creature belonging to an entirely different class of animal life. In this case the messmate is a singular crustacean, known as Gebia stellata, that burrows in muddy sand. No doubt the Lepton acts, to some extent at least, as a scavenger, feeding upon the excretions and surplus food of Gebia, whilst the flatness of its shell enables it to keep out of the way as the Gebia scuttles up and down his burrow.

The Shining Coin-shell (L. nitidum) is a much smaller species, as will be seen on reference to the figures, which are of the natural size. It differs from squamosum by the shell being less flat, less thin, with the beaks more prominent, and the animal appearing to be more gelatinous. The lower edge of the shell is less straight, and the fine rib-marks run only in one direction-that is concentrically. 
The shell is white with a tendency towards a yellowish tint, which is the hue of the opalescent epidermis. An enlarged figure of the hinge-teeth is given; they are more highly developed than in squamosum. The foot is more distinctly blue, flecked with white, and the siphon is placed in

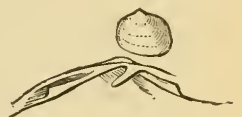

Shining Coin-sheil and enlarged hinge front instead of behind. It occurs sparingly on all our coasts where there is coarse sand, between 10 and 90 fathoms. The form sometimes described as a separate species under the name of the

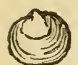

Convex Coinshell Convex Coin-shell (L. convexum) appears to be a variety (convexa) of $L$. nitidum. It is distinguished by the shell being slightly more convex, and marked all over with coarser pits than those found only round the beaks in the type.

The Furrowed Coin-shell (L. sulcatulum) is almost circular in outline and flattened; its substance thin and almost transparent, like that of $L$. squamosum, but instead of the pit marks we have here a numerous series of broad concentric ribs covering the surface. The cardinal tooth in the left valve is strong and erect, whilst the corresponding one in the right is very small. The length of the shell is only about one-twentieth of an inch. It appears to be a southern form, and has been found in the Chamnel Islands among corallines below the lowest tide-marks. Clark's Coin-shell (L. clarkice) is another minute species, but of more yellow tint than the last, streaked with fine white lines that radiate from the beak. Instead of the ribs of $L$. sulcatulum, the sculpture here consists of numerous fine concentric grooves. The outline is 
triangular-oval; and the cardinal tooth in the left valve though strong is more oblicyme thin erect. It has been found on erravelly sand on various parts of our coasts, both north and south, ranging in depth fiom is to so fathoms.

'l'urton's Weasel-eye (Galeomma turlomi) is the sole British representative of its family and gemms. 'The thin oval shell is equal-sided, with mimute beaks, and sapes widlely in front. 'The hinge is withont terth, and there is no epidermis. The animal has a long foot flattened to form a narrow sole, mpon which it endiles after the mammer of a smail. The edgess of the mantle are joined, but at the

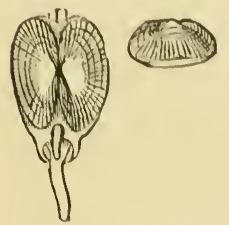

Turton's Woasol-oyoopen and closed front there is an orifice for protruling the foot, and there is a siphon at either end. Contrary to the habit of most bivalves, which keep their shells as nearly elosed as possible, the Weascl-eye spreads open its valves to the fullest extent, and so flatifened out, as in our first figure, it glides over the weeds and corallines, in water between 5 and 20 fathoms, on our sonthern coasts. It attaches itself hy a byssus, but when it wishes to move away the byssus is thrown off from the loot. It will be at once seen in the light of previous remarks that there is distinct relation hore betweon the habits of the creature and the absence of hinge-tecth. $\Lambda$ mollusk that uses its widely expanded valves to protect it has little need of the teeth with which miny other species lock their valves together-so the teeth are not derelopert.

leaving the seashore for a time, we must repar to 

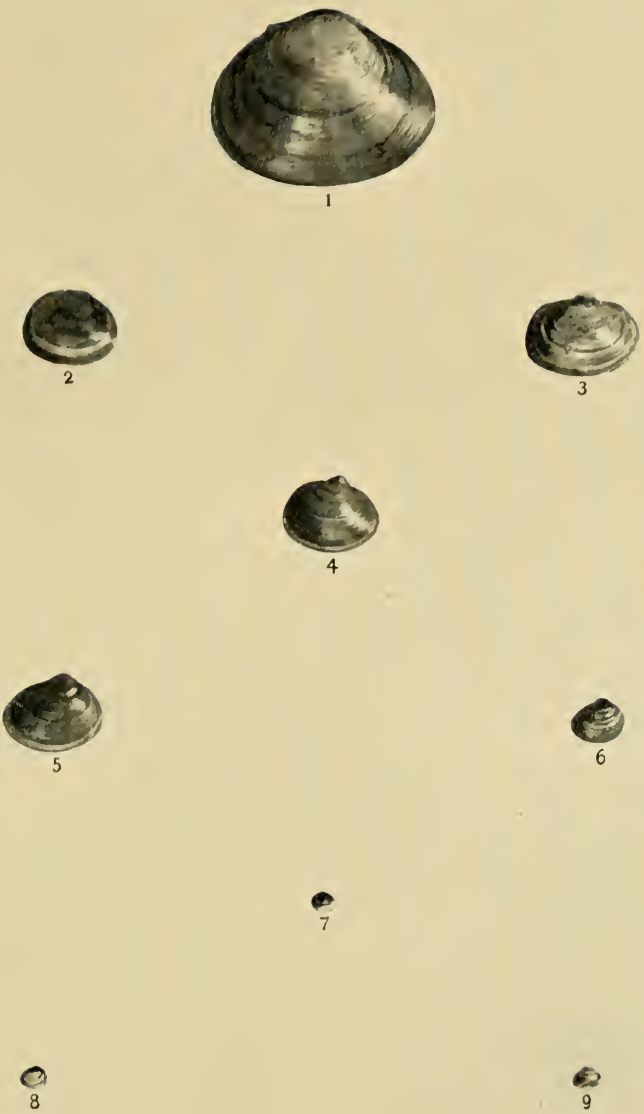

$\frac{2}{7}$

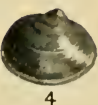

4

8

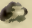

9

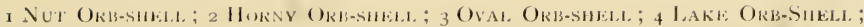

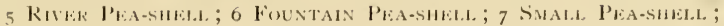

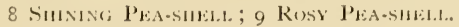



the fresh-water pond or stream, in order that we may consider some of its inhabitants in their proper order. There on the mud or climbing the weeds we shall find a number of little bivalves, to which the popular name of Fresh-water Cockle has been applied. The nine species found in this country belong to two genera of one family - the Sphæridæ-and are not at all related to the true Cockles (Cardium). Their thin shells are more or less globular, the valves being of equal size but not equal-sided. The hinge is provided with both cardinal and lateral teeth, and their general character may be gathered from this figure of the hinge of Splccerium corneum. The animals are very active, and by means of the mobile foot can not only climb weeds, but by spreading it out on the surface of the water can float with their shells inverted after the manner of the pond-snails. From such a position

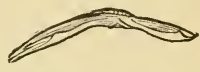

Hinge-teeth Sphcerium they often descend gradually to the bottom by spinning a thread of mucus, the end of which remains at the surface or attached to a floating weed. By means of these threads they can reascend to the surface or remain suspended half-way. They hibernate in the fine soft mud at the bottom, becoming active again when the warmth of spring has penetrated to those depths. The eggs are retained in a broorl-pouch within the gills until they hatch, and the young remain there for a time, finally being shot out through the siphon when developed sufficiently to take care of themselves. The four species of Sphcerium have each two siphons, a character which serves to separate them from the five species of Pisidium. which have one siphon only. 
The Horny Orb-shell (S. corneum) is common in most ponds and streams throughout the country. The beaks are placed almost in the centre of the upper margin of this almost globular shell, which is covered with a thin glossy Horny epidermis. The colour is that of horn with some lighter bands rumning parallel with the lower margins. The teeth are well developed. The length is about half an inch, and the animal's span of life is about two years. The Nut Orb-shell (S. rivicola) is a much larger, more oval, and more solid-looking shell, and its colour is yellowish brown. It is covered by a thick brown epidermis, and has strong concentric ribs. The hinge-teeth are similar to those of $S$. conneum, but much stronger. The interior of the shell has a pearly coating. The animal, like $S$. corneum, is greyish, but the broader

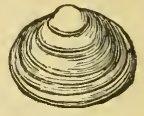

Nut Orb-shell foot is less pointed, and the shorter siphons are nearly of the same length and whiter. Though not found in stagnant water, it is not partial to rapid streams; but may be sought in the gently flowing rivers, brooks, and canals of England, from north Somerset and Surrey to south Northumberland. The Oval Orb-shell ( $S$. pallichum) is a local shell of oblong form, much flatter than the foregoing, thin and semi-transparent, with fine concentric grooving. The animal is white, with a long tongue-shaped foot, and the long siphons are connected almost throughout their length. It occurs only in England, and there its range is limited to Surrey, Middlesex, Warwickshire, Lancashire, and Yorkshire, where it is found in ponds and canals. The last of the quartette, the 
Lake Orb-shell (S. lacustre), when looked at from the side is much like S. corneum, but from either end it is seen to be somewhat compressed, the beaks central, and usually capped by the nucleus of the shell; very thin, semi-transparent, and glossy, of a greyish-brown hue. The white animal has a foot twice the length of its shell. The siphons of this mud-loving species are long, and exhibit a marked difference between

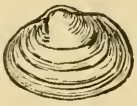

Lake Orb-shell the respiratory and excretory tubes: the former being cylindrical with a wide mouth, whilst the latter is slightly conical with a small mouth. It is well distributed over England and Wales in still waters, but is only found locally.

As already indicated, the five species of Pea-shells (Pisidium) may be recognised as such at a glance by their possession of one siphon instead of two. Their shells are also much smaller and less equal-sided than those of the Orb-shells. The River Pea-shell ( $P$. (mnicum) is solid, glossy, somewhat triangular, and swollen; deeply grooved, greyish brown in colour, with a thick epi-

River

Pea-shell dermis, and a quarter of an inch in length. The greyish animal is almost transparent, with a long broad foot and a short siphon. It is generally distributed in rumning waters. The Fountain Pea-shell ( $P$. fontincle) is similar in shape to the last, but smaller, less solid, faintly grooved, of a paler grey colour, with more prominent beaks, and a thin epidermis. It is widely distributed in similar situations to those affected by the last named. The Small Pea-shell (P. pusillum) is oval and thin, with little gloss, finely but irregularly grooved; of a brownish- 
grey colour, with very thin epidermis, and the beaks nearly central. The animal is pale pinkish, with a long slender foot, and short conical siphon. It is the only native Pisidium of an oval form, so it will be readily identified by this feature, and by the almost central position of the beaks. It is generally distributed in pools, ditches, and marshy places. The Shining Pea-shell (P. nitidum) is nearly round, very glossy and iridescent, pale yellow or pale brown, more strongly grooved than in the other species. The interior is whitish. The animal is also whitish, with a long, finely-pointed foot, and short, funnelshaped siphon with a notched margin. It is found in lakes and ponds throughout the country. The Rosy Pea-shell ( $P$. milium), though very glossy like the shell of $P$. nitidum, and grooved in a similar manner, is more nearly oblong than round, and the lower margin is straight instead of curved. 'In colour it is yellowish or pale brown, the interior pearly and white. The animal varies in hue from white through yellow to rosy red, and has a long, slender, somewhat conical foot. Like the other species, this is generally distributed throughout the country in still waters.

All these Orb-shells and Pea-shells are but tiny representatives of the marine Cockles, and, of course, are cockles only by popular courtesy. The Freshwater Mussels are even more widely separated from their salt-water namesakes, though our native species are not of the insignificant sizes of the Fresh-water Cockles. It has been suggested that all of these fresh-water bivalves have originated in marine, or at least estuarine, species which have become 
accustomed to a certain admixture of fresh water, and have gradually wandered farther up the rivers and their feeders until they have finally become used to water that is absolutely fresh. As they have got into quieter waters, where, too, enemies are less abundant, their shells have become thinner and less solid, with modifications of the animal to match.

The Pearl Mussels (Unio) are represented in our waters by three species, of which the best known is the Painter's Mussel (U. pictorum), so called because the valves were formerly used to hold artist's colours, just as they are used to-day to hold the gold and silver for illuminating. The oblong compressed shell is covered by a thin epidermis through which show the yellow ground-tint, the parallel lines of

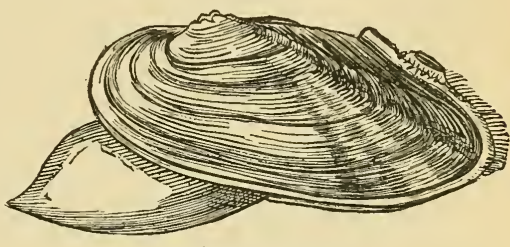

Painter's Mussel

brown, and the rays of green on the hinder part. The beaks are considerably forward from the centre; the lower margin is almost straight. The interior is pearly, and the muscular impressions are distinct. A notched tooth on the front of the left valve fits into a groove formed by the margin of the shell and a strong tooth on the right valve; whilst a long plate-like tooth on the back of the right valve fits into the groove of a similar plate on the left valve. The animal has a large, broad, tongue-shaped foot of a reddish or yellow colour, with which it burrows into the mud of ponds and slow rivers." Owing to the thinness of the epidermis on the beaks-these being 
the oldest portions of the shell-the shelly matter at this part frequently becomes eaten away by the action of gases dissolved in the water. It is about 3 inches long. The animal is coloured light red tinged with grey, and the mantle is bordered with brown. The siphons of Sphererium and Pisidium are represented in Unio by a couple of orifices on the hinder margin of the mantle, of which the dark brown upper (excurrent) is somewhat more elongated than the lower grey (incurrent). This may be regarded as an English, rather than a British, species, for it occurs only in the rivers and ponds of England and Wales, and does not extend north of Northumberland, or occur in Ireland.

The Swollen River Mussel (U. tumidus) is a slightly more solid shell than the last, and viewed endwise presents a much greater thickness-hence its name. In colour it is a glossy brown, the lines of growth often tinged with green. The interior is bluish and pearly, with strongly marked impressions of both mantle and muscles. The hinge-teeth, though similar to those of the last named, are of a stronger character. The animal differs in colour from $U$. pictorum in being greyish instead of red. Its distribution is nearly the same as that of $U$. pictorum, except that it does not occur north of Yorkshire. Both of these species produce pearls, but they are very small and of inferior quality. The Pearl Mussel is U.margaritifer, which has a shell of more oblong shape, much flattened, though of solid material. There is no gloss upon its rough, blackish-brown surface. Its length is about $5 \frac{1}{2}$ inches. The interior is pearly, but in this case the tint is flesh-colour, varied with 


\section{Heart-Ciockle and Fresh-water Cockle I I 3}

stains of dull green. The animal is usually greyish with a tinge of red. It is a northern species, not occurring south of Pembrokeshire and Yorkshire. This is the species which produces the British pearls, at one time a somewhat important article of jewellery. The so-called "fishery" appears to have been abandoned, probably on the ground that "the game is not worth the candle." We are told that in the

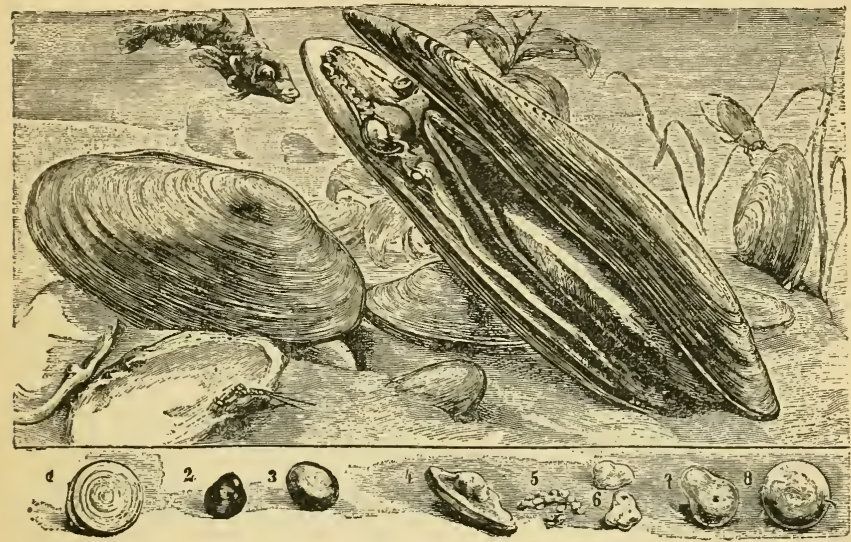

Pearl Mussels, showing pea:l within the shell, and detached pearls $(1-8)$

iniddle of the eighteenth century the Perthshire Tay in three years contributed to London pearls valued at $£ 10,000$. These varied in hue from white, through pink and green to brown and black, the white predominating, and the pink most in demand. The peasants used to collect the mussels from the mountain streams just before the corn-harvest, and in the oldest and most deformed specimens they were most likely to find the pearls. Yet it is said that not 
one per cent. of the shells contained a pearl, and that only one pearl in a hundred had any great value. The best of these, very regular in form, clear in colour, and the size of a pea, would be worth $£ 3$ or $£ 4$.

The Swan Mussels (Anodonta), of which we have two forms, are less regular in outline than the Pearl Mussels, and are, as their scientific name indicates,

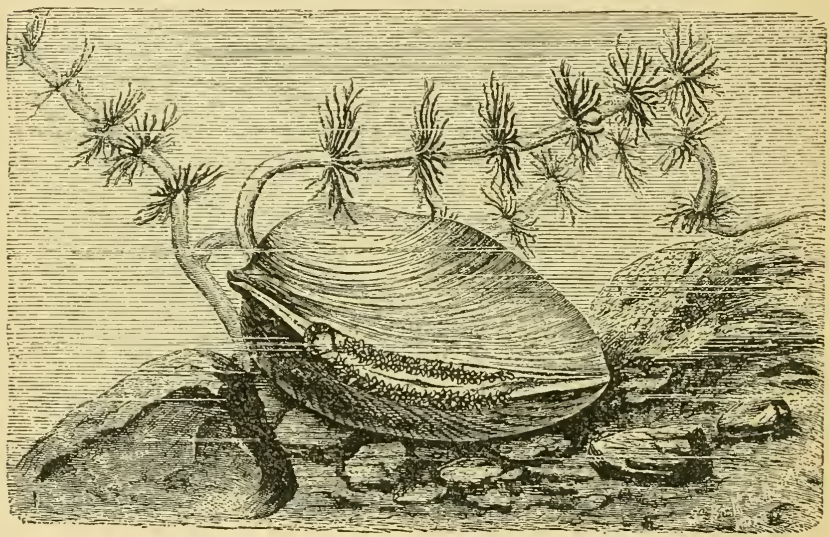

Swan Mussel-end view

practically toothless, though the hinge-teeth are represented by sharp ridges on the valves. I have already described their structure in the Introductory Chapter. They occur in similar situations to those affected by the Pearl Mussels, but are more generally distributer throughout Great Britain. The large Swan Mussel (A. cygnea) has an oral shell, but with a straight hinge-line, and with the beaks placed well away from the centre, forward. The 
forepart is swollen, and the upper part above the beaks compressed. Greenish yellow is the colour of the shell, which is covered by a thin, brown, glossy epidermis. The lines of growth are strongly marked, and the interior is white with a pearly iridescence. The animal is grey, tinged with red or yellow; the large foot yellow or orange; the edges of the mantle tinged with brown and fringed. It occurs in slow waters and ponds almost throughout Britain, usually in large colonies. It is calculated that full-grown specimens are twelve or fourteen years old. The Duck Mussel (A. anatina) is considered by many conchologists to be merely a variety of $A$. cygnea. There can be no doubt that it is very closely related to it, and probably arose quite recently as a variety, but it appears to be now a permanent form, and perhaps would be more cor-

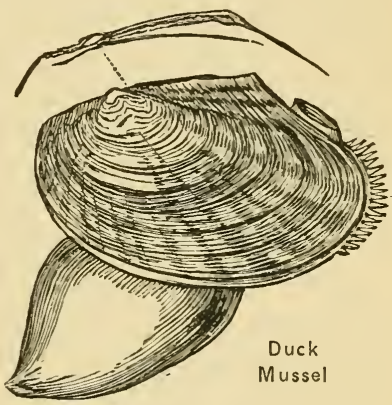
rectly described as a sub-species of $A$. cygnea. The shell is proportionately longer, and less swollen, of thicker material, olive or brown in colour, with darker concentric bands, and with green rays from the beaks. The hinge-line is slightly curred, and higher than in $A$. cygnea. The animal differs from its congener chiefly in the larger size of the lower siphon, which is also fringed with more numerous and more delicate tentacles. It is found in similar situations to the last, but is not so widely distributed, and does not appear to occur in Ireland. 
The only remaining fresh-water bivalve to be described represents a distinct family - the Driessensiidæ. It is the Zebra Mussel (Driessensia polymorph $($ ), which is very similar in appearance to the Common Mussel (Mytilus) of the sea-coasts, but differs from it in having a partition extending across the tip of each valve and thus dividing this portion of the interior into two. The shell is sharply keeled along each valve, and is dull brown in colour. The hinge is without teeth, and the pearly interior is but faintly marked by the muscular impressions. The animal is dark hued, with a paler, clearer, slender and cylindrical foot which spins a strong byssus.

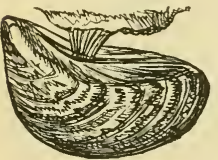

Zebra Mussel From all this it will be seen that Driessensic approaches much more nearly to the marine species than to other fresh-water bivalves. All the latter retain their eggs until they hatch; Driessensic, like the marine bivalves, discharges her eggs into the waters, and the young larve that come from them are free swimmers. They appear in the middle of the summer on the surface of the water in great numbers. After apparently feeding on the microscopic plant-life of the surface for about eight days, they sink to the bottom. By this time the foot has formed and become very long and narrow, and the shell round, much like that of Sphcerium. The swimming organ-the velumhas disappeared, and in future the creature must use its foot and its byssus for locomotive purposes. Another point connecting this species with those of the sea is the fact that the edges of the mantle are united almost throughout their length. 


\section{Heart-Cockle and Fresh-water Cockle i I 7}

The history of Driessensia in this country is very singular. Geological evidence shows that in later Tertiary times this species was abundant, not only in Britain but over a good portion of Continental Europe also. Then it vanished without leaving any evidence why, but held its ground in the AraloCaspian rivers, whence during the last one hundred and fifty years it has been spreading once more over Europe. In 1824 Mr. J. Sowerby discovered that it had reached London. It was found in the Thames and the Surrey Commercial Docks, and the very natural conclusion was reached that it had come over from the Baltic attached by its byssus to some of the timber-laden vessels. It has since spread very considerably about the country, and we have even heard it whispered that a certain London water company has occasionally supplied it to their customers, who had only bargained for water. 


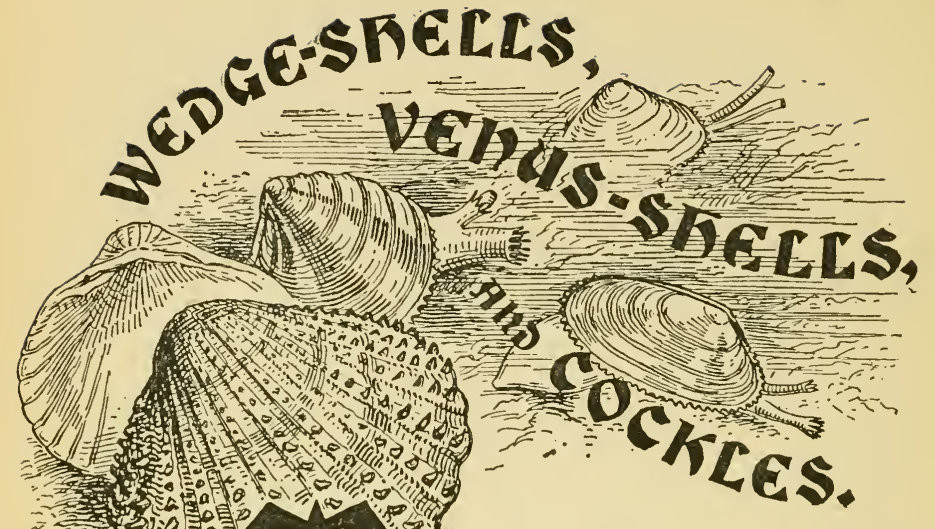

HE members of the Tellin family (Tellinacea) are distinctly deep burrowers in sand or mud, and this habit has had effect in developing the foot to be a powerful organ, and in lengthening and separating the siphons to give them greater power and mobility that they may reach up above the sand to the clear water. The lips also are large, the gills unequal in size, and the mantle fringed with tentacles. The general appearance may be gathered from the figure opposite. The name Tellina was applied by Dioscorides and other of the ancients to certain species of marine mollusks, not necessarily those for which the word is now used. There are seven British genera in the group, with over a score of native species.

The Pomegranate Tellin ( $T$. balaustina) had its naine suggested to Linnæus by the resemblance 
between its colouring and that of the pomegranateflower. It is a thin almost transparent shell, somewhat swollen and of a triangular-oval outline. The surface is slightly polished, marked by exceedingly fine lines and slightly raised concentric plates, which, however, have in many specimens been rubbed off. The colour is white, delicately tinged with yellow, whilst from the beaks to the lower margin faint streaks of pink radiate. The beaks are small, incurved, and almost touch. The epidermis is thin

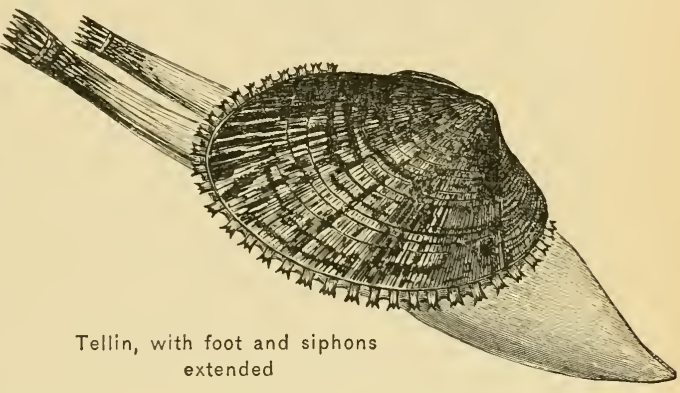
and iridescent. The interior, which is tinged with orange, is polished. It is about 1 inch in length. The animal is semi-transparent, greyish white, with transparent tubes. It is an inhabitant of fine sand in deep water (18 to 80 fathoms); but although generally distributed in the Mediterranean, and found in many parts of the North Atlantic, it does not appear to be plentiful anywhere on our shores. It has been found at Falmouth, in the Moray Firth, at Stornoway, Skye, Shetland, and in Birterbury Bay, County Galway.

The Blunt Tellin (T. crassa) has a yellowish-white shell with faint pink rays from the beaks to the lower margin, and marked by numerous strong concentric ribs. The left valve is much flatter than the right. In young specimens the shell may be found covered 
with a fibrous yellow-brown epidermis, but this soon gets completely cleaned off as the mollusk burrows in

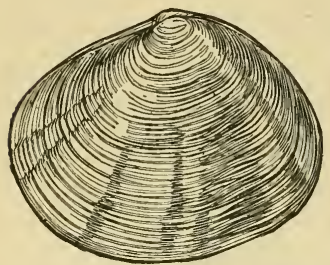

Blunt Tellin the sand. The Baltic Tellin (T. balthica) has a glossy shell, somewhat triangular when viewed from the side, but rather globular as seen from the end. In colour it varies from white to crimson, occasionally with bands of a deeper tint; and the surface finely grooved. The animal is yellowish, tinged with brown; the upper siphon larger than the lower. Its habitat is in sandy gravel and mud, between tide-marks, all round our coasts. The Thin Tellin (T. tenuis) is triangular-oval, flattened, thin, and semi-transparent, varying in colour from white, through yellow to rose;

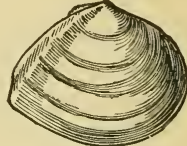

Baltic Tellin the right valve larger than the left. The animal is yellowish whice, its siphons nearly equal in length. It frequents sandy beaches about

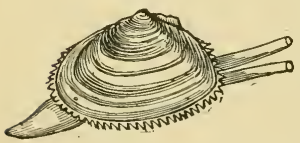

Thin Tellin low-water mark, but it does not burrow deeply. The Bean-like Tellin (T. fabula) has a triangularoval, thin, and semi-transparent shell, glossy, pearl-white tinged with yellow. The animal is similar to that of the Thin Tellin, of a clear white colour and with slightly longer siphons. It is common in sandy bays from low water to 15 fathoms.

The Rough Tellin (T. squalida) is flattened and thin, the valves slightly unequal, opaque, satiny, of 

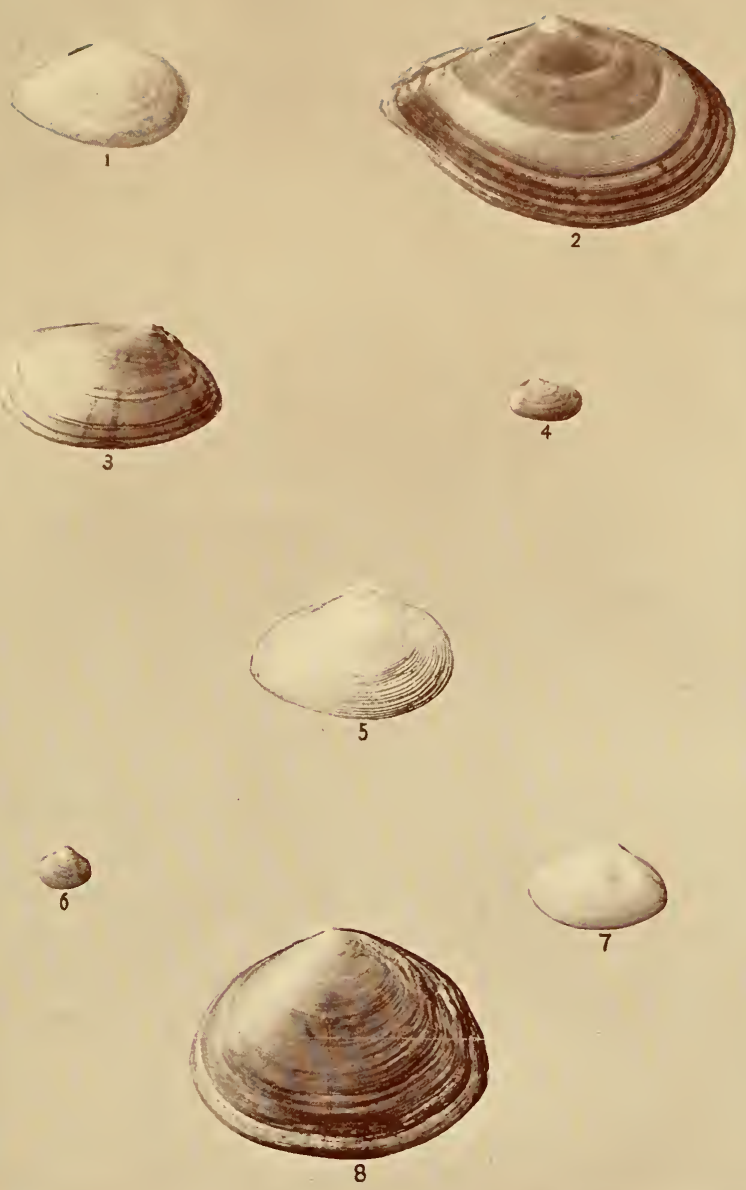

I Bean-like TelliN; 2 Rough TelliN; 3 Donax-like Tellin ; 4 Little Tfilli ; 5 Brittle Tellin; 6 Thin Furrow-shell; 7 White Furrow-shell; 8 Peppery Fl'RRoW-Shell. 

a pale orange tint, reddish near the beaks. The animal is whitish tinged with flesh-colour; the tubes speckled and the mantleedges strongly fringed; foot large. It is not a common species, but it may be found on sandy shores on the south and west of these islands, at depths between 7 and

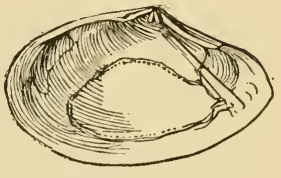

Rough Tellin-interior

15 fathoms. The Donax-like Tellin ( $T$. donacina) is triangular-oblong, compressed, somewhat glossy, of a yellowish-white colour with pink rays. The animal is white, with the edges of the mantle finely toothed, and the long slender tubes marked with white along their sides. It burrows in shell-sand and nullipore, between 4 and 25 fathoms. The Little Tellin ( $T$. pusilla) is very like the last mentioned, but smaller, more convex, and more solid. Its colours, too, are brighter, and may be white, yellow, pink, or rose, with rays of deeper tint. The animal is transparent white, the edges of the mantle quite plain, and the siphons nearly contiguous and equal in size, the excurrent being four or five times the length of the incurrent. The foot is toothed along the sides. It occurs on sandy shores at depths from 3 to 85 fathoms.

The Brittle Tellin (Gastrana fragilis) has been separated by Schumacher from the genus Tellina, because of its more wedge-shaperl and swollen shell, and because the lateral teeth of the hinge are wanting and the cardinal teeth of the left valve are very unequal in size. This, the only British species so separated, has a rather thin, but opaque, shell of triangular form and pale yellow hue, with fine 
concentric ridges. The animal is yellowish white, with a large foot, and tubes nearly twice the length of the shell. It is a local species, found burrowing in sand between low water and a depth of 12 fathoms.

The Furrow-shells (Scrobicularia) are so-called on account of the shape of the cartilage-pit, which is in this genus a narrow chink under the beak. The shell differs from that of Telline in the fact that while the right valve has two cardinal teeth, the left has but one. The shells are white, with concentric grooving, and gape behind for the extrusion of the siphons. The Prismatic Furrow - shell ( $S$. prismatica) is almost flat, of an oblong wedgeshape, thin, fragile, and semi-transparent, highly polished but minutely striated. The prismatic effects are due to the thinness of the epidermis. The animal, which is very active, is pearly white; its foot large and pointed, its siphons slender, and the mantle edges finely fringed. It is not a common species, though generally distributed on sandy ground in from 3 to 90 fathoms of water. It may be obtained most easily from the stomachs of flat-fishes and haddocks. The Glossy Furrow-shell (S. niticla) is more oval than the last, and the valves gape more widely. The animal is clear white, with a large foot and very long siphons; the mantle is fringed with short cilia. It is a more local species than mismatica, and occurs in muddy sand between 3 and 100 fathoms.

The White Furrow-shell (Syndosmya alba) is oval, thin, opaque white, polished, but with minute concentric grooves. The animal is whitish tinged with 


\section{Wedge-shells, Venus-shells, and Cockles I 23}

blue and spotted with pure white; the siphons are as long as the shell, and the mantle is edged with several rows of minute fleshy points. It is a mud-lover and social, and may be found in quantity in bays and estuaries from extreme low water to 40 fathoms. In spite of its dirty surroundings, the shell

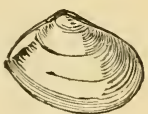

White

Furrow-shell is always remarkably clean. The siphontubes are protected from the mud by a lightbrown epidermis. The Peppery Furrow - shell ( $S$. piperata) is triangular - oval, nearly equal - sided, thin, opaque, flattened, without gloss; the colour

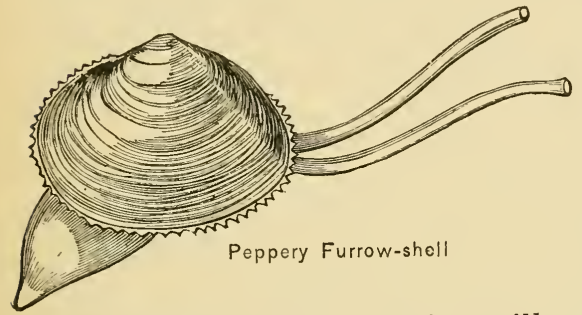

is greyish white, stained with yellow or black from contact with the mud; the epidermis glistening. The accompanying figure of the hinge-plate in this species will give a good idea of the character prevailing in this group, where the lateral teeth are greatly reduced or wanting. The hinge-plate it will be seen is thick, broad in the centre. There are two cardinal teeth in the right valve, thin, plate-like, and parallel; in the left valve there is one cardinal, but often this is double. There are no laterals, but their $\begin{gathered}\text { Hinge-plate of } \\ \text { Peppery Furrow-shell }\end{gathered}$ purpose is served by the ridged sides of the hinge-plate, which keeps the valves from shifting. The animal has a pale yellowish body, the mantle-edge scalloped irregularly and minutely 
fringed. On some parts of our coast this mollusk is known as the Mud Hen. It has a fondness for stiff mud and clay beds at the mouth of rivers, a little below low-water mark. It burrows to a depth of about 6 inches, keeping open communciation with the water above by means of its long tubes. The Thin Furrow-shell (S. tenuis) is a much smaller and more triangular species than the last; more convex, thin, opaque, iridescent; greyish white, often stained by burrowing in clay. The animal is white, with a delicate fringe to the mantle. The inhalent tube is twice the length of the shell, the exhalent tube one-third less. It appears to be fond of brackish water, for it is found chiefly in mud at low water along the estuaries of the south coast from Kent to Devon.

The Wedge-shells (Donax) are more triangular than the Furrow-shells, the valves glossy though partially scored by crossing grooves. The beaks are a good deal behind the middle line. The valves do not gape behind, and their inner margins are usually "milled," so that the closed valves interlock. There are two cardinals in the left valve, a double central one in the right, and a lateral fore and aft in each. The animal has a fringed mantle, short thick diverging siphons, and a very large and pointed sharp-edged foot. They are found in sand from low-water mark to about 8 fathoms, but as they burrow only an inch or so below the surface there is no necessity for long siphons. The Banded Wedgeshell ( $D$. vittatus) is the best-known species. It is variously coloured yellow, brown, olive, or purple, often with three white rays from the beaks, and with 
concentric bands of deeper tint than the ground colour. The animal is very agile, of a purplish red or yellow colour; the siphons are pale orange, and not more than half an inch in length. It is plentiful at low water in most sandy bays. The Polished Wedge-shell (D.

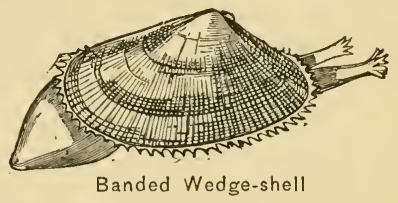
politus) may be at once distinguished from the preceding by the absence of the milling along the

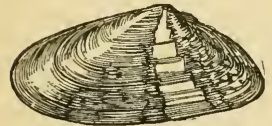

Polished Wedge-shell inner margin of the valves. The colour is chestnut-brown varying towards olive, with a broad creamcoloured ray and some marbling of the same tint. It burrows in sand at extreme low water and a few fathoms below it, chiefly on the coasts of Devon, Cornwall, and the Channel Islands. The Abrupt Wedge-shell (D. trunculus) has been taken occasionally on our southern shores. It is larger than the Banded Wedge-shell, and may be distinguished from it by being more acutely triangular, the striations more delicate, and the inner edge not milled beneath the hinge-ligament. Further, the hinder part of the shell does not slope gradually to a point, but abruptly as though cut off:

The Trough - shells (Mactra) are represented by five or six species. The shells are triangular-oral, swollen, with a slight gape behind. There are two erect diverging cardinals, and large plate-like laterals on each side of them-two in the right, one in the left valve. These lateral teeth have their edges milled in $M$. elliptica, M. solida, and M. sub- 
truncata. The animal has a thick mantle with fringed edges. The siphons are united throughout their length, but the exhalent tube is fitted with a tubular valve. The foot is large, tongue-shaped, and very extensible, used for burrowing and leaping as in the Cockles. They inhabit sandy coasts, burrowing but slightly below the surface, and ranging from lowwater mark to about 35 fathoms.

The Thick Trough-shell ( $M$. solida) is, as its names indicate, both thick and solid. In shape it is very nearly an equal-sided triangle, only the angles are rounded. Its colour is yellowish white, and it is marked with slight concentric grooves, but in spite of these the surface is quite smooth. The measurement from end to end is less than that from the beaks to the lower margin. The animal is white or yellow tinged with brown. The siphons are short, their mouths fringed with yellow or red filaments. It is common in coarse sand at low water and a few fathoms below it, all round our islands. The Elliptical Trough - shell (M. elliptica) is by some authors regarded as a mere variety of $M$. solida.

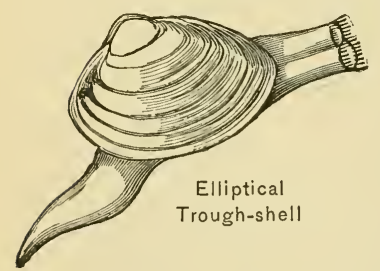
The shell is smaller, thinner, more elliptical than triangular, the greater measurement being from back to front, instead of from beak to lower margin. It occurs in deeper water (10 to 100 fathoms) than $M$. solida. The Cut Trough-shell (MI. subtruncata) has the ends of the shell much contracted, so that the beaks are very prominent, and the general aspect is hatchet-shaped. There is a heart-shaped depression 

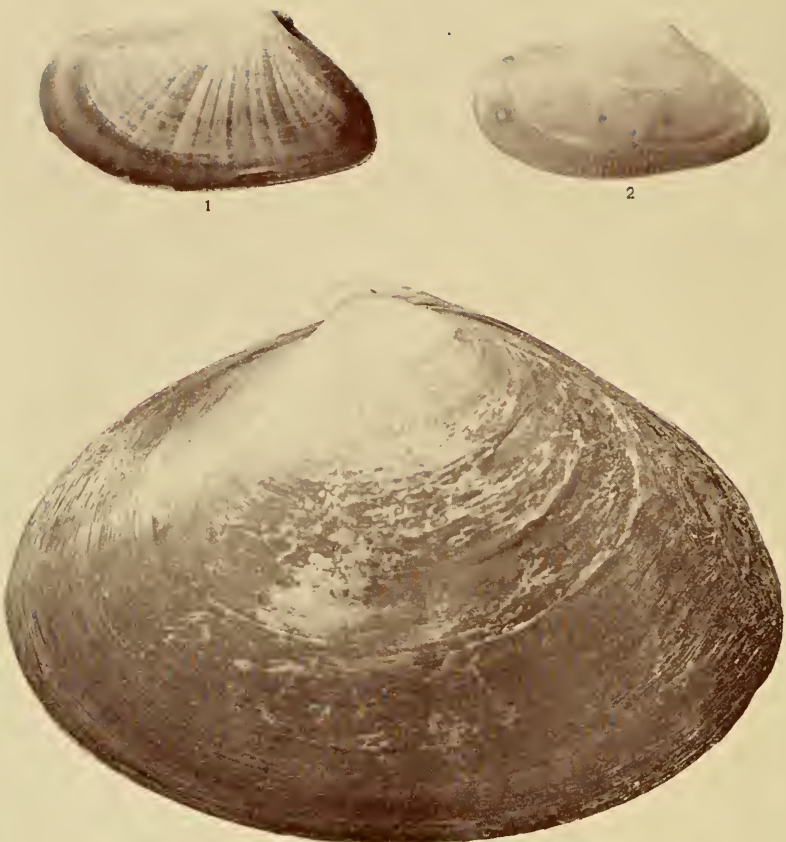

3
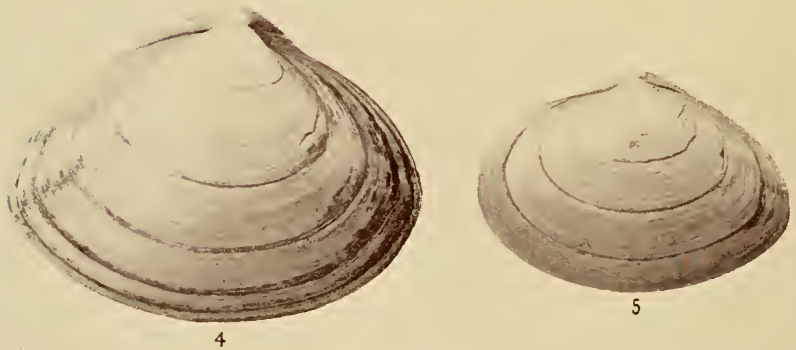

I Abrupt Wedge-sheli, ; 2 Banded Wedge-shell, 3 Gi.aucous Tkough-shel. ; 4 Thick Trough-shell; 5 Elliptical Trough-shei.l. 
both before and behind the beaks. The animal has the mouth of its siphon-tubes fringed with two rows of yellow or red filaments. The foot is yellowish and slender; the mantle with a toothed edge. It lives in coarse sand from low water to 27 fathoms. In the north of Ireland it is known as Lady Cockle; in the Clyde district it is the "Aikens."

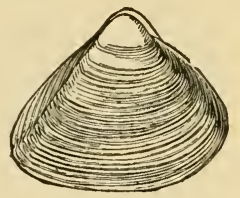

Cut Trough-shell

The Rayed Trough-shell (M. stultorum) is of the same general shape as $M$. solida, but thin and glossy,

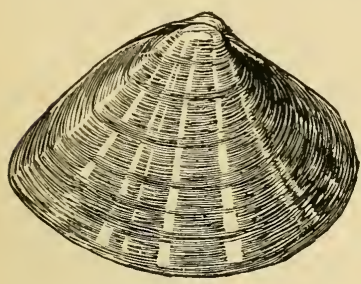

Rayed Trough-shell and the yellowish ground is largely covered by broken rays of brown from the beaks to the margin. The animal is white, tinged with blue; the mantle fringed with white filaments; the foot white, thick. It is common on all our shores, the animal burrowing in sand between extreme low water out to 18 fathoms. The Glaucous Trough-shell (M. glauca) is triangular-oval, rather thin and glossy; yellowish white, with rays of yellow-brown or fawn colour, and the upper margins marked with brown. It is covered with a brown, satiny epidermis. The animal is white, its mantle fringed with white filaments; the siphon-tubes short and conical, tinged with yellow and streaked with red-brown. It is a rare species, but it occurs on the Cornish coast, where it ranges over the sand in shallow water, quickly burying itself to a depth of two or three inches when the tide goes out. 
The general characters of the mollusks comprising the sub-order Veneracea are an almost round or oblong shell of equal valves, whose hinge has three diverging cardinal teeth, the muscular impressions oval and polished, and the mantle impression showing a deep sinus into which the siphons are retracted when not in use. The animal has unequal gills which are slightly folded; the foot is large, tongueshaped, and adapted for burrowing in sand, gravel, or mud, in which the species live. The siphons are unequal, cylindrical, and in general short, showing

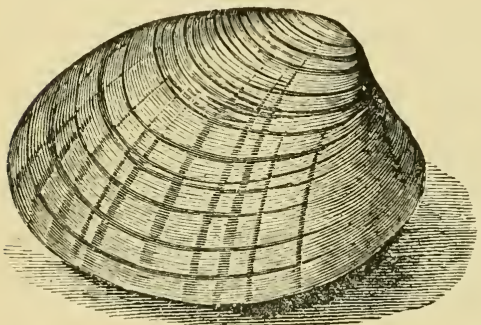

Smnoth Venus that the mollusk does not go far below the surface, and in most cases they are speckled in a way that makes them harmonise with the sand. The deep sinus of the mantle-impression is a character serving to distinguish any member of the family from related genera. A good example of the family may be found in the Smooth Venus (Venus chione), whose massive shell may be found after gales thrown up on sandy beaches of the Cornish coast. But our enumeration of the species must begin with one that is not so typical, because, its tubes being so very short their withdrawal has not produced a deep sinus in the impression of the mantle within.

The Little Circe-shell (Circe minima) is the only native representative of its genus. It has a nearly round, flattened shell, with broad, flattened, plate- 
like ridges with slight furrows between. It is of various tints,-white, yellow, red, brown, purple,sometimes streaked, rayed, or spotted with deeper shades. The animal is transparent greyish in colour, the mantle spotted with brown and fringed with short cylindrical points. The tubes are unequal in length. Its habit is to burrow slightly among sand and nullipore in from 5 to 85 fathoms of water.

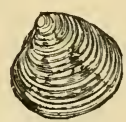

Exterior
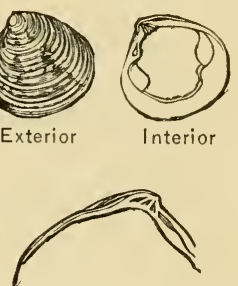

Enlarged plan of hinge Little Circe-shell

The Rayed Artemis (Dosinia exolet $\iota$ ) has an almost circular shell - thick, solid, flattened, anrl

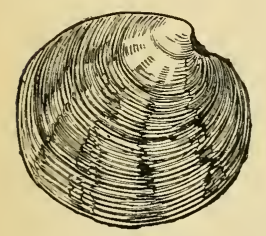

Rayed Artemis covered with ridges, but, unlike those of Circe, these are finer, much more numerous, and overlap. It is cream coloured, marked with several faint rays of red-brown, and some irregular spots of the same colour scattered over the rays. Owing probably to the epidermis being worn away in early life, this shell has the appearance of having been tossed about a good deal on the shore, and it was this aspect, no doubt, that struck Linnæus when he named it exoleta-worn away. The animal is pale yellowish, the mantle fringed with white lashes, and the siphons short and united. The

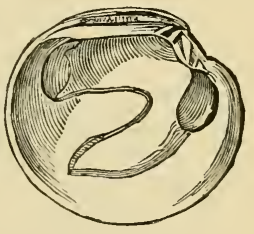

Interior of Rayed Artemis large foot is white and axe-shaped. All around these islands it may be found in sandy bays at a 


\section{I30 Shell Life}

depth of a few fathoms. The Smooth Artemis (D. lupina) is similar to the Rayed Artemis, but

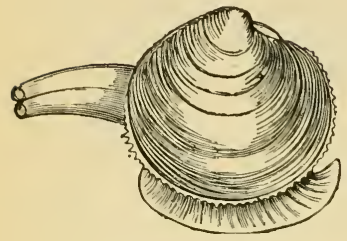

Smooth Artemis smaller, smoother, and less round in outline. The sides and lower margin may be, indeed, in Jeffreys' words "an arc of three-fifths of a circle." The animal is greyish white in colour, the mantle-margins fringed with short tentacles. The siphons are united except at the mouths, and are capable of extension to three times the length of the shell, showing that this species is in the habit of burrowing more deeply than the previous one. It is equally common, and may be found as near as low-water mark on sandy ground.

The Smooth Venus (Venus chione) is one of the finest of our native species; its thick, heary shells

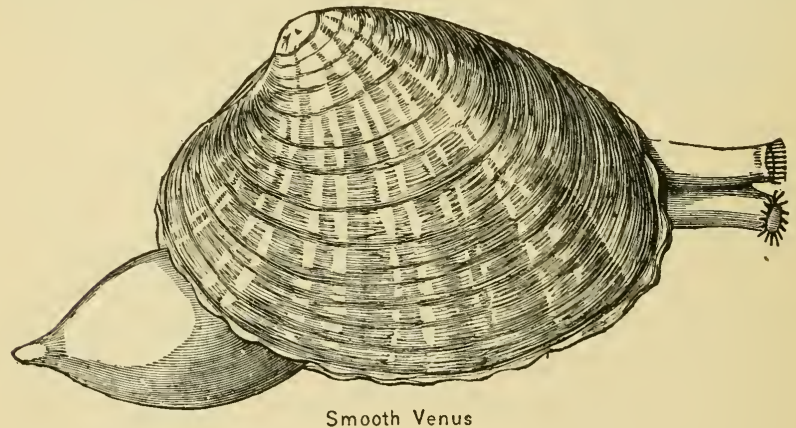

being nearly 4 inches in longest diameter. Its shape is described as triangular-oval. In colour it is a light pinkish brown, with a varying number of narrow rays of darker hue from the beaks to the lower 

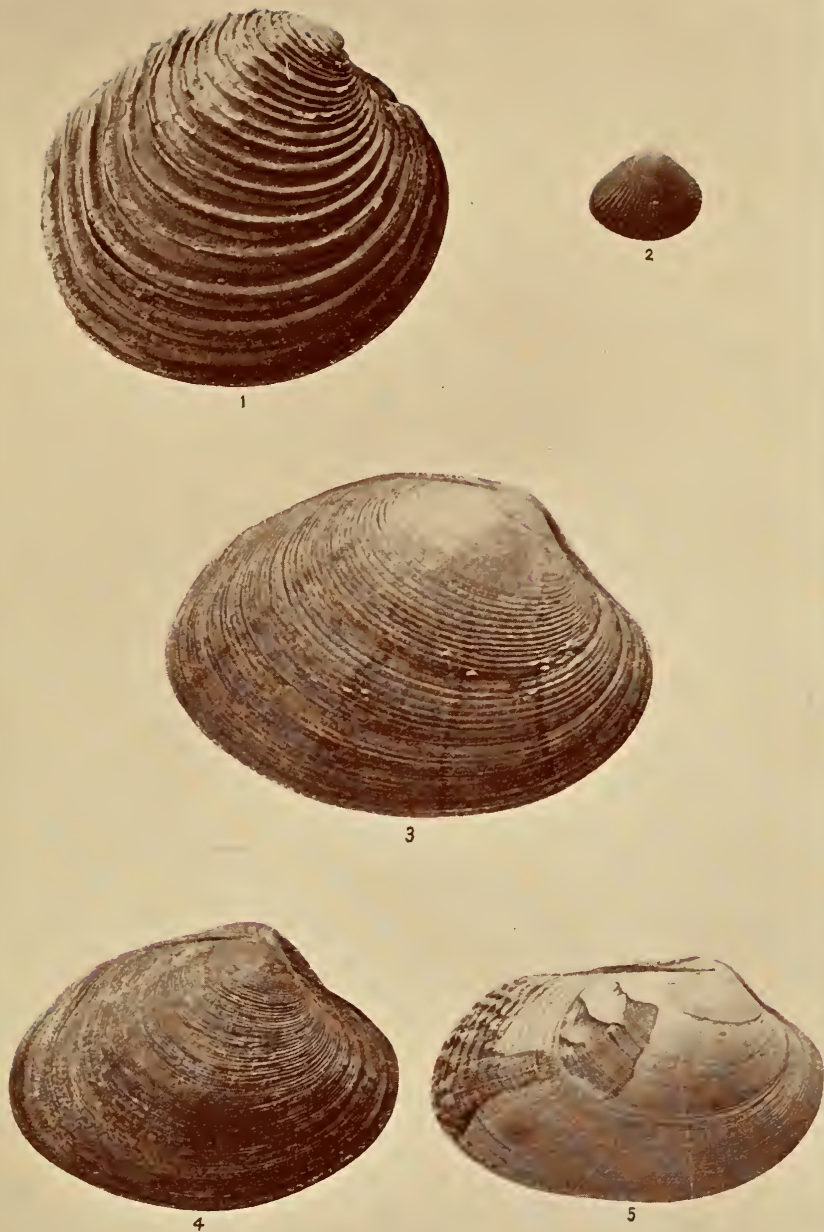

I Pale Venus; 2 Oval Venus; 3 Banded Carpet-shell ; 4 Golden Carpet-shell; 5 Plillet Cariet-shell. 

margins, which are round-edged, and perfectly smooth. The concentric lines are so slight that they at first sight appear to be more due to colour than to sculpture; and the character of the epidermis is such that it resembles a coat of rarnish. The animal is flesh-coloured with a tendency towards orange. The mantle is slightly scalloped along the lower margin, and has a few tentacles at the front. The orange tubes of this species are not united all the way, and their mouths are fringed with black-tipped tentacles. The large, thick foot is dark flesh-tinted. It is not generally distributed, its range in our waters being confined to the south and west, where it dwells in sand at depths between 12 and 25 fathoms. It is a good edible species, not only for man, but is also appreciated by fish and bird; hence its thick hard valves, which probably are

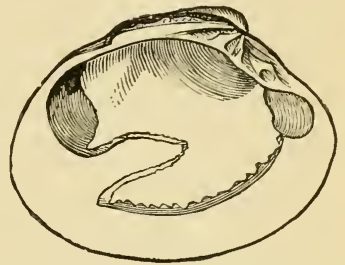

Interior of Smooth Venus needed not only to resist the jaws and palate teeth of big fishes, but to prevent injury from rolling about in great commotions of the lower waters. We have seen it washed up on Cornish beaches after continued heavy gales, and have seen the Razor-bills and Puffins attack it with their powerful bills, nipping off a little of the shell at one end to admit the point of their beak in order to sever the adluctor muscle which keeps the valves closed. It is to these muscles and the exceedingly powerful hinge-teeth that the inviolability of the shell is due, for there are no cogs along the margins by which the valves may interlock. 
The Banded Venus (I. fuscicta) has a solid shell with sharp-edged concentric ribs, variable in colour

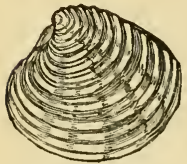

Banded Venus through yellow, pink, red, to brown, marked by several rays of darker tints. The margins of the shell inside are beautifully milled, except just below the ligament. The animal has its mantle bordered with red and fringed with white. The short yellow tubes are united, save at the tips, where they are fringed with white. The thick, white foot is lance-shaped. It is a generally distributed species, occurring on all our coasts, at all depths, among gravel, sand, and nullipore. The Pale Venus ( $V$. cusinu) is very similar to the last, but much larger ( $1 \frac{3}{4}$ inches across), the ribs on the shell more plate-like, and less robust, more strongly scored between the ribs, more unicolorous and pale. Of wide distribution, but only local occurrence, on sandy ground, from 5 to 90 fathoms.

The Warty Venus (V.verrucosu) is still larger than the Pale Venus, and an advance is made in the passage of the ribs to concentric ridgres which are, in this species, broken into wart-like irregularities, especially towards the hinder margin. From the beaks to the lower margin, crossing as it were beneath the concentric ridges, run a great number of evenly and closely set ribs, which are more evident in the older

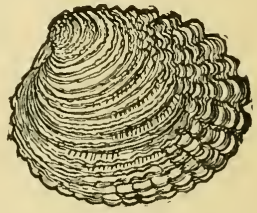

Warty Venus (one-fourth nat, size) portion of the valves where the ridges are less prominent. The lower margin is milled inside, as shown by the figure of the interior of a left valve. 


\section{Wedge-shells, Venus-shells, and Cockles I 33}

It is a dull, rough-looking shell of drab or pale brown colour, sometimes with a few darker rays, and its distribution is restricted to the south and west coasts, where it occurs in fine gravel and sand at depths between 7 and 20 fathoms; in the Channel Islands it may be found at low water. The Oval Venus ( $V$. ovcetc) has a dull shell of triangular-oval shape, whose

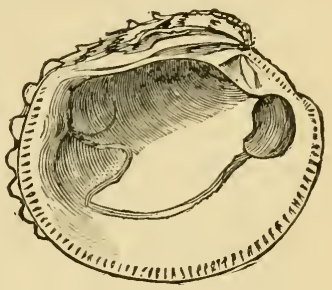

Warty Venus-interior longest diameter is little more than half an inch. From 40 to 50 ribs radiate from the beaks, and are crossed by half that number of concentric thread-like ribs, a scale or wart arising where the lines cross. The colour is yellow tinged with pink or red, and occasionally blotched or spotted with red-brown. The inner margin is milled all round. The short siphons are of equal length, and connected almost to the mouths. It lives among sand and nullipores from extreme low water to deep water.

The Striped Venus ( $V$. gallina) is of somewhat triangular form, the shell solid, of a pale yellow hue, with three obscure rays of red-brown spots. Its

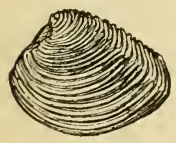

Striped Venus (one-third nat, size) sculpture consists of overlapping concentric ribs. The inner margins are milled. The animal is white, and the white filaments which fringe the mantle are disposed in tufts. The long slender siphons are united almost throughout. It is generally distributed and common in sand, from low water to 85 fathoms. The Clam (V.mercenuric), an American species, has 
become naturalised in the Humber, where it was first observed in 1864, from which date it appear's to have gone on increasing in numbers. As it is an edible species highly appreciated in the United States its continued increase will probably bring joy to local epicures. It may be noted that the word "mercenaria" refers to the former use of these shells in making "wampum" - the strings of beads which passed as money among the North American tribes.

The Wavy Venus (Lucinopsis unclutu) is very like the Round Double-tooth (Diplodonta) described in
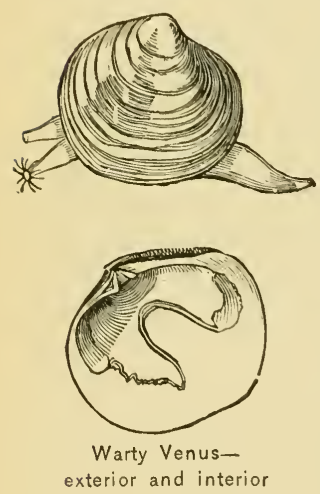
the beaks. The mantle-nurgin is wavy or uneven, but neither fringed nor toothed. The orange siphons are widely separate, protruding from the lower rather than the hinder margin, and the lower tube is longer than the upper, while both are fringed. It is a common species everywhere in fine sand, even when mixed with mud, and ranges between 3 and 100 fathoms. Full-grown specimens measure $1_{ \pm}^{1}$ to $1 \frac{1}{2}$ inch in diameter. 


\section{Wedge-shells, Venus-shells, and Cockles I 35}

The following four species, though belonging to the same family, form the genus Tapes, and are familiarly known as Carpet-shells from the colour-markings suggesting the patterns of tapestry. The shells are solid, more rhomboidal than triangular, and the beaks are set very near the front extremity. This character, combined with the shape of the shell, is sufficient to determine the genus, and the four native species are so distinct from each other that they may be readily identified.

The Golden Carpet-shell ( $T$. cureus) is yellowish white with little gloss. Finely incised, crowded but shallow lines run from the beaks to the margins, and are broken by the very distinct bands marking periods of growth, and which are often greyish in tint. The margins of the shell are quite plain. It is confined chiefly to our south and west coasts

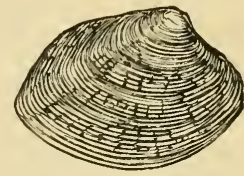

Golden Carpet-shell (two-thirds nat. size) in sandy gravel between 3 and 18 fathoms. The Banded Carpet-shell ( $T$. virgineus) is more distinctly oblong than the last. The exterior of this shell has polish, though it is not very

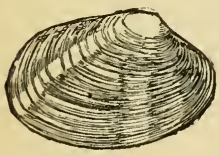

Banded Carpet-shell (one-fourth nat. size) glossy. The surface scarcely appears broken by the flattened, close-pressed ribs, which are slightly rounded only at the front and back. The ground colour is pale yellow, overlaid with dots, spots, and splashes of purplish brown, which are arranged in about three wedgeshaped masses, leaving clear rays between them. The glossy interior is tinged with yellow, orange, or purple in its upper half. The margin of the 
mantle is partly toothed and partly waved and scalloped. The siphons are separate for only a fourth

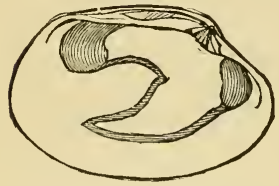

Banded Carpet-shellinterior of their lengrth, and are pale yellow, tinged with brown and purple, and with fringed mouths. It is a generally distributed species, and may be found among sand and nullipores from low water to over 100 fathoms.

The Pullet Carpet-shell ( $T$. pullastra) is triangularoval, yellow, marked-especially on the hinder part -with dark purple-brown. The concentric lines are finer and closer on this shell as compared with the last, and in addition there are a vast number of delicate lines radiating from the beaks. The colouring is in some specimens very suggestive of the plumage of a speckled hen, and it is probably from such individuals that the mollusk has got the name of

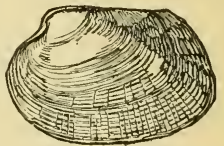

Pullet Carpet-shell (one-fourth nat. size) Pullet, which is locally applied to it on parts of the Devon coast. The animal varies in colour from white to grey and yellow, and its mantlemargins may be waved or jagged. It is quite a common species, and may be found in the muddy sand of the shore between tide marks, in crevices of the rocks or in the root-like bases of the larger seaweeds. In these situations, or in the deserted holes of rock-boring mollusks, it usually spins a byssus after the manner of the Mussel. The Cross-cut Carpet-shell ( $T$. (lecussuta) is decidedly the Carpet-shell, but it is the back of the tapestry that is shown by its sculpture. The lines from the beaks break the surface up into 
radiating wavy ribs which are crossed and broken by concentric lines. There is not the faintest gloss or polish on the shell. Its colour is a yellowish drab, stained irregularly with purple. The animal is cream coloured or grey, its mantle-edges scalloped or edged with white; the siphons separate throughout their length and fringed with brown at

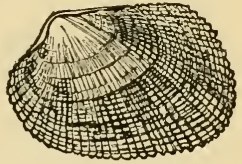

Cross-cut Carpet-shell (nne-fourth nat. size) the orifices. This species appears to be confined to the south and west coasts, where it burrows in the gravel and sand about low-water mark. The Banded, the Pullet, and the Cross-cut are used in different parts of the Continent as human food, and the two last named are eaten in Sussex and probably some other parts of this country.

In external appearance the Rock Venus (Venerupis irus) offers little resemblance to the Carpet-shells, yet a glance at the interior shows very near relationship. The valves do not fit closely at the hinder end, showing that the siphons are rarely withdrawn.

There are fifteen or more

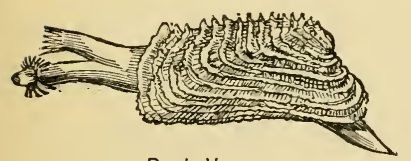

Rock Venus concentric rilges, thin and high, with toothed edges, and beneath these, running from the beaks, a crowded series of fine lines. The animal is white, tinged with pink, the siphons united for half their length, and the valve of the lower protruded beyond the fringe. The foot is rather small, compressed, and adapted for spinning a byssus. The favourite habitat of this species is in the holes of limestone rocks bored by Saxicava, also in the 
cavernous bulbs or so-called roots of the large Lamincurice. But it is only in parts of the west and south-west that it need be looked for, such as the shores of Cornwall, Scilly, Guernsey, Devon, Dorset, Glamorgan, and Pembroke; it also occurs round Ireland, except on the north. Its zone is that of the big seaweeds a little below extreme low water. The form varies according to habitat. 'That figured is the finest, and it lives either in rock chinks or in the empty valves of Pliolas dactylus.

The Rock-borers (Petricole lithophaga and $P$. pholudiformis) are not British, but they are found occasionally on our shores. They bore into limestone

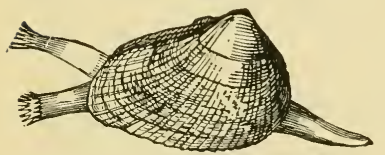

Rock-borer (Petricola lithophaga) and mud. The first named -which is also figured-is a native of the Mediterranean and the French coasts, but the second comes from North America. This, which has a more elongated, more strongly ribbed shell than $P$. lithophaga, appears to have got established in recent year's about the estuary of the Thames and in the river Crouch, Essex; it has also been taken at Herne Bay just above low water. It is very probable that it has been introduced among oysters that have been imported from America and laid down in these districts.

The Cockles are the British representatives of the sub-order Cardiacea, which gets its name from the

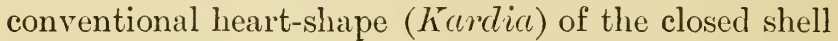
when viewed enclwise. The two valves are exactly alike, very convex, with prominent beaks, from which strong ribs radiate. These ribs and the in- 



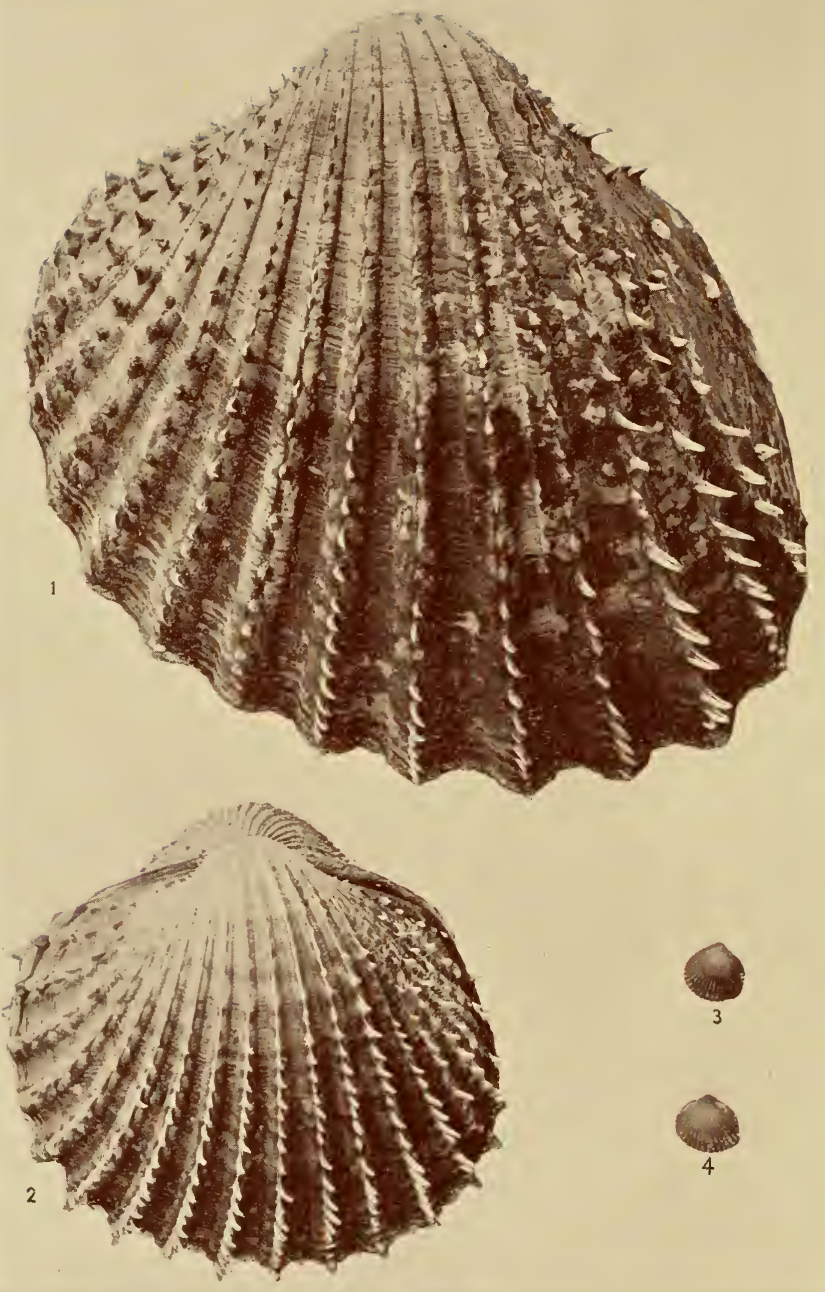

I Stiny Cockle; 2 Prickly Cockle; 3 Knotted Cockle; 4 Least Cockle. 
tervening furrows being continued right to the margins of the shell, those of the two valves interlock, fitting in a very accurate manner. There are one or two cardinal teeth in each valve, and a strong lateral on either side at some distance from the cardinals. The gills are long and much folderl back, the siphons rather long, the foot large, long, and cylindrical, the inantle-margins jagged. These mollusks live in sand and mud, from low water to a considerable depth, and by means of their foot can rapidly sink into or rise above it. Pigment spots serving as visual organs are scattered over the margins of the mantle and over the tubes.

The Spiny Cockle or Red-nose (Cardium aculeatum) is the largest of our native species, and measures as much as 3 inches across. The valves are somewhat thin and glossy, covered by about 20 strong broad ribs that radiate from the beaks and bear a number of stout curved spines whose points are directed backwards. The colour is yellowish tinged with red. The animal is coloured bright red, and the red foot, which gives it the popular name of Red-nose, is long and awl-shaped. It is found in deep water along sandy shores, chiefly in South Devon; at Weymouth, Guernsey, and Dublin Bay. The Prickly Cockle (C. echinatum) is not so large as the foregoing, being little more than 2 inches across; but the shell is more solid, has a duller surface, and a less oblique curve to the front margin. The radiating ribs bear short, stout, triangular spines, curved backwards. The colour is yellowish white, stained with red. The animal varies in colour from white to pink; the foot is finger shaped, with a flesh- 
coloured or red skin, twice the length of the shell. It is common on sandy shores on all our coasts, ranging from 5 to 100 fathoms. At Jersey very fine specimens may be taken from muddy sand at low water. The Rough Cockle (C. tuberculatum) resembles the last

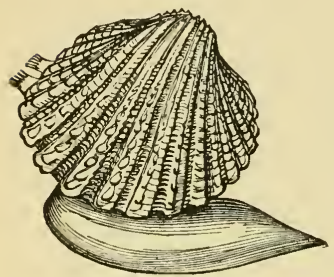

Rough Cockle species in general appearance, but differs from it in having a larger, more solid, and globular shell. The ribs are coarser, and the spines upon them are interrupted by intervening spaces, whilst in C.echinatum the rows are continuous; some of the spines (in tuberculatum) are short and blunt, others flattened. This also is a southern form, found in sand at extreme low water to about 12 fathoms on the coasts of Dorset, Devon, Cornwall, Guernsey, and Bantry. Diameter 3 inches.

The Warty Cockle (C.popillosum) is a small species whose longest liameter is little more than half an inch, the shell globular, solid, glossy, with about 25 flat ribs close together. It is coloured yellow and streaked with reddish brown. It occurs in the Channels Islands in coarse sand, between 15 and 20 fathoms. At Herm it has been taken at low water. Fresh valves have also been drerlged at Falmouth (19 fathoms), and Scilly (40 fathoms). The Little Cockle (C. exiguum) has a small, solid, dull shell, with about 20 compressed ribs, which are covered in young examples with white warts; white or yellowish, sometimes

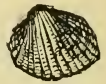

Little Cockle streaked with brown. It is pretty generally distributed along our shores, occurring in soft ground a 
little beyond low-water mark. The Banded Cockle (C. fasciatum) is another minute species, with about 25 ribs bearing overlapping scales. The shell is thinner, the valves less swollen. The name is suggested by the reddish-brown bands, but these are by no means unfailing marks of identity, for the species is a very variable

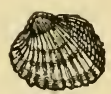

Banded Cockle one. The animal is white, with a plain-edged mantle, and the long, slender, finger-shaped foot is transparent. It is a common shell on all our coasts where there is gravelly sand, in from 5 to 90 fathoms of water. The Knotted Cockle (C. nodosum) is similar to the Banded Cockle, swollen near the beaks, with from 24 to 28 ribs, covered with little knobs or oval plates. The colour is white, sometimes tinged or banded with yellow or brown. The white animal is somewhat transparent; the mantle fringed with white filaments, and the siphons pale yellow; foot white. It is generally distributed, and occurs among sand and shell-gravel at depths between

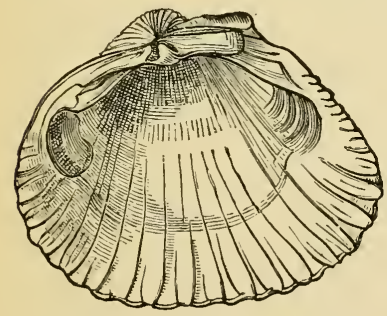

Common Cockle-interior

3 and 86 fathoms.

The Common Cockle (C. ectule) is so thoroughly well known that it stands in need of little description. The shell is somewhat rhomboidal, solid, and without gloss, traversed by ribs varying in number from 24 to 28 , and by minute lines crossing each other at right angles. The animal has a white body, but the mantle is pale yellow, its edges with a short white fringe. The short 
siphons are separate throughout, with white filaments along their sides. The white or yellow foot is proportionately small, though long, and ends in a thin flat point. It occurs in great numbers on all our sandy shores from low water to about 5 fathoms; and a smaller, thinner variety extends up estuaries into brackish water, as, for example, up the Thames as far as Gravesend. It is said to occasionally depart from its burrowing habit and to take to climbing up submerged posts, spinning a byssus to aid it. The raking in of Cockles for food and bait forms no inconsiderable item of what is comprehensively called the fishing industry. The Least Cockle (C. minimum) might at first sight be taken for a young example of the last mentioned. It has a roundish-oval, thin, glossy white shell, crossed by 28 or 30 flattened, radiating ribs, which bear minute arched scales. It is subject to little or no variation, but individuals that have lived in coarse sand may be found with the ribs cleaned off by attrition, whereas those found in muddy sand have the ribs beautifully sharp and fresh. It is not widely distributed; but it has been found off the west of Scotland, Shetland, Ireland, Isle of Man, Scilly, Lundy, the Smalls, and West Orkneys, burrowing in fine sand at depths between 5 and 100 fathoms.

The Smooth Cockle (C. norvegicum) differs from all the others in appearance, not only by reason of its smoothness, but also of its shape. The shell is distinctly triangular in outline, wedge-shaped when viewed from the ends, and crossed by about 40 ribs, which are all but obliterated owing to their lowness and the shallowness of the intervening grooves. The 

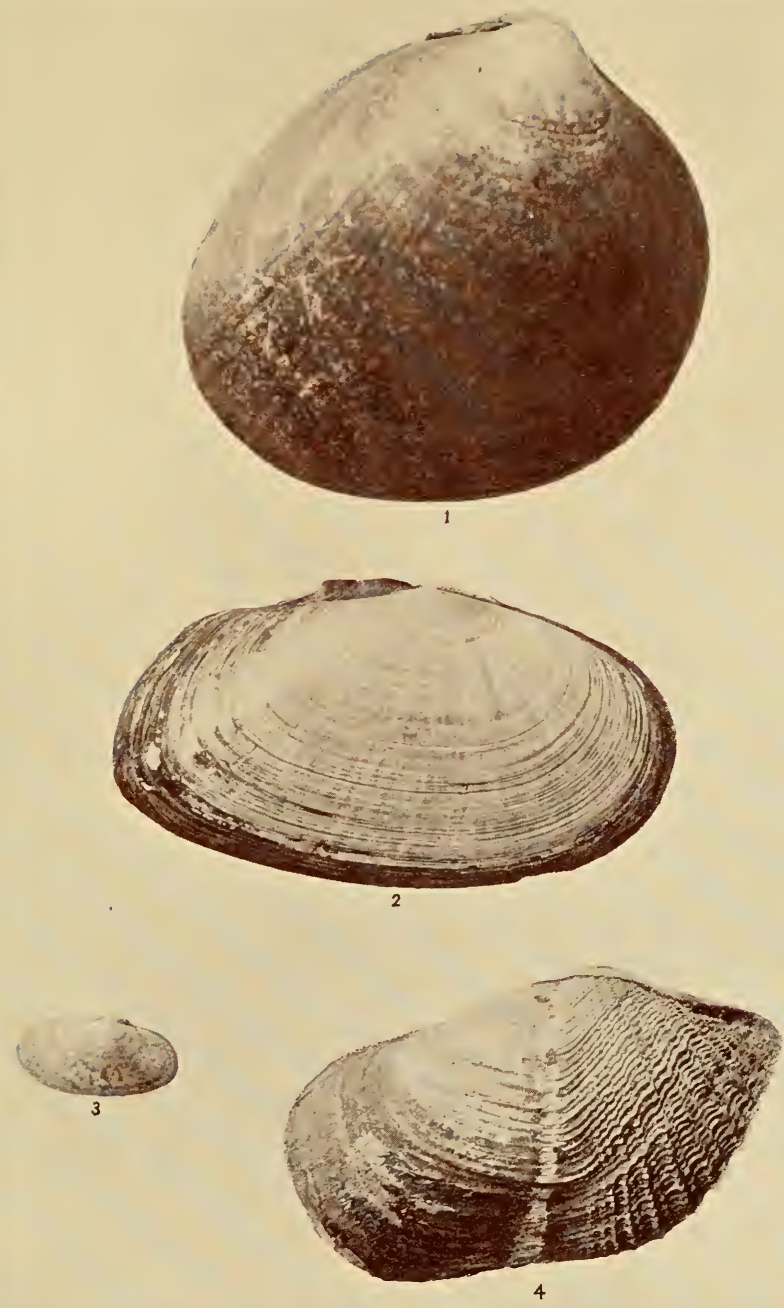

I Siooth Cockle; 2 Large Sunset-Shell; 3 Ribbed Sunset-shell; 4 Oval Piddock 

Wedge-shells, Venus-shells, and Cockles I 43

colour is whitish, faintly mottled with flesh-tint where the greenish-yellow epidermis has been worn off; at the ends of the valves there is no trace of the ribs. The animal is yellowish white in colour, the mantle tinged with red and its edges plain. The siphons are separated throughout their length but united at the base. It has a large and powerful rounded foot, with a rough flesh-coloured coat. It is a local but plentiful shell, dispersed generally along our shores in from 5 to 80 fathoms, where there is sand or nullipore. 


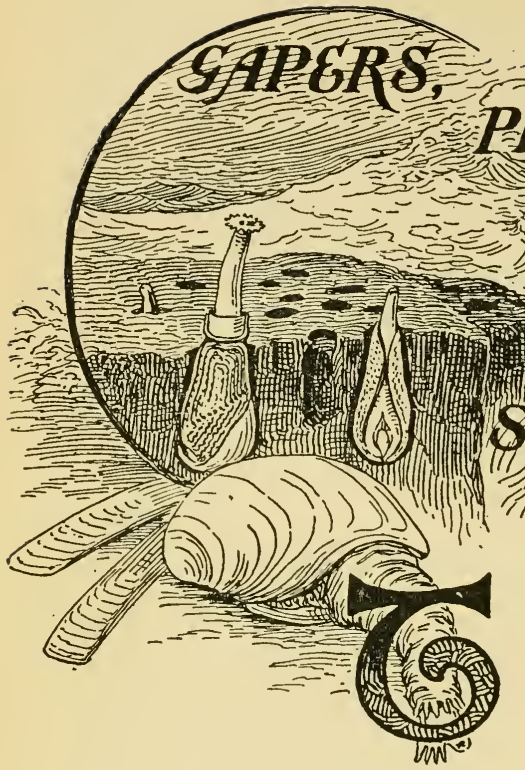

HE species included in this chapter form several sub-orders, the first of which is the Myacea, agreeing pretty closely with Cardiacea in the form of the gills and the mantle, the variability of the mantle impression, and the want of uniformity in the union of the gills. But the foot instead of being cylindrical is more or less flattened from the sides, and more tongue-shaped than finger-shaped. The shells gape at one end or both, and this, as we have already pointed out, is due to the fact that the siphons are almost constantly extended, and consequently when the shell is enlarged by normal growth these edges are not permitted to come together. The subjoined figure, showing the position of the Blunt Gaper when alive, will help to explain this constant ex- 
tension of the siphons. The Gaper burrows deeply into sand and mud, not for its food, but for safety-its flesh being prized by fishes. At the recess of the ticle they are searched for by gulls, and if they are too near the surface they pay the penalty with their lives. Their siphons are stretched upward until they reach the water, when their mouths are opened and the streams set in motion: one downward, charged with microscopic life to be filtered out and used as food; the other, upward, discharges the water that has passed over the gills and been relieved of its oxygen.

The first genus in this group is the Sunset-shells (Psammobic ), of which four species are found in our seas. They have long slender shells, much compressed and gaping slightly at each end, the foot being usually extended as well as the

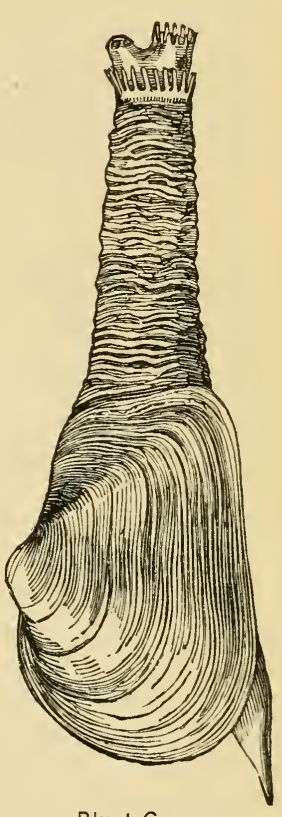

Blunt Gaper siphons. These siphons are long, and separate; the foot comparatively large; and the mantle-edges fringed. The popular name is due to

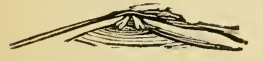

Hinge-teeth of

Pscemmobia

the fact that the yellowish shells are marked by radiating bands of red, the notion being that when a valve is held with the beak below these red bands present the appearance of beams from a sun that has just sunk below the horizon. The character of the cardinal 
teeth is shown in this figure of a right valve; in the left valve the hinder cardinal is much smaller and not cleft. The beaks are turned slightly to the hinder end of the shell.

The Tellin-like Sunset-shell (P. tellinella) is thin, glossy, yellowish white, marked with fine concentric ribs, the grooves as well as the ribs being polished, and the radiating bands are of pink, red, or violet. A streak of crimson usually runs along the upper edge of the valves before and behind the beaks. The interior is highly polished, with

Tellin-like Sunset-shell the external colouring repeated. The animal is white, its mantle with a tooth-like fringe, and the upper (excurrent) siphon is marked by fine lines of white from end to end. This brilliant little mollusk occurs locally all round our coasts, burrowing in sand between 4 and 85 fathoms, and occasionally swimming after the manner of the Pectens by flapping its valves.

The Ribbed Sunset-shell ( $P$. costulata) differs from the last chiefly in the character of the posterior slope of the shell, which bears from 12 to 20 slight but sharp ribs running from the beak to the hinder margin, which is notched in consequence. In addition the shell is thinner, the valves mequal, and the less regular rays are of deeper tints. The animal is white tinged with pink, the mantle edges thickened and slightly fringed. This is more local than the last, and can only be obtained by dredging, as its habitat is in fine sand in from 15 to 85 fathoms of water. It is slightly more than 1 inch in length. 
The Faroe Sunset-shell (P. ferröensis) is larger, more opaque, and duller, marked with close low concentric ridges, which become higher just before reaching the clearly marked posterior slope, across which they are very distinct. In that particular region they are crossed by half a dozen (on each valve) fine radiating ribs from the beaks.

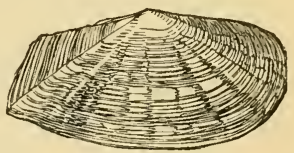

Faroe Sunset-shell The shell is more or less covered by a dull greenish epidermis, but where this is worn away the colour is seen to be pink with indefinite rays of a deeper tint and small oral spots of white. The inside is coloured with some shade of purple, and very highly polished. This is a common species on all our coasts, in sand, at depths between 4 and 90 fathoms of water.

The large Sunset-shell ( $P$. vespertina), which is the largest of the native species, is of a more oral form. It is somewhat solid, compressed, and glossy where the thick olive epidermis has worn off. Where it is thus bared the shell is seen to be of a yellowish-white hue with rays of purple-brown or lilac. The sculpturing of the surface is very slight, and has the appearance of having been worn down; it consists of concentric ridges, and more evident lines of growth, crossed by obscure radiating lines. Interior coloured yellow or purple. The animal is yellowish white in colour, with a fringed mantle, and a broad thick foot. It is a local species, but found widely distributed, chiefly on the south and west coasts of both England and Ireland, and on the west coast of Scotland. Like the others 
of its genus, it is a sand-dweller, and its range is from extreme low water to 4 or 5 fathoms. It attains a maximum breadth of 21 inches, and fairly large specimens are used for food in the west of Ireland.

Of the Gapers ( $M y a)$ we have only three species, and one of these we have already figured as a type of the sub-order. The siphons are connected throughout their length, and though they may be, and are at times, completely withdrawn into the shell, they are usually kept fully extended. This has caused the hinder end of the shell to gape wirlely. 'They are deep burrowers, and therefore

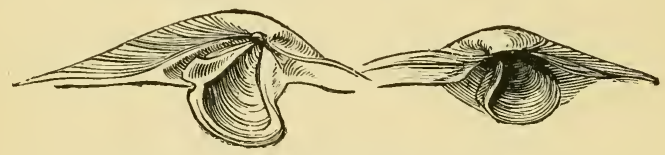

Hinge and cartilage process of Gapers

assume the position shown in our figure, the foot downwarls and the siphons reaching straight up through sand or mud to the water above, with the long axis of the shell at right angles with the surface. Looked at from this point of view it will be seen that the fore-end of the shell is shaped like the bows of a boat, that the tongue-shaped foot may pull it down more easily. These shells are commonly buried to a depth of eight inches, sometimes a foot. There is a remarkable development of the hinge-teeth beneath the beak of the left valve in the shape of a hollow shelf to hold the cartilage, with corresponding ridges to fit it in the right valve. 
The Sand Gaper or Old Maid (M. arenaric) has the valves of the shell not quite equal, the right being a little larger than the left. The shell is traversed by coarse, irregular, concentric lines, partially covered by a wrinkled, paperylooking epidermis of a muddy grey colour. The shell gapes at each end, and the epidermis is continued back orer almost the entire length of the siphons, as though they required protection from the material through which they have to push. Where the epiclermis is worn away the shell is a dirty white, stained with rust near the beaks. The mouths of the siphons are coloured with red and fringed. It is a generally distributed species, and is found in soft ground from low water to about 25 fathoms. It has a preference for estuaries,

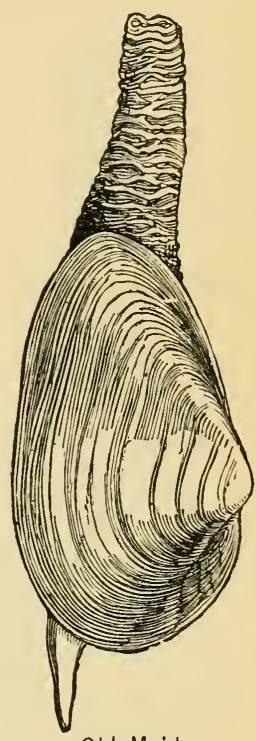

Old Maid (one-fifth nat. size) and has no objection to brackish waters. Large numbers are consumed for food, under the name of "old mairls" and "clams," on some parts of our coasts. The shell is about 4 inches wide when full-grown.

The Blunt Gaper (11. truncata) is very like the foregoing species, except that the shell-which is about one-third less in width than that of $M$. arenaria-ends abruptly behind as though sawn across, and there is less disparity in the size of the valves. It is found in similar situations to 
the other, with a marked preference for the open sea over estuaries.

The Small Gaper (MI. binghami) has a wedge-shaped

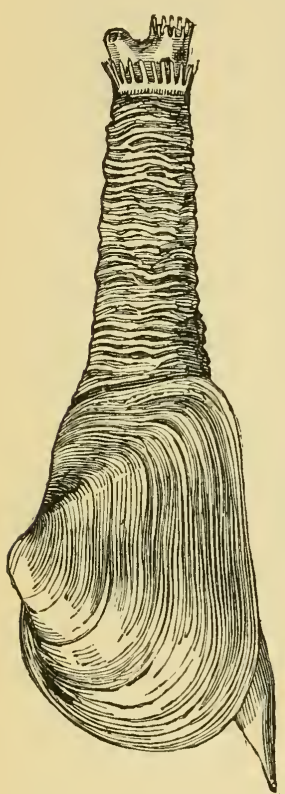

Blunt Gaper (one-fifth nat. size) shell, with unequal valves which gape behind, smooth, and with fine lines instead of the coarse ones of the other species. It is white beneath the epidermis, which is pale brown. The siphons are short, especially the incurrent one. This species does not burrow in the ground as its congeners do; instearl, it takes possession of holes that have been made by the Rock-borers (Saxicava), the empty tubes of Serpulæ, and the crevices of the so-called roots of the great Tangles and Wracks, between 5 and 25 fathoms. It attaches itself by means of a byssus. Individuals that live this free, out-of-door life, so to speak, are liable to be mistaken for Saxicava or Thracia.

The Basket-shells (Corbula), though a large genus, are represented in this country by a single species, the Common Basket-shell ( $C$. gibbu), in which the unequal size of the valves noticed in $M y c$ is much accentuated, so much indeed that the left valve appears almost like an operculum to the right. The shell is also drawn out behind to make a cover for the siphons, which are so short as to be only slightly protruded. The shell is white tinged with 
yellow and brown, ornamented by concentric ribs in the right valve, but these become mere raised lines in the left. The hinge-teeth in the right valve consist of a thick, curved cardinal, flanked by a riclgelike lateral on either side; in the left valve the cardinal is hollowed to take the cartilage, and beside it is a cavity

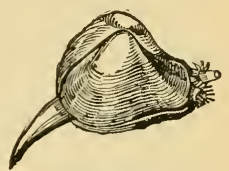

Basket-shell to fit the cardinal of the right. The animal has a comparatively large and thick foot, which it uses for burrowing just below the surface of sandy and gravelly shores, from extreme low water to about 70 fathoms.

There are, however, other Basketshells beside those of the genus C'orbula, of which the subjoined figure of the Pointed Basket-shell (Nererc cuspidata)

Interior of Basketshell, showing hinge-teeth

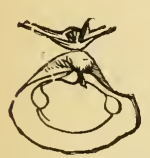

will servo a

will serve as a type. In this genus, of which we have three species, the shells are thin, fig-shaped, and with unequal valves, though the disparity is not here so great as in Corbula. The siphons are longer, and the hinder part of the shell is drawn out to partially cover them;

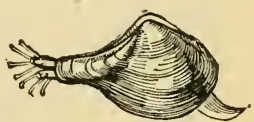

Pointed Basket-shell

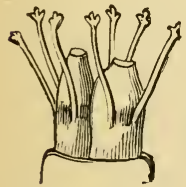

Siphons of Necera (enlarged)

their orifices are protected by long tentacles whose ends are divided into several finger-like points.

The Pointed Basket-shell (N. cuspi(late) is much drawn out behind, tolerably solid,--more so than in the other species,-much swollen, and the left valve larger than the right. Its colour beneath the red-brown epidermis is whitish. The horn- 
coloured cartilage is covered by a chalky band (ossicle) free from the shell, and a strengthening rib runs from under the beaks towards the centre of the siphon-outlet. It has been taken from deep water (12 to 90 fathoms) in muldy sand, off various parts of our coast, but chiefly Scotland and north-west England. The Short Basket-shell (N. abbreviat ${ }^{+}($) is almost transparent and extremely fragile, of a triangular-oval shape, swollen, and the valves almost equal. The surface is slightly glossy, ornamented by about a dozen concentric folds, and a curver sharp rib which runs from behind the beak. It is greyish in colour, covered by a yellow-brown epidermis. It has been taken chiefly in deep water ( 40 to 75 fathoms), off muddy ground, in Loch Fyne and around Shetland and Skye; though in the Kyles of Bute it has been found in 18 fathoms.

The Fine-ribbed Basket-shell (N. costellata) is similarly semi-transparent and fragile with the previous species, but is much smaller, less swollen, the valves less equal, marked with from 20 to 30 fine ribs radiating from the beaks. It has been taken with the last mentioned, of which it may be only a variety.

Another small genus of this order is known as the Otter-shells (Lutraria), of which we have two species. The shells gape at each end like those of the Gapers, and the long siphons are similarly covered by a coarse epidermis; but there are differences in the hinge-teeth which separate Lutraric from $M I y$ ", that of the Otter-shells closely resembling the cardinal teeth of the Trough-shells (Mactra). There is a spoon-shaped hollow for receiving the cartilage in 
each valve; in the left valve there is a double cardinal just below the beak which fits into a cavity of the opposite valve formed by two large diverging cardinals. The ligament uniting the valves is exceedingly short, and admits of considerable movement of the ends without opening the shell throughout. With the valves in their ordinary positions the shell gapes equally at each end, but the arrangement of teeth and ligament is such that the front of the shell may be entirely closed by more widely expanding the rear, or the hinder gape may be nearly closed by separating the fronts of the valves. They burrow vertically into deep mud, the siphons reaching up to the surface, and the only evidence that Lutrorice lies perhaps a couple of feet below is an occasional spurt of water from the excurrent siphon. To dig them out from this deep retreat is the only way to obtain living examples; but as the

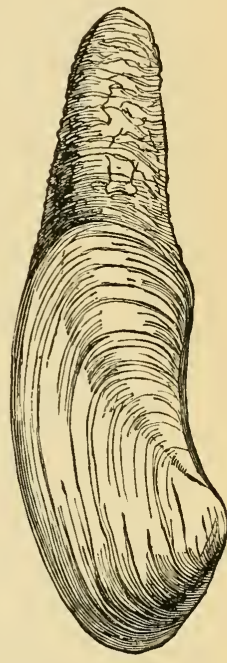

Oblong Otter-shell (one-fourth nat. size) situations they frequent are usually beyond the lowest of tide-marks, this is no easy matter. Yet the people of Herm, one of the Channel Isles, contrive to get a sufficient number to eat; they know them under the name of "Clumps." - It is an open question whether the two so-called species are not forms of the same.

The Common Otter-shell (L. elliptica) is elliptical in shape, somewhat flattened, solid and heary without being very thick. Where the olive 
epidermis has been worn off the shell shows a dirtywhite coloration. The growth lines form the principal surface ornamentation, though there are finer lines between, but these are quite obscure. In addition to the cardinal teeth already described, there are in this species two laterals in the left valve and one in the right, though only the foremost of those in the left is at all distinct. Full-grown specimens measure 5 inches the longest way by 3 inches at right angles. The animal is white; the mantle edges

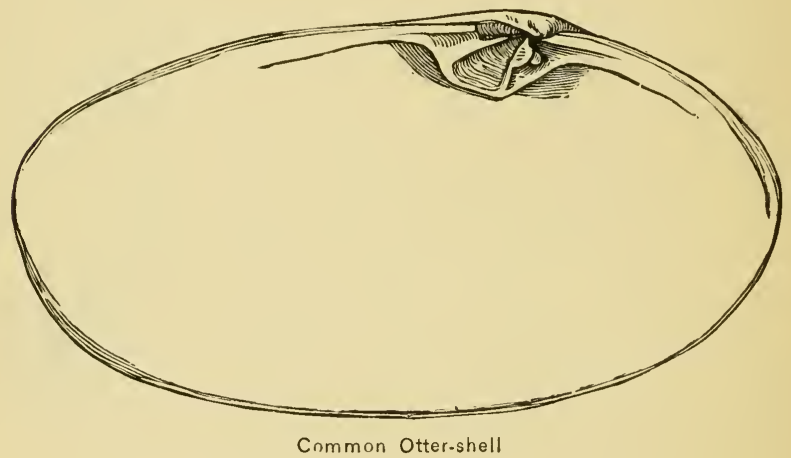

closed for two-thirds of their extent, and fringed with white. The siphons, connected throughout their length, are included in a common sheath, which is 12 or 15 inches in length, covered by an extension of the shell epidermis. The large thick foot is capable of considerable extension. It may be found all round our islands from just below low-water mark to a depth of 15 fathoms; it has a fondness for the more muddy ground of estuaries. There is a variety (intermedia) which is so well named that it 
strengthens the doubt as to the specific distinctness of elliptica and oblonga.

The points by which the Oblong Otter-shell ( $L$. oblonga) is distinguished from the foregoing are: the shape of the shell is more slender, with an upward curve behind, not quite so flat, more solid; the front cardinal tooth of the right valve is double, the only lateral is on the fore-part of the left valve. Its habits are the same as those of the foregoing, but it is of more local occurrence, and appears to be a more strictly southern form. Its longest measurement rarely exceeds 4 inches, but sometimes reaches 5 inches. Both species are subject, from

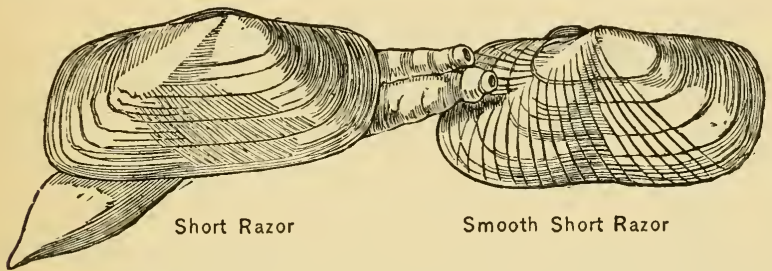

their attitude, to be annoyed by grains of sand slipping between the mantle and the shell. These have to be cemented over and left as evidence by which the collector may know of their trouble.

We now reach the Razor-shell family, characterised by having the valves of the shell of equal length, long and narrow, gaping at both ends. The animal has a large and powerful foot of a more or less cylindrical shape.

The Short Razor-shell (Solecurtus scopula) is of an elliptical shape, convex, with a central depression, crossed by a large number of overlapping low ribs, some of which radiate from the beaks to the front 
end, and the remainder cover the hinder end. The colour is yellowish white, and the epidermis is brownish yellow. The hinge is strengthened by a shelf-like rib on which are-in the right valve two stroug curved cardinals, in the left one cardinal and a short lateral behind it. This is a local species found in sand in from 20 to 85 fathoms, but sometimes being taken from a little below the extreme limits of low water.

The Smooth Short Razor (S. antiquatus) has the shell more compressed, the ribs and lines less distinct; the colour white, epidermis yellow-brown. The cardinals are larger, with jagged crests. It is

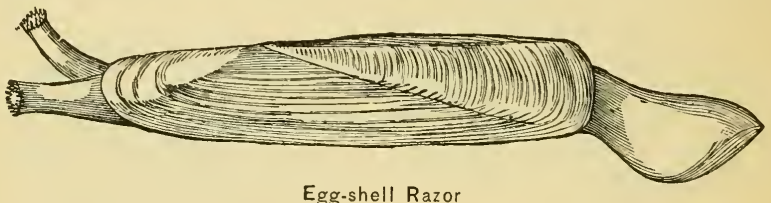

found sparingly on all our sandy shores in from 4 to 50 fathoms.

The Egro-shell Razor (Ceratisolen legumen) occupies a position between the Short Razors and the Razorshells (Solen), having the beaks almost central as in the former, but the shell material is similar to that of Solen, as also are the teeth. The shell is semitransparent and glossy, finely grooved in the line of growth, and yellowish white in colour. Epidermis pale or deep yellow; thimner and paler above. There are two cardinals in the left valve, and one in the right that fits between them; the laterals are one in each valve, a little behind the cardinals. The interior is pearly white, faintly marked by the 
mantle impression. The animal is pale yellowish the mantle tinged with red, and its edges fringed where not united. The siphons are listinct for the greater part of their length, reddish; and the purplered foot is club-shaped when extended It lives in the sand of extensive bays on the coasts of Hampshire, Devon, Wales, and Ireland, at the limits of low water.

The Pod Razor (S. siliqua) is known in Scotland as the Spout-fish. The shell is familiar enough to all who wander across sandy shores after the spring tide has receded, though it is only the empty and mostly broken valves they see. When full-grown these shells are 8 inches long and $1_{4}^{1}$ inch broad. A glance at the exterior of one of these valves is very instructive, for it shows at once in what manner the shell is enlarged. In most of the bivalves we have been considering the concentric ridges point to the fact that on three sides of the beaks the shell-margins have been added to pretty equally; or, if the ribs were more closely

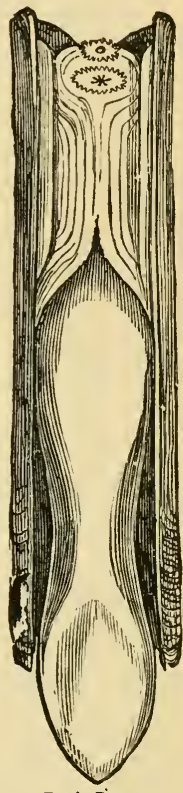

Pod Razor

(reduced) crowded at the ends than towards the front margin, that less material was added to the ends than to the lower edge. The lines on the shell of the Razor show us clearly that the chief addition is made to the hinder end of the valves, next to the lower margin, very slightly to the upper margin. To the fiont end scarcely any audition is made-certainly 
not so much as half an inch during the entire life of the Razor. This mode of enlargement explains why the hinge occupies its singular position at the extreme front of the upper margin. In the left valve this hinge consists of two stout curved cardinals, and one or two long hooked laterals behind them and below the ligament; in the right valve there is one thin broad cardinal that fits between the cardinals of the other valve, and behind it a single lateral fitting under the hook of its fellow in the left valve. It is remarkable how so one-sided an arrangement suffices to keep the long and heavy valves together. That it does suffice is evident on

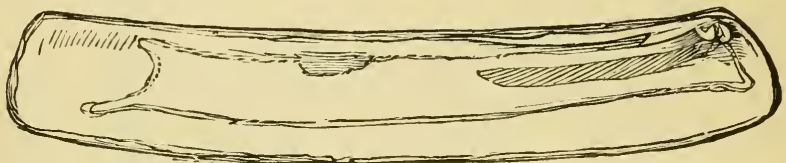

Pod Razor interior of left valve

handling the empty shells; yet during the life of the mollusk the power of the hinge-teeth is greatly reinforced by the adductor muscles, whose positions are marked by the shaded portions in the above figure.

The animal is of a pale drab colour, with a yellowish, tongue-shaped foot. Except at the foreend for the passage of the foot, and a minute opening on the lower surface, the mantle-edges are united throughout. The siphons are exceedingly short, united, and their openings fringed. At the base of these filaments there are grooves in which are situated pigment spots highly sensitive to light; and a shadow cast over the sands when the Razors are 
exposed is sufficient to cause their surdden disappearance. They burrow in the sands about extreme low-water mark; not vertically but diagonally. When the sands are covered with water their shells are at the surface with the siphons exposed, but when the sea goes out they retire beneath the sand, going to the depth of a foot or two. If dug up and placed upon the surface they bury themselves with the rapidity of a mole. They can also dart rapidly through the water, apparently by ejecting water through the siphons. In many places they are considered excellent food, and for this purpose they are caught with a bent or barbed wire thrust through the open valves. The shells sometimes show at the hinder end that like Lutraria they have no means of ejecting sand that gets between the mantle and shell, so are compelled to cover it over with a coat of shell-matter. The late Mr. D. Robertson of Cumbrae relates a singular experience. On the recess of a spring tide he found three examples of this Razor, whose shells protruded above the sand to the extent of an inch and a half, and the mollusks were unable to pull them down lower. To each shell was attached several mussels who had attached their byssus threads before the Razors realised what it meant; but when the extra-low tide came these tightly-moored mussels effectually prevented the withdrawal of the Razors.

The Sword Razor (S. ensis) in most respects agrees with the Pod Razor, except that the shell is curved as shown in the figure, and it never attains the dimensions of the former species -4 inches being about its maximum length. It is more slender 
than young Pod Razors of similar length, and it inhabits deeper water, being found usually between 3 and 20 fathoms, but at Jersey and Herm it occurs

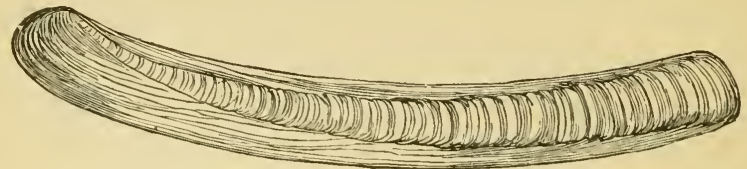

Sword Razor (slightly reduced)

at low water. Linnæus regarded it as a variety of $S$. siliqua, and I think it very likely that he was right.

The Transparent Razor (S. pellucidus) is similar to the last named in form, but with thinner though scarcely transparent shell, and the hinge not quite so near the end. Length about $1 \frac{1}{4}$ inch. It is very doubtful whether this again is any more than a juvenile form of $S$. siliqua.

The Grooved Razor (S. vagina) resembles S. siliqua generally, but is more cylindrical, quite straight, of equal size from end to end, and possessing but one cardinal in each valve, which is rounded and stalked. Its English name is due to a constriction at the fore-end "as if it had been tied while in a soft and plastic state with a string" (Jeffreys), but this constriction is frequently found in specimens that otherwise agree with $S$. siliqua. I fear there is but one British species of Solen, with several variations from the typical form.

The Rock-borers (Saxicava) have the mantle entirely closed, save for a narrow orifice to allow the passage of the finger-like foot; the siphons are long and partially united; the shell gapes at each 
end; the teeth are obsolete or wanting altogether; and the mantle impression shows only a shallow sinus. They bore holes, chiefly in limestone, and live in these cells with only their red siphons visible at the entrance.

'The Wrinkled Rock-borer' ( $S$. rugosa) is a very common shell, yet it is very seldom seen save by the conchologist, who knows where to find it and how to chip it out from its cell in the rock. The shell has an odd, clistorted appearance, being much stouter in front, and pinched in the middle of the lower margin, gaping behind or at each end, and with one valve often larger than the other. It is dirty white in colour, with a dull, rough surface, irregularly wrinkled in concentric

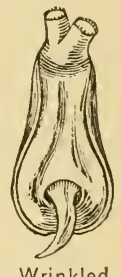

Wrinkled fashion. The teeth, when present, are two small erect cardinals in the left valve receiving one small cardinal in the right valve. The animal

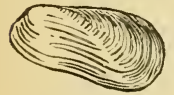

Wrinkled

Rock-borer is whitish tinged with yellow. The siphons - represented in our figure as being retracted as far as possible-are capable of great extension, and are covered almost throughout their length by a brown sheath, somewhat similar to that of the Gapers; their extremities are red. Wherever chalk, limestone, or red sandstone is found on our coast, there this species may be looked for from a little below ordinary low-water mark to a depth of about 30 fathoms. When touched or alarmed it forcibly ejects a stream of water from its siphons. A small variety, often distinguished as a separate species ( $S$. arctica), spins a slight byssus and attaches itself to the so-called 
roots of the larger seaweeds. The shell is more angular, the wrinkles become ridges, and the teeth are more evident. Its specific distinction

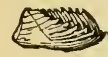

Arctic

Rock-bore from $S$. rugosa is very doubtful.

Norwegian Rock-borer (S. norvegica). A much larger species, attaining the dimensions of 3 inches by 2 , has been found in deep water (30 fathoms) between the Dogger Bank and the east coast of England, where it bores into thick mud. The outline of the shell is an irregular oval, the right valve larger than the left. It gapes at both ends, and is similar in colour, texture, and ornamentation to its smaller relative. The teeth are similar to those of the foregoing. The siphons are protected by a dark leathery sheath, and the lower tube is larger than the upper one. From its restricted area in British waters, and the difficulty of obtaining specimens, it is one of the most highly priced of native shells in the catalogues of the dealers, a good example costing a sovereign.

The Flask-shell (Gastrochcena dubia) bears some resemblance to a young mussel when viewed from above; but below, towards the foremost end, there is an enormous oval gape as shown in our figures. It is very variable, smooth, of the whitish grey so frequent in the shells of borers, but covered with a yellow-brown epidermis. There is a broad thin hinge-plate, but no teeth in either valve. The

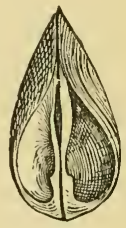

Front view

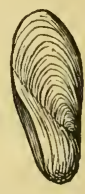

Side view

Flask-shell animal is pale reddish brown, with the mantle lobes united below and having only sufficient aperture to 
allow the foot to protrude. The siphons are long, semi-transparent, united, and capable of extension to several times the length of the animal. It bores into limestone, old shells, and red sandstone, but always fashions for itself, when full-grown, a flask-shaped jacket composed of shell-fragments and sand cemented together. It occurs only on the south coast of England, the Welsh coast, and the south and west of Ireland, from low water to 20 fathoms. At Torbay its burrows in the new red sandstone are beautifully finished off as though lined with porcelain.

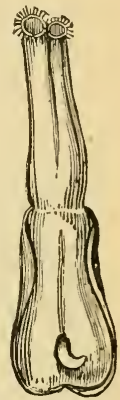

Flask-shell

The Pidlocks form the sub-order Pholadacea. They are all borers into rock or wood, and they exhibit a remarkable advance in shell develop-

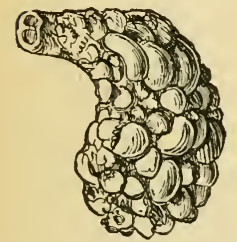

Case of Flask-shell ment, the typical species being provided with supplementary valves in addition to the two that normally enclose the animal. The white shell gapes at each end, and though thin and brittle, is exceedingly hard, the front part often armed with toothed ridges that form a good rasp. There are no hinge-teeth and no ligament, the valves being held together by the adductor muscles only. The hinge-plate is continued outside, and folds over the upper margin of the shell, where it is protected by a portion of the mantle. To protect the mantle, one or more accessory valves cover it at this part. The front pair of adductor muscles are attached to the hinge-plates, where their impressions will be found. The mantle impression 
has a very deep sinus, showing that the siphons are fully retracted. The animal is somewhat club shaped: the siphons large, united nearly to the fringed orifices, and covered by a sheath as in the Gapers; the foot also large, but short. They perforate, in

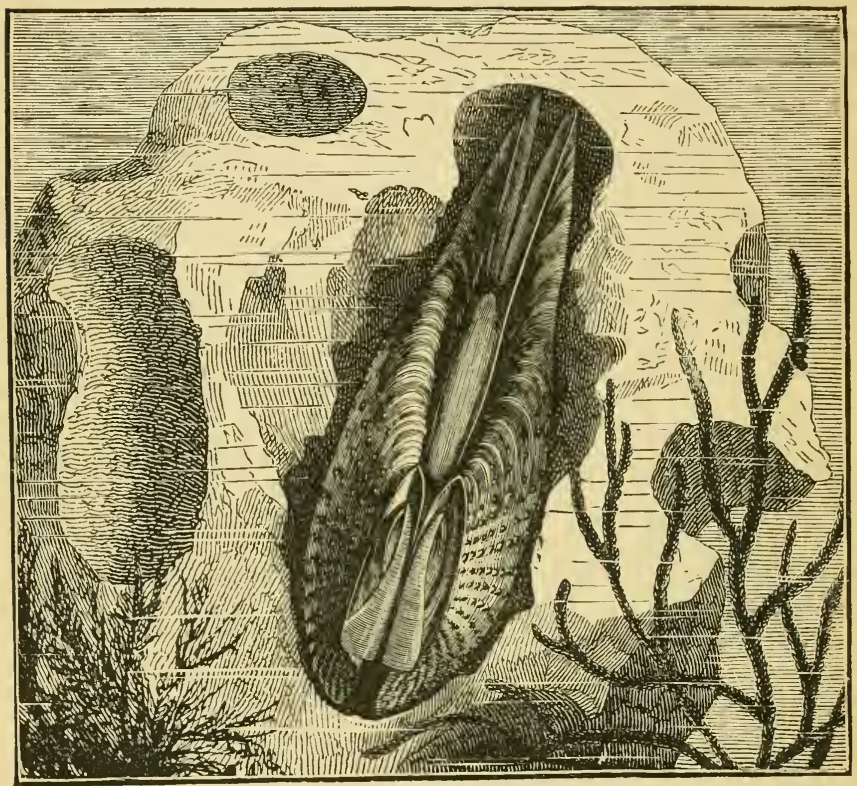

Ploolas in its burrow (nat. size)

shallow water, rocks, wood, and other substances that are not so hard as their shells, making vertical symmetrical burrows. Having marle a burrow -whether in limestone or in thick mud-the maker of it remains in it for life. This is very different from the habits of ordinary burrowing mollusks, 
who are constantly changing places. They seldom interfere with each other by breaking through their neighbour's party-wall, but as a rule make their burrows to run parallel. The boring appears to be effected by the flattened foot, assisted by the rasp-like forepart of the shell in some species. The natire species are:-

The Common Piddock (Pholas dactylus), the largest by far of those found on our coast, its elongated shell often measuring 5 inches in length. Each valve is traversed by from 40 to 50 rows of prickly scales,

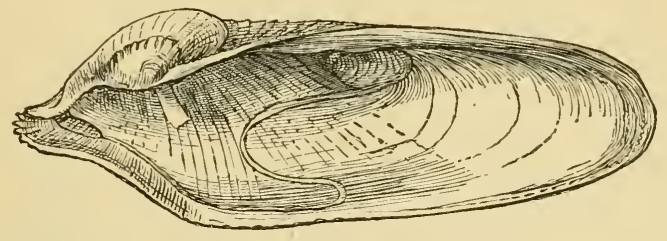

Right valve of Common Piddock

which are most developed in the front part. There is a pale brown epidermis, but it is mostly worn away except at the edges. The accompanying cut shows the interior of a right valve of this species. The hinge-plate, reflected over the beak in a double fold, is strengthened beneath by a number of transverse partitions, as shown in this figure. Within the shell there runs down from the hinge-plate a curved shelly band,

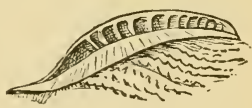

Portion of hinge-plate called an apophyse, to which the muscles of the body are attached. Upon the external folds of the hingeplate, what are known as the accessory valves are placed; but it must be remembered that these are 
not of the same character as the two large valves that enclose the animal, so that it will be better to speak of them as dorsal shields. In this species there are four of these dorsal shields; two in front and side by side, a third more solid, behind and interlocking with these, whilst the fourth is long and slender, and protects the mantle and upper margins of the valves. The animal is whitish like its shell. The siphons are covered with little fleshy points, the sheath brown or speckled. Although chiefly found in the English and Bristol Channels, it is recorded from Seacombe, Lancashire, and along the south, east, and north coasts of Ireland. It is not particular in Dorsal shields

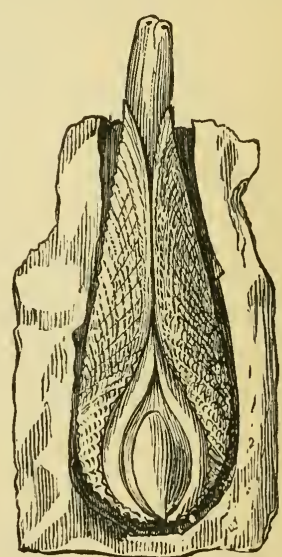

Common Piddock in its cell hinge-plate forms but a single fold externally, which is not partitioned off into cells: and there is but one dorsal, lance-shaped shield with 
a central groove. The animal is white, tinged with brown; the siphons longer and more slender in proportion than in the Common Piddock, and longitudinally grooved within. It is a very sensitive creature, and readily takes alarm, retiring into its chamber. It is about $2 \frac{3}{4}$ inches long.

The Little Piddock (P. parva) has a more solid, less convex shell than the last, and is traversed by many rows of overlapping scales, chiefly on the forepart of the valves, gradually getting less towards the middle, and scarcely evident behind; often stained with red from the

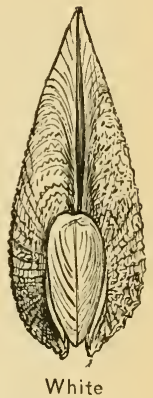

Piddock clay and red sandstone in which it is found. The beaks are much nearer the centre than in the other.

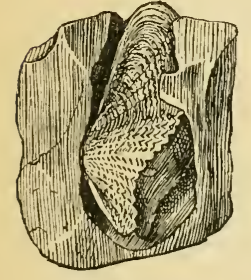

Little Piddock species. The hinge-plate is furnished with a knob, apparently to prevent the valves coming too close together at that part. As in the White Piddock, there is but one dorsal shield, and this is of similar pattern to that of $P$. cancicla. It is a south coast species, and has been found also in Guernsey, Dublin Bay, and near Belfast. Its length is about 2 inches.

The Oval Piddock (P. crispata) has the shell oval instead of oblong as in the other species; convex, solid, coarse-looking, with a broad furrow extending from the beak to the lower margin almost in the middle of each valve. In front of this furrow there are about 20 rows of overlapping sharp scales. The 
broad hinge-plate folds over and is attacher to the beaks, but there is no knob as in the last species. The dorsal shield is exceedingly small, and of triangular form. The animal is of a red-brown colour, with long siphons; these have the orifices fringerl with branched filaments. It is a little more than 2 inches-sometimes as much as 4-in length, and has been found on many parts of our coasts embedded in mica-schist, shale, oolite, Oxford clay, etc.

The Paper Piddock (Pholadidea papyracea) has a shell that is exceedingly thin and delicate, oval and

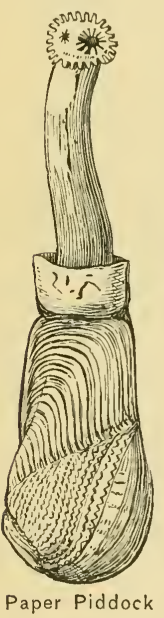
convex, the forepart with transverse ridges cut into little teeth. The beaks approach towards the centre of the upper margin as in the last two species. The broad hinge-plate is reflected over the front. In addition to the short apophyses, there is what may be regarded as a triangular cardinal tooth in each valve. The dorsal shield consists of two small plates, often united. At the hinder end of the shell there is a remarkable horny cup surrounding the siphons-which are entirely connected throughout their length. This cup, which is not found in young specimens, appears to be the beginning of a sheath to surround the siphons, but which is not further developed in this species. It burrows in sandstone, hard clay, peat, and submerged wood, chiefly along the coasts of Devon and Cornwall, and at various places round Ireland; at low water of spring tides.

The Wood Piddock (Mylopleaga dorsalis) is a con- 
necting link on one side with the foregoing Pidrlocks, and on the other with the destructive Ship-worm (Tereclo), yet to be mentioned. The shell is like that of a Pholes, but remarkably abbreviated, being in fact globular in shape. It is glossy and almost transparent; crossed near the front end by a furrow with marginal ridges. There are two dorsal shields, similar to those of the Paper Piddock, but proportionately larger. The globular animal has long and slender siphons, connected throughout the greater part of their length, and marked by crested ridges. The foot is thick and capable of consiclerable extension. There can be no doubt, in this case at least, that the foot is the boring instrument, for the epidermis is conspicuous over

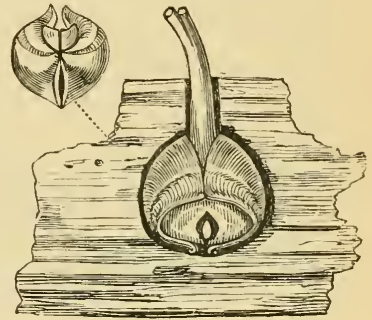

Wood Piddock the front of the shell, where it would be rapidly worn off if the shell were used as a rasp. This species is called the Wood Piddock, because it neglects the rocks and bores only into submerged or floating timber, preferring oak, pine, and birch, and evidently not objecting to other vegetable substances, for it has been found in the tarred hemp envelope of an ocean cable. It penetrates only to a sufficient deptl ( $1 \frac{1}{2}$ inch) to bury itself, as shown in our figure.

The remaining genus (Tereclo) of this sub-order' includes a few species of insignificant appearance, but of sufficient power to have made them the despair for centuries of all who owned wooden ships, timber-built quays, piers, and stages in salt water. The people of 
Holland have more than once had their welfareperhaps their existence-threatened by the ravages of the Ship-worms among the piles of their embankments. In the days of "the wooden walls of England," prior to the use of copper-sheathing, we also suffered greatly; but now that so many of our vessels are of iron or steel, the Ship-worm's sphere of activity must be greatly curtailed. The "infallible" remedies in the shape of washes and paints that have been put forward to check the ravages of this little sea-monster must number several hundreds. This, perhaps, is a matter that, could it be known to the Ship-worm,

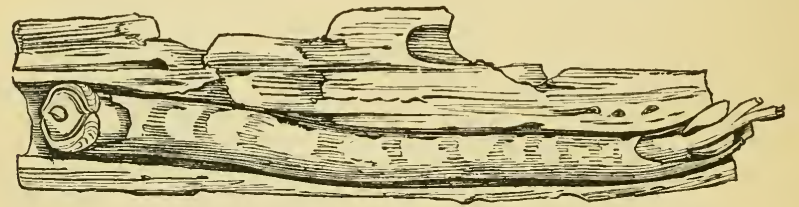

Ship-worm

might cause it to feel proud, that it had instigated so much enterprise in others. Most of this, however, must have been misdirected zeal; but there is one case on record of its having inspired a great piece of engineering. The elder Brunel is said to have declared that the method adopter in the construction of the Thames Tunnel was suggested to him by the Teredo.

The Ship-worms are very like Wood Piddocks, with an enormous development of the siphons, which may exceed a couple of feet in length. The shell is even more gaping than that of the Piddocks, for the valves touch only at the beaks and at a point on the opposite margin ; it is helmet-shaped, marked as in Xylophaga, 
but without any dorsal shield. Each valve is threeloberl, and the hinder lobe is usually spoken of as the auricle or ear. The animal differs from the shell in its shape, which is worm-like, and for the protection of this part a chalky tube is secreted-of great length in some foreign species, and extending to a couple of feet in our own T. norvegica. At the mouth of this tube the animal has developed a pair of accessory valves (known as pallets) in the shape of paddles, the handles of which are attached to the body, and the blades serve to close up the tube when the siphons have been withdrawn. They all burrow into submerged vegetable substances, including all kinds of timber, and are never found in rocks. They appear to do all the boring by the action of the small foot, though it is probable that the valves may be used to enlarge and round off the cell. The burrows run with the grain, and consequently parallel with each other. It is popularly supposed that the Ship-worms destroy timber in this way to serve as food, but though the excavated material is passed out through the exhalent siphon it does not appear that the animal derives any alimentary benefit from it, but derives its nutriment from the microscopic life of the seas, just as the oyster and the cockle do. The species are:-

The Conmon Ship-worm (T. navalis), usually about a foot long, sometimes as much again. The shell is rather thin, and finely ridged. The pallets have an oval blade, which is indented deeply at its free end, glossy without, polished and flat within. It is found in pine, ehm, oak, and teak that have been used for boat-building, piers, piles, etc. This is the 
species that has caused so much damage and anxiety to the Dutch. The Norwegian Ship-worm ( $T$. norvegica) is very similar to the last, but larger in

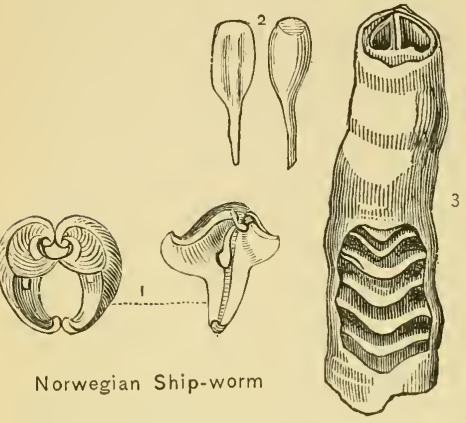

1, shell; 2, pallets; 3 , part of sheath, broken to show internal plates

all respects, the shell more solid and coarser in its sculpture. The large pallets have oval blades with squarish ends, concave on the inner side. Although found all round our islands, it is a local species, and appears to confine its attentions to fixed timbers, and to

let floating spars and logs pass. The Guernsey Ship-worm (T. pedicellata) is also very similar to the Common Ship-worm, but much smaller in every way; probably, indeed, it is only the young condition of a variety. Its chief claim to be considered distinct lies in the shape of the pallets, which have long stalks, a square blade, and an oval portion between the blade and the stalk. It has been found in submerged timber in several of the Channel Islands. The Drifting Ship-worm ( $T$. megotara), although occasionally found in fixed timbers on our shores, is chiefly known to us as a common inhabitant of the drifting logs and spars that come no one knows whence, and get cast on our shores in stormy weather. Full-grown specimens are intermediate in size between T. navalis and T. norvegica. There is an expansion of the hinder margin of each valve known as the ear 
or auricle. In the present species this auricle is very large, and the hinge-plate is very broad and thick, with a knob and a tooth in the centre. The sheath, too, is shorter, and often absent.

Several other species of foreign origin are frequently found in drift-wood on our shores.

The animals comprised in the sub-order Anatinacea have a single gill on each side, the outer fold of which is prolonged over the back; the mantle margins united almost throughout; the siphons more or less united and their orifices fringed. The shells are thin, the valves often unequal, usually coated with nacre within. The impressions of the mantle and muscles are not well marked.

The Pandora-shell (Pundora incequivalvis) not only has the valves unequal, they are inequilateral also. They gape behind where the short siphons protrude. It will be seen in the figure that these siphons are united almost to their full length, yet diverge considerably from each

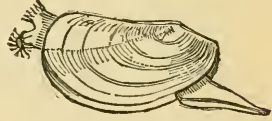

Pandora-shell other. The left valve is flat, the right convex and overlapping the left. They are of variable thickness, glossy without and of a pearly

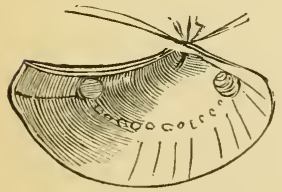

Left valve of Pandora white colour. The horn-coloured cartilage reposes in a groove of each valve. The hinge-plate of the left valve bears a rib which fits into a corresponding furrow in the other valve. There is one cardinal tooth in each valve, that of the right valve being erect, that of the left horizontal. The Channel Islands, Weymouth, and Studland are the only British 
localities for this species, and there it may be found burrowing slightly in the sand at low water. It has a trick of squirting water from its siphons when alarmed, like the Piddocks. There is a variety obtusc found in deeper water (from 7 to 50 fathoms), and the difference in habitat has produced a corresponding difference in the shape of the shell. The normal shallow-water form has to burrow beneath the surface in order to escape the effects of the surf, and consequently its shell is extended into a blunt beak behind to protect the lengthened siphons. In deeper water there is no fear of such disturbance, and there is no need for burrowing so deeply; therefore the siphons are shorter and the shell less drawn out behind. This is another object lesson in Nature's manufacture of species. The Norwegian Lyonsia (Lyonsic norvegica) is in general shape much like Pandora, but the upper margin is more horizontal, and there is less difference in the size of the two valves. It is very thin, but opaque and yellowish; the surface made dull by fine radiating lines crossed by the lines of growth. The pale brown epidermis is gelatinous, and has the property of attaching grains of sand and fragments of shell to itself. The golden cartilage is contained in grooves as in Pandora, and the hinge-plates are similarly ribbed and furrowed; but the cartilage is covered by a plate, called an ossicle, that is not attacherl to the shell but formed separately. The interior of the shell is iridescent. The animal is white with a yellowish tinge. The forepart of the mantle has a slight fringe of a few projecting points. The siphons are short, fringed at their orifices, and having a few filaments round the 
base of each. The white foot is tongue-shaped, extensible, and grooved for the production of a byssus. It is not a common shell, but it occurs all round our islands on sand between 4 and 86 fathoms. Where these conditions exist it may also be looked for in the stomach of the Red Gurnard. It is about $1 \frac{3}{4}$ inch in length.

The species of Thracic have nearly oval, more symmetrical, and somewhat flattened, thin shells, with a free ossicle as in Lyonsia. The shells gape behind to allow of the continuous extrusion of the long separate siphons. The Thin Lantern-shell (T. protenuis) has the right valve less flat and a trifle larger than the left, which it slightly overlaps. It is finely marked with lines parallel to the edges of the shell, and the hinder slope is also studded with minute tubercles. The shell itself is white, but the epidermis is of a creamy

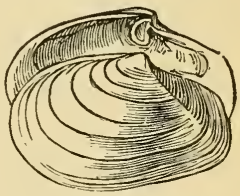

Thin Lantern-shell (two-thirds nat. size) tint. The dark coloured ligament behind the hinge is so small that it cannot be seen in dried specimens. Attached to the hinge-plate is a spoon-like receptacle for the golden cartilage. The ossicle is sickle-shaped. The animal, including the tongue-shaped foot, is white. It occurs in sand on many parts of our coast from extreme low water to 60 fathoms. It measures about $1_{2}^{\frac{1}{2}}$ inch across. The Papery Lantern-shell (T. papyracea) is smaller than the last, much thinner, less equivalve, and more convex. Ligament pale and large; cartilage more brown than golden, its pit or spoon more oblique; the ossicle shaped like half a ring. The 
animal varies in colour from white to pale brown. The siphons are short and wide, marked at their extremities with faint lines.

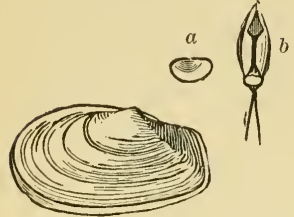

Papery Lantern-shell

$a$, ossicle; $b$, ditto in position The foot has a bluish tinge. It is found in sandy bays a little below extreme low-water mark. The Large Lantern-shell $(T$. pubescens) is larger, more solid, and more oval; the left valve smaller and flatter than the right. The surface is marked with fine granulations, and the part near the hinge is concentrically ribbed. The colour is dull pale yellow. It is nearly 4 inches across. It is found only in deep water off the coasts of Dorset, Devon, and Cornwall. The Convex Lantern-shell ( $T$. convexa) is swollen, almost four-sided, thinner than the last-named, but solid and glossy, and with more delicate ornamentation - the granulations in wavy lines. Its colour is pale brown. It measures a little over 2 inches. It burrows deeply in muddy sand, in from 4 to 70 fathoms of water, on all our coasts, but living specimens are sometimes washed up the beaches. The Little Lantern-shell (T. distorta) is the smallest of the British species, and measures little more than half an inch. It is very variable in shape, and, owing to its habit of dwelling in the burrows of Saxicave, and in rock crevices, it is usually distorted. It is proportionately of more solid structure than its congeners, of a white colour and without any gloss. The dingy brown epidermis gets rubbed off in its favoured haunts, and can only be detected at the edges of the shell. The 
granulations are arranged in irregular concentric lines. Ossicle half-moon shaped. It is a local species, but not confined to any particular stretch of our shores. It appears to range from a depth of 5 to about 35 fathoms, hiding in old shells and rock crevices. Occasionally at extreme low water it may be found nestling among tufts of Corcllina.

The Skye Gaper (Poromya granulata) is a fragile little pearly shell, with almost equal valres, of rhomboidal form, gaping behind; the right valve overlapping the left. It is ornamented by minute and rather crowded granulations, and lusky coloured, with traces of the brown epidermis at the edges only. Hinge-plate thickened, bearing in the right valve an erect thick cardinal, in the left a small triangular cardinal and a plate-like lateral behind. There is no ossicle. The animal is cream coloured, with a long, slender, transparent foot. The siphons are short and thick, encircled at their base by about 20 long filaments which curve back over the shell. It is found in mud on rocky shores in Skye, at a depth of about 40 fathoms. This little mollusk has the distinction, not only of being the only native representative of its genus and family, but also of its Natural Order, the Septibranchiata, which is distinguished from the other orders by the gills being replaced by a muscular partition (septum), which reaches from the first adductor muscle to the siphons. 


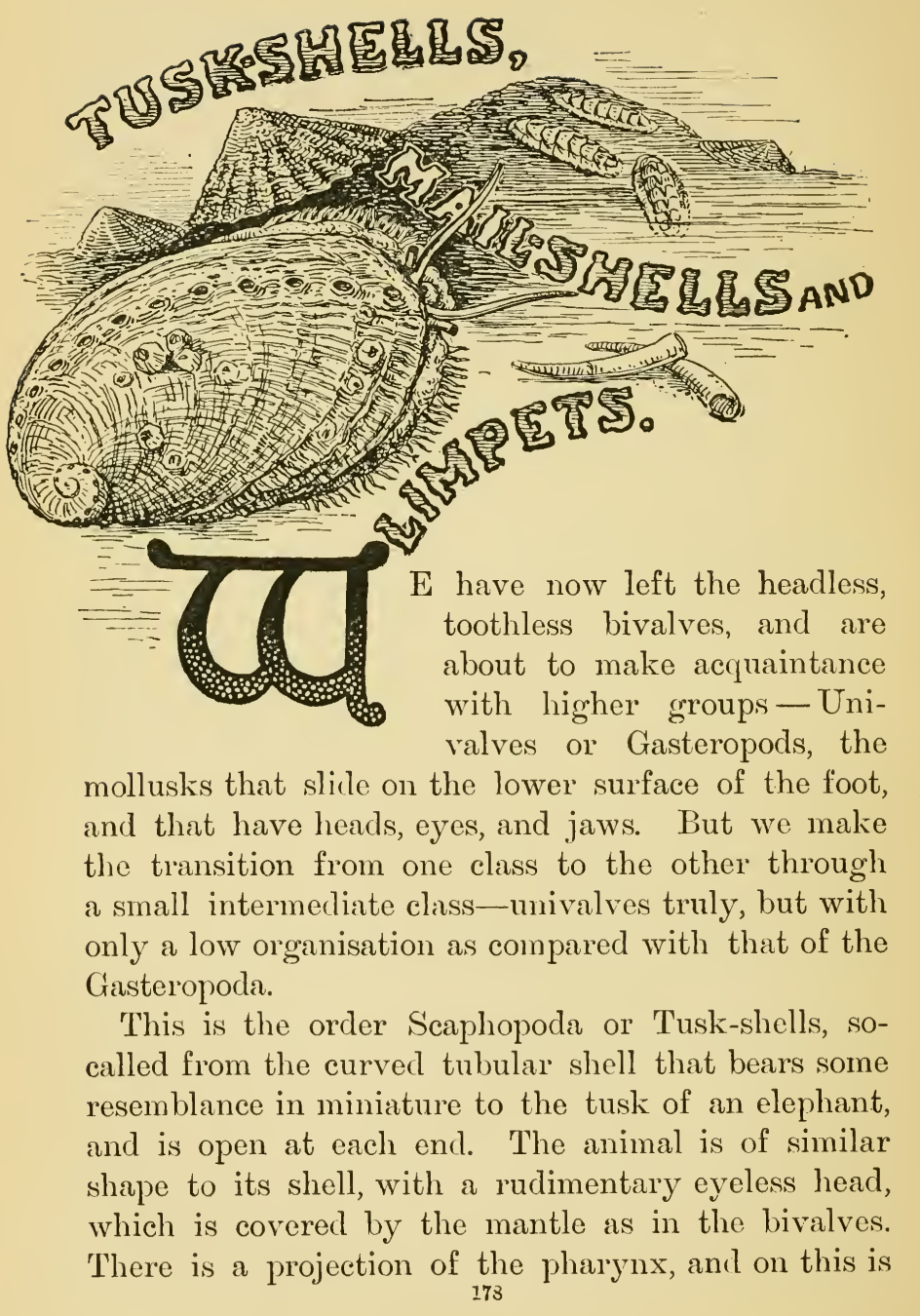


situated the mouth. The buccal mass may be found at the base of the long, pointed, and bilobed foot, which projects from the large end of the shell. Within the buccal mass is the tooth-ribbon or radula, similar to those described in pages 44-46; but in this class it differs somewhat from all the others. It is broad and oval, with only 5 teeth in a row; the central tooth a broad simple plate, the lateral strong, arched, with two or three points, and the marginal is a four-sided simple plate. The sexes are separate in these creatures, the liver is paired and consists of a number of radiating tubes, but there is neither special respiratory organ, heart, nor circulatory system. The nervous system is similar to that of the bivalves. Around the mouth are bunches of filaments (capte-

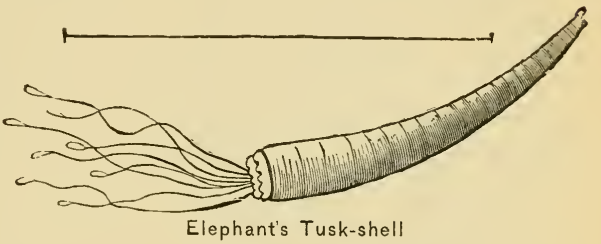
cula), which are thrust out for the purpose of catching the Foraminifera and minute mollusks upon which the Dentalium feeds. The edges of the mantle are united, so that it forms a tube open in front and behind, and the entire surface of this appears to absorb oxygen for purifying the blood. It will thus be seen that these mollusks form an actual link connecting the bivalves with the univalves. In most points they agree with the bivalves; in only two respects-the shell and the radula-do they agree with the univalves, and even in the matter of the shell they begin life as bivalves, for in the embryo this consists of two plates which later 
become united to form a tube. There are two native species :-

The Elephant's-tusk Shell (Dentalium entalis) whose white shell tapers, and curves slightly upwards, solid and smooth; marked by the transverse lines of growth, finely scratched longitudinally at the narrow end, which is eut off obliquely in mature specimens and furnished with a tubular appendage. It is also often notched at this end on the lower (convex) sicle. The animal is white, the captacula with oval tips, and the lobes of the foot scalloped irregularly. It is found buried in sand at all depths below 3 fathoms, usually in companies; more plentifully on the north than the south coasts. The

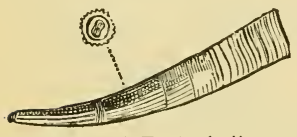

Grooved Tusk-shell

Grooved Tusk-shell (D. tarentinum) differs from the foregoing in being a little shorter and stouter, more solid, more curved, and with a duller surface. The colour, too, is a cream tint. The lines of growth are less evident as sculpture, but are sometimes indicated by brownish coloration. The tubular appendage at the smaller end is central; there is no notch in the shell, but the hinder half is regularly grooved longitudinally as shown in the section above the accompanying figure. The animal has a yellowish tinge; the captacula are ringed and end in little disks; and the foot-lobes have a wavy margin. It occurs in similar situations to the last, from extreme low water to a depth of 25 fathoms.

The Mail-shells (Chiton) introduce us to the class Gasteropoda, to which all the Univalves belong. It is a vast assemblage of orders, genera, and species. 
The orders are only four, but several of these are so large that they have been divided into sub-orders. The first of these orders (Amplineura) consists of the Mail-shells and some worm-like forms. 'The Mail-shells alone constitute the sub-order Polyplacophora. They differ from the vast majority of Gasteropods in not being exactly univalve, for the shell consists of eight overlapping segments or plates,

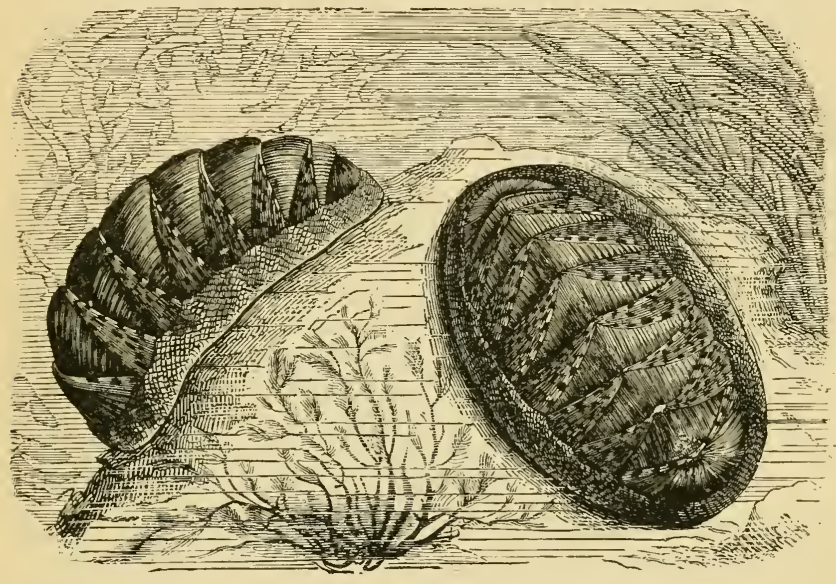

Mail-shells

the whole series surrounded by a muscular marginal belt (the girclle) which partly retains them in position. There is sufficient freedom of movement in these plates to allow the Chiton, when alarmed, to roll up after the manner of a Wood-louse. The under portion of these plates is of the ordinary shelly material, but the upper layer is chiefly of chitin. This layer is the sculptured portion, and it is divided off into three 
triangular areas, known as the median and lateral areas. The first and last plates are not so divided, and are generally sculptured in harmony with the lateral areas of the intermediate plates. Turned over on its back the Chiton will be seen to have a close likeness to the underparts of a Limpet. But closer inspection will show that though it has a head there are no tentacles and no eyes. The respiratory organs, too, differ from those of the Limpet. These matters we have already dealt with in the early chapters. As the shell-plates are perforated by
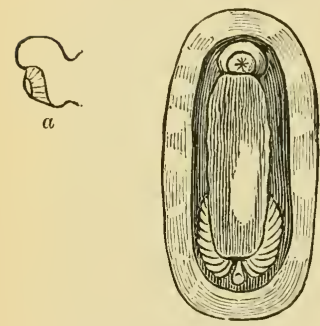
numerous pores whose mouths are occupied by sense organs, it is probable that the animal can get on as well without eyes as the Limpet can with them. The Mail-shells are provided with a radula of much more advanced type than that described in the Tusk-shells. In that of Chiton

there are 17 teeth in each row. Underside of Chiton, and $a$, profils of head There are ten or twelve native species of Chiton; the large figure on the previous page is not British but a well-known West Indian species (C. squamosus), selected as a type on account of its superior size. The British forms are:-

The Bristly Mail-shell (C. fascicularis), whose distinctive feature is the spiny girdle and the series of tufts of bristles along either side of the shell-plates. The latter are shield-shaped with a central keel, and equal to three-fifths of the entire breadth of the animal. The colour varies a good deal from yellow and orange to pink, red, or deep brown, marked with lines and 

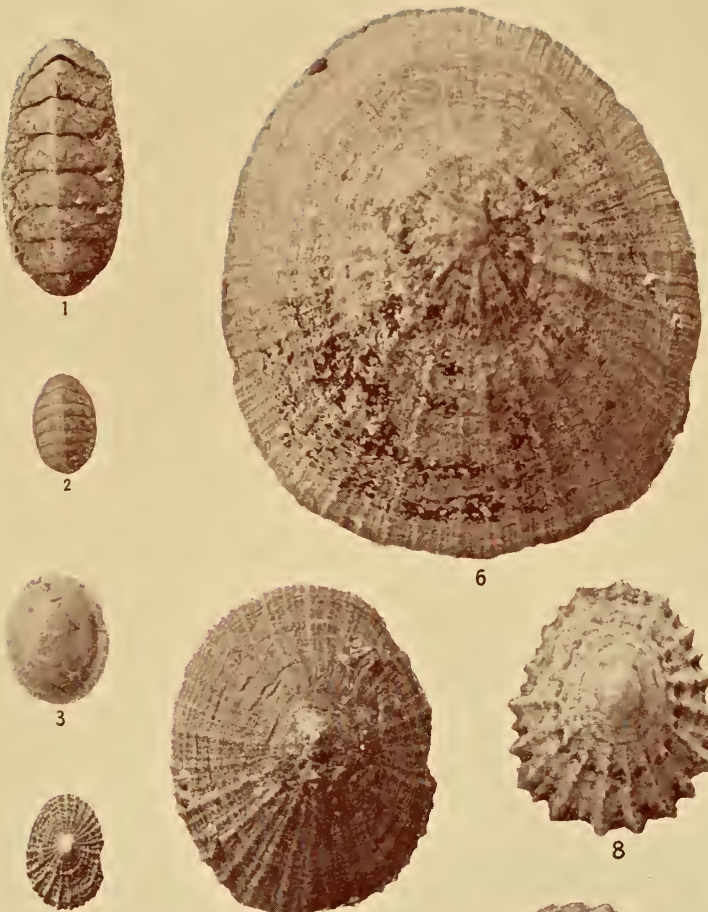

4
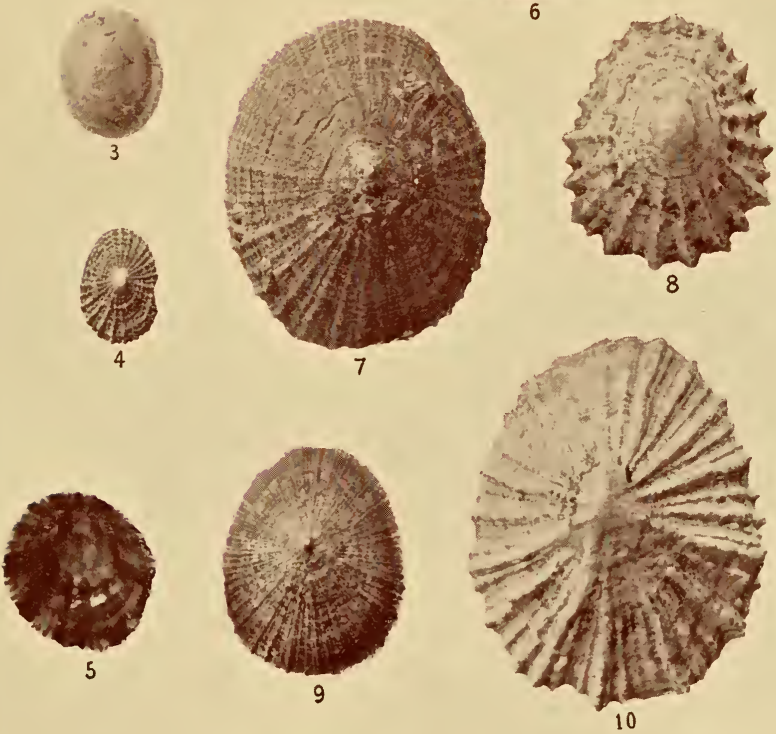

I Velvety Marl-shell; 2 Grey Mail-shell; 3 White Tortoiseshell Limpet; 4 Keyhole Limpet; 5 to io Comion Limpet and varieties. 

blotches of white, green, or brown. The heal-plate has five slight marginal notches, the other plates two each. The orange-coloured foot is oblong in shape, broader in front and running off to a blunt point behind. It may be found all along our coasts on the under-side of stones and the face of rocks, stationary and avoiding the light by day, and ranging in search of food by night. Its range extends from low-water mark to about 25 fathoms. The Velvety Mail-shell (C. discrepans) is similar in many respects to the former

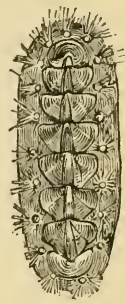

Bristly Mail-shell species, but larger and proportionately more slender. The girdle is broader, covered with a dense greyish pile, from which arise tufts of white or reddish spines as in C. fuscicularis. Plates shield-shape, one half the width of the animal, greyish, mottled with brown, the keel darker, notches deeper. The two species have the surface of the plates covered with granulations like shagreen; but in Hanley's Mail-shell (C. hanleyi) the granules become tubercles arranged in lines. There is no distinct keel, and the margins are not notched. The colour is ashy brown. The narrow girdle is clothed with short pale spines, with a tendency to form tufts behind each plate. This is a deep-water species, obtained by trawling at depths between 20 and 80 fathoms. It measures about onethird of an inch.

The Latticed Mail-shell ( $C$. cancellatus) is rery convex, plates narrow, covered with minute round granules, arranged in chain-like rows, the links producing a lattice-like effect. There is no keel, and the margin is not notched. The colour is very pale 
yellow. The narrow girdle is fringed with short spines, and the surface coated with polished yellowish granules. It is less than a quarter of an inch long; and it may be found on stones and about the smaller seaweeds just beyond low-water mark. The Grey Mail-shell (C. cinereus) is similar to the last species, but larger and more compressed; shell with slight but distinct keel, the sculpturing not producing the latticed appearance. The girdle is broader, and more thickly covered with granules. The colour of the shell varies from pale yellow to brown, streaked with dark lines, but the general effect is an ashy grey. It is one of the most frequent of all our Chitons, and may be found on rocks, stones, old shells, etc., on all our shores from low water downwards.

The White Mail-shell (C. albus), which is less than half an inch in length, is a local northern form. Its white has a yellow bias, but it is unmarked by lines or mottling of another tint. It is similar in general appearance to the Grey Mail-shell, but is more slender and convex, has a more prominent keel, the granulations finer, more radiating than chain-like. The margins are slightly notched; the hearl-plate having 13 notches, the tail-plate 11, and the intervening ones 2 each. The brownish girdle is broader and more regularly beaded, whilst its margin is fringed with short spines. It occurs in the Isle of Man, and at various places on the coasts of Scotland, Shetland, and the Orkneys. The Bordered Mail-shell (C. murginatus) is similar to $C$. cinereus, but larger, narrower, and more convex; the plates broader, with a surface like shagreen, mottled or variegated with yellow, red, and green, and their edges deeply notched. 
The girdle is evenly covered with minute granules, vari-coloured, and fringed with short yellow spines. It is one of our commonest forms, and may be found everywhere under stones at various depths, even above ordinary low-water mark. It is represented of the natural size in our figure. The Red Mail-shell (C. ruber) is much like $C$.

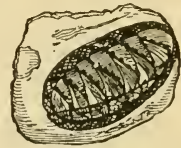

Bordered Mail-shell marginutus, but more slender, more convex, of a reddish-brown tint, and presenting a smooth appearance. The girdle, too, is broader, and chequered with small patches of red and white. It is a species of general distribution on our coasts, from low water to a depth of 20 fathoms, where it may be found on rocks, stones, and at the base of the Laminarias.

The Sinooth Mail-shell (C. levis) is convex, broad, and glossy, marked with microscopical scratches and minute tubercles. It is reddish brown in colour,

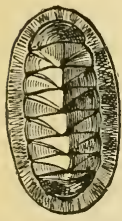

Smooth Mail-shell veined with white, or variegated with green or pink. The head-plate has from 16 to 20 deep notches, the tail-plate 15 , and the others 2 each. The broad girdle is covered with small spine-like scales, their tips towards the margin, which is thinly fringed with short pink spines that readily fall off. The animal is about an inch long. It is widely distributed, and extends from extreme low water to about 70 fathoms. The Marbled Mail-shell (C. marmoreus) is the largest of the British species. It has a broad glossy shell, almost smooth to unassisted sight, but under a lens showing many minute tubercles; coloured with red- 
brown marked with streaks and specks of white or yellow. There is a fairly broad girdle of dusky

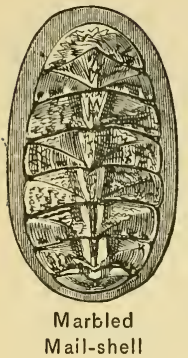
brown fringed with very short yellowish spines. The hear-plate has 8 notches, the tail-plate 9 , and the intervening plates 2 each. It occurs among stones and weeds a little beyond low water, but not south of Yorkshire.

Through the Limpets we become acquainterl with the order Prosobranchiata, which includes the great majority of native Gasteropods. The name signifies that in this order the plume-like branchiæe or respiratory organs are usually placed in front of the heart. The animals have a distinct head, which is furnished with a pair of tentacles and a pair of eyes. They are mostly marine animals, protected by a shell and mostly by an operculum; the sexes are separate. It is divided into two sub-orders, and these again into sections. The species described in this chapter belong to the sub-order Diotocardia, most of the animals comprising it having two auricles to the heart, but the Limpets are exceptional in that they possess only one auricle and one ventricle.

The Tortoiseshell Limpet (Acmece testudinalis) has a conical but depressed shell, with growth lines fairly strong, and with fine scratch-like lines both radiating and concentric. It is rather thin, with a dull surface, the ground colour grey, irregularly marked with

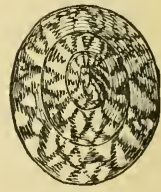

Tortoiseshell Limpet reddish brown, sometimes with white in addition. The interior is polished, except the broad, bevelled margin, 
which is only smooth. Half-way between the margin and apex is a chocolate mark of horseshoe shape. The animal is white, with a large head and long awlshaped tentacles, with small eyes at their base. Foot oval and broad. It occurs under stones, from low water to a depth of 20 fathoms, but comes no farther south than Northumberland and Durham. One form of it found on the narrow leaves of Sea Grass (Zosterce marina) has the shell compressed so that it becomes narrow and higher. This form is sometimes distinguished as $A$. alvea. The White Tortoiseshell Limpet (A. virginea) is similar to the last, but only half the size, rather glossy, pinkish, with brownish and white rays, rather than white, though a pure white variety occurs at Scarborough. Its ordinary length is little more than a quarter of an inch, but at Guernsey it exceeds half an inch. It is generally common on stones just below low-water mark. In Acmeca the apex of the shell is turned forwards; in Lepete backwards.

The Fulvous Tortoiseshell Limpet (Lepeta fulva) is rather smaller than the last; of a yellow, bright or dull orange colour, with white rays and fine radiating ribs; thinner and semi-transparent, not glossy. The Blind Limpet (L. ceca) is white, thin, finely grooved from the beak, about half an inch long. The animal is whitish, with short tentacles, but no eyes. It is a Scandinavian species, which has been taken occasionally in a dead state from deep water between Scotland and Shetland.

The Curled Limpet (Propilidium ancyloides) is another eyeless species similar to Lepetu, but with longer tentacles, and the beak of the shell curled 
backwards into a spiral. Within it has a triangular shelf-like plate, occupying half of the crown. It is a deep-water (18 to 100 fathoms) species, plentiful on nullipores around Ireland, Scotland, and Shetland.

The Common Limpet (Patella vulgata). So generally common and well-known a species is in need of no description, beyond saying that the shell is conical and solid, with ribs radiating from the beak. It is variable in colour, some young specimens being olive-grey, others more yellowish with purple rays. As it gets older the beak gets completely worn

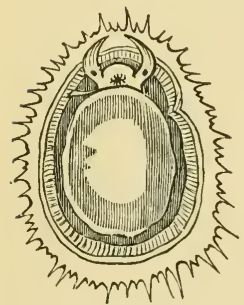

Common Limpet away, the ribs rubbed down, and possibly the whole surface made smooth and almost even. Other old specimens get covered with nullipore, or support a forest of delicate weerls. The inside is very glossy, being coated with nacre, which exhibits greenish opalescent gleams. Through this layer the purple rays may be seen more or less clearly, though all trace of them may have gone from the outside. In the centre there is a large white patch showing the attachment of the muscle; it is in the shape of a broal-mouthed amphora. A less distinct depression around it marks the attachment of the mantle. The general appearance of the Limpet from beneath when detached from the rock is shown in the cut. In the centre is the broad muscular "foot" by which adhesion to the rock is effected; in front of it the distinct head, with mouth, paired tentacles, and eyes; around the whole is the fringed mantle, and between the mantle and the foot there extends a frill of gill- 
plates. There is reason to believe that the primitive Limpet was not endowed with this extensive frill, which is a more recent development to fit the species for changed habits. In the Tortoiseshell Limpets the breathing organ is a single plume-like gill attached to the right side of the neck, and protruded when the creature goes a-walking. It is believed that the original Limpet had a pair of these plumes, one on each side ; and if the modern Limpet be taken from its shell, and the mantle cut away so as to expose the upper side of the neck, a little yellow body will be found on each side of it. These are the remains of the true gills, which have gradually dwindled away to useless vestiges as the new and-from the functional point of view-more important frill has developed. It is probable that, like Acmace, the primitive Limpet lived constantly in the water, and consequently the work of the two small gills ever exposed to the water was sufficient to keep the blood oxygenated; but now the Limpet spends the hours between the fall and rise of the tide entirely out of water, and can only manage to keep its gills sufficiently moist to carry on the process slowly. It therefore seems probable that, in order to keep the blood pure, the slower respiration must be maintained over a much larger surface. The change of habitat and the development of these pseudo-gills might go on pari passu: early Limpets with merely the beginnings of the frill restricting themselves to those lower rocks that are only uncovered for a short time. But this is not the only change produced in the. Limpet by its altered habits. As it has learned to endure fresh water by its exposure to rains and to 
the, in some places considerable, percolations from the cliffs, so also the shape of the shell appears to have been modified. Canon Norman pointed out years ago that "the nearer ligh-water mark the shell is taken, the higher-spired, more strongly ribbed, and smaller it will be; and that the lower down it lives, the flatter, less ribbed, and larger it becomes." This result, I should suppose, is due to the action of natural selection. One of the principal enemies of the Limpet is the Oyster-catcher, whose bill is admirably adapted for wrenching it from the rock when its shell is slightly lifted for fresh air or locomotion. It will be evident that the flatter, smoother, and larger the shell may be, the more easily it may be lifted, so that the birds are more likely to select such specimens in preference to the less easily obtained small, high-spired, and ridged examples : the former, therefore, must become scarce on the rocks most quartered by the larger shore-birds.

The tongue (radula) of the Limpet when uncoiled is found to exceed the shell in length; it is furnished with nearly 2000 teeth, with which it scrapes the surface of the rocks, clearing off the delicate growths of weeds and leaving a peculiar zigzag track.

The means by which the Limpet adheres to the rock has long been a fruitful subject for controversy, many naturalists appearing unwilling to believe that it could be held there by the same powers as those that hold the Winkle-the muscles and mucous of the foot, which by excluding air establish so close a contact that considerable pulling force is required to dislodge it. Reaumur experimented with the Limpet's 
power in this respect, and says that for several seconds it supported a quarter of a hundredweight attached to its shell. Some authors imagined that the foot contained a number of-presumably invisiblesuckers; others, that by drawing up the centre, after the manner of the street-boy's leathern sucker, it created a vacuum which held it to the rock. Reaumur was troubled by some of these notions, but he disposed of the vacuum theory by cutting a Limpet-shell and all-right through, and as the two halves still adhered to the rock it was clear there could be no vacuum.

It has long been noticed that the Limpet sinks pits corresponding exactly to the margin of the shell, but deep or shallow according to the softness or hardness of the rock. In this way it overcomes the difficulty of shutting down its shell closely upon an irregular surface, by making its own little patch level. Various agencies have been invoked to explain how these pits are sunk; an acid secreted by the foot, and carbonic acid given off in respiration, being among them. No doubt on chalk and other soft rocks we need look no further than to the pulling action of muscular contractions of the foot. Even on the hard slaty rocks of the Cornish coast, I have frequently noticed that Limpets taken off for use as bait have thin laminæ of rock still attached to the foot. But the most remarkable of the Limpet's habits is that of returning to the identical spot to roost after each excursion in search of food. Given a particular area of rocks it would be almost impossible to find two pits so exactly alike that they would equally serve as lodginent for a particular Limpet. 
It was this fact, probably, that led some of the earlier naturalists to contend that the Limpet never wandered from the particular spot it had selected in early life, though Aristotle had recorded its foodseeking excursions more than two thousand years before. Not only do they do this whilst still covered by the sea, but after the tide has receded and whilst, the rocks are still wet. At such times I have often listened to the noise made by hundreds of Limpets dragging their shells over the rough acorn barnacles, and to the rasping sound produced by the radula as it scraped the minute vegetation off the rock.

There is no need to say anything of the importance of the Limpet as food and bait, except that on some parts of our coast this is very great, many tons of the mollusk being consumed yearly by the poor. Judging from the contents of the shell-heaps (Koliken-middings) left near their former rude dwellings by the aboriginal inhabitants of these islands, the Limpet had a much greater importance as a food in earlier days.

There are several well-marked varieties of the Common Limpet which have distinctive names given to them, and certain of these have been elevated to the rank of species by some writers. The var. elevata has a smaller, rounder, and higher shell; var. picta is smaller and thinner, with alternate blue and reddish rays; intermedia is smaller, flatter, and oval, with yellow centre inside and out, the animal dark-coloured; depressa, much flatter, more oblong, ribs finer and sharper, beak nearer front, centre of interior orange; ccerulea, flat, roundish oval, ribs delicate, somewhat irregular, interior dark blue. 


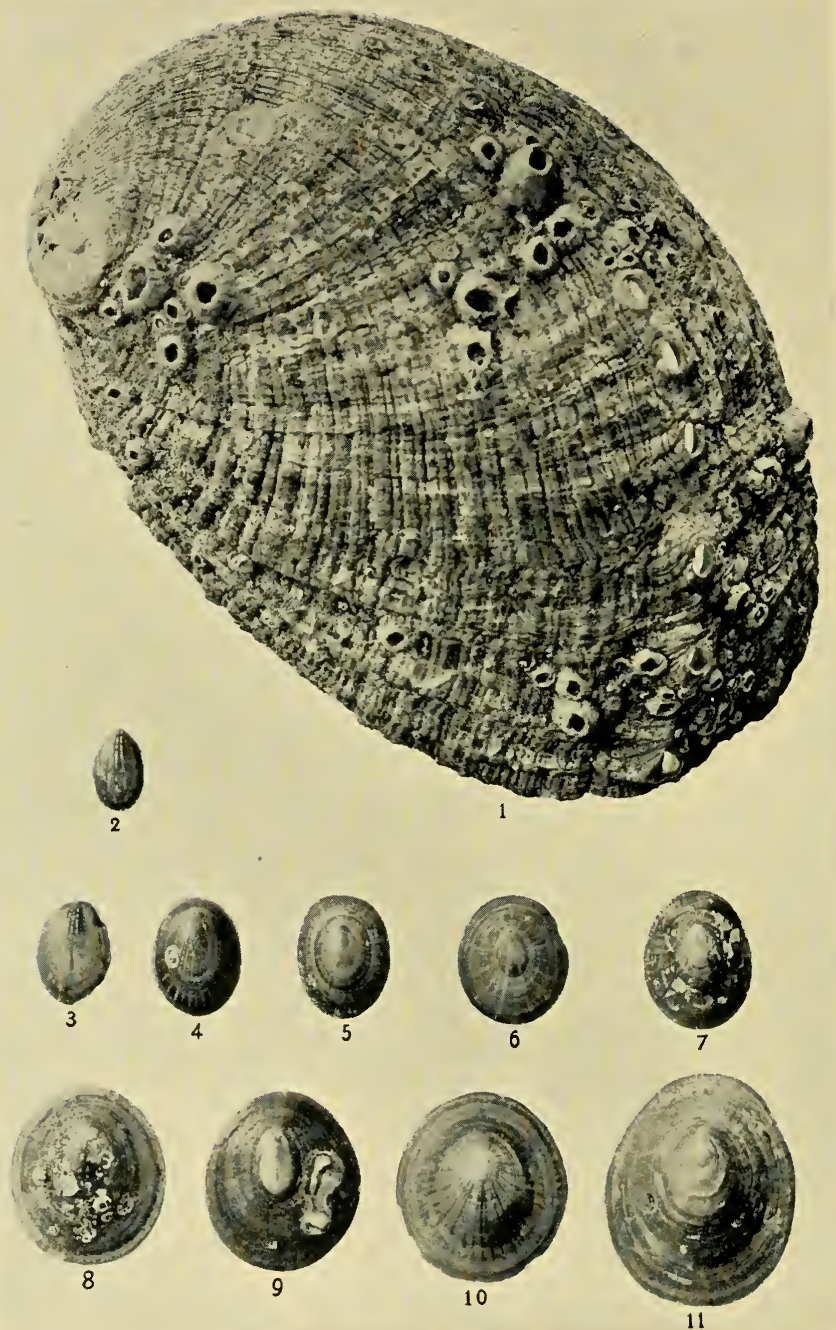

i ORMER OR SEA-EAR; 2 TO II Blue-RAyed Limpet and varieties. 
The genus Helcion differs from Patella in the fact that the frill of gill-plates arising from the left side of the neck is not continued completely around the animal, but ends in front of the head. In early life the shell of the Blue - rayed Limpet (Helcion pellucidum) is oval, thin, semi-transparent, rounded above, with the slight beak above the front extremity. The colour varies from ochreous to olive, and from the beak thin broken lines of vivid blue

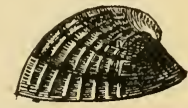

Blue-rayed Limpet run to the margins. The number of these lines varies greatly, but, as a rule, they are about 7 , though they may be 40 . The animal is cream coloured, tinged with brown; mantle fringed with long and short filaments; tentacles slender, eyes small. I have already alluded to the changed appearance of the shell when the animal becomes old (page 36). The young Helcion lives upon the fronds of the larger seaweeds, where it is not very conspicuous, but in later life it descends

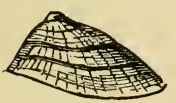

Blue-rayed Limpet, older specimen the rounded stalks, thickening its shell, compressing the sides and fashioning the mouth so that it fits the rounded surface accurately. By this time the blue lines have vanished, as being a source of danger rather than security in the new situation, and the shell has no resemblance to its former self. The animal cuts out a cavity in the stalk, which it resembles in colour, and there it remains embedded.

The Slit-limpets (Fissurellidee) form a family remarkable from the fact that their limpet-like shells have a slit which serves the purpose of an 
excretory orifice, corresponding with an oval tube in the mantle. The animal has two large gills, placed one on each side. It is probable that from some such form the bivalves were produced, the development of these organs into the plate-like gills producing corresponding changes in the mantle, and consequently of the shell.

The Keyhole Limpet (Fissurella greece) in the juvenile stage has a distinctly spiral beak and a slit margin, but as the shell grows, and the ernbryonic portion becomes the apex, the slit finally

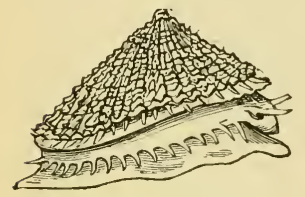

Keyhole Limpet appears like a keyhole at the top of the shell, and the mantle is protruded through it. It is a pale yellowish shell, with rays of some tint of brown, and about 50 rugged ribs radiating from the beak, which are alternately larger and smaller. The animal is some shade of yellow; the mantle extends beyond the margin of the shell, and is fringed with short stout processes corresponding with the ribs of the shell which are produced by them. A similar fringe decorates the upper part of the foot. The Keyhole Limpet is found all round the British Islands with the exception of the east of England and the east and north of Scotland. It extends from low water to a depth of 15 fathoms. The Punctured Limpet

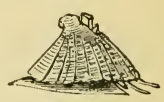

Punctured Limpet (Puncturella norelina) is much smaller than the last, but agrees with it in having a slit, which does not, however, take the place of the beak, but is a little in front of it, as shown in annexed view from 
above. The beak remains spiral as in the embryo. The "Keyhole" of the previous species has a thickened margin internally, but in the present species there is a vaulted process beneath the slit. The shell is white, ribbed in a manner similar to that of $F$. greca, but less rugged. It is a deep-

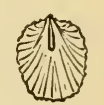

Punctured Limpet, from abovo water ( 25 to 90 fathoms) species, and a northern-not being found south of Yorkshire.

Common Slit-limpet (Emarginule fissure). In the genus Emcrginulce the slit instead of appearing in very early life and travelling to the crown of the shell, as in Fissurelle and Puncturella, appears when the animal is nearly adult and remains at the margin, becoming partially filled up with age. The mantle protrudes from this slit to form an excurrent siphon, as in the other

Common

Slit-limpet
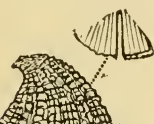

Hognest

members of this family. The shell is white, and crossed by ribs much as in the other species, but here they are less numerous. It is generally distributed, and may be found on rocks and stones from extreme low water to a depth of over 100 fathoms. The Rosy Slit-limpet (E. rosec $\iota$ ) is a much smaller species, with proportionately narrower shell of distinct Phrygian cap form. The ribs are more equal in thickness, and the pits caused by their intersection round, whereas in the preceding species they are more square. The slit is

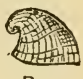

Rosy Slitlimpet shorter, the mouth often tinted with bright rose colour, and the usually white shell sometimes tinged with pink. It is a southern form, but may be found commonly in deep water (7 to 25 fathoms) 
on the coasts of Dorset, Devon, Cornwall, and the Channel Islands. The Large Slit-limpet ( $E$. crussa) is much larger than the last two species; the white shell measuring $1_{4}^{\frac{1}{4}}$ inches in length. It is a less elevated cone, and the radiating ribs number between 80 and 100, alternately broad and narrow, each of the former often divided into three. In addition to the concentric wrinkles that cross these, there are radiating rows of minute glistening dots. The mouth of the shell is oval, and is notched in agreement with the ends of the ribs. It has been found under stones at Oban at periods of extremely low water, but otherwise only by dredging on rocky ground off the west coast of Scotland, Shetland, Antrim, and Dublin, in from 20 to 75 fathoms.

The Ormer or Sea Ear (Haliotis tuberculata). The claims of this mollusk to be included among

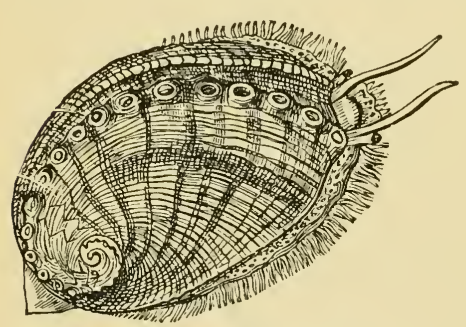

Ormer (one-fourth nat. size) native species are political rather than natural, for its only "station" north of St. Malo is the shores of the Channel Islands, where it is used for food, after being beaten to make its muscular foot tender. Flat and shallow as the reddish-brown shell is, it is distinctly spiral, with the last whorl very large. Its exterior is rough and shabbylooking, but it is linel with the iridescent "mothero'-pearl" which makes these shells so valuable to 
the manufacturer of fancy articles. Instead of the central or marginal slit, such as we have seen in the Keyhole and Slit-limpets, the Ormer has a long spiral series of round holes. As the creature grows the oldest of these perforations are successively filled up, the last remaining open serving as an anal aperture; whilst the others admit fresh supplies of water to the pair of branchial plumes, of which the left plume is the larger. Filaments from the mantle also pass through these holes, and doubtless serve as sense organs. The animal has a broad head, from which a short snout protrudes. The tentacles are long and thread-like, connected at their base by a fringed lobe, and at their outer bases are placed the stalked eyes. The large fleshy foot is fringed by two rows of delicate filaments, with green tubercles between. The animal creeps along after the manner of a Limpet, and, like that species, rests with the margins of the shell pressed against the rock, from which, however, rats and birds contrive to force it.

Curled Slit-shell (Scissurella crispata). The minute thin white shell of this mollusk shows an advance towards the spiral form of the snails. The last or body-whorl forms the greater part of the shell, but instead of being spread out and shallow, as in the Ormer, the sides are contracted, and when the animal retires within the orifice is closed by a thin oval operculum. In adult specimens the margin of the shell is slit in front. The animal has a rather long foot, a prominent head, and a pair of long fringed tentacles with the eyes at their base. Along each side of the foot there are two short 
pointed lappets, and beyond these two long fringed feelers. It has been taken on stony ground from 18 to 75 fathoms deep, in Shetland, but the shells were empty; also at Orkney, Wick, Caithness, Skye, Antrim, etc. 

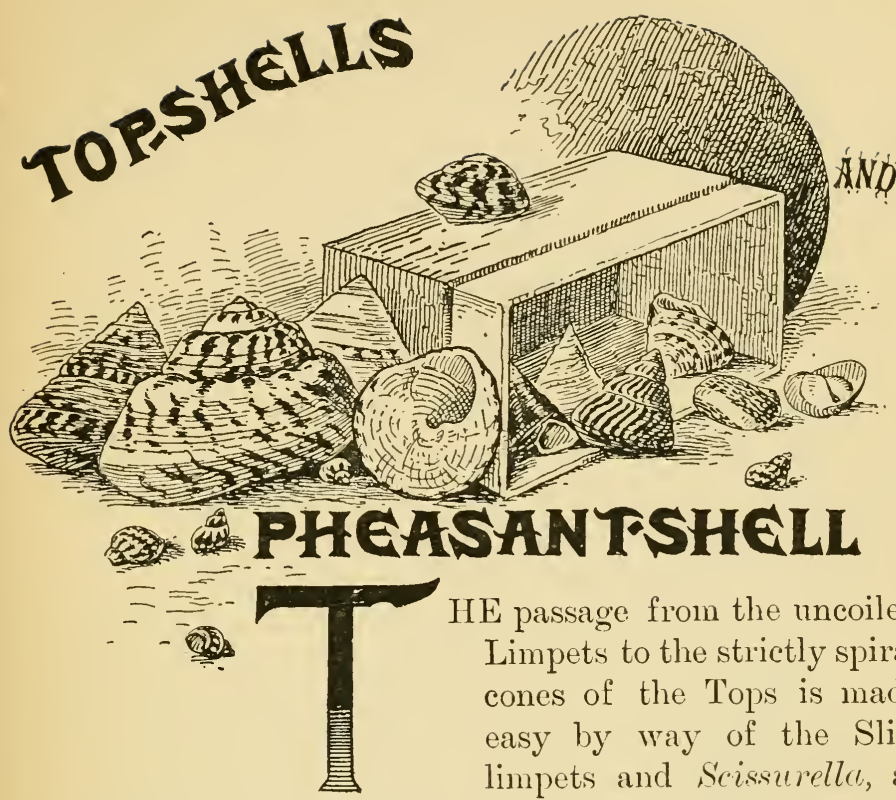

HE passage from the uncoiled Limpets to the strictly spiral cones of the Tops is made easy by way of the Slitlimpets and Scissurello, as shown in the previous chapter. A further advance in that direction is seen in the tiny Dolphin-shells (('yclostrema), of which we have three species. They are more orbicular thin Scissurella, and without the slit margin of the almost circular mouth. The coiling of the shell round an imaginary axis leaves a deep cavity, known as the umbilicus, which we shall meet again and again from this chapter in our story, and shall find that it is often a raluable clue in the discrimination of species. Another feature encountered for the first time is the operculum, a thin horny plate attached to the hinder part of the mollusk in such manner that when it withdraws into 
its shell the operculum comes last and accurately closes the inouth of the shell. In some species this operculum is composed of hard shell material, but in the Dolphin-shells it is horny and of spiral structure. The Shining Dolphin - shell ( $C$. nitens) is thin, white, glossy, and slightly iridescent, with three whorls and a thickened lip. The animal has a bilobed snout, thread-like tentacles from the head, and tentacle-like appendages to the foot-three or four on each side. It is found in the coralline zone on the coasts of Devon, Cornwall, Guernsey, all round Ireland, and the west of Scotland. The other species is the Flat Dolphin-shell (C. serpuloides). The specific name of this mollusk was bestowed because the shell was thought to resemble the shelly tunnel of the Tube-worm (Serpulu). It is almost flat, the spire being scarcely raised. It occurs between low water and a depth of 25 fathoms on all our coasts. It is thought by some that the species described below as Troclucus duminyi should come here under the name of Circulus stricetus, but as the shell alone is known we think it best to retain it provisionally where Jeffreys placed it, as the discovery of the animal will almost certainly lead to other arrangements.

The Top-shells (T'rochus) are closely related to the Dolphin-shells, as will be evident on comparing the animals with their ciliated tentacles and side appendages, although systematists have placed them in separate families. These differ from the last in the shells always having a layer of pearl beneath the outer coat of shell material, and in the mouth of the shell being oblique and somewhat 
angular. The umbilicus is not always present, and is very variable even in the same species. The head of the animal is furnished with lobes, as shown in this figure of the Grey - top's head. At the "tail" end of the animal an iridescent horny disk, showing a spiral structure, will be seen; this is the operculum, which closes the

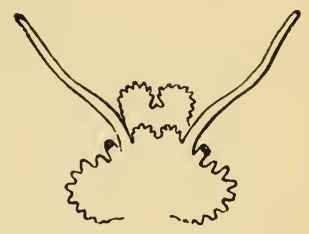

Head of Grey-top shell when the creature has retired.

The Common Top-shell (T'. zizyplinus) is regularly pyramidal with an almost flattened base, solid, and somewhat glossy. Ridges of various sizes run spirally from the sharp apex to the rhomboidal mouth;

Operculum the largest ridge being that which
marks the base of each whorl. The ground colour varies from flesh colour to purple overlaid with interrupted or zigzag streaks of dark red. There are from 10 to 12 whorls in a full-

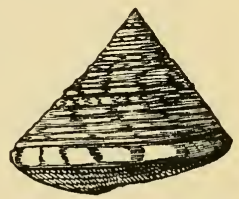

Common Top-shell grown specimen. The animal is yellowish, variegated with crimson, purple, and brown. The prominent head has a small bilobed veil; tentacles with a brown central streak; eyes large, with black pupils, on stout footstalks. The side appendages are usually four pairs. The operculum has 15 or more whorls. Like all the members of the genus, the Common Top feeds upon seaweeds, and it may be found in plenty in the zone below low - water mark, where the great wracks and oar-weeds grow. It also extends to a depth of 85 fathoms, and some of the finest 
examples have been obtained by trawling in deep water.

The Western Top-shell (T. occidentulis) is pyramidal, thin, semi-transparent, glossy, opaline, with pale golden spiral ridges, and about 7 whorls. Animal like the last species, but with usually three pairs of side appendages. The shell is about half an inch high, and somewhat less across the base. It has been found on the fishing banks of Shetland, the Orkneys, and Aberdeenshire, in deep water-40 to 90 fathoms.

The Granulated Top-shell (T. granulatus) is solicl and opaque; pyramidal, but with the lowest whorl larger than the other nine put together, ridged as in the previous species, and tapering abruptly to a sharp high point. Its colour is pale yellow, tinged and spotted with reddish brown. The animal is similar to the foregoing, but the eyes are dark blue with black pupils, and are mounted on short white stalks; side appendages three on each side. In height and breadth it is about $1_{4}^{1}$ inches. It is a southern species, and may be sought in the coralline zone along the coasts of Dorset, Devon, Cornwall, and the Channel Islands, in the Isle of Man and on the south and east of Ireland. The name is suggested by the fact that the larger ridges have their surface raised into granular points.

The Many-grained Top-shell (T'. miliaris) is similar to the last, but smaller, measuring only about half an inch either way, and the ridges broken into granulations by the crossing of numerous oblique grooved lines. The ground colour is more white than yellow, but marked with brown and purple as in the last. 
The animal is covered with short prickly points, and the tentacles-which are marked with three lines of brown-have blunt tips. The eyes are on the under-side of tubercles at the outer base of each tentacle. Side appendages three pairs, with a brown eye-spot just behind each. It occurs chiefly in the west of Scotland, but has been taken on many other parts of our coasts, even to Devon, Cornwall, and the Channel Islands, in from 2 to 70 fathoms.

The Grooved Top-shell (T. striatus) is narrow at base in proportion to height, flattened beneath, the whorls 7 in number, of which the lowest 5 are flattened and distinctly keeled. The whole surface is crossed by innumerable oblique lines which break up some of the ridges into little knobs. The ground colour is whitish, streaked obliquely or speckler with brown. It is about a third of an inch across at base, and a little more in height. It occurs along the south coast from Dorset to Cornwall, in the Channel Islands, and at Cork, Baltimore, Bantry, and Dublin Bay; its labitat from low water to a depth of 15 fathoms, and it appears to be fond of the Grass Wrack (zosterre). Montagu's Top-shell ( $T$. montucuti) is similar to T. striatus, but a little smaller, the whorls not flattened-though somewhat compressed-and the base more convex. It occurs on all our shores between 7 and 95 fathoms.

In all the foregoing species of Top-shells there is no umbilicus in the alult, though the fry of some species show one temporarily. All the species that follow have this perforation, though in the Thick Top it is almost filled up in the adult. 
The Thick Top-shell (T. lineatus) is not pyramidal but conical, very thick and dull. Young specimens exhibit the spiral ridges, but these have disappeared in the adult. The ground colour is yellowish or greyish, overlaid by zigzag purple streaks. The apex of the rather low spire is always eroded by the time the shell is full-grown. Whorls 6 ; mouth large and oval, the inner lips bearing a strong toothlike tubercle. The large shallow umbilicus is partly covered by the inner lip. Its measurements are an inch either way. It is a local shell, but may be found from Dorset to Cornwall, and up the western coast to Anglesey; also in Ireland and the Channel Islands, between tide-marks.

The Round Top-shell (T. duminyi) is a minute shell, which is equally convex above and below, flat spired, and has a very wide and open umbilicus. It is white, semi-transparent, glossy, and has fine whorls spirally ridged. The mouth is almost square. It occurs at Bundoran, Donegal Bay.

The Flat Top-shell (T. umbilicatus) is much larger (half an inch across) than the last, flat-based and almost flat-topped, without any approach to the pyramidal form. The spiral ridges are sharper and fewer; the colour grey, streaked with red lines or zigzags; outer lip bordered with orange and green. It occurs in numbers, feeding on the Saw-edged Wrack (Fucus serratus), in the littoral zone along the south coasts up the Bristol Channel, around Ireland and the Isle of Man, and along the west coast of Scotland.

The Grey Top-shell (T. cinerarius) is the most abundant of all our Top-shells. It varies a good 


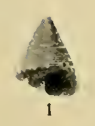

2
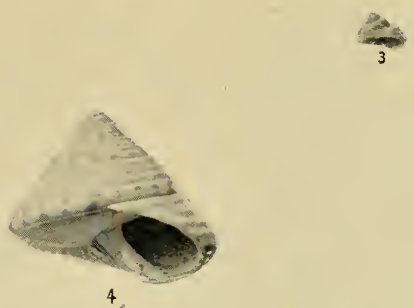

4
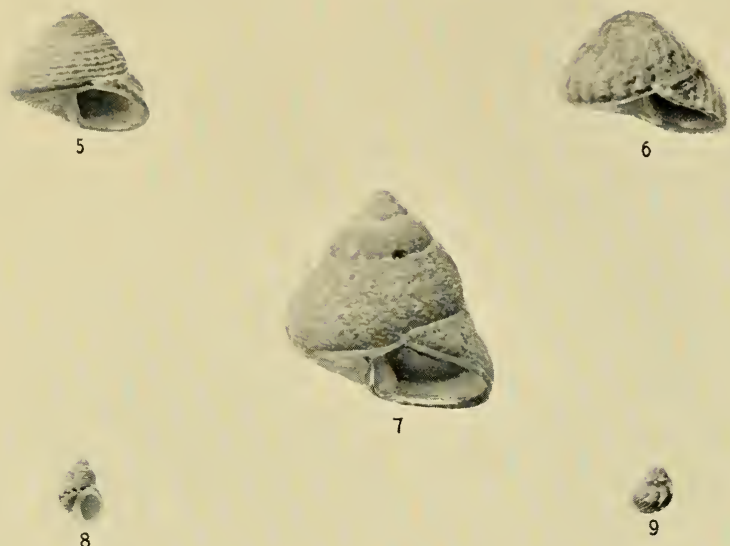

8
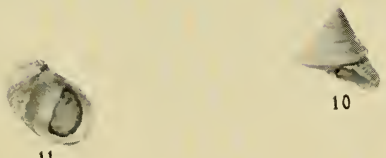

10

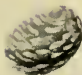

12

I Grooved Top-shell ; 2 Small Pearly Top ; 3 Swollen Tor ; 4 Common Top;

${ }_{5}$ Grey Top ; 6 Flat Tor ; 7 Thick Top; 10 Many-grainfod Top;

8, 9 Pheasant-shell; i 12 Freshwater Nerite. 

deal in appearance according to its habitat; those living on the rocks between tide-marks resembling our figure, but when living upon oar-weed below the littoral zone it is much more depressed. There are 6 or 7 whorls; the lower ones flattened and the upper ones rounded. There are a few threadlike ridges on the body-whorls.

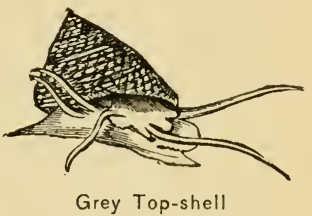
The ground colour is light grey, overlaid with crowded oblique streaks of dark purple-brown. The umbilicus is small and narrow, somewhat one-sided. It is very widely distributed all along our shores. Its height is half an inch, and its breadth a little more.

The Swollen Top-shell (T. tumidus) is solid, the 6 or 7 whorls less convex than in the last, presenting a turreted appearance; spiral ribs fine and numerous. Umbilicus large and one-sided. The colour is white or yellow, overlaid with spiral rows of red-brown spots. The mouth oblique, with a slight tubercle in the middle of the inner lip. About one-third of an inch in height and of similar breadth. It is rather common and widely distributed, occurring in the laminarian zone and deeper water down to 95 fathoms.

The Painted Top-shell (T. magus) is a very

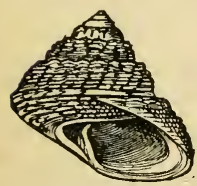

Painted Top distinct species, the shape of the three largest of the 8 whorls giving the solid shell a decidedly turreted appearance. A number of irregular ridges run spirally round the shell, and these are broken up into little knobs. A more prominent ridge runs round the base of the shell. 
The ground colour is pale yellow, almost covered by short streaks of red and purple. Umbilicus wide and very deep, bordered by a smooth broad ridge. It is a species of our southern and western shores, to which may be added Ireland, Man, the Channel Islands, the Orkneys, and Shetland. It affects a sandy bottom between low-water mark and 40 fathoms. Its vacated shell is a favourite cell for Prideaux's Hermit-crab, which has for companion an anemone, the Cloaklet, that wraps the shell completely round, and by secretions from its under-surface dissolves out the mineral portions and leaves only a soft mass resembling sodden paper more than shell.

The Pearly Top-shell (T. cinctus); this and the two following species are characterised by their pearly lustre, and their possession of an umbilicus. The shell of the present species is pyramiclal, semitransparent, pure white with a pearly iridescence. The largest whorl has two large and several smaller ridges, some of which are continued along the other 6 whorls. The mouth would be circular but for its interruption by the spiral ridge which encircles the deep umbilicus. It is a small species, its height being one-third of an inch and its breadth a little less. It was first found by Mr. J. G. Jeffreys in 1861, who dredged it on fine sand and gravel in 85 to 95 fathoms, about 25 miles north-north-west of Burra Firth Lighthouse, Unst.

The Greenland Top-shell (T. groenlandicus) is rather rotund and solid, slightly glossy, with fine spiral ribs. There are 6 whorls, and the upper part of each is puckered up irregularly. The colour is a flesh tint, without streaks or spots. The um- 
bilicus is narrow, but very deep. It is a quarter of an inch across and a little less in height. Its British distribution is limited to the west of Scotland, Shetland, and the Orkneys, where it occurs on rocks about the base of the Laminarias, from low water to a depth of 40 fathoms.

The Small Pearly Top-shell (T. helicinus) is less conical and shorter than the last, less solid, semitransparent, and highly polished. There are no ribs, and the suture or hollow line that separates the 5 whorls is less deep than in the last. The umbilicus is also less deep. The colour is orange varying to reddish brown, occasionally tinged on the upper-side of the whorls with blue or purple. It is a quarter of an inch across the base, which is almost twice the height. Its habit is similar to that of the Greenland Top, but its habitat must be extended by the addition of the east coast of Scotland and its continuation as far south as Yorkshire; also Belfast, Dublin Bay, and

Connemara.

The Pheasant-shell (Pluasianella pullus) belongs to a family (Turbinicle) distinct from the Topshells, and this is its solitary representative in this part of the world. The home of the genus Plasianella is in Australia, where the shells are large, $-P$. australis is 2 inches long and 1 inch across,

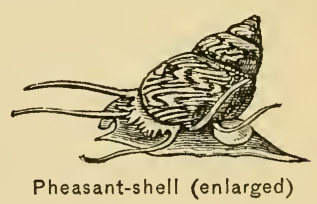

-in the Philippines and India they are much smaller, whilst in the Mediterranean, the British seas, and the West Indies they have dwindled to very small examples. Our own species is no more 
than a third of an inch in length, and a fourth of an inch in brearlth, but it makes up for its small size by its exceeding

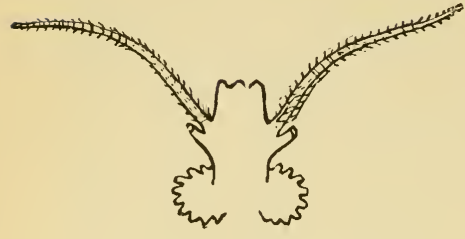

Head of Ihasiunella (enlarged) beauty. The animal is very like those of the Top-shells, and like some of them it moves one half the foot at a time in gliding. The operculum, which we found to be thin and horny in the Top-shells, is solid and shelly, ear-shaped, and concave below. The shell, which is oval, semi-transparent, and highly polished, has usually a clear yellow or white for its ground colour, upon which are laid numerous variable oblique or zigzang streaks and spots of crimson or purple. There is no umbilicus. It is a common species on the south and west coasts of England; round Ireland; Oban, Mull, Stonehaven, Aberdeen, Caithness, in Scotland; and the Channel Isles. It may be found feeding upon Clondrus crispus and the similar Gigartinu mumillosa, a little above and below low-water mark.

The Fresh-water Nerite (Neritince fluvicatilis) is the sole representative of the family Neriticle in this country. It takes us away from the sea for a brief space, for this is a mollusk, no doubt descended from the marine Nerites of Fresh-water warmer climes, that has ascended the Nerite rivers and become modified by the changed habitat. The shell is obliquely oval, of a solid character, and with a glossy surface. The ground colour is yellowish, and is chequered 
with white, pink, or purple. There are but 3 whorls, and the last of these is equal to at least two-thirds of the whole shell. The operculum is half-moon shaped, corresponding with the shape of the mouth, shelly and solid, coloured yellow or orange, and spirally grooved; beneath there is a sickle-shaped projection which serves to keep it in position when it closes the shell. The animalwhich is yellowish grey spotted with black, and has a black head-shows its relationship to the Top-shells by its possession of a strong snout. It has long tentacles, almost transparent, streaked with black; and large black eyes on short foot-stalks. It is found in clear gravel-bottomed rivers, sparingly at the mouth where the water is brackish; more frequently in the upper reaches. The globular egg-capsules are usually deposited on the shell of another individual, and a singular provision is made for the welfare of the young-though at seemingly great expense. Each capsule contains 50 or 60 egg's, but only one embryo is permitted to develop, and this sets to work to demolish its brothers and sister's. 


\section{DECKLACESLELLS}

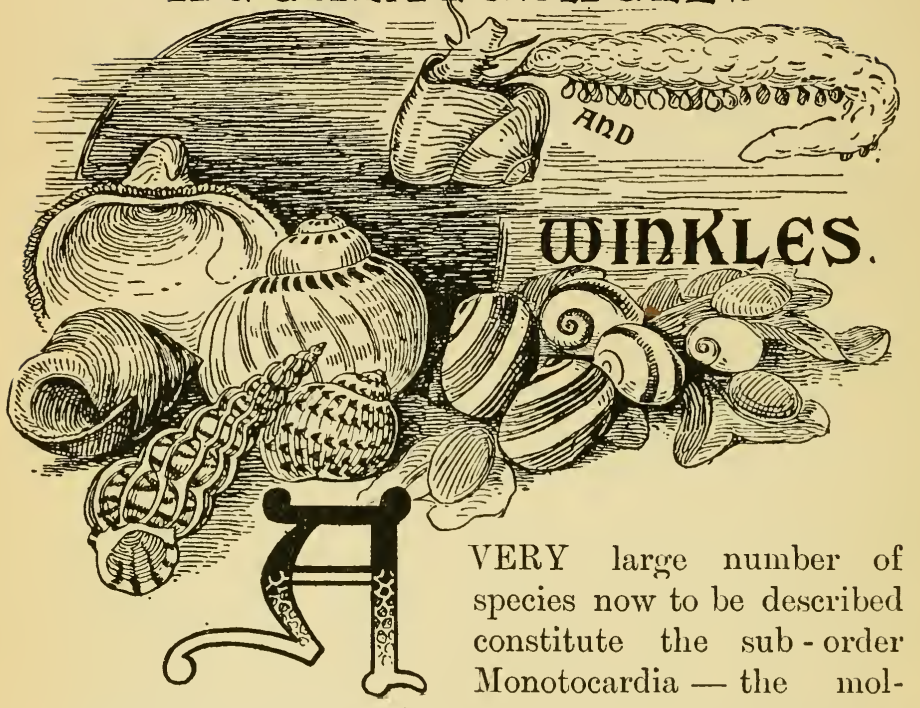

lusks that have only one auricle to the heart, a single gill-plume (the left), one kidney, the nervous system more concentrated, and mostly with a proboscis.

The Violet-snails (Iantlina), of which several species are found washed upon our western shores, are not natives, but their shells are so frequently found in a fresh state, if not tenanted by the living mollusk, that some general reference to them is necessary. They are what are termed pelagic species-living entirely at the surface of the sea, where they feed upon the smaller species of jelly-fishes. The destruction of Velella in this way led to the supposition in the eighteenth century that Ionthina 
produced the Velellue, which were seen apparently issuing from its mouth. For such a mode of life their shell must be thin and light, and to enable them to float unnoticed by sea-birds and fishes it is

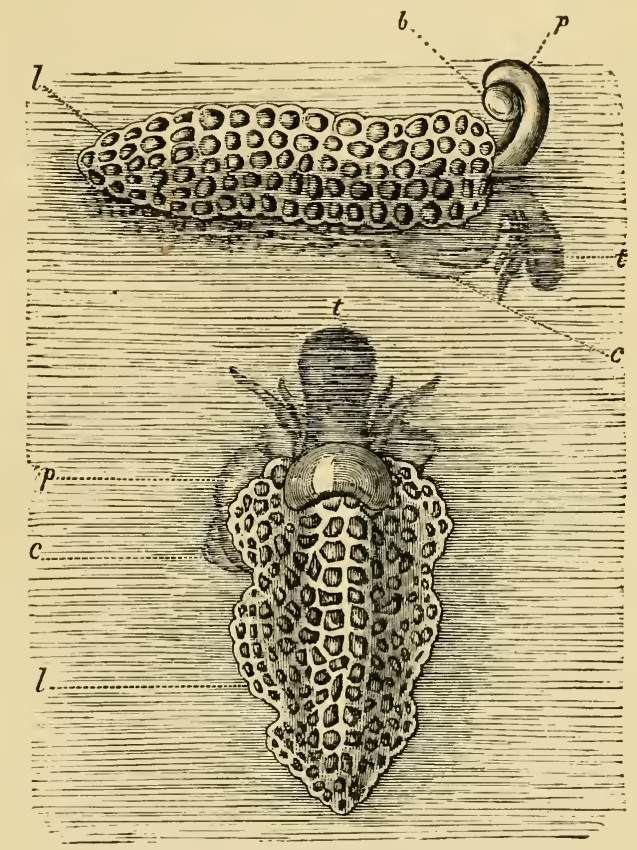

Violet Sea-snail (Ianthina) with its float

$b$, a bubble about to be joined to the float; $c$, shell; $l$, float; $r$, foot; $t$, head

coloured violet, the lower whorls, which are most exposed from above when the creature floats, being of a darker tint, whilst the upper whorls may be white. The mouth of the shell floats uppermost, and 
to steady the creature in this position it fabricates a kind of raft by the excretion of slime in which it imprisons bubbles of air. To the under-surface of this raft the egg-eapsules are attached, and on examination of these it will usually be found that those nearest to the animal contain eggs, those in the middle young with fully formed shells, whilst those near the farther end are broken and empty, the young ones having departed. When touched, the Violet-snail exudes a violet fluid which clouds the water around. They have no power to rise or sink at will. At least two species-I. rotundata and $I$.

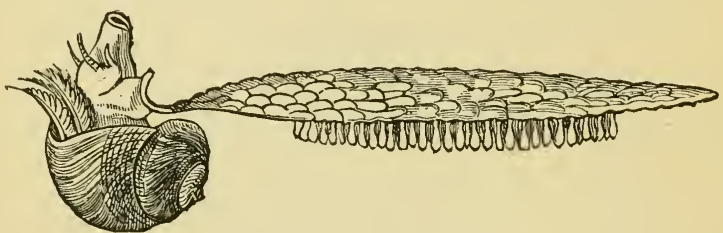

Violet-snail and float-side view

communis-drift to our shores. They have no eyes, and are sometimes termed the "Blind Snails of the Sea."

The Wentletraps (Scalaria) are well known not by reason of our several British species, but because of the high commercial value attached formerly to the Large Wentletrap ( $S$. pretiosa) from China. Rumphius records that in 1701 this shell sold for forty guineas; fifty-two years later the price had fallen 50 per cent., and since then there has been so continuous a slump in Wentletraps that a few shillings are now sufficient to purchase a good specimen. The shells are distinct from those of any other of our native 
mollusks by reason of the ridges that regularly cross each whorl. The almost round mouth has a flat, projecting, and continuous lip. As in many other shells, the stages of growth are indicated by the lips successively formed standing up as ridges, but in few cases do they stand out so prominently as in this genus. The mouth is closed by a horny ear-shaped operculum. The hearl of the animal is short, but provided with a retractile proboscis of a cylindrical shape. The tentacles are

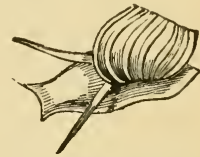

Head of Wentletrap awl-shaped, and at the outer side of their bases the eyes are situated on short stalks. Like Ianthina the Wentletrap animal ejects a purple fluid when molested.

'Turton's Wentletrap ( $S$. turtonce) is rather glossy, and consists of about 15 whorls, crossed by slightly

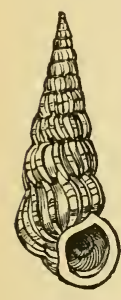

Common Wentletrap (three-fourths nat. size) curved and flattened ridges, of which there are 12 on the largest whorl. The colour is light yellowish brown with three spiral bands of purple-brown, the lowest of which is visible only on the last whorl; operculum dark brown. The length of the shell is an inch and three-quarters, and it is half an inch across at the base. It is by no means a common shell, but it may be found along the coralline zone on many parts of our coasts. The Common Wentletrap ( $S$. communis) is similar to the last, but the ridges are merely folded back, not flattened, and there are only 9 on the body whorl; they are also connected from whorl to whorl, so that they form continuous but oblique lines from the apex to the base. The spiral 
bands are not continuous as in S. turtonce, but broken into short streaks or mottling. Whorls about 15 , separated from each other. Operculum dark brown. It attains a length of nearly 2 inches, and its habitat is similar to that of $S$. turtonce.

Trevelyan's Wentletrap ( $S$. trevelyana) is fawn coloured, thinner than in S. communis, the white ridges connected as in that species, but narrower and more flattened, with a short spur on the upper part; there are 14 ridges across the lowest of the 14 or 15 whorls, which are not separated. Operculum pale brown. The shell seldom exceeds 1 inch in length. A deep-water species-15 to 100 fathoms. The Small Wentletrap (S. clcthratulu) is small, semitransparent, white, with thin ribs of regular size. There are only 12 or 13 whorls, and the lowest of these bears 18 ridges. Operculum yellow-brown. Length about half an inch. It occurs sparingly in the coralline zone all round our islands.

The Aclis-shells (Aclis) are much like those of Scclaria, but without the transverse ridges on the whorls. The mouth of the shell is oval and slightly expanded, the outer lips thickened. The animal is slender, with a long retractile proboscis, long tentacles with the eyes at their base, and the square-fronted foot pushed out in front of the head in walking. There are only two native species. The

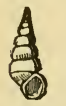
Glossy Aclis (A. supra-nitida) is about a quarter of an inch in length, white, with or Aclis-shell inclining strongly to roundness. The Little Aclis (A. ascaris) is only about one-tenth of an inch in length. It is more slender than the Glossy Aclis, 
and has fine strong spiral ridges. Though agreeing in colour, the form is different, the base being proportionately narrow, and the whorls fewer. They are both obtained by dredging, and their range extends down to about 80 fathoms, but empty shells are often to be picked out of shell-sand on the shore. Two somewhat similar shells formerly included in this genus are now known respectively as Pherusa gulsonce and Cioniscus unicus.

The Necklace-shells (Natica) are so-called because of the peculiar manner in which their eggs are arranged in strap-shaped bands which coil into the form of quoits. The capsules (each containing a dozen or more eggs) are connected by a gelatinous material, at first flaccid and sticky, but by the adhesion and incorporation of sand it becomes firm. These may fre-

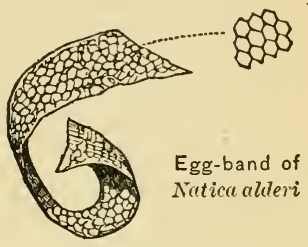
quently be picked up on the shores of sandy bays. The shells are glossy, almost globular, with a low blunt spire, and a large ear-shaped mouth. The animal has a long retractile proboscis, which is usually concealed beneath a flap of the front of the foot, which is turned up over the creature's head. The Naticas prey upon other species, chiefly bivalves, which they hunt in the sand, and whose shells are drilled by the proboscis. This important organ and the head are protected from injury in their passage through the sand by the frontal flap; but in consequence of this covering the eyes have become very small or are altogether wanting.

The Large Necklace-shell $(N$. catena) is a rery 
globose shell of rather handsome appearance, pale buffcoloured and polished, the upper side of the whorls

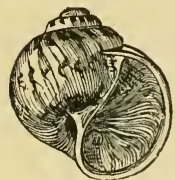

Large Necklace-shell (one-fourth nat. size) ornamented with a series of dark red or violet zigzag or $\mathrm{V}$-shaped marks. The epirlermis is retained only within the umbilicus. There are 7 whorls and a large deep umbilicus. The operculum is horn-coloured. The shell ordinarily measures $1 \frac{1}{4}$ inch each way, but this is often increased to 2 inches. It is tolerably common, between extreme low water and a depth of 10 fathoms; from the south of England to the north of Scotland. The Sordirl Necklace-shell (N. sor(licla) is similar to the last named, but somewhat smaller and more deeply, less clearly coloured, more oval-longer than broad - and thicker, without the markings. The whorls are 5 or 6 . The horncoloured operculum edged with white. It frequents sandy shores

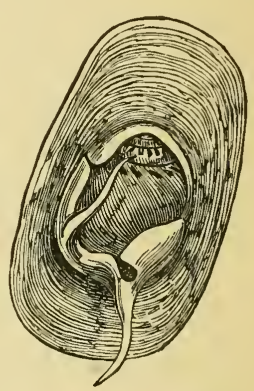

Life aspect of $N$. catenc of a somewhat muddy character in from 7 to 90 fathoms, from Shetland to Scilly, but is more local than $N$. catena, and the individuals far less numerous.

The Greenland Necklace-shell (N. gronlandica) is thinner, almost semi-transparent, without gloss, white, with a cream-coloured epidermis; whorls 4 or 5. The umbilicus is narrow, and the operculum thin, lemon coloured. Its measurement is less than 1 inch either way. It is a deep-water species, and is dredged from muddy ground in from 40 to 50 fathoms in 
Shetland, and off the coasts of Yorkshire, Northumberland, and Durham. The Common Necklaceshell (N. glaucimu) is a pretty little species, plentiful on sandy shores from low water to great depths. The shell is thick and solid, highly polished; the colour varies from white to orange, and the markings - which

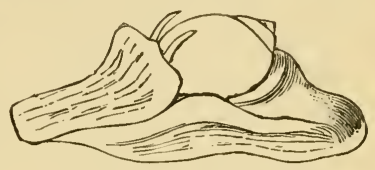

Common Necklace-shell are five spiral lines of V's and zigzags-vary from orange to chestnut. There are 6 whorls, and the spire is blunt. The umbilicus is contracted at the mouth, and the operculum pale horn coloured. The length is little more than half an inch.

Montagu's Necklace-shell (N. montacuti) is the smallest of the native species. It is more globose than the Common species, the colour usually fawn, but varying to buff, often with a whitish band along the upper part of the 5 or 6 whorls, but free from other markings. The spire, too, is shorter, the umbilicus rounder and more open, and the operculum rather more solicl. It occurs at depths between 15 and 90 fathoms where there is a sandy or gravelly bottom mixed with mud; all round the Scottish, Irish, and Manx consts where these conditions exist, also in the north of England, reappearing in Devonshire and Cornwall. The Iceland Necklace-shell ( $N$. islandica) differs from all the others in its less solid and semitransparent character, and by having the spire more elevated. Beneath the dull yellow epidermis the shell is white, without markings. There are from 5 to 7 whorls. The umbilicus is small, and the operculum thin and golden yellow in colour. The 
average length is about 1 inch, but the breadth is less than seven-tenths. It is a rare shell, restricted to the north of these islands in from 7 to 80 fathoms, but most of the specimens have been taken from the stomachs of haddocks.

We have seen how the various species of Natica partially envelop the shell in folds of the foot and mantle; in the next species the shell is completely hidden by the mantle.

The Transparent Marsenia (Marsenia perspicua) is ear-shaped, with a very small spire, but eleventwelfths of the whole consists of the borly-whorl, which is almost flat. It is exceedingly thin and transparent when fresh, but becomes less clear in dying and loses a little of its form. The animal, which is much larger than its shell, varies a good deal in colour from white to yellow or orange, with spots and blotches which vary to contrast with the ground colour. There is a pair of long awl-shaped tentacles, with black eyes at their base only visible from below, or when the creature swims inverted at the surface. The ground colour and the markings are examples of protective coloration, for the creature feeds upon Compound Ascidians and its colour assimilates to that of its food, whilst its markings resemble the common openings of their colonies. Years ago Mr. Peach devoted a good deal of time to a study of this creature, and found that it resorted to patches of Leptoclinum gelatinosum, as he thought for the sole purpose of excavating a pit in which to deposit its eggs. Professor Herdman, however, a few years ago called attention to the fact that Mursenia fed chiefly upon Leptoclinum, and that its colouring was protective. 
We have had many opportunities for checking Herdman's observation, and can fully endorse it. The gelatinous semi-transparent body of the mollusk so closely matches the ascidian that it is difficult to see it, and there is no doubt that the likeness protects it from those creatures that would prey upon it if they could see it. It is probable that the creature and its shell have been greatly modified by its mode of life. It was necessary at first to hide the shell beneath the spotted mantle, then it would be gradually flattened out so that the mollusk's back did not rise so high above the ascidian, and when the resemblance between the two creatures had become sufficiently strong the shell would no longer be necessary as a protecting shield-therefore it would be reduced to its present filmy texture. It is not a common species, as it occurs chiefly in deep water - down to 90 fathoms - but may be found on the recess of the spring tides on the vertical faces and under-sides of rocks and boulders where the Leptoclinum colonies are.

The Velvet-shell (Velutina lavigata). There is a general resemblance between this mollusk and the last, but though the flaps of the mantle are turned over the shell the latter is not hidden. Its name is due to the character of the thick pale brown epidermis, which is distinctly velvety. The animal feeds

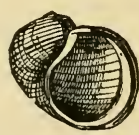
Velvet-shell upon Alcyonium and other zoophytes, and is found on stony ground in the laminarian and coralline zones (from 1 to 50 fathoms) all along our coasts.

The Hairy-Keel Shell (Trichotropis boreulis) is a beautiful little shell with a superficial resemblance to 
the Sting-winkle (Murex). It has an elevated spire of 7 whorls, with several spiral ribs or kecls upon which the epidermis develops into thorn-like points or bristles of a pale brown hue. It has a small curved umbilicus, and the pear-shaped mouth is closed by a yellow-brown operculum. The animal is white or cream coloured speckled with yellow, and has a short bilobed snout separating the long blunt-tipped tentacles. The small black eyes are stalked. The animal lurches from side to side as it walks. It is a northern and local species, its range in Britain embracing the Dogger Bank to the west of Scotland, Ireland, and the Shetlands. Its habitat is in the coralline and deep-sea zones.

The Bonnet-limpets (Capulida) have the muzzle extended, the eyes situated on the base of the tentacles, and but one gill-plume, which is finely and deeply divided. Roughly speaking the shell is limpet-shaped, but with considerable difference. Two genera are represented in this country, each by a single species. They have been considered by various authors never to move from the spot to which they have attached themselves in early life, but judging from my experience with specimens in captivity, I regard this as no nearer truth than the similar statement formerly made respecting the Common Limpet.

The Hungarian Cap or Cap of Liberty (Cupulus hungaricus) is shaped much like the cap of Liberty, the beak or apex being spirally curled back; semitransparent, cream coloured, but the greater part of the shell is hidden by a coarse epidermis of dirty pale brown hue, which also hides the radiating ribs. This epidermis is usually rubbed off the upper end of 
the shell, and orerlaps the edge of the mouth. The lines of growth are very prominent, but so irregular that the shell appears to have been broken several times and patched up. They are found from low water to 100 fathoms, attached to rocks and shells; they are particularly fond of oyster and scallop-beds, where they attach themselves to the upper

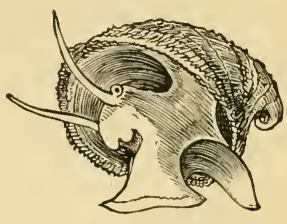

Hungarian Cap valves. Their food appear's to be both animal and vegetable. Clark and Alder have described this species and the next as carrying their spawn, till hatched, between the muzzle and the forepart of the foot.

Cup-and-Saucer Limpet (Calyptrea chinensis). In this species the shell is buckler-shaped or conical, with the beak in the centre; lines of growth spiral. The outside dull greenish or with a violet tinge; the inside similarly tinted, but highly polished, with a twisted

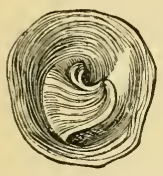

Cup-and-Saucer Limpet-interior plate or diaphragm attached to the hinder part. It is a local species, found on the south coast from Milford Haven westward; also in the Channel Islands. It occurs from low water to a depth of 15 fathoms attached to shells or pebbles; in the former situation the cone is very low-almost flat-but on small pebbles it becomes much more elevated. The pebbles selected for residence often present a surface scarcely larger than the mouth of the shell, so that increase in the diameter of the latter gives place to vertical enlargement. Audouin and Milne Edwards declare that the female 
retains her egg capsules beneath her foot until they are hatched. The internal plate of the shell appears to serve for attaching the animal, and obviates the development of a very powerful muscle such as is found in the Common Limpet.

The Periwinkle family (Littorinirle) have a solid spiral few-whorled shell, with a round mouth closed by a horny operculum. The animal

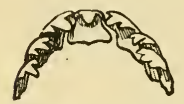

Single row of teeth from the radula of Periwinkle

has a broad extended muzzle, and awlshaped tentacles with the eyes at their base. The under-side of the foot is marked by a central line, and in gliding the sole on either side of this line is adranced alternately. Most of the species are strictly littoral in their habits, and seldom wander far below extreme low-water mark; one of our native species, indeed, is only covered by the sea at the periods of very high tides, and when heavy seas throw their big waves far up the shore. Respiration is effected by means of a single gill-plume, which is contained in a chamber formed by the mantle. Their principal food at least is of a vegetable nature, for the rasping of which they are provided with a very long radula. The sexes are distinct; the males smaller than the females. The relative position of the organs will be seen in this diagram of a partial dissection.

The Dwarf Winkle (Littorina obtusata) is the yellow, red, brown, purple, or green shell that is so abundant on all our beaches. In the empty condition it is piled up at the base of the rocks after a storm; in the living state it will be found in profusion on the Bladder Wrack (Fucus vesiculosus), where it very 

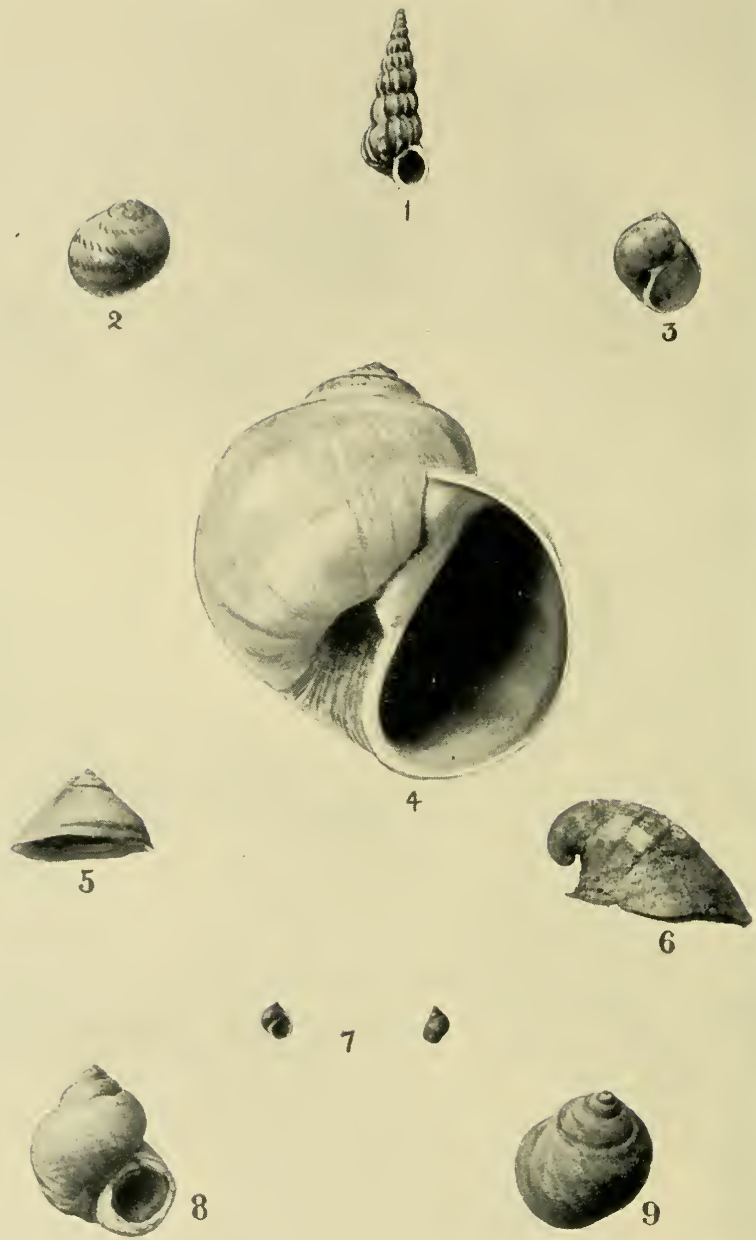

I Turton's Wenteetrap; 2, 3 Cumanon Necklace-shell ; 4 Large NecklaceSilel.l; 5 Cul'and-Saucer Limper; 6 Hungarian Cal'; 7 Nerite Winkle; 8, 9 Rough Winkle. 
closely resembles the bladders of that seaweed. The term dwarf applies to the almost suppression of the spire, a condition also indicated by obtusata, blunted. There are 5 whorls, but the first four form a very small part of the entire shell. Occasionally pure white specimens may be found, and frequently it is banded lengthwise with redb row n. I t measures about half an inch either way. The $\mathrm{N}$ e rite-like Winkle (L. neritoides) has a decidedly conical shell, and the last

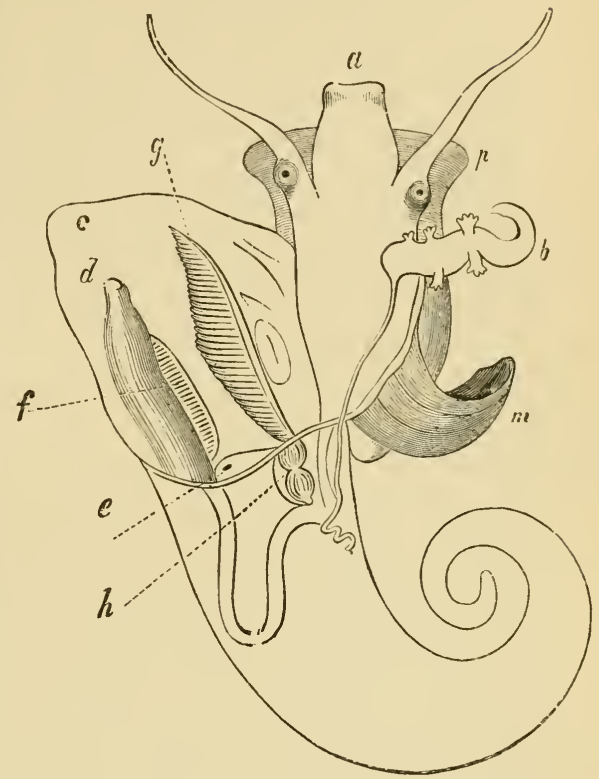

Animal of male Periwinkle, with the shell removed

$a$, mouth; $b$, sexual organ; $c$, reflexed mantle; $d$, vent; $e$, kidney; $f$, slime-gland; $g$, gill; $h$, heart; $m$, shell. muscle; $p$, foot

whorl only accounts for two-thirds of the whole. The colour is a dark red-brown, paler at the base, where there is sometimes a yellowish zone. In height it is a little more than a quarter of an inch, and in breadth a little less than a quarter. It is usually found clustered on the sides of rocks above ordinary high-water mark, where during the period of neap-tides it must remain dry for days in calm 
weather; but the gill-chamber holds sufficient moisture to enable respiration to proceed.

The Rough Winkle ( $L$. ructis) has a less pointed spire of from 6 to 9 whorls, of which the last whorl occupies in the male one-half, and in the female two-thirds of the whole; the mouth, too, is much larger in the female than in the male. The colours range from white, yellow, and orange, to red, brown, purple, and black, usually with spiral bands of another tint, and spiral flattened ribs. The female retains her eggs until they are hatched, and this is said to be the reason why this species is not used for food, the minute shells rendering the parent gritty and dangerous to the teeth of the eater. It is everywhere plentiful where there are rocks and stony beaches. It is half an inch across, and about fiveeighths in height. Experiments made by Professor W. A. Herdman with this species show that it is capable of living out of water for long periods. Marked specimens upon the rocks were found not to have moved within thirty-one consecutive days. It appears to endure life in the water less than life in air, and to be undergoing the change of habit from

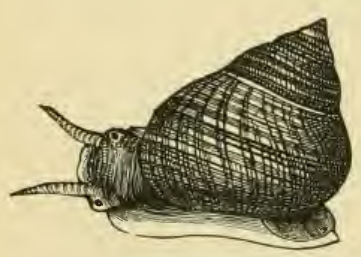

Periwinkle sea to land that must in past ages have brought about our land mollusks.

The Periwinkle or Common Winkle(L.littorea) comes nearest to the Rough Winkle, but differs from it in being twice the size, with flatter whorls, a longer and sharper spire, a much slighter suture or channel between the whorls; the disproportion in size of the 
sexes is not so great in the present species, because the female does not retain her eggs but deposits them in masses upon weeds and rocks. The colour of the shell is yellowbrown, greyish yellow, or olive, with red-brown or dark brown bands, and flat spiral ridges. There are 7 or 8 whorls. The cen-

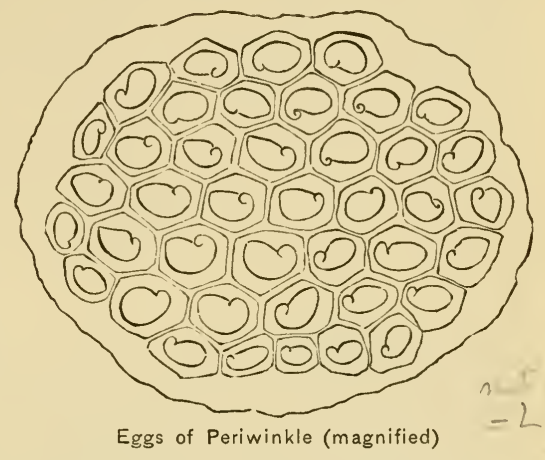
tral pillar round which the spiral is wound is always white. Winkles are exceedingly common below ordinary high-water mark all round our coasts, and thousands of tons are gathered annually and sent into the towns to be sold as a delicacy among the poorer classes.

The Chink-shells constitute the genus Lacuna, which is represented by four native species. They are chiefly distinguished from the Winkles by the fact that the lobe to which the operculum is attached is large, and ends in a pair of long tentacle-like filaments. The head tentacles are flat and smooth, and the mouth of the umbilicus is a long slit in the pillar, whence the names Chink-shell and Lacuna (a fissure). The shell lacks the stony solidity of the Winkleshells, though the animal also feeds upon seaweeds, but not so much about rocks. Loven has observed that the animals are coloured to harmonise with the weeds upon which they feed. 
The Thick Chink-shell (L. crcssior) is rather solid, opaque, brownish yellow, turreted, with thick epidermis; the spire raised, with blunt tip; whorls 6 or 7 , suture deep; mouth expanded below, with thin lip. The fissure is not always present. The animal is very active, and moves along with a jerking of opposite sides of the foot alternately. Like the Winkles it is fond of getting out of the water into the air. It is rather a local species; but is widely distributed, and may be found on small weeds below

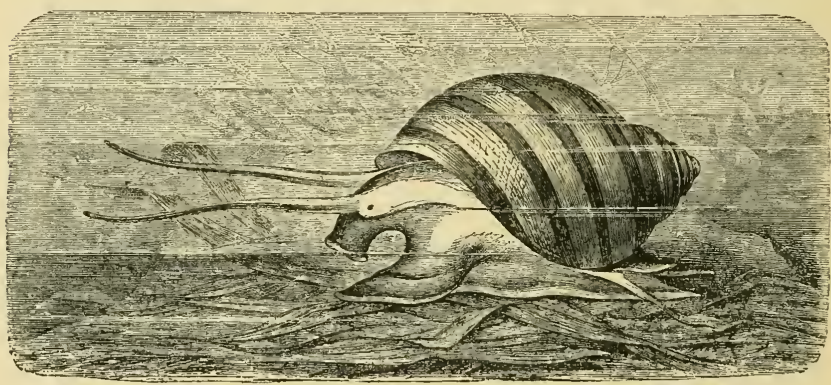

Banded Chink-shell, Lacuna divaricata (enlarged)

ordinary low-water mark where the bottom is sandy. The shell is half an inch long, and less than a third in breadth. The Banded Chink-shell (L. divaricata) is conical, thin, semi-transparent, with

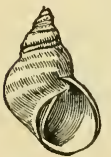

Banded Chink-shell slight spiral lines (also present in L. crussior, but there hidden by the epidermis). The colour varies from white to pale brown, usually with four bands of reddish brown; whorls 6, suture not deep. Fissure wide. The animal is shy and restless, and has the same awkward mode of progression as L. crassior. 

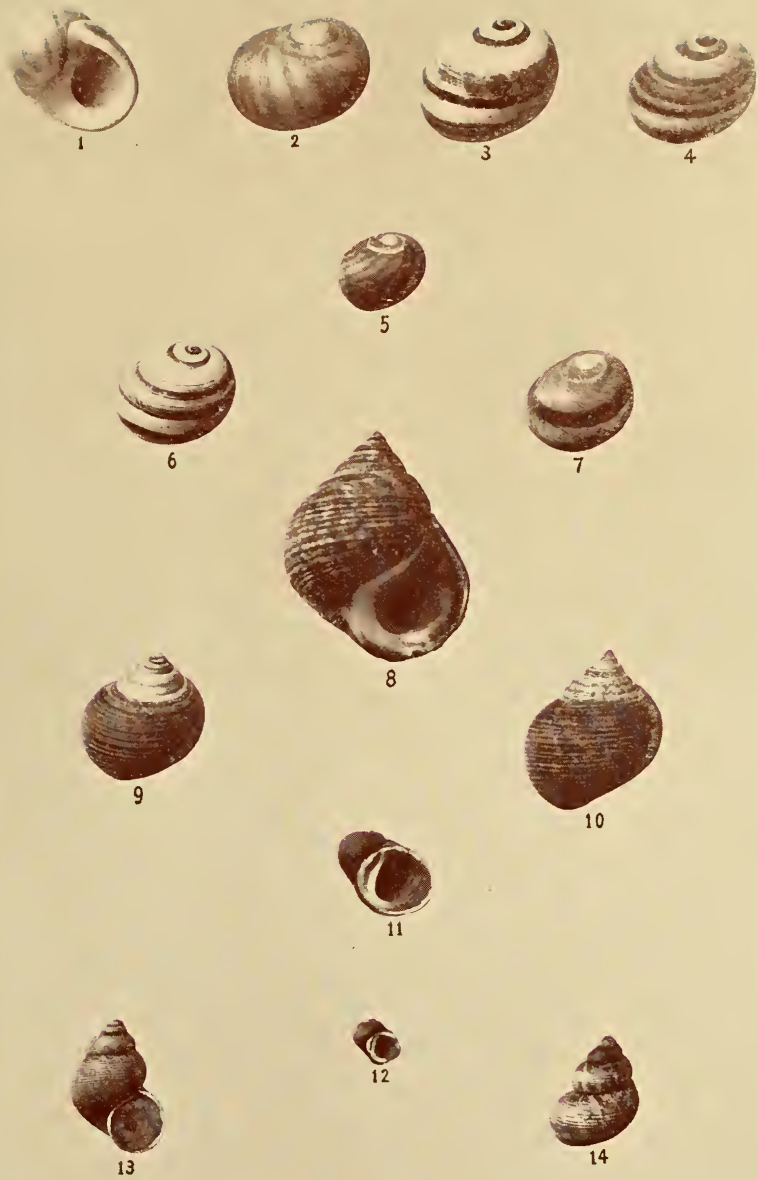

I to 7 DWarf Winki.e and varieties; 8 to io Periwinkle; $x$ Pallin Chink. Sheli, ; 12 Globular Chink-Shell; I3 $_{3}$ I4 Round-moutheil SNatl. 

The shell is about three-quarters of an inch in length and onc-third in breadth. It is quite abundant on the weeds at low-water mark and below, on all our shores.

The Globular Chink-shell (L. puteolus) is rather solid, glossy, and opaque, the whorls not rounded but rather angular in the centre (periphery); yellowish white, with or without three reddish bands, sometimes uniformly dull reddish brown. Spire scarcely raised

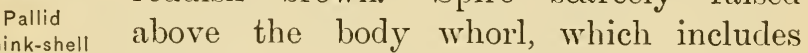
four-fifths of the entire bulk of the 3 or 4 whorls. Mouth expanded, with a somewhat angular base; fissure wide and deep. It may be found in numbers feeding on small weeds, such as Carrageen (Chondrus crispus), about low - water mark. The Pallid. Chink-shell (L. pallidula) is almost triangular, greatly expanded in front, thin but opaque, glossy, of a yellow-green colour; epidermis somewhat thick; mouth very large. The fissure in this species is exceedingly large and fumnel-shaped, exposing

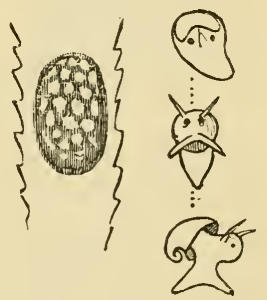

Eggs and young of Pallid Chink-shell nearly all the hollow spire. Although widely distributed along our shores, this species is found chiefly on the south and west, at low water and for a few fathoms below it. The eggs are deposited in oval patches on seaweeds, as shown in our figure, where also are depicted some aspects of the fry. 


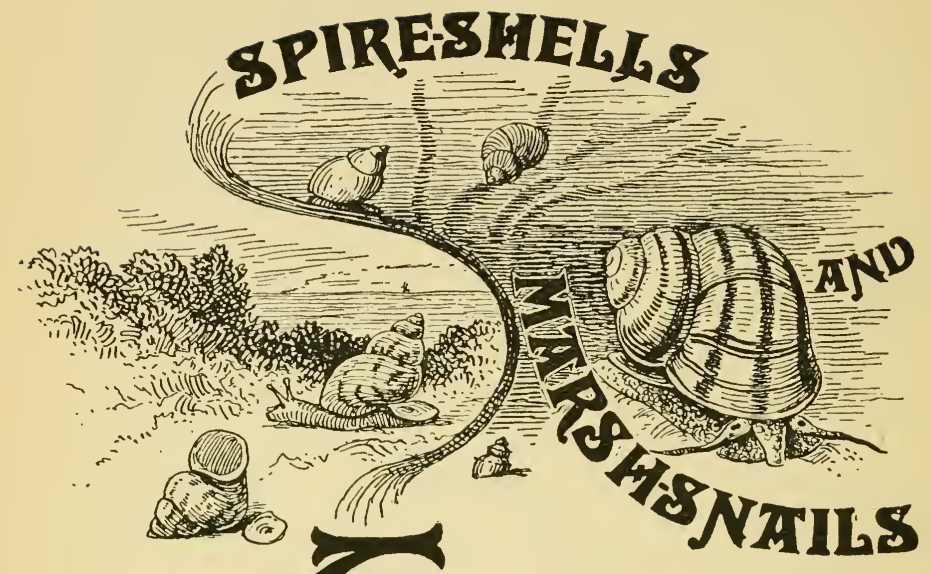

HE mollusks considered in
the previous chapter were rocks that are uncovered for hours each day when the tide has receded. To protect some from the evaporation of their fluids in such a situation, and to preserve others from enemies when swept off the rocks by rough seas, all those that had distinct whorled shells had the orifice closed by a door or operculum. It can be clearly seen how such an arjunct to the open shell made a transition from marine to terrestrial life easy. Such a form as Littorinc ructis, that spends weeks above high water, and is believed to be in the process of changing to a land-snail, was probably the ancestor of the Roundmouthed Snail (Cyclostoma elegans), which is clearly a marine snail that has been so modified that it lives 228 
far inland on the dry chalk-downs as well as keeping up its connections by living along the coast-lands. A glance at the figure will show that so far as externals go it makes out a good case for being classified not very far from the Winkles. There is the long proboscis, the same contractile tentacles with eyes at their base, the longitudinal division of the foot, and an operculum, only this has become shelly instead of horny. If we inspected the radula we should find the number and arrangement of the teeth to agree with that of the Winkles. But there is one great difference: instead of the gill-plumes of the Winkles, aëration of the blood in Cyclostoma takes place in a chamber formed under the mantle behind the head, the blood circulating about the living tissues of this chamber and taking up oxygen from the air. This arrangement led to the Cyclostoma being grouped

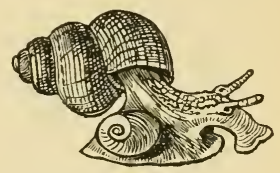

Round-mouthed Snail -until lately-with the land and fresh-water snails that have a closed branchial chamber or lung; but it is now recognised that there is a great difference in the two. It is an exceedingly interesting case, for it gives a distinct clue to the probable origin of other land-forms that have got much more modified. It must not be assumed that Cyclostome originated in this country from a Littorina. The genus is a tropical one, and the probability is that $C$. elegans had a southern origin, for it is found in the Canaries, in Portugal, France, Italy, and Central Germany. It extends no farther north than Yorkshire and Donegal.

Its habits are rather singular. A regetable feeder, 
its favourite resort is on dry hedge-banks, especially on chalky soil. In dry weather, also in winter, it partially buries itself, and in excavating a hole it uses its proboscis for the removal of earth. When climbing it is said to use this same organ as a hand to take hold by. It is very shy, and withdraws into its shell on the slightest alarm, closing its door and dropping to the ground. This species and the next are the only native land-snails that possess the operculum, and its retention in so highly developed a condition by the present species may be explained not only by the nature of its breathing apparatus, but by reference to its enemies. There is a small beetle known as Drilus flavescens, and its larva or grub devotes itself to the destruction of the Roundmouthed Snail. This is how it effects its fell purpose -in spite of the stony door that shuts out most enemies. The Drilus-larva waits patiently at the mouth of the snail's shell until the door opens and the mollusk comes forth; then it contrives to cut the muscular attachment of the operculum, so that when the snail withdraws the door of its fortress will not close properly. The Drilus can now complete its work at leisure; it enters the shell and consumes the body of the snail, then changes into the pupal condition and waits within the shell until it has attained to its final form as a complete beetle.

There is one other native species included in the same family, though it forms another genus. This is the Point-shell (Acicula linecta), whose name indicates, though it does not accurately describe, its dimensions. Its form is cylindrical, with a slight tapering to the upper end; the whorls 6 or 7 , 
pale brown, glossy, and semi-transparent. The animal is much like the Round-mouth, but its tentacles have not the enlarged tips of that species, the operculum is horny instead of stony, and fits into an oval mouth. It is an active little creature, and may be detected by sharp eyes as it ranges over the moss, dead leaves, and decaying trees in damp woods or dry ditches.

The Spire-shells (Rissoa) form one of the most largely represented genera of British shells, something like a quarter of a hundred native species being included in it. Like Acme they have an elongated shell, but here the shape is distinctly conical, the last or body-whorl constituting onehalf to two-thirds of the whole. The mouth of the shell is more or less round, fitted with a horny operculum; there is rarely an umbilicus. The animals are very like Winkles; the body is slender,

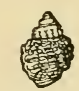

Latticed Spire-shell

(Rissoa cancellata)

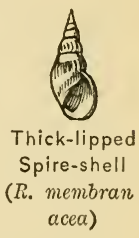

the head produced into a bilobed snout, and the mouth armed with a pair of jaws and a short radula. The blunt-tipped tentacles are more or less hairy, and bear the eyes on small prominences near their base. The foot is divided down the middle as in the Winkles, but only half-way. From the hinder extremity of the lobe to which the operculum is attached, an appendage like a tentacle is given off from each side, thus showing a relationship with the Chink-shells (Lacuna). The shells are all very small, but their forms are beautiful. The Spire-shells may be found on seaweeds and Zosterc at all depths between high water and 100 fathoms, according to species. The 
mollusk has the faculty for spinning invisible threads, and by this means suspending itself from the weeds or from the surface of the water. It is impossible here to give descriptions of the numerous species, whose names will be found in the list at the end of the work.

The Red Spire-shell (Burleeia rubra) is distinct from the Rissoce only in that the opercular lobe is without appendages and the operculum more solid. The genus Hydrobia, too, is but little removed from Rissoa, and less so from Barleeia, with which it agrees in the absence of tails to the operculum lobe. The shells are smooth, and just beyond the mouth there is a chink which appears like the approach to an umbilicus. We have four species, of which one, the Laver Spire-shell (H. ulvce), is partially marine. It feeds in

Laver

Spire-shell (Hydrobia ulva) great numbers on the Laver or Sea Lettuce (Ulva latissima), whether this be between tide-marks on the secishore, in rock-pools, or in estuaries, and as far up tidal rivers as the salt water extends. The other species ( $H$. similis, $H$. ventrosa, H. jenliinsii) have taken themselves up the rivers where the fresh water greatly predominates over the salt, $H$. similis being found in the muddy ditches of the Thames marshes between Greenwich and Woolwich, where it has for company so distinctly freshwater a form as Bithynic tentaculata and the more marine Assiminia grayana. In the small genus Jeffreysia the minute shells are thin and glossy, and the operculum has a slight projection from the straight inner side. $J$. diaphana occurs on Delesseria and other seaweeds at low water; $J$. 
opalina on Corallina officinalis and Laminaria; $J$. globularis on Laminaria at Croulin Island, Skye.

In the genus Bithynice again we come upon two fresh-water species that have obviously been derived from marine forms. The name is badly chosen, for it might indicate that the species inhabit deep water, whereas streams, ponds, and ditches are their usual habitat. The figure represents the Common Bithynia (B. tentaculat $($ ) of the natural size. The pale brown shell is a symmetrical spiral of conic-oval outline, fairly solid; the oval mouth closed by a thick shelly operculum; umbilicus a narrow chink. The animal is dark brown or black above, paling to a dirty grey below, with a long deeply cleft snout, one branchial plume, and thread-like diverging tentacles. The prominent black eyes are not stalked. Leach's Bithynia ( $B$. leachii) is a much smaller species (a quarter of an inch long), with a thinner, semi-

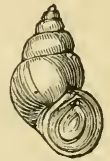

Common Bithynia transparent shell, swollen whorls, and a more distinct umbilicus. The mouth of the shell is nearly round, and the operculum almost circular. Both species frequent sluggish rivers and still waters, but whereas the larger form is widely distributed everywhere in England, Ireland, and Wales, the smaller is more

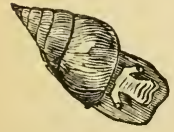

Dun Sentinel local and less abundant. They feed indifferently on animal and vegretable substances; and lay their eggs in bands on stones and water-plants.

The Sentinel-shells (Assiminea) have been so-called because their eyes are borne upon long stalks which give them the power of elevation 
possessed by some of the Crabs, and are therefore supposed to be able to keep a sharp look-out as a sentinel should. These eyestalks are of the same length as the tentacles, to which they are united. The shell is very like that of Hydrobia. The Dun Sentinel (A.grayana) lives in brackish water, coming up the Thames as far as Greenwich. Another of these small-sized mollusks is the Slienea planorbis, whose reddish or tawny shell at Dun first sight looks like one of the small fresh-
Sentinel water Flat-coiled Shells (Planorbis), whence its specific name. The spire is flattened, the four rounded whorls loosely coiled, the mouth round, and the spiral operculum horny. In habit it is very like the Winkles, for though it has been dredged from a depth of 40 fathoms, and may be taken from Conferve in the rock-pools, it also feeds upon Lichina pygmaea, which spends half the day submerged and the other half dried and shrivelled in the air. A somewhat similar but less depressed shell is the White Belted-shell (Adeorbis subcarinatus), which makes up for small dimensions by having a long scientific name, as many other small creatures do. There are only 4 whorls, and these have 6 strong narrow ridges or keels. The large mouth does not show quite so even an outline as in our figure, the ridges usually producing corresponding indentations of the mouth. The operculum is thin. There is a large umbilicus. It is a local species, occurring at various places on the south and west coasts, and at a few places in Scotland and Ireland.

The obvious natural relationships of the species 
considered in this chapter causes us to jump frequently from the seashore to the estuary and the inland waters. So, also, from considering some of the smallest of our native species we have now to mention the largest of the fresh-water gill-bearing

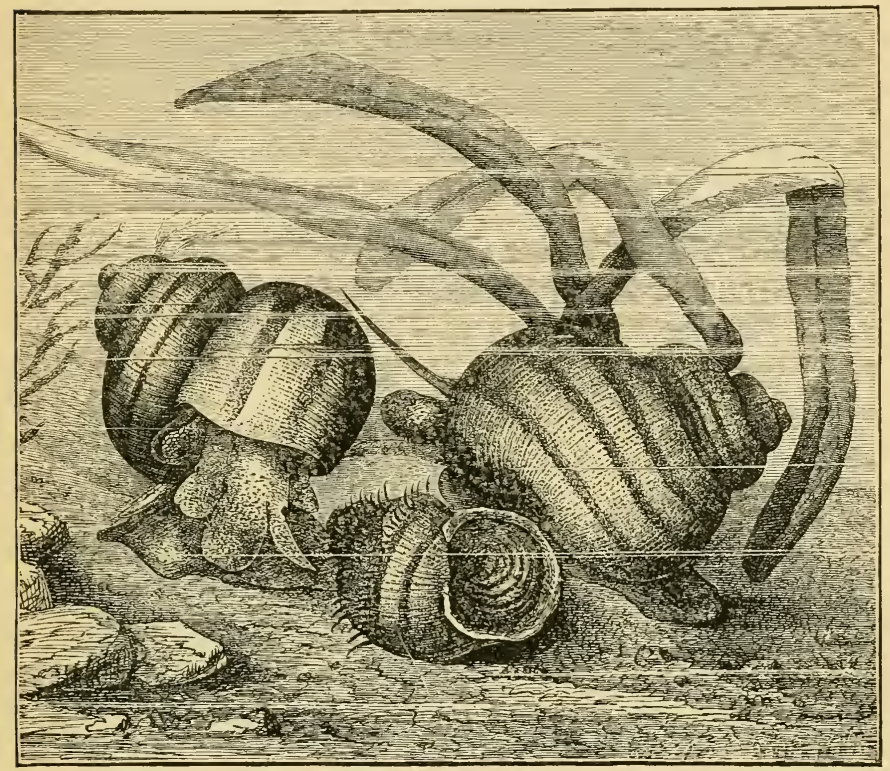

River Snails, Vivipara; male on left, female on right, young (magnified) in front

mollusks-the River Snails (Vivipara). Like many others that have been under notice the animal has a prominent snout, the eyes are placed outside the base of the tentacles (in this case on short stalks), the shell has a symmetrical spire, and an oval mouth, closed by a horny concentric operculum. They are 
herbivorous mollusks. The males are smaller than the females, because the latter retain their egors until they are hatched, and, therefore, require more roomy whorls for their accommodation. The two native species are much alike superficially, but nature has been kind to the tyro in giving them marks that serve to distinguish them readily.

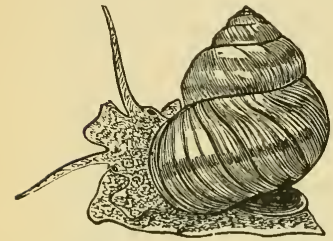

Common River Snail (one-half nat. size) The Common River Snail ( $V$. vivipara) has a thicker and longer shell, a blunter apex, less swollen whorls, a less circular mouth, ard the umbilicus is reduced to a small narrow chink. Lister's River Snail ( $V$. contect $\iota$ ) is a little larger than the other, has a more circular mouth, and a distinct and deep though small umbilicus. It is a much more local species than the other. They are both fairly active animals, and tolerably hardy, for $V$. contectu ranges from Finland to the Pyrenees, and $V$. vivipara has been known to produce a batch of young shortly after having been thawed out from a temperature of $23^{\circ} \mathrm{F}$.

The last of these operculate freshwater species we have to glance at

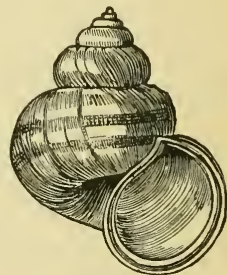

Lister's River Snail (one-half nat. size) are the so-called Valve-shells (Valvata), of which we have two-so distinct in form that there is no difficulty in identifying them. The animals are built much on the same plan as the foregoing-the head drawn out into a long snout, and the eyes at the base of the tentacles, but in this case on the 
inner side. When gliding through the waters the branchial plume is exserted from beneath the mantle, and with it a long tentacle-like outgrowth from the mantle, which is regarded as also employed in respiration, and thought by some as the other branchial plume aborted. The sexes are united in each individual, but only one sex is functionally active at one time. They inhabit slow and still fresh waters all over these islands. The Common Valve-shell (V. piscinalis) has a blunt spire, and the general form of the shell is globular, brownish yellow in colour, and marked with spiral ridges. The um-

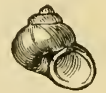

Common Valve-shell bilicus, though round and deep, is not large. The Flat Valve-shell ( $V$. cristuta) differs in the form of its greyish shell, which is always flat, like that of a Planorbis, and the animal has a smaller snout and stouter tentacles. The umbilicus, too, is proportionately larger and more open. 

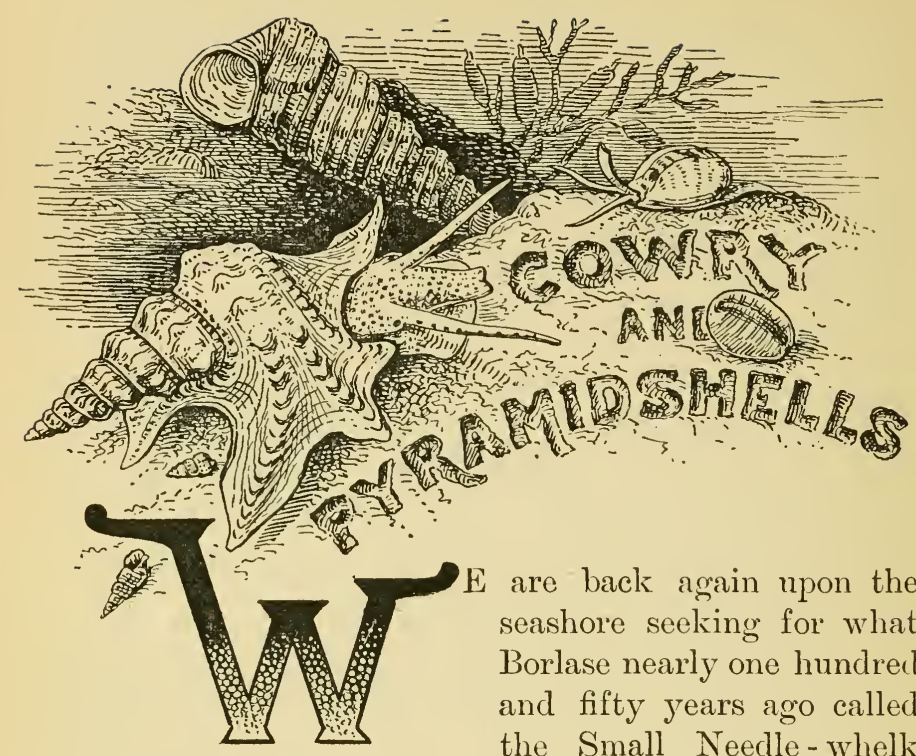

(Bittium retrculatum), a name we believe not in use among the folks along our coasts, who usually lump a large number of species together under a kind of generic title, according to size or habit. Thus these Horn-shells (Bittium and Cerithium), small Nassas, Pheasant-shells, Necklace-shells, and others, are all known along the Cornish coast as "Shillifillies." In the Horn-shells there is a long pyramidal spire of many whorls ornamented with little bosses in spiral lines, a small mouth with a little groove on its lower margin, a horny operculum, and no umbilicus. The animal is much like those last described in the previous chapter, but the branchial siphon is merely a short fold of the mantle, 

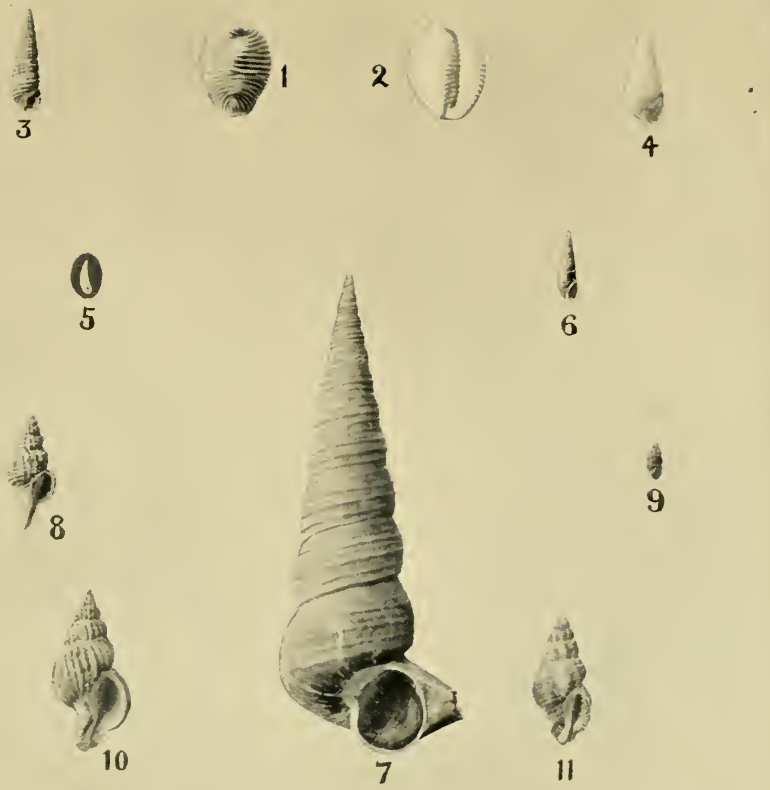

9
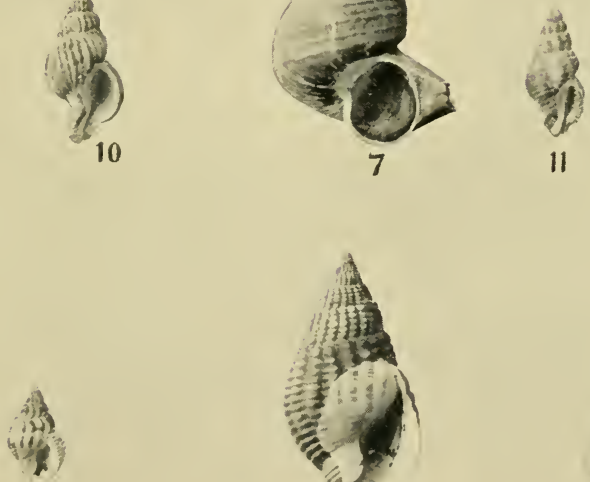

13

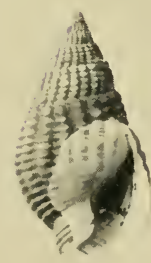

12

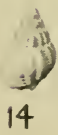

I, 2 European Cowry; 3 Silall Needle-Whelk; 4 Polishen Eulima ; 5 Distorted Eulima; 6 AWl-shaped Eulima; 7 AUger-Shell; 8 Prickly ShINde;

9 LeAst WhelK; io Ribbed SHINdLE; i I SMALL STING-WINKLE; 12 Netted Dog-Whelk; 13, I4 Thick-Lipped Dog-Whelk. 

the tentacles are awl-shaped, and the eyes are placed on little prominences at their outer base. The sexes are distinct. The Common species, $B$. reticulatum, figured here, is about half an inch long, of a reddish-brown colour. It feeds upon decaying animal and vegetable matter, and abounds on all our coasts between half-tide and about 15 fathoms. The Reversed Horn-shell (Triforis per-

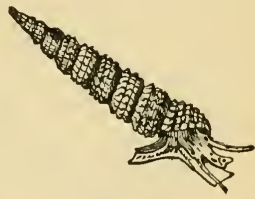

Small Needle-whelk (enlarged) versa) is a smaller shell with the spiral turned in the opposite direction. B. reticulatum, like most spiral shells, has the open mouth on the right hand of the observer when the shell is held with the spire upwards; in T. perverse the mouth is to the left hand. It is by no means so plentiful as $B$. reticulatum, and is found chiefly on our southern and western shores, in the Channel Islands, and all round Ireland. It is found sparingly in Scotland, the Orkneys, and Shetland. Its range is from low water to about 20 fathoms. The Obelisk-shell (Lovenella metula) is a third species, of whitish hue, about three-quarters of an inch long, found rarely on the Shetland fishing banks in from 45 to 96 fathoms.

Another group of Horn-shells is placed in a separate genus Cerithiopsis, - that is having a likeness to Cerithium,-and these are chiefly distinguished by the groove at the base of the mouth being developed into a distinct though short canal, which is lined by the mantle tube or branchial siphon. The British species are C. tubercularis, C. barleei, C. pulchella, $C$. metaxce, C. concatenata, and C. costulcita.

The only example we have of the Screw-shells I6 
(Turritella) is the one to which Pennant gave the name of the Auger (T. communis), on account of its resemblance to that boring implement. It is a giant

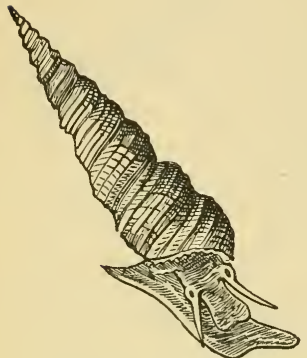

Auger-shell

(two-thirds nat. size) compared with the little Hornshells. The whorls are spirally ridged, the mouth comparatively small and round, though with a suggestion of squarishness, and without a canal or groove. The operculum is round and horny. The mantle is fringed with a triple row of fine filaments. As the new whorls increase in size to accommodate the growing animal the older whorls at the top of the spire, being too narrow for occupation, are partitioned off by the deposit of shell internally. It occurs on all our shores above sand and mud in from 3 to 100 fathoms.

We have just mentioned how the owner of an old house shuts off the rooms that are no longer large enough for use, more spacious apartments having been erected. Some other species having thus partitioned off the old from the new, deliberately knock the older portion against stones in order to break it off; in other cases the making of the dividing wall appears to cause the older part to perish. Shells that have undergone this process are said to be decollaterl. Perhaps the case of the Blind-shell (Ccecum (enlarged) trachea) is still more remarkable, as the entire appearance of the shell is altered by the conduct of the animal. It begins life with a shell coiled 
flat (discoid), but after a time the new portions are added in almost a straight line; then the animal constructs a conical division across the interior to separate the straight portion from the spiral, which soon falls off. Later another division is made in order to get rid of a portion that is too narrow. So that we have here a creature beginning life with a spiral shell, and arriving at maturity with one of a cylindrical character like a Tooth-shell (Dentalium), except that the exterior of this is marked off into rings whilst that is plain. The ringed appearance accounts for its specific name trachea as recalling the structure of the windpipe. The round opening of the brown shell is closed by a flat brown operculum. It may be found in fair abundance in water from 15 to 50 fathoms deep on the coasts of Dorset, Devon, Cornwall, Wales, Guernsey, the Clyde district, Bantry, and Galway. The animal is extremely active, but not so agile as that of the minute Smooth Blind-shell (C. glabrum), which has a thin, smooth transparent white shell closed by a convex operculum. It is found all round these islands between the depths of 15 and 50 fathoms.

The Pelican's-foot (Chenopus pes-pelicani) when fully developed brings to mind the Strombs and Wing-shells of the tropics, and it is interesting to note how easily this form may be produced from a shell of entirely different appear-

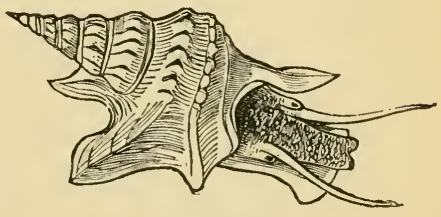

Pelican's-foot ance. In earlier life the shell is shaped like the Auger-shell (Turritella), but by successive additions 
made to the lip the latter expands into a broad flap with five triangular processes, each grooved beneath. There are three thick spiral ribs which are more or less broken into tubercles. The colour is yellowish-white tinged with brown, and the mouth is closed by a pointed operculum. The animal is of similar structure to those we have been recently considering: the foot continued for-

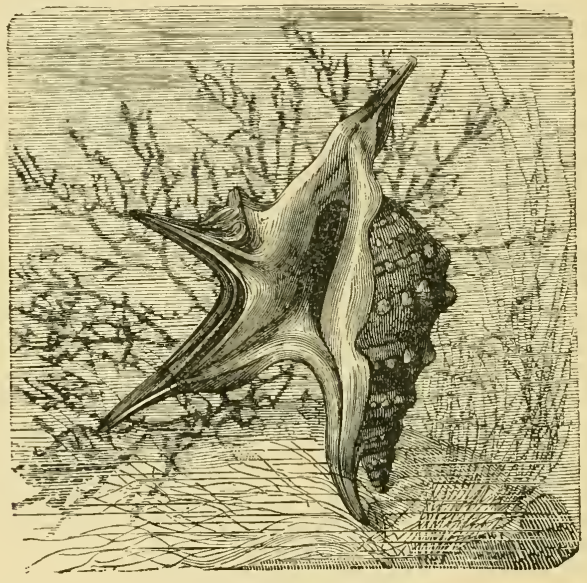

Pelican's-foot-from below

ward in advance of the head; the long snout and awl-shaped tentacles, with the small black eyes on little footstalks at their base. It is cream coloured, mottled with purplish brown and flecked with yellow and white, the whole effect being that of the sand upon which it glides awkwardly in the coralline zone (15 to 50 fathoms), as though its shell were an encumbrance to it. The Shetland Pelican's-foot 
(C. macandrece) is a much smaller and more delicate species, found only on muddy sand off Shetland in from 60 to 80 fathoms of water. The five points from the mouth of the shell are relatively longer and more distinct, the one that is nearest the spire often exceeding it in length and running parallel with it. The colour is paler, so is that of the animal.

A more striking object-lesson in the evolution of shell-structure is afforded by the three British members of the Cowry family (Cypreide), each of them representing a separate genus. In all of them the mantle is furnished with a pair of large side-lobes which fold over the shell and almost meet above it. The mouth of the shell is mostly as long as the shell, and is not closed by an operculum. The animal has a short muzzle, a broad foot with a squarish front, and a long siphon. They are carnivorous, feeding upon zoophytes, etc. Of these three forms the Smooth Margin-shell (Erato levis) best illustrates our meaning. It will be seen that the body-whorl is three or four times longer than the remainder of the shell, and that the mouth is almost as long as this whorl. The lip of this is at first quite thin and sharp-

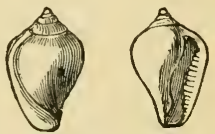

Margin-shellfrom above and below

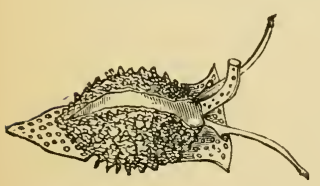

Margin-shell and anima! edged; then it is turned in a little but still has a plain edge, but afterwards it is considerably thickened and becomes toothed on the inner margin. Now the animal-which is of a lively disposition - does not permit us to see much of this white shell when he is on active service, for the mantle-lobes are 
thrown well up over it, and only a narrow streak of the shell shows between. The shell is little less than half an inch in length, and occurs locally all round our islands on sandy ground in from 12 to 85 fathoms. The white foot is speckled with orange, pink, and black, to harmonise with this ground, whilst the mantle-lobes are dotted with purple-brown marks and studded with pale yellow tubercles in imitation of the zoophytes on which it feeds.

The Poached Egg (Ovula patula) has a mouth that is much longer than the shell-proper, and it appears to be all body-whorl. But

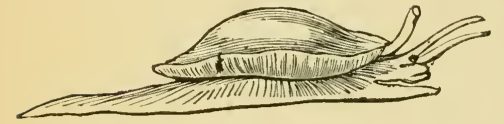

Poached Egg

if we look again at the Margin-shell and imagine the outer lip extended to a greater length than the spire, the result would be spindle-shaped, much like the shell of the Poached Egg when freed from the mantle-lobes. This shell is thin, glossy, and almost transparent, whitish with a tendency towards yellow. Young specimens exhibit a brief spire within the canal formed by the extension of the outer lip above, but the adult shell is of the form shown in this figure. The animal is yellowish white tinged with brown; the mantlelobes, which sometimes completely cover

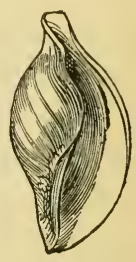

Poached

Egg-shell the shell, are marked with brown transverse lines and small spots. It feeds upon the zoophyte Tubularia indivisa, and lives among the colonies of its victims, the brown stripes of the mantle-lobes helping to disguise it from its own enemies by assimilation to the clustered tubes. Its distribution is not general, 
but restricted to Dorset, Devon, Cornwall, Guernsey, Sark, and a few places on the Irish coast, in the coralline zone.

The shell of the beautiful though common European Cowry (Cyprcece europaca) undergoes a similar change. At first it is a spired shell, though the spire is very short; the outer lip is thin and sharpedged, but as it grows this turns in, thickens, and so reduces the opening considerably. The shell of difference between the young and the adult cowry Cowry shells is so great that the naturalists of a few generations back classed them as belonging to distinct

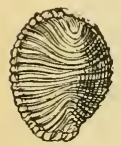

European Cowryfrom above and below species. When the identity of the animals was proved it was believed that the earlier was abandoned when it got too small, and a new one of a different pattern made to shelter the more adult animal. The animal varies in colour from yellow to pink or brown, but most frequently it is orange. The mantle-lobes, which are covered with yellow or white raised points, and red or purple spots, well cover the shell. The ground colour of the shell is white, but in halfgrown individuals this is

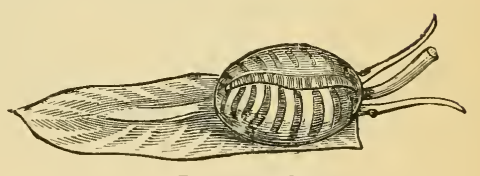

European Cowry crossed by transverse lines of deep flesh tint. In old specimens the white spaces between these lines become elevated into ridges which are continuous with the ribs that protect the mouth. That part of the shell where the mantle-lobes meet is often marked with three dark brown spots, of which the central one 
is the largest and the least sharply defined, but plain specimens are far more plentiful. The animal is very active, but also shy, for it rapidly withdraws into its shell on very slight alarm. The old English form of the name was Gowry. On some parts of the coast it is the Nun, in others the Stick-farthing.

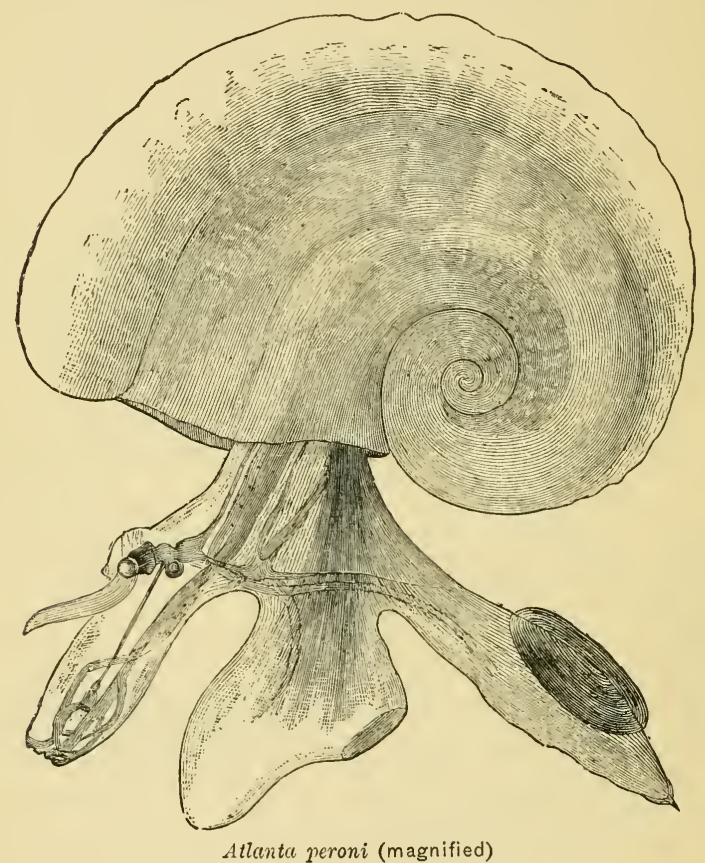

Between the Cowries and the Naked Tongues (Gymnoglossa) there comes a group of sea-snails who have become specially modified for a free-swimming life in the open ocean. The foot, instead of being 
flat for crawling, as in those that crawl upon rocks or weeds, is developed into fin-like expansions. With these they swim in an inverted position at the surface. The shell is not present, or is very small, in one family (Pterotracheridce); in another (Atlantidce) it is spiral, and sufficient to entirely accommodate the animal, which shuts itself in with an operculum. Both shell and animal are perfectly translucent, so that the internal organisation is clear without dissection. These creatures had not been regarded as coming within the British area, though they swarm in the warmer parts of the Atlantic, as well as in the Indian and Pacific Oceans; but in September 1888 Professor M'Intosh took in the waters of St. Andrews Bay "a small transparent univalve, like a finely fashioned shell of glass, containing its inhabitant." It measured about one-twelfth of an inch, and was probably a young example. It was evidently a species of Atlantu, nearly allied to that figured, but having a flat margin instead of the keel that is present in Atlanta peroni. Such a capture is of great interest, for hitherto these creatures were considered to exist only in more genial seas. 


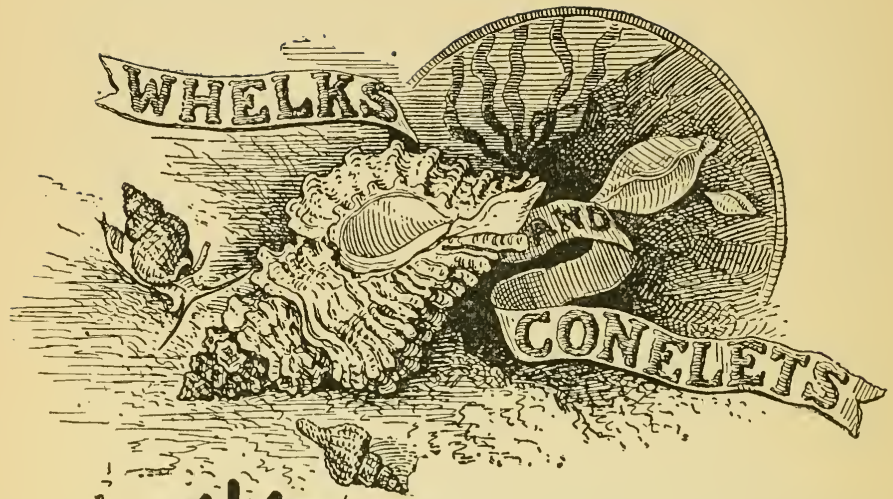

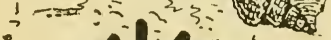

"EFORE clescribing the creatures
at a couple of orders collectively
known as the Gymnoglossa, or Naked Tongues, from the fact that the radula (as well as the jaws) is absent. Their true position in the systems of classification is still a matter of contention among the "doctors who differ," but they appear to be closely allied to forms such as Rissoa and Hyclrobia, and to have lost their teeth owing to a very distinct change of habit-many of them being parasites. The mouth is developed into a proboscis, used in the parasitic forms for sucking the juices of the host.

The Eulima-shells (Eulima) consist of half a dozen native species with polished awl-shaped semi-transparent shells that taper to a very fine point, but as the animal in growing has to vacate the older 
portion the tip of the spire is frequently broken off. The mouth of the shell is oval, closed with a horny operculum, and the outer lip thickened inside. The animal has a foot whose broad front extends far in advance of the head, which is kept under shelter though it shows through the shell, as seen in the figure. The siphonal fold of the mantle is very rudimentary, and the eyes are behind the base of the tentacles, which are united at their origin.

The Polished Eulima (E. polita) has a highly polished shell resembling ivory, about three-quarter's of an inch in length. The animal is also white, but streaked and tinged with yellow; the snout marked with a golden $\mathrm{V}$, the black eyes ringed with yellow. Unlike its fellows, this species is not parasitic, yet it lacks a radula just as much as they do. This appears to point to the fact that the original species of Eulima was a parasite who had no use for

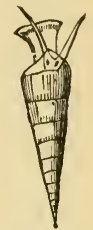

Polished Eulima a radula and exehanged it for a proboscis through which fluids and soft food could be drawn; but that $E$. polite on giving up the parasitic ways of its ancestors has not found the need for teeth. The Intermediate Eulima ( $E$. intermedia) is not quite so large, more spindle-shaped, semi-transparent, and less distinctly white; and the animal is without the V-mark on the snout. The Distorted Eulima (E. plitippi) owes its name to the curved spire of the slender, nearly transparent shell, which is less than a quarter-inch in length. The Awl-shaped Eulima (E. subulata) has an awl-shaped, semi-transparent thin shell, half an inch long, with three pairs of spiral tawny bands. The Two-lined Eulima (E. bilineata) 
is very similar to the last, but little more than a quarter of an inch long and with only two of the spiral bands. Most of these Eulimas attach themselves to the shells of bivalves, the opercula of gasteropods, or to the interior and exterior of the Sea Cucumbers (Holothuria).

The Urchin Snail (Stilifer turtoni), of which we have but one species, agrees with Eulima in having no teeth. It is, however, housed in a shell of different shape, the body-whorl being large and broad, the greater part of the spire above being so slender and cylindrical that it has suggested the Greek stylus. It differs from Eulima again in having no operculum. The head of the animal is snout-like and ends in a suctorial mouth. The tentacles are cylindrical, and the mantle-edges turn up and overlap the margins of the shell. This creature is found only on and among the spines of Sea Urchins, where it appears to feed upon the excreta of the Echinis.

The Pyramid-shells (Odostomia) are well represented on our shores by a score of species. The shells are all small, conical or awl-shaped, A smooth or spirally grooved, with the apex coiled the reverse way (sinistral) to the Conical greater part of the shell, and the mouth with Pyramid-
shell a tooth-like projection on the inner lip-hence the name Odostomia $=$ tooth - mouth. The animal is very like Eulima. The proboscis is only protruded for the purpose of feeding, which appears to be at the expense of the jelly-like polyps and sponges whose softer slime-like portions they can obtain by suction. Some of them appear to subsist 
upon the excreta of other mollusks, the Pallid Pyramid (O. pallida) being frequently found on Pectens near the excretory outlet; others are found under clusters of mussels, on the opercula of other gasteropods, and at the base of seaweeds. As in the case of other parasitic mollusks the shell is white or nearly so. Space will not allow of an enumeration of the species in the body of the work, but a list of the British species will be found in the Appendix. Jeffreys included in the genus the species often separated to form the genera Turbonilla and Eulimella. The genus Turbonilla consists of a dozen species distinguished by having the central pillar straight (instead of curved as in Oclostomia) and in most cases without the tooth-like projection. The shell, too, is more elongated, and the whorls have ribs running across them, as shown in the figure of the Staircase Pyramid (T. scalaris). The six species comprised in the genus Eulimella agree with Turbonilla in the elongated shell with its

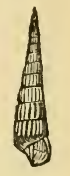

Staircase Pyramid straight and seldom-toothed pillar, but it is in this case free from ribs of any sort and is polished.

The remaining families to be mentioned in this chapter are grouped together under the name of Rachiglossa, on account of an agreement in the disposition of the teeth on the radula. Instead of there being a large number in each row, there are here only three; but each tooth has its front edge broken into a number of long sharp points, varying with each family. The proboscis is long, but can be completely retracted. In the type family, Muircidce, the radula is contained in the proboscis, and its 
central teeth have three or more strong cutting points, or cusps, whilst the side teeth are plain. It is

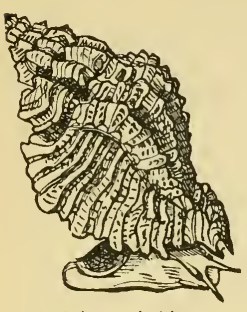

Sting-winkle Ocinebra erinacea to the skilful manipulation of these central teeth that those neat round holes in bivalve shells are due, the members of this family being mostly carnivorous. A further character of these mollusks is seen in the shells, the mouth running off into a spout, as shown more clearly in the figure of the Ribbed Spindle-shell (Trophon truncatus). This spout is for the accommodation of the siphonal fold of the mantle, and is commonly referred to in handbooks as the anterior canal. Through the siphon fresh supplies of water are drawn into the branchix. It is worthy of note that as a rule (to which there are several notable exceptions) this form of shell and siphon indicates carnivorous propensities, and the reason for its existence may be found in the habits of the creature. Much of the food

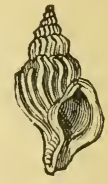

Ribbed Spindleshell of these mollusks is tainted, often putrid; and whilst the mouth is immersed in such a pabulum it would clearly not serve the purpose of respiration to draw in water from the immediate neighbourhood. The long siphon is extencled to one side, or over the top of the shell, and the water taken in from as remote a point as possible.

The Little Spindle-shells (Trophon) are represented by three species, of whelk-like form, all being about two-thirds of an inch long. The Prickly Spindleshell ( $T$. muricutus) is slender, dull, the whorls 
crossed by swollen, sometimes prickly ribs, which are broken by a series of spiral channels. The colouring is a flesh tint with touches of reddish brown. The mouth is small and ends in a long anterior canal. The operculum is pear-shaped, with the nucleus at the narrow end. It has been found chiefly on the shores of Devon, Cornwall, and Guernsey, in the Isle of Man, Tenby, Dublin Bay, Cork, etc., in soft ground between 15 and 50 fathoms. The Ribbed Spindleshell ( $T$. truncatus) is broader, slightly more glossy, and paler, the ribs not broken into tubercles by the spiral grooves. The upper part of the spire is smooth and polished, the mouth oval and the canal short. It affects hard ground from 2 to 50 fathoms deep, on the east coast, around Scotland, south and east Ireland, and the Isle of Man. The Berwick Spindle-shell ( $T$. barvicensis) is more like the Prickly Spindle but broader, much more glossy, the whorls crossed by fewer but more prominent, almost toothed, ribs. The cusps on these ridges are stronger above, so that the top of the whorl appears to be encircled by spires. The colour is white. This is a more northern form, occurring on stony ground from low water to 50 fathoms on our northern coasts, coming only as far south as Yorkshire and Northumberland.

The Sting-winkles (Ocincbra) have the same form of shell, but it is disguised by the ribs and great thickening of the lip from time to time. What are known as varices or "growth lines" really represent periods of comparative rest from shell production. At least, the shell is not enlarged internally, but only thickened at its mouth. These are, of course, the 
same as we have described as ribs crossing the whorls in the case of Lachesis, Trophon, and others, but in Ocinebra erinacen they are more varicose. In addition there are several spiral ridges running from the mouth to the apex, and in crossing the varices they produce that rugged appearance so characteristic of the species. A figure is given on page 252. The animal is yellowish, mottled with white. It is found chiefly on the southern and western coasts, including Wales, and all round Ireland. It inhabits rough ground from a little below low-water mark to about 30 fathoms. It is one of the great enemies of the oyster, boring neat round holes in the upper valve of young oysters and so gaining admittance. It is from this nefarious practice that the fishermen interested in oyster-beds have called it the Sting-winkle, its "sting" being the proboscis with its boring implement. Like the Murex trunculus so well known to the ancients, and like Purpura, the Sting-winkle carries about a small quantity of fluid capable of dying fabrics violet or purple, and which is probably ejected in the water for defensive purposes. The shell attains a length of about $2 \frac{1}{4}$ inches. The triangular egg-capsules, each containing from a dozen to twenty eggs, are deposited separately but in little groups. The Small Sting-winkle (O. aciculata) is similar in appearance, but of a dark red-brown colour, with more numerous spiral ridges, and only about half an inch in length. The animal is bright red, sometimes flecked with yellow. It has been found only in the Channel Islands, where it is moderately plentiful.

The Purple (Purpura lapillus), commonly known 
as Dog-winkle, and in Ireland as Horse-winkle, is one of the commonest of marine snails. It may be found in abundance high and dry on the rocks after the recess of the tide, where, like the Rough Winkle, it appears to enjoy a prolonged air-bath. Such a habit should expose it to grave dangers from shore-birds, but its shell is thick and stony, and in some places it appears even to have developed something like protective coloration, but whether the cases adducerl would be sufficient to deceive birds is open to question. Its colour is a more or less pure white, spirally banded with orange, red-brown, or brown; but the proportions and intensity of these hues, as well as the sculpturing of the shell, varies greatly. The Rev. A. H. Cooke, M.A., in the Cambridge Nutural History, remarks that "in many cases the variations may be shown to bear" a direct relation to the manner of life. Forms occurring in very exposed situations, e.g. Land's End, outer rocks of the Scilly Islands, coasts of north

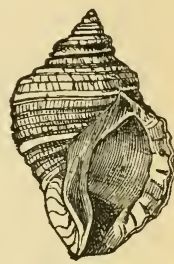

Purple or Dog-winkle Devon and Yorkshire, are stunted, with a short spire and relatively large mouth, the latter being developed in order to increase the power of adherence to the rock, and consequently of resistance to wave force. On the other hand, shells occurring in sheltered situations, estuaries, narrow straits, or even on open coasts where there is plenty of shelter from the waves, are comparatively of great size, with a welldeveloped produced spire, and a mouth small in proportion to the area of shell surface." The same author also thinks that in some places (Newquay, Cornwall, for example) the spiral bands of white and 
colour agree with the veined rocks to which the Purple clings. In this connection it is interesting to note that Linnæus must have been struck by the pebble-like appearance often assumed by this species, for he called it lapillus (a little stone or pebble). As in the case of the Periwinkle, already referred to, this stoniness has relation to the hard knocks littoral species experience in stormy weather, when they may be dashed off the rocks and churned up among actual stones.

The animal is of the pattern usual among the family, yellowish in colour, more or less tinged with brown. It attacks limpets in much the same manner as that adopted by the Sting-winkle; but its farourite food is the Mussel, whose shell can be perforated much more rapidly than that of the Limpet. According to Spence Bate, a mussel-shell keeps the enterprising Purple busy for a couple of days, and then it has the reward of its patience in the succulent flesh of the bivalve. But it must not be supposed that the Purple has its own way entirely in this matter of dainty feeding; it has a Nemesis in the form of a Starfish who is also fond of Mussel. The Starfish may be poetically regarded as taking revenge for the Purple's depredations on the mussel-beds. The Starfish has no means of forcing open the Purple shell as he does with the Oyster, but silently and slowly he creeps to a spot where several Purples are within reach of his long fingers, and laying hold of them with the delicate suckers of his under-side he brings them all beneath his central mouth. Then his stomach is turned inside out and envelops the Purples, which are dissolved out of their shells, in spite of the 
protecting operculum, by the powerful digestive fluid of the Star. The yellow egg-capsules of the Purple are very common objects on rock-ledges; each one contains from 20 to 40 embryos. II. Cailliaud declared not only that these are hatched by the parent, but that the father and the mother take turns to protect and incubate them. This, however,

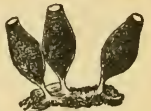

Egg-capsules of the Purple may be dismissed as "embroidery" not warranted by the observations of others, and in absolute opposition to all we know of the habits and customs of those mollusks that deposit eggs.

The Dog-whelks (Nussil) are almost as well known as the Purples, though their habits are different. The animal may be distinguished from those of neighbouring genera by the "tail" of the foot, which, instead of ending in a blunt point, becomes divided and finishes like a pair of tentacles, as shown in the figure of the Netted Dog-whelk ( $N$. reticulata). This species is common on sandy shores all round our islands, where it devours the bait on the "spillers" of the flat-fisher and also that in the lobster-pots. The animal is got up to resemble the sand in its colour and markings; the ground colour is yellowish, over which is thickly sprinkled dots of white and various browns - a pepper-and-salt mixture that assimilates closely to the sand. When at rest, and on the Netted Dog-whelk exposure of the shore by the receding tide, the shell is half-buried in the sand. It is strongly ribbed in two directions, so that a network pattern is produced 
by the depressions, but the prominences are so nearly equal in height that it does not present the bold

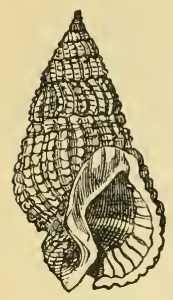

Netted

Dog-whelk aspect of some allied species. The colour is a dull buff tinged with brown, except the inner and outer lips, which are white, highly polished, the outer lip with 12 or 14 tooth-like elevations. The eggcapsules in this case are flattened oval pouches, attached by a short footstalk to the fronds of the Grass-wrack (Zostera). Full-sized specimens measure about $1 \frac{1}{4}$ inch.

The Thick-lipped Dog-whelk ( $N$. incrassata) is little more than half an inch long, entirely different in appearance from the Netted species, the ridges across the whorls being stronger than those having a spiral direction, the colours being brighter, and the outer lip being greatly swollen, white, with an almost black spot in the canal. The colour varies from white or flesh colour to a pale warm brown, the whitish specimens being more or less striped or mottled with brown. It is equally common with the last species all round our islands, but affects stony ground, at all depths between low water and 145 fathoms. The Dwarf Dog-whelk (N. pygmeca) is a less solid shell, the spiral ridges fewer and finer, the colour always yellowish white tinged with tawny, the outer lip even more swollen, white, but brown within, and therefore showing no spot in the canal. It does not attain the length of half an inch, and it is much more restricted in its range. It has been found in the coralline zone on the coasts of Dorset, Devon, and Cornwall, also at 
Connemara, Bantry Bay, Dublin Bay, and County Antrim.

The Spindle-shells (Chrysodomus) are well represented in our seas by seven species. With the Whelks (Buccinum) they constitute the British section of the family Buccinide. This family is distinguished by having the central tooth of the radula armed with from 5 to 7 stout points, and the lateral teeth with 2 or 3 cusps. They have a rather long siphon, eyes at the outer base of the tentacles, a thick spindle-shaped shell closed by a small horny operculum. The Red Whelk or Buckie (C. antiqua) has a solid yellowish or reddish shell with dull surface marked with slight spiral ridges. The thin epidermis has nearly always worn away. It occurs nearly all round our islands, in the coralline zone, but in Shetland it comes into the laminarian zone and descends into deep water below the coralline. The animal is largely used as bait in the long-line fishery, and as human food. Fleming tells us how the cottagers of Shetland make use of the shell as an elegant lamp by suspending it horizontally, filling it with oil, and allowing a wick to lie in the canal, the lighted portion protruding. It owes its name antiqua to the fact that it is plentiful as a fossil in the Crag, where also the "reversed" form with the left-lianded spiral is found. Ordinary specimens are between 3 and 4 inches in length, with a breadth of 2 inches, but occasionally they may be found as long as 8 inches. The eggs are deposited enclosed in pouch-like capsules, flat on the lower, convex on the upper side, and these are attached one to another in overlapping clusters. The Wide-mouthed Whelk 
(C. norvegica) is a paler shell with a larger bodywhorl and mouth, the outer lip expanding outwards, and the canal short. It is only found on some of our northern shores, as those of Yorkshire, Durham, and Northumberland, below the coralline zone. Its average length is $4 \frac{1}{4}$ inches. The egg-capsules are not clustered, but attached singly by the flat side, chiefly to the interior of empty bivalves.

Turton's Spindle-shell (C. turtoni), or Long-neck, is somewhat larger and more solid than the last, more nearly white, tinged with purple, and further differing from it in having a longer spire, flatter whorls, and stronger spiral-ridges; moreover, the operculum is a long triangle with rounded base, whereas in $C$. norvegica it is more rhomb-shaped, with three of the corners rounded. The Slender Spindle-shell (C. gracilis) is more truly spindleshaped. Beneath the yellowish epidermis, which is

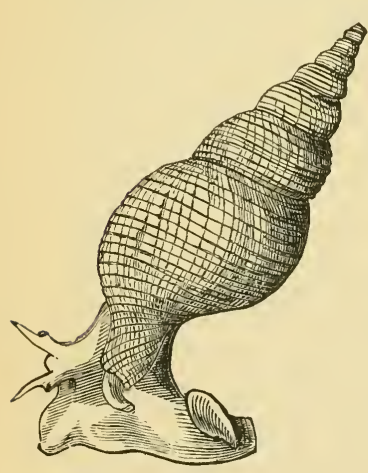

Slender Spindle-shell usually partly grone, the shell is white or nearly so, with some approach to a glossy surface; and the operculum is rather solid and triangular-oblong. Its length is between 3 and 4 inches, with a breadth of $1 \frac{1}{4}$ to $1 \frac{1}{2}$ inches. Although found in from 20 to 145 fathoms all round our islands, it is a rare shell in the south and a common one in the nortl. The capsules are solitary, like those of the last named. A similar but smaller species (C. propinquus) may be distinguished by its "more delicate texture, finer and 
closer sculpture, longer, turreted, and regularly tapering spire, deeper suture, hispid epidermis, less abrupt curvature of the canal, and especially the symmetrical apex" (Jeffreys). It occurs on mud and sand in deep water (15 to 80 fathoms) from Yorkshire to Shetland. The Northern Spindle-shell (Troschelia berniciensis) is distinguished by its spiral ridgeswhich are alternately large and small, being crossed by strie which produce a network especially noticeable on the upper whorls. The thick brown epidermis rises into little points along the spiral ridges, which give a bristly appearance to the shell. The earshaped operculum is rather thin. The shell, which is about $3 \frac{1}{4}$ inches in length, is found on soft ground in the coralline zone on the coasts of Yorkshire and Northumberland.

The White Whelk (Liomesus dalei) is a very rare species in our waters, only a few well-authenticated captures being on record. The shell is oval, spirally striated, of ivory-whiteness, covered by a filmy yellow epidermis; the spire short and blunt, the canal short and open, and the operculum triangular with its nucleus placed on the inner base of the mouth. The teeth on the radula are without the cusps usual in the family. It has been recorded from County Cork and the west coast of Ireland (100 fathoms); from the neighbourhood of the Dogger Bank (40 to 50 fathoms), Aberdeenshire and Shetland (72 to 87 fathoms).

In the true Whelks (Buccinum) the spindle-shape is quite lost and the shell is relatively broader in proportion to its length. The Common Whelk (B. undatum) is so well known that no detailed description is necessary. The whorls are crossed by 
curved broad ribs which are traversed by the spiral lines. This species is widely and plentifully distributed all round our

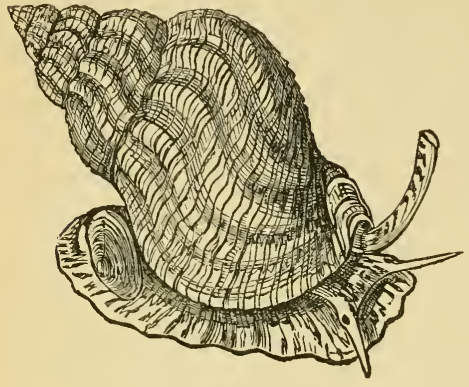

Common Whelk islands, on all kinds of bottoins and at all depths of water. A creature found under so many conditions should show a great amount of rariation, if there is anything in the views already set forth in these pages, in which it has been claimed that the form and substance of the shell has relation to the habitat. Littoral species, we have pointed out, like the Winkles and the Purple have thick solid shells to withstand the hammering of the waves and the pounding of stones; and all those individuals who do not develop a thick shell will be broken up and destroyed, leaving only those with thick shells to survive and perpetuate the species. What is true of the species living under one set of conditions differing from another species living under other conditions, applies also to the individuals of a species that yet live under varying conditions of depth, climate, and surroundings. The var. litoralis lives among stones and on mud in the upper part of the laminarian zone, and consequently is less elongated, broader, more strongly ribbed than the var. flexuosa that dwells on hard ground in the coralline zone in the Hebrides, etc. Then the var. paupercula owes its dwarfed and puny proportions to living in brackish 
water, where probably food is not so plentiful. The var. striate lives in the coralline zone of England, Ireland, and Wales, where the waters are quieter and the rocks less liable to being set spinning; so the thick shell is not developed

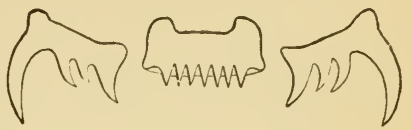

Row of teeth of Common Whelk and the strengthening ribs have to be carefully looked for. The var. pelarica lives out in the deep

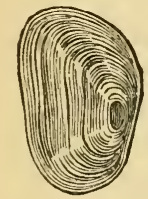
waters of the Dogger Bank, and produces a thin shell of twice the normal dimensions; with a longer spire and a smaller mouth. The Whelk is also given to the production of abnormal forms to which the general term monstrosity is ap-

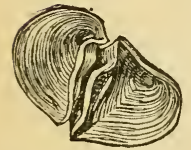

Opercula of Whelk -normal form and double plied. Among these abnormal forms are included reversed spiral, keeled whorls, the spire or the body-whorl greatly lengthened, and the duplication or triplication of the operculum. Double opercula are fairly numerous on the shores of Kent and Sussex.

The egg-capsules of the Whelk are clustered together in masses that vary in form according to the nature of their base. They appear to have given some trouble to naturalists, for John Ellis, the historian of the "Corallines," included them in his book as a species of Alcyonium. Dr. Jolınston later said they resembled

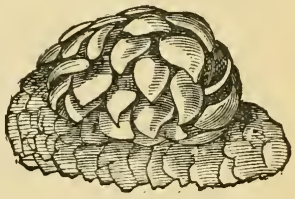

Cluster of Egg-capsules the nest of a humble-bee, and yet more recently Dr. J. G. Jeffreys described the cartilaginous pouches 
as being "of the size and shape of a large splitpea." The split-pea he had in mind must have been abnormally large. Each capsule contains several hundred eggs, but when a few have hatched they begin to feed on the unhatched and on their less robust follow-fry, so that it is computed that only about a seore of young Whelks issue from each pouch. A common form of the capsule-cluster is shown in our figme, but sometimes it assumes a cylindrical form. Besides their extensive use for bait, Whelks form no inconsiderable item in the food supplies of the poorer classes, and they are in a sense trapped for this purpose, carrion being buried under a heap of stones or in a basket. The Whelks have a keen scent, and soon finding out the whereabouts of the bait they swarm over it. They are also caught by dredging for them. Five-and-thirty years ago when a Bill for the extension of the Whitstable Oyster-fishery was before Parliament, it was stated in evidence before a select committee that the Whelkfishery on part of Whitstable Bay yielded a revenue of $£ 12,000$ per annum-the Whelks being used partly for London's food, and partly for baiting the lines of the cod-fishers.

The Shetland Whelk (B. humphreysianum) is a small species, with a shell of more oval shape, less than 2 inches long, thin, somewhat glossy, the sculpturing not being visible to the unassisted eye, and the epidermis being absent. It occurs among the Shetland Isles and the Hebrides; also on the shores of County Cork and Connemara.

The Least Whelk (Donovania minima) has an oval operculum with the nucleus at the side. The shell, 
which is solid, reddish brown in colour, and rather glossy, has the whorls crossed by narrow ribs which are themselves crossed by broad, flattened spiral ribs. It occurs at low water and a little below on the rocky parts of the coasts of Dorset, Devon, Cornwall, and the Channel Isles. It has a trick - unusual among the Whelks-of swimming on

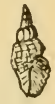

Least Whelk the surface with the foot uppermost. It is not quite a quarter of an inch in length.

The Conelets (Conidce) are well represented by twenty-eight species, none of which exceeds 1 inch in length, and few of them attain half that measurement. They are the representatives of the tropical Cones, carnivorous mollusks with a remarkable arrangement of teeth - we might almost say absence of teeth, for the central and lateral ones have dis-

Sevenribbed appeared and only the marginal ones are Conelet left. The shell is conical or spindle-shaped, with a narrow mouth. The Seven-ribbed Conelet (Hodropleurce septangularis) is distinguished by its 7 waved ribs that cross the body-whorl, and are paler than the red-brown ground colour. The outer lip has a broad but shallow notch, and the amber-coloured operculum is pearshaped. Its length is little more than half an inch. The south-western and western coasts of Britain and the whole of Ireland between 7 and 25 fathoms, are the habitat of this species. The Red Conelet (Bela ruf $(e)$, though similar to the last, has several

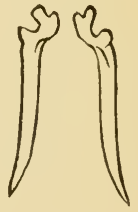

Teeth of Bela points of difference. It quite lacks the slight gloss of that species, the general outline is less conical, the 
whorls are turreted, the ribs are narrow, less strong and more numerous ( 14 or 15 ), the operculum earshaped. It has much the same range as the last named with the addition of the south and east coasts. It is half an inch long, and varies in colour from white (var. lactea) to orange and purple-brown, the latter being the more usual hue, in spite of the name. The Turreted Conelet (B. turricula) Red
Conelet

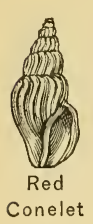
is more distinctly turreted than $B$. $r u f u$. The ribs are pretty equal in height, so that they are not very prominent, and they are crossed by a number of spiral lines. The colour is yellowish white or flesh colour (var. rosec). It is nearly thee-quarters of

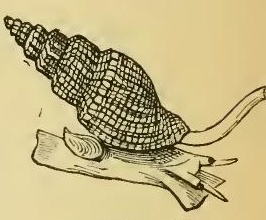
Turreted Conelet an inch in length, and its habitat is sandy ground at various depths pretty well all round our shores. 

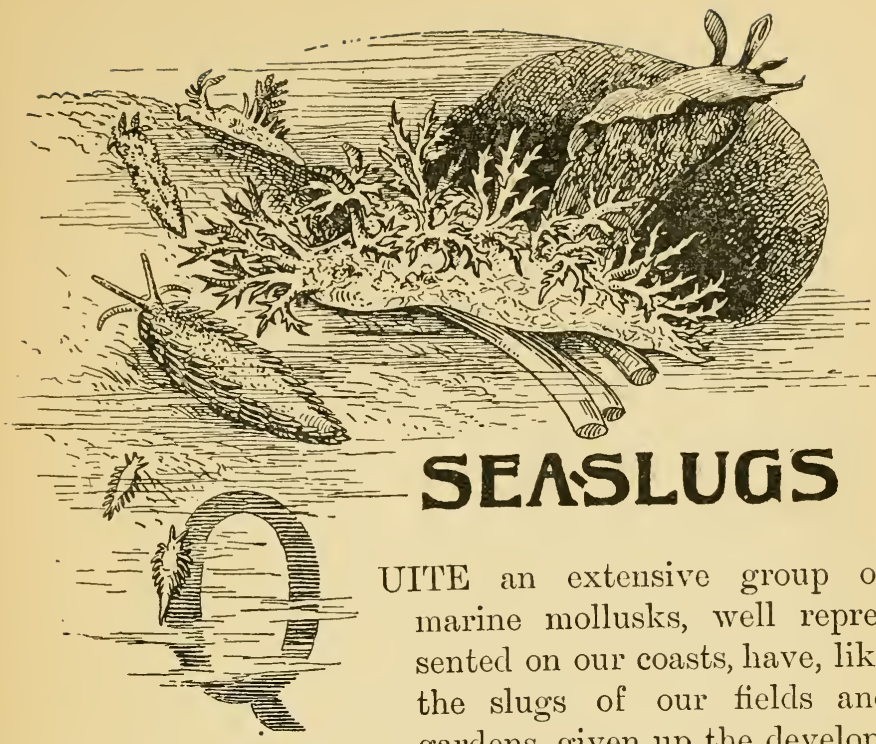

UITE an extensive group of marine mollusks, well represented on our coasts, have, like the slugs of our fields and gardens, given up the development of shells or have restricted their production to small shields more or less covered by the mantle. They are included in the order Opisthobranchiata, which is so-called because the creatures it comprises have their breathing organs behind the heart (opisthen, behind). Each individual combines the special functions of both sexes. The foot often bears side wings, which fold up over the thin shell and protect it. In these cases the shell is variously moditied, its solidity and spiral character being reduced in proportion to the amount of protection it acquires. The comb-like gill is, in some genera, suppressed altogether, or secondary branchix are substituted for it. In some groups the liver emerges from the body- 
mass in a number of little points or long waving plumes (ceratc), which are often coloured by portions of the creature's food or by the bile. These colours appear in different instances to have the effect of disguising the mollusk or of warning its enemies that it is not grood to eat.

Until recently the remarkable forms and colours of these creatures were not consiclered to have any special significance, and it is particularly surprising that even Darwin failed to note the relation of form and habit here, so keen as he always was in such cases. It is true that here he was seeing through the eyes of others. Had he been addicted to the study of marine zoology in his later years he would probably have modified or rewritten certain paragraphs in the Descent of Mun: for example (p. 261):"We can in our ignorance of most of the lower animals only say that their bright tints result either from the chemical nature or the minute structure of their tissues, independently of any benefit thus derived. . . So ... with many animals, especially the lower ones, the bile is richly coloured; thus, as I am informed by Mr. Hancock, the extreme beauty of the Eolidie (naked Sea-slugs) is chiefly due to the biliary glands being seen through the translucent integuments - this beauty being probably of no service to these animals." And again (p. 264): "That many of the nudibranch mollusca, or sea-slugs, are as beautifully coloured as any shells may be seen in Messrs. Alder and Hancock's magnificent work; and from information kindly given me by Mr. Hancock, it seems extremely doubtful whether these colours usually serve as a protection. With some species 
this may be the case, as with one kind which lives on the green leaves of the algæe and is itself bright green. But many brightly coloured, white, or otherwise conspicuous species, do not seek concealment; whilst again some equally conspicuous species, as well as other dull-coloured kinds, live under stones and in dark recesses. So that with these nudibranch mollusks colour does not stand in any close relation to the nature of the places which they inhabit."

Since the reawakening of interest in marine biological investigations, Professor Herdman, Mr. W. Garstang, and others, have published observations on the group which prove that form and colour have a most important bearing upon the habits of Sea-slugs. In the case of deep-sea forms observation under natural conditions is impossible, and even of those species that may be found along the shore at low water much remains to be recorded.

A clue to the probable origin of the Sea-slugs may be found in certain species possessing shells, but which make a point of constructing them of very thin material and covering them with the side flaps from the foot already mentioned. Starting from Acteon-which has a spiral shell partially covered in front by lobe-like tentacles from the head-to Pleurobranchus or Aplysia, whose shell is reduced to a mere flat plate and completely hidden, it is not difficult to understand how with a tendency to increase the covering of the shell, the shell itself would probably be reduced both in size and thickness as the mantle or the foot-lobes, as the case may be, more and more effectually protected the breathing organs. Some species have a spade-like disk, which 
spreads up from the head to cover the base of the shell and so protect it from destruction by the sand through which the creature burrows; others swim in the open waters by means of their foot-expansions; but most of them crawl over seaweeds, sponges, or corallines, much after the manner of the land-slugs. Some of them feed upon seaweeds and then agree with these in colour, whether green, olive, or red; but many devour living sponges, sea-squirts, and zoophytes, and then often reproduce in the decoration of their own bodies the pattern and colour of the surface upon which they are at once feeding and being hidden.

The order Opisthobranchiata is divided into three sub-orders, each divided again into sections, families, and genera. We cannot go into all these divisions, but we will glance at representative species from each of the families found in British waters. The first sub-order is the Tectibranchiata, or those whose gill-plume is covered by the folds of the mantle. They possess a shell, which is more or less enveloped in folds of the mantle or foot, and is often rudimentary. Some of the families included in the first section (Bulloidea) appear to have no claim to be reckoned annong Sea-slugs; but these species, otherwise closely allied to those whose shells have vanished, must be included, and they indicate the probable evolutionary course travelled by the entirely shellless kinds. Take the Actæon-shell (Actcon tornatilis) to begin with. The oval shell is sufficiently solid in structure for its neatness and regularity to have suggested to Linnæus that it had been turned in a lathe, so he called it tomutilis to express that idea. 
But the shell is also large enough to accommodate the entire animal, and it is closed by a horny operculum that fits its irregular mouth. The animal presents a strange appearance with its broad, bilobe-fronted foot, the large broad head bilobed in front and ending in the pair of broad leaf-like tentacles which stand erect or lie back on the shell. The little black eyes are almost hidden-sunk in the skin.

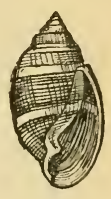

Actæon shell The animal is pale yellow tinged with purple and flecked with white; the shell is coloured with flesh pink, the bands shown in the figure being white. It is a widely distributed species, and though not common cannot be considered rare. Its range extends from extreme low water to about 20 fathoms in sandy bays. Another species, Actwon exilis, was taken in 1215 fathoms on the south-east of Rockall, during the cruise of the Porcupine in 1869.

Many of the species of Bulloidea are known as Bubble-shells because of their thin, inflated character. The Blunt Bubble-shell (Tornatina obtusa) is nearly cylindrical, and looks as though the spire had been cut off. It is only about a quarter of an

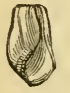

Blunt Bubbleshell inch long, white, but covered by a brown epidermis. The animal is white, with a very short head, erect tentacles at the sides, and the eyes not perceptible. It is tolerably common on the sand and mud of estuaries, where it ranges from low-water mark to about 15 fathoms. There are five other species. They are provided with powerful gizzards in which they crush Hydrobice and other small mollusks, for some of which they have to burrow. 
The Canoe-shell (Scaphander lignarius) is a manywhorled spiral of reddish hue, whose lines and grooves

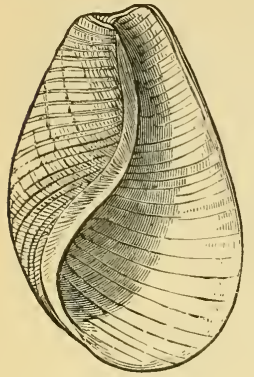

Canoe-shell give it some resemblance to the grain of fir-wood. The yellowish animal has a large shield-shaped head, and the tentacles are united to form a squarish lobe behind it. The eyes are not developed owing to the fact that this mollusk burrows in the sand for its food. It persistently hunts the little Tusk-shell (Dentalium entale), crushing the shell in its powerful gizzard and digesting its contents. Jeffreys says it "does not despise any kind of animal food, from minute Foraminiferc to the Sea-mouse or Aphrodita, the spines of which I found in the gizzard of one individual. Corbula gibba is evidently a favourite morsel; and I have observed Dentalium entalis, Oclostomia rufa, and Ditrupa arietina in other specimens." It occurs generally in the coralline zone in from 50 to 90 fathoms. Another species, Scaphander punctostriatus, occurs at Shetland and the Butt of Lewis in deep water.

The Cylindrical Bubble-shell (Cylichna cylindracea) is distinctly cylindrical, with blunt ends, and about 1 inch in length, though the animal is much longer. Both animal and shell are white, but the latter has a dark yellow epidermis.

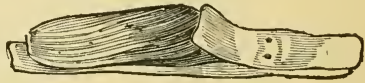

Cylindrical Bubble-shell

It presents a singular appearance with its flattened head and flap, consisting of the united tentacles, ex- 
tending backwards over part of the shell. It is tolerably plentiful along our sandy bays, between 15 and 50 fathoms, where it grubs, pig-like in the sand for food with its flat snout. When irritated it pours out a yellow fluid, apparently to drive off enemies. A smaller species, the White Bubble (C. alba), has been taken in deep water on fine sand off Unst, cylindrical Shetland ( 84 to 95 fathoms); Butt of Lewis (189 to 530 fathoms); West of Ireland (430 to 1366 fathoms).

The Glassy Bubble-shell (Amplisphyra liyalina) is oval, equal at both ends, of glass-like clearness, and about a fifth of an inch long. The whitish animal has a bilobed head, with small eyes, which are withdrawn into the shell when the animal is at rest, but show through. It is a native of the laminarian zone. There are three other species, found in Skye and Shetland.

The typical Bubble-shells (Bulla) are solid, with the crown perforated and exposing part of the spire. B. utriculus has an oval glossy shell, fairly solid yet semi-transparent, with impressed spiral lines. It is only half an inch in length, and is found in muddy

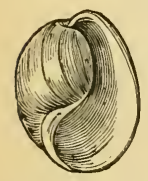

Southern Bubble-shell sand in from 20 to 86 fathoms on various parts of our coast. B. semilevis was taken off the south of Ireland in 1000 fathoms by the Flying Fox expedition, 1889.

The Southern Bubble-shell (Haminea hydatis) is distinguished from Bulla, with which formerly it was associated, by being thin, the crown not perforated, and the outer lip so expanding as it grows that the spire is completely 


\section{$274 \quad$ Shell Life}

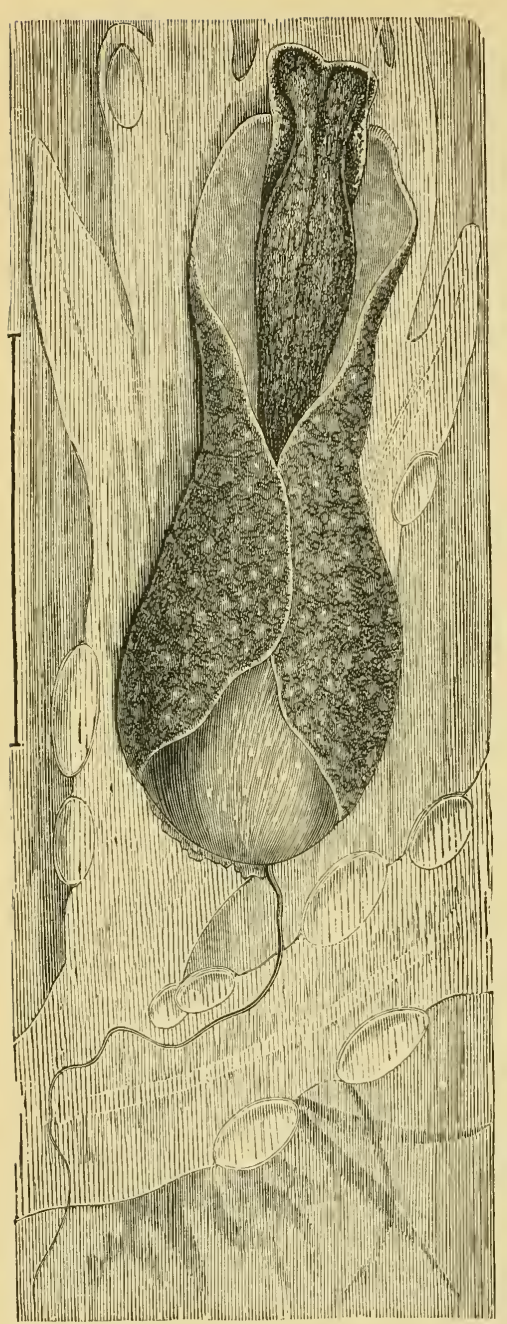

Soft Bubble-shell (twice nat. size) hidden. It is 1 inch long, greenishyellow, except the crown and pillar, which are white. There are large side lobes to the foot, which are turned up on occasion so as to partially envelop the shell. It is a local southern species, found on sandy and muddy shores from half-tide down to about 15 fathoms. It sometimes uses the side lobes of the foot as swimming organs.

The Soft Bubbleshell (Acera bullata) is thin, flexible, almost transparent, white tinged with green. It is almost entirely covered by the side lobes of the foot, and partly by the mantle. The animal is grey or whitish, with minute dots of lighter and 
darker tints, and broken lines of purple-brown. The creature has no tentacles (hence its name, Acerc, without horns), and its small black eyes are not conspicuous. Its gizzard is not so powerful as that of the Canoe-shell, but it is well provided with a number of triangular horny plates for the trituration of its food. When alarmerl it is

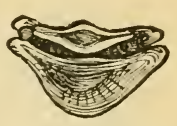

Gizzard-plates of Acera

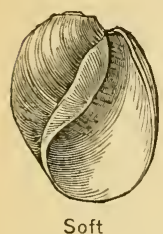

Bubble-shell said to eject a purple fluid. Like Haminea it uses its foot-lobes for swimming purposes. It occurs chiefly on our southern shores and the coasts of Scotland and Ireland, in from 3 to 15 fathoms, on ooze and inud.

The Lobe-shell (Philine aperta) has its delicate, thin white shell completely invested by the transparent white mantle; but though covered in this way, so clear is the mantle that both shell and gizzard may be seen through it. This pellucid covering is dotted with opaque white specks which give a very close resemblance to certain of the Compound Ascidians. This likeness, no doubt, serves its purpose in avoiding destruction. It is said to be capable of swimming by using its

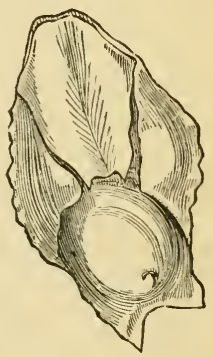

Lobe-shell side lobes. It is common on sandy shores from extreme low water to about 50 fathoms, all round these islands. There are seven other native species, of which the names will be found in the Appendix; among them is the Dotted Lobe-shell (P. punctat $\iota$ ), a minute species only about an eighth of an inch in 
length, found aniong zoophytes, etc. The shell is nearly round, and is marked by an incised pattern

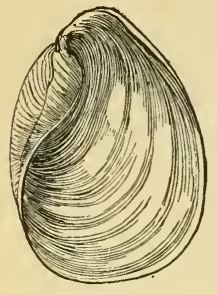

Lobe-shell of dots arranged in spirals. It may be found among shell-sand but is not common. Another form, P. catena, somewhat larger, has the ornamentation in the form of numerous rings arranged in chain-like series. There is a broad zone more transparent than the rest of the shell, and the chainlike marks included in that zone are more strongly defined than elsewhere. An allied species, Colpodaspis pusilla, of which only two specimens had previously been recorded, was taken at Plymouth in 1894.

In the Sea Hare (Aplysia punctata) the shell is reduced to a more or less flat shield beneath the integuments.

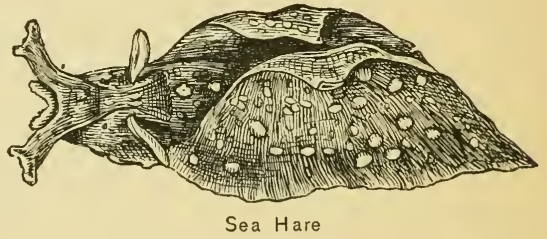

It is oblong, almost transparent, and flexible. The animal is of the remarkable form depicted; the small head connected with the humped back by a long neck.

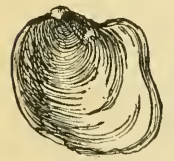

Sherl of

Sea Hare

From the foot two ample lobes fold up over the back, but they may be expanded and used for swimming. In the middle of the back is the gill, covered by the shell and a fold of the mantle which is continued back to form a siphon. The head bears two pairs of tentacles, the hinder pair when erected resembling ears. Viewed from the front, when this creature is gliding, it 
presents a singular resemblance, in miniature, to a hare, and this likeness led our forefathers to bestow the present popular name upon it. But because the Sea Hare when interfered with pours out a purple fluid from the edge of its mantle, they said some unkind things of it - that this fluid caused an indelible stain, and they called it Aplysia (from a and plus, unwashable). They also averred that this fluid was a poison, and that contact with the mollusk would cause all the hair to fall from the head of the person touching or being touched by it. Specimens of various sizes are found to differ greatly in colour, and these have been thought to be different species; but there can be little doubt that in their progress from infancy to maturity they change their depths along the shore and occupy consecutive zones of vegetation to which they closely assimilate in colour. Thus young Sea Hares of a bright crimson colour spotted with white may be found in an extended motionless attitude on the crimson fronds of Delesseria, and then so closely resemble shoots of the weed that it is difficult to distinguish them. When they become larger their colour tones down to a brownish red, then to deep red-brown, much the colour of Dulse (Iridece). Purple-brown, olive-brown, and olivegreen are other colour-phases reached by it, in the course of which it matches with the great tangles and the smaller wracks. When fully grown and fully extended the Sea Hare is 6 inches in length. Sometimes the light spots are entirely absent.

The Sea Hare is a well-protected creature. Not only does its colour harmonise with the weeds upon which it glides, but the purple fluid ejected when 
irritated rapidly creates a cloud under whose shelter it can escape. It has a nauseous scent, which makes it objectionable to many creatures; and when it is contracted it closely resembles the Beadlet Anemone, which is common in the places it haunts and is also objected to as food by most fishes. Not only does the Sea Hare profit by this resemblance to the anemone, but I have found that the mollusk varies its seaweed diet by at least occasionally lunching off a Beadlet. The eggs are deposited in spring among the weeds. For years much confusion existed respecting the identity of this creature; it was generally referred to $A$. depilans, a Mediterranean species, which, however, has been taken occasionally on our south coast. Major A. R. Hunt recorded many examples taken in Torbay in the years 1875 and 1877, some of which weighed from 1 to $2 \frac{1}{2} \mathrm{lbs}$., and had shells as much as $2 \frac{1}{2}$ inches in length.

The Side-gilled Sea-slug (Pleurobranchus plumula) belongs to the section Pleurobranchide, and differs from the Sea Hare in several respects. Its broader foot has no side lobes, there is but one pair of broad tentacles with the eyes at their base, and a large gillplume projects from between the right under-side of the shell and the pointed foot. There is a large internal, oblong, thin and flexible, almost flat shell, but whose nucleus shows that it once had a tendency to spiral growth. The animal is about 1 inch in length, of a pale yellow colour, and its habitat is under stones and in empty bivalves. There is another species, the Rough Side-gilled Sea-slug ( $P$. membranaceus), whose broad foot has a rounded extremity and waved margins, whilst the back is 
covered with little conical points. Both the foot and the flaps of the mantle are used for swimming. The general colour is red-brown, paler above, and with blue-grey spots beneath. The shell is a very thin and flexible transparent plate, similar to that of the last-mentioned species. The coloration of the animal makes it a conspicuous olject, and no doubt it would suffer greatly from the attacks of fishes but for the fact that from its entire surface it can pour out a distinctly acid secretion - so acid, indeed, that blue litmus paper is turned strongly red by it. Acid is much objected to by fishes, and the presence of a very small quantity in otherwise desirable fish-food is sufficient to disgust the fish. When at rest this species frequently folds up the sides of its broad foot over the body, though the foot is not divided into lobes as in some of those already described. Mr. W. Garstang thinks we may find in this habit a clue to the origin of foot-lobes in other species. "In Oscanius [that is Pleurobranchus] the sides of the foot are frequently folded over the body of the animal when at rest, and this habit is still more marked in Haminea. Now the animals are found to live on muddy bottoms, and a broad flexible expanse of foot is obviously advantageous for gliding over such surfaces. But the habits of Aplysice are different. Aplysic lives upon alga, and for creeping over the narrow stems and fronds of seaweeds a wide plantar surface would be not only unnecessary but disadvantageous; so we find that the median portion of the originally broad foot has become specialised for creeping purposes, while the lateral portions no longer form part of the plantar surface, but arise from the vertical sides of 
the median portion, and retain only their power of flapping for the purpose of natation. The series of forms illustrating the evolution of the lateral folds of Aplysia is so complete as to leave no doubt about the truth of this view." 1

The Crowned Runcina (Runcina coronata) is even more distinctly slug-like, for it has no shell. It is of a brown colour with a distinct mantle. There are no tentacles, but there are three slightly plumose gills. It frequents tide-pools and shallow water, crawling over mud and brownish weeds, but avoiding those of green hue upon which its colour would be dangerously conspicuous. It is quite small, full-grown specimens being less than half an inch long.

The foregoing species represent the sub-order Tectibranchiata, in which the mollusks agree in possessing a gill on the right side more or less concealed by a fold of the mantle. The following suborder though called Nudibranchiata is chiefly characterised by the absence of both gill and shell-the latter, however, being present in the embryo. Many species are covered with long fleshy points (cerata), enclosing portions of the liver, and some have the tentacles ringed with projecting sense-organs (rhinophores). They form two groups, the Holohepatica, in which the liver is entire and internal, and Cladohepatica, in which the ramifieations of that organ are generally branehed or twiggy.

Cerata are frequently present in the Holohepatica, but they serve the function of gills only, and are grouped in the middle line of the back; there are

${ }_{1}$ Joumal of the Marine Biological Association, vol. i., n.s., p. 419 . 
usually no jaws. The most noticeable of this section are the Sea Lemons, so-called from the resemblance of one species to the half of a lemon; at least this was the likeness that struck the naturalists early last century. To-day the marine zoologist admires the remarkable mimicry of sponges in their colours and markings. They are elliptical in outline, and more or less flattened. They are completely covered above by the mantle, which extends even beyond the head and foot, and is seldom smooth, being usually thrown up into little tubercles or granules and stiffened by having calcareous spicules embedded in its substance. The eyes are mostly hidden by the integument, and can only be seen by dissection or in the larval stage. The pair of tentacles on the back come through apertures in the mantle, and are covered with overlapping plates; these are the sense-organs (rlinophores). At the other end of the Sea Lemon's back is a rosette formed by spreading leaf-like organs arranged round a central cavity. This is the opening of the anus, and the surrounding leaves are the gills, all connected at their base and capable of being retracted into a cavity in some species, though not in all.

The best-known member of this group, and that to which the name Sea Lemon was first applied, is the Rough Sea Lemon (Doris tuberculata), which is usually about 3 inches in length, though examples may sometimes be found as long as 5 inches. The prevailing colour is pale yellow or dull orange, but it varies from white to orange, and may be marbled or clouded with grey, pink, and green. The encrusting sponges of the genus Halichondria, especially Hali- 
chondric panicea, that form large patches on our rocks at low water and below, and upon which the

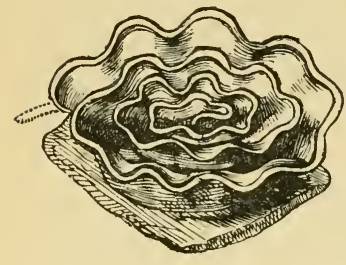

Spawn of Doris

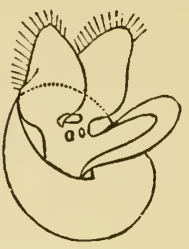

Young of Doris, with shell

Sea Lemon chiefly feeds, equally vary in tint. Where this Halichondria or Crumb-of-bread Sponge grows the Sea Lemon may also be found, and when the slug has moved away from the sponge the former becomes a very conspicuous object, but when upon or beside it the slug has every possible chance of escaping notice. Its back is the same colour as the sponge, and the numerous little warts help the resemblance. The circle of gill-plumes resembles the osculum of the sponge. Not far off in spring we are almost sure to find the remarkable egg-ribbon, of which each individual produces two or three each year. It is a ribbon 9 or 10 inches long and 1 inch broad, with wared free edge, the other being glued to the rock as deposited and coiled in a spiral. Each ribbon is estimated to contain on an average 50,000 ova. There are eight other members of this genus, differing in size, colour, and other points. One of these, the Red Doris (D. coccinea), is figured. It is only about 1 inch long, is of a bright scarlet colour, dotted

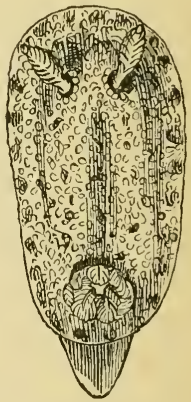

Red Doris with black. It occurs on the Cornish coast, feeding on the sponge Halichondric sanguinea, where it is 
easily overlooked. Johnston's Sea Lemon (D. jolınstoni) is another small species, of a creamy white colour, which harmonises with the paler form of Crumb-of-bread Sponge upon which it feeds. There are dark spots on the back which give the impression that they are deep pores like those of the sponge.

The Hairy Sea Lemon (Acanthodoris pilosa) varies in colour from pure white through yellow and brown to grey and even black. It is covered with soft,

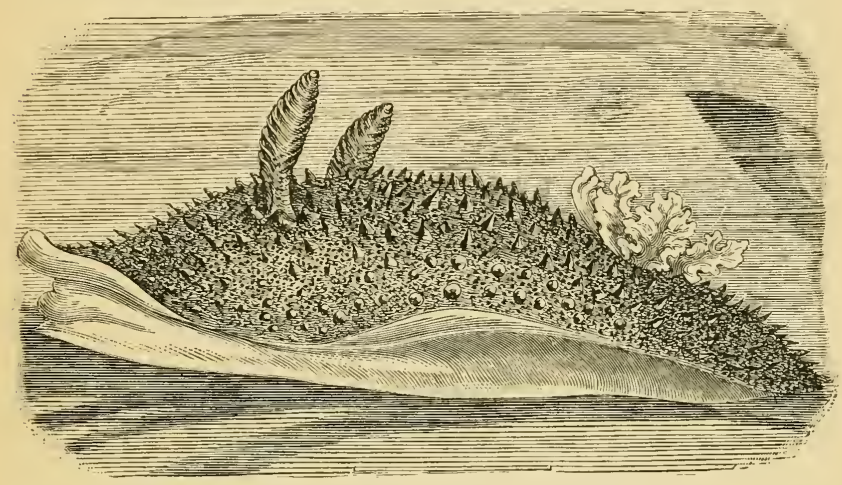

Hairy Sea Lemon (enlarged three diameters)

conical points which give it a pilose character, and make it very sponge-like in appearance. It occurs between tide-marks, but its habits have not yet been satisfactorily made out; though the very spongelike texture of the surface leads one to expect that it will be found to feed on several of the encrusting sponges. A second species (A. subquadrata) is pale and semi-transparent, very squarish at either extremity.

The Rough Doris (Lamellidoris aspera) is less than 
half an inch in length, white, and almost transparent, covered with stalked tubercles that mimic the closed tentacle-crowns of certain polyps. Most of the twelve British species of this genus have similar tubercles, and it is therefore not surprising to find that several of them have been taken in the act of feeding on Polyzoa which they resemble in colour and markings.

The Angled Doris (Goniodoris nodosa) is about 1 inch in length, of a transparent white colour tinged with rose and sprinkled with opaque white or yellow dots. The mantle has a wavy margin, and at the rear it is cut into a number of cusps which suggest the name. A second species, G. castanea, is somewhat smaller, of a reddish-brown tint usually, covered with soft tubercles which are blotehed with yellowish white. This species feeds upon colonies of Compound Ascidians (Botryllus), and when so engaged is very inconspicuous.

The Venus Slug (Idalina elegans) is obviously got up to look like a beautiful anemone. It is about $1_{2}^{1}$ inches long, the back much more elevated than usual, of a delicate pale-rose tint speckled with a deeper shade. The edge of the mantle is drawn out into a number of filaments of an orange colour with yellow tips. The foremost two of these filaments are developed to a large size, and being just below the tentacles look very like an additional pair. The true tentacles and the branchial plumes are all colourer like the mantle filaments, so that they appear to be the waving tentacles of an anemone. In spite of its brilliant tinting Idalina does not, like so many of the Sea-slugs, seek surroundings of similar colour, but goes where it will be highly conspicuous, 
trusting no doubt to the anemone-likeness, coupled with the knowledge of anemones that must pervade the waters-it being sufficient to resemble an anemone in order to discourage would-be destroyers, for the anemones are known to have stinging powers, a tenacious hold, great storage capacity, and a bad taste. Iclalina buries itself in the bodies of Simple Ascidians (Cynthia), protruding its tentacles and filaments in a very anemone-like manner. Alder and Hancock, who never suspected the object of the remarkable forms and colour-ornamentation of the Sea-slugs, describe the discovery of the species. They say:-

"This valuable addition to our Fauna was dredged in the summer of 1853, near Castle Cornet, in Guernsey. From a curious habit, hitherto unknown in this tribe, of concealing itself in the test of an Ascidian (Cyntlice tuberosa), it escaped observation on being taken from the dredge, and was put into our collecting-box as an Actinia [anemone] partially expanded. On examining the contents of the box in the evening, we were delighted to find we had got a beautiful Iclalia, which had crept so far out of its place of concealment as to display its true form. A second individual was afterwards found amongst the contents of the box, with only its head and anterior filaments protruded from the test of another Cynthic of the same species." There are five other native species in this genus.

'The Crested Slug (Ancula cristata) appears, like Idalina, to carry a little anemone on its back. It is not more than 1 inch in length, transparent white except the sense-organs (rlinoploores), and the tips of 
all other appendages, which are bright orange or deep yellow. It haunts the neighbourhood of rocks, where it is not molested by fish, who decline to feed upon it. Whether it is that the appendages produce a false impression of its nature, or whether it is dangerous food and the yellow is a warning colour, is not altogether clear; but it is certain that for one or

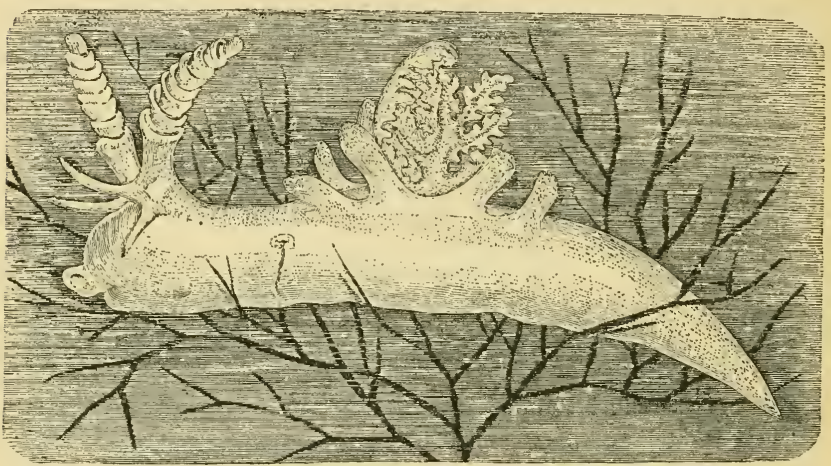

Crested Slug (enlarged four diameters)

both of these reasons the Ancula is a protected species.

Homberg's Triton (Tritonia hombergi) begins that section of the Sea-slugs that are ornamented by a profusion of waving plumes due to their habit of wearing their gills, or gills and liver combined, outside. Homberg's Triton is a giant, for it runs to 6 and occasionally 8 inches in length, though examples of 4 inches are more plentiful. Even these we shall only obtain by the dredge or from fishermen's lines. It varies in colour from white to purple-brown; its back covered with soft tubercles, and along each 


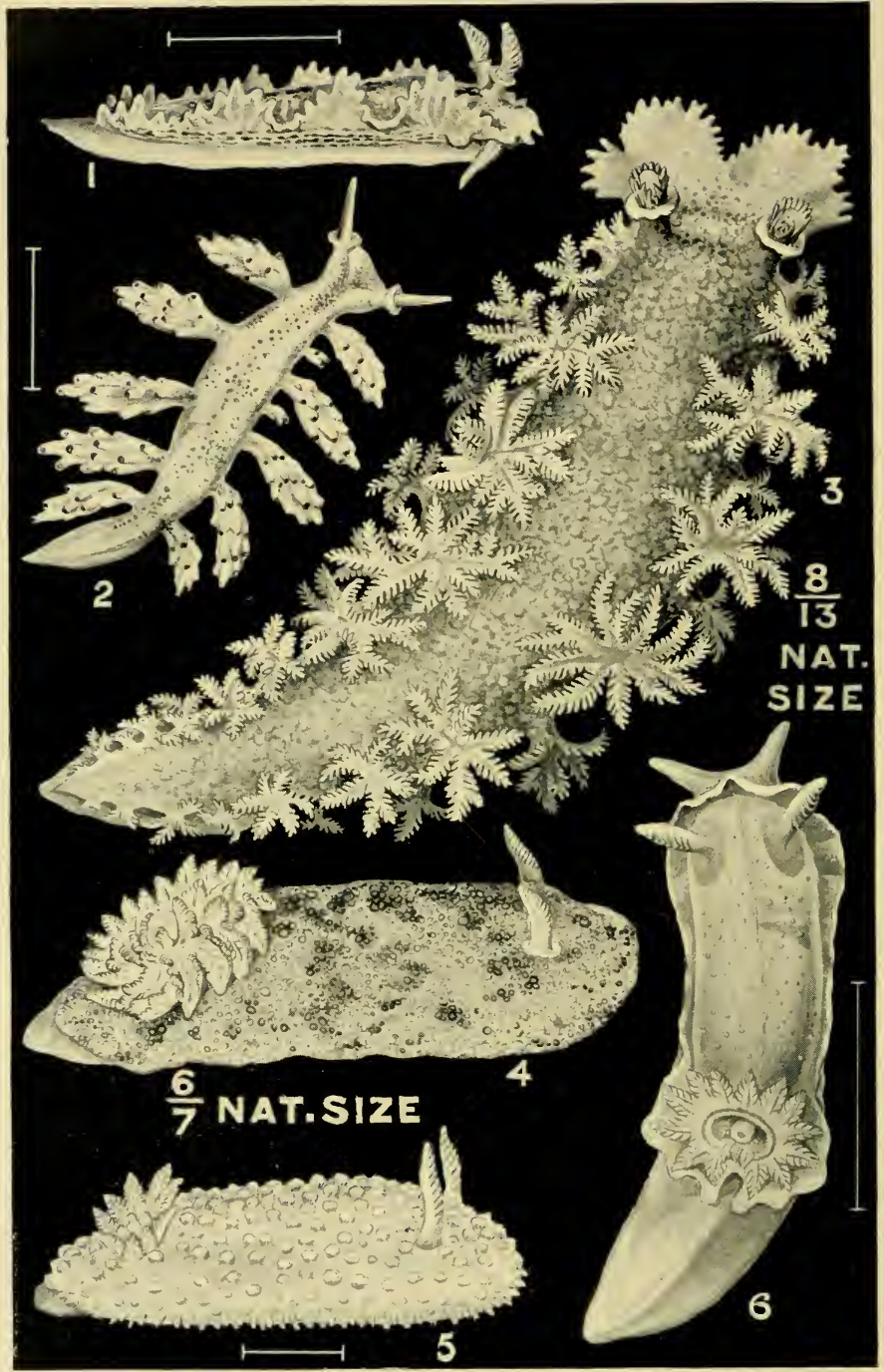

i Marbled Slug; 2 Crowned Sea-nyaph; 3 Homberg's Triton; 4 Rough Sea lemox; 5 Rough Doris; 6 Angled Doris. 
sille from under the edge of the mantle extend many branched cerata, much like curled and crisped fronds of one of the smaller seaweeds. The liver does not extend into the cerata in this genus. The head is sheltered by a lobed and toothed veil. The tentacles issue from large sheaths with spreading mouths, and the rhinophores take the form of a circlet of fern-like plumes. 'This slug is never found away from the Deadman's Fingers (Alcyonium (ligitatum) whose closed polyps are mimicked by the tubercles on the Triton's back. The colour variation in this and some other species appears to have relation to their food; for $T$. lombergi has been experimentally kept without its favourite food, when it lost all its colour and became transparent. There are three other species, of which the best known is the Common Triton (T. plebeia), a much smaller species, found in similar situations to the last named. It is just as variable in colour-just as the Alcyonium is variable, and in the same tintsand its rhinophores equally mimic the half-extended crown of tentacles of the polyp. But plebeic is little more than 1 inch in length, and its head veil, though divided into seven or eight finger-like appendages, is not lobed.

The Gulf-weed Slug (Scyllee pelugica) is a quaint little creature less than 1 inch long, with rhinophores in long sheaths, and two pairs of spreading cerata along the

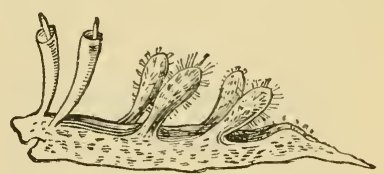

Gulf-weed Slug sides. It is found only on floating seaweeds, and was at one time thought peculiar to the Gulf- 
weed. It is singular among Sea-slugs in having its stomach fitted with plates of chitin to break down its fool. In this species the liver branches out into the cerata, an arrangement that permits of more room for the stomach, and, as we shall see in some other species, helps to protect the slug by showing the colour of the food taken.

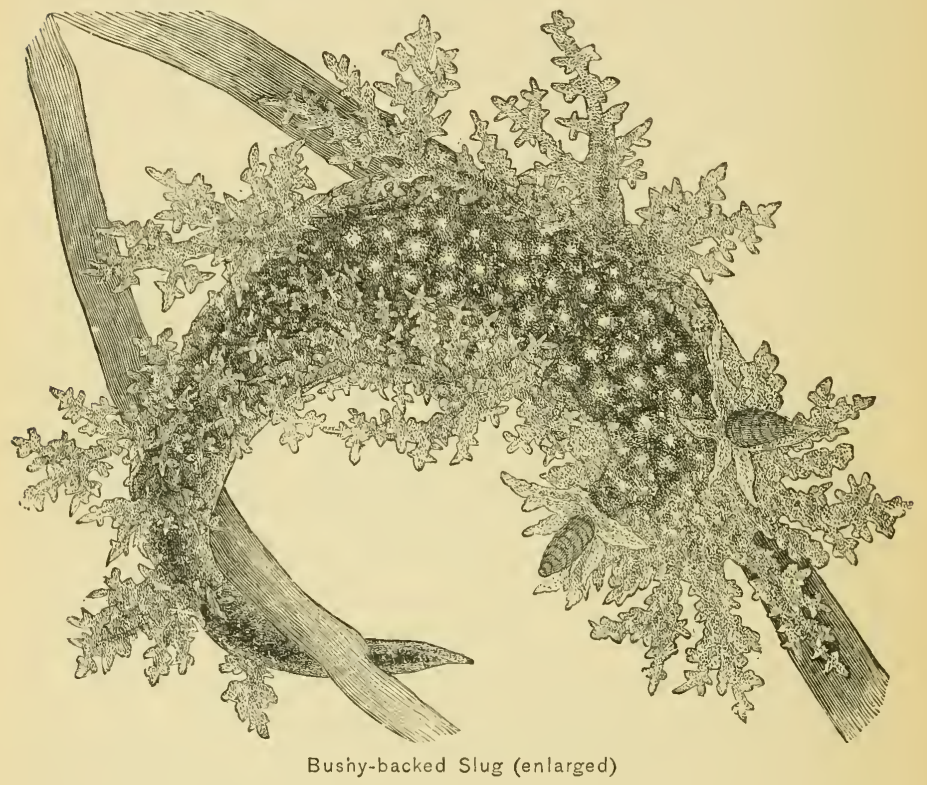

The Bushy-backed Slug (Dendronotus frondosus) is obviously adapted for a life among seaweeds and corallines. The cerata, which form a single series along each side of the back, are branched and toothed in a fashion that makes them to closely resemble some of the small red-brown seaweeds (Callithamnium). 
The sheaths of the rhinophores, and the front of the head, are cut into similar forms. It is about $1 \frac{1}{2}$ inch long. It is said to be highly edible, having nothing in its flavour to displease the taste of the most fussy fish; and therefore its disguise is absolutely necessary to the species. The colour varies, but most frequently it is red marbled with brown and with white or yellow spots. The liver does not extend to the cerata. It occurs between tide-marks and in the laminarian zone among seaweeds and corallines.

The Crowned Sea-nymph (Doto coromata) feeds upon Hydroids and Corallines, and consequently harmonises closely with them in general form and colour. The body is slender, but from each side there extends a number of narrow lobes which bear the bright coloured cerata. The liver is entirely contained in these cerata, which render the animal very conspicuous when taken from its habitat, but this is the under-sides of large stones and rock-ledges where grows Clava multicomis in abundance, and its tentacles and sporosacs are closely mimicked by the cerata and markings of Doto. In deeper water it will be found to preferably affect the Sea-firs (Sertularic and Plumularia). The tentacles are slender, and issue from long vase-like sheaths. There are no true branchix. It is only half an inch in length. D. fragilis is 1 inch long, more robust in form, and coloured a dirty yellow, spotted with white. There are nine pairs of cerata, and these individually bear a very close resemblance to the Hyclra tubc stage of certain Jelly-fishes. It feeds upon corallines, especially that named Lobster-horn 
(Antennularia antennina), at whose base it is fond of resting, and there, no doubt, its erect cerata ningle with, and pass as, the Hydra tubu. There are two other species.

The Marbled Slug (Lomanotus marmoratus) has the head hidden by a slight veil which appears to be a modification of the true tentacles. These are mimicked by prolongations of the foot in front. The rhinophores are club-shaped, and withdrawn at pleasure into sheaths. From the back four or five pairs of rounded and fringed lobes spread out, their colour varying from fawn to reddish or dark brown, spotted with white or brown. It attains a length of $2 \frac{1}{4}$ inches, and feeds upon corallines which it closely resembles in colour and ornamentation. It swims with considerable rapidity. Three other species are included in the British list, but $\mathrm{Mr}$. Garstang considers all four to be but varying forms of one species which he proposes to call Lomanotus genei.

The Plumed Eolis (Eolis pupillosa) is very sluglike, but the back is covered with numerous cylindrical overlapping cerata, arranged in rows of about ten, and with two erect slender tentacles such as in many of the foregoing species bear the organs of smell (rhinophores), but which are plain in this instance. There is, in addition, a pair of ordinary tentacles from near the mouth. The slug attains a length of nearly 3 inches ordinarily, but examples have been recorded measuring 4 and $4 \frac{1}{2}$ inches. Its colour is purple-brown, which harmonises with the smaller wracks growing near low-water mark. The cerata serve a double-nay, a fourfold-purpose: first, they are the breathing organs, oxygenation of the blood 
groing on in their outer layers, but their centres are filled with isolated portions of liver directly comnected to the stomach, whence partially digested food is sent. At the tip each of these cerata is pierced, and through the minute channel the Eol is ejects stinging threads for the annoyance of such creatures as would essay to experiment upon the foorl value of the slug: A fourth use of the cerata is found in their power to mimic the tentacles of the Cave-dwelling Anemone (Sugartice troglodytes). Further, when the Eolis is molested it can throw off some of its cerata to occupy - and probably disagree with - its enemy; this appears to entail little or no injury to the slug, for the place of the missing cerata is soon taken by newly-grown ones. M. Giard has observed, at Wimereux, how closely this species resembles the Cave-dwelling Anemone, but it is difficult

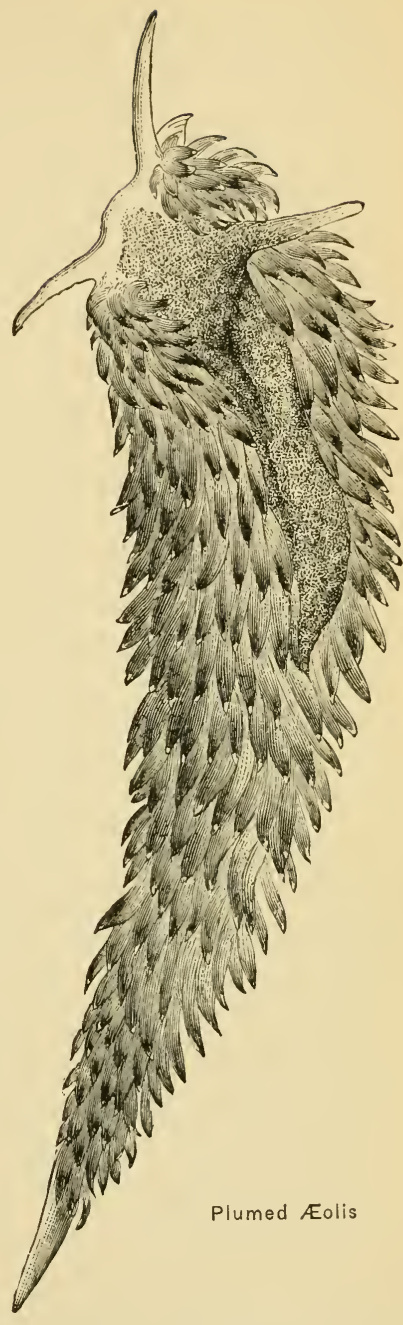
to say which is really the species that profits most by 
the resemblance, for both are well protected. All the Sagartices are provided with stinging-threads, which are shot out from their tentacles with great force and rapidity and are able to pierce the shells of shrimps and the scales of small fishes; in addition they are mostly umpleasant to the taste and smell. This would be a good reason why Eolis which feeds upon anemones should mimic Sugurtira; but the case is complicated by the fact that Eolis, as we have seen, has also stinging cells at the tips of its cerata, and is known to be otherwise unpalatable to fishes. The Plumed Eolis is among the most active of the Sea-slugs, gliding and swimming with equal ease. It is subject to considerable colour variation, and this is affected to a large extent by the colour of their food. We have found that the paler, rose-tinted variety found on the Cornish coast changed in confinement according to the colour of the anemone we allowed it to eat.

Alder's Little Eolis ( $E$. clderi) was first discovered by Mr. W. P. Cocks at Falmouth. It is only about 1 inch long, and has about fifteen rows of cerata on each side. These vary from greenish fawn colour to clark brown with pale yellow tips. Owing to the small amount of liver in the first two rows of cerata, these form a white frill behind the head, which is a very distinct character with this species. On being touched the head is immediately withdrawn into the body, and the cerata are erected, until the creature bears a striking likeness to a small anemono often found in its neighbourhood. E. glauca is much larger than the last (nearly 2 inches), and its broad foot suddenly finishes behind in a sharp point. The 
back is coloured pale red, and the rery worm-like cerata are sage-green tinged with red and spotted with white.

The Dwarf Eolis (Cuthona nana) is only a few lines in length, pale buff on the back, the head and tentacles white. The cerata are also white, but the central tube is red, and a rosy tint shows through; they are arranged in eight or ten close rows. Like other species, it is very sensitive, and when alarmed brings its head and tail together, and so assumes an anemone-like aspect. The Orange-tipped Eolis (C. auranticece) is similar, but larger, attaining a length of half an inch. It has a buff coloured back, and the cerata are in about ten rows. The tips of the latter are coloured bright orange, below which there is a white belt, and then the purple-red of the central tube shows through the transparent remainder. This lower portion is subject to much variation of tint, probably due to differences of food. It has been found from Shetland to Cornwall, feeding on Tubularia, etc.

The Green Eolis (Cratena virictis) is entirely tinged with green, though it is not so distinctly green as some other species. The long slender body is white with a yellow-green tinge. The cerata, which are arranged in nine or ten rows, have pointed white tips, the central tube being some shade of green with darker spots. The first four rows of cerata come close together, the other rows are quite distinct one from the other. It feeds on Sea-mats (Flustra), Lobster-horn (Antennularia), etc. We have no less than thirteen representatives of the genus Cratena. Of these $C$. amonce might easily be mistaken for 
C. viriclis, yet by attention to three points it may as easily be distinguished: the eiglit rows of cerata are more distant, except the first three rows which are close, the head and shoulders are sprinkled with opaque white raised points, and the back and cerata are dotted with dark brown. The Olive Eolis (C. olivacea) is also greenish, but, as the names indicate, dull brownish green. The body is yellowish white, dotted with opaque white, and stained about the head with rosy streaks and a big blotch of the same tint.

The Despised Eolis (Tergipes despectus) is a minute creature, only about a third of an inch in length, but except on this ground in no way deserving its name. The foot is transparent and colourless, to let the colour of the Laminaria on which it glides show through. There are only four cerata on each side, and these are arranged alternately, not opposite as is customary in the family. The head and shoulders are streaked with rose colour, and this extends up the tentacles, and often along the sides of the foot. The digestive track is clearly seen through the back, coloured with pale olive or yellow-brown, taking a bold zigzag course and sending out a branch at each angle to one of the cerata. The centre of these is similarly coloured, but the tip is opaque white, and the intervening transparent band sometimes red. It feeds upon the Hydroid Obetia geniculata, or upon the minute algæ which grow upon its stems. Obelic is abundant on the fronds of some of the large Oarweeds, and as $T$. despectus crawls about them, and the colour of the weed shows through it, little but the digestive track and the connected cerata can be seen ; 


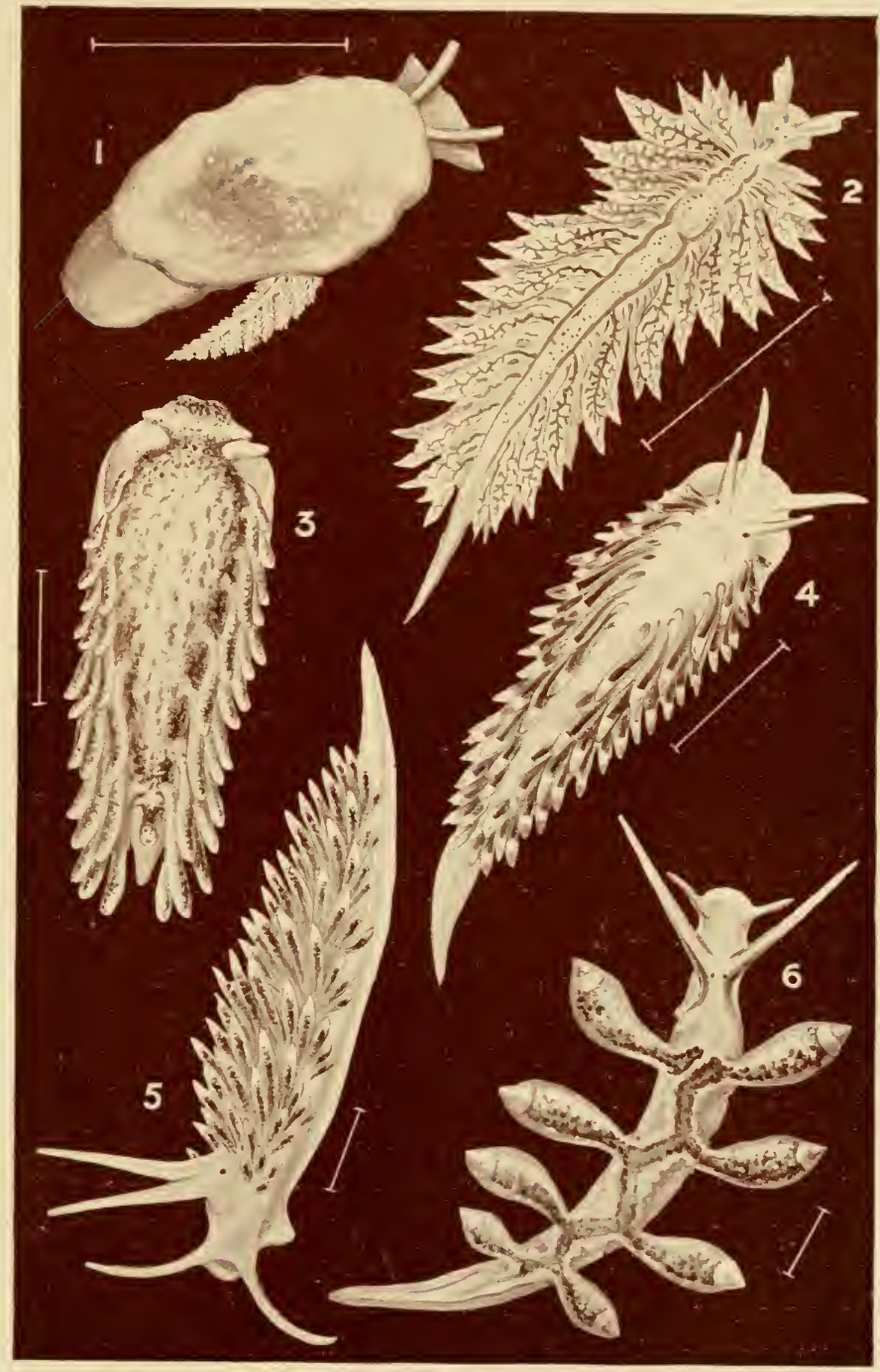

I Side-gilled Sea-slug; 2 Crinison Hermea; 3 Alder's Slug; 4 Orange-tipped Eolis; 5 Green Eolis; 6 Despised Eolis. 

but these almost exactly reproduce the stem and capsules of the Hydroid.

Embleton's Eolis (Embletonia pulclin re) is a more minute example, being only about one-fifth of an inch. It has only one pair of tentacles-the dorsalbut the front of the foot spreads out into lobes apparently to supply the place and functions of the missing oral pair. The comparatively large oval cerata are arranged alternately as in Tergipes, but in this case there are five on the right side and six on the left. They are transparent, dotted with opaque white, but the central cavity is bright red, as also is the digestive track, clearly seen through the back. There are two other species-E. minuta which is very similar but more slender in all its parts; and E. pallida, which has a double series of cerata along each side, and the tentacles closer together. There is a variety (var. grayi) which has adapted itself to fresh, or almost fresh, water, for it is found in the Victoria Docks, London, where it feeds upon the Freshwater Sponge (Cordylophora lacustris).

The Minute Eolis (Galvina cxigua) is a somewhat similar species, with a double row of cerata on each side and two pairs of tapering tentacles. It is found upon Halecium and other Hydroids whose capsules are mimicked by the form and colour of the cerata. It may be colourless with white cerata, or these and the tentacles may be banded with olive-green, whilst patches of the same colour may be present on the back. It is only about one-fifth of an inch in length. There are six other species of this genus found on our shores, of which the Three-coloured Eolis (G. tri- 
color) attains the length of 1 inch. It is semitransparent, white or orange in colour with yellow tips to the cerata, and the central tube violet fading to orange-brown towards the base. It feeds upon Obelict. The Painted Eolis (G. prictr) has the several rows of inflated cerata spotted with opaque white and orange-brown, whilst the centre is pale buff. Farran's Aolis (G. farmini) is pellucid white, the tentacles and cerata tipped with orange. The Belted Eolis (G. cingulatu) is a very beautiful form less than half an inch in length, white blotched with rich olive-brown. The cerata are set in eight or nine distant rows, and have a pale yellow centre and three olive-brown belts. The tentacles are banded by red or reddish brown, and behind them is a patch of olive-brown.

In the genus Corypliellu, of which we have six species, the cerata are not arranged in rows but in ill-defined cluster's.

The Red-gilled Eolis (C. mufibranclialis) is about 1 inch long, very slender, and well covered with slender cerata which are ringed with white near the tip, and whose irregular central tube is scarlet or rose coloured. The Slender Eolis (C. gracil is) has large and conspicuous eyes, the tips of the cerata ringed or patched with opaque white and the centres reddish yellow. In $C$. smaragelina these cerata centres are emerald green; in C. landshurghii they are orange-red. This last-named species, which is, apart from the cerata tubes, of a beautiful transparent pale violet tint, is found on Hydroids in deep water.

The White Eolis (Favorinus albus) is nearly half 
an inch long, pellucid white tinged with yellow, except the dorsal tentacles, which are brown with white tips. A little below the tips these tentacles swell out and then contract again. The cerata are arranged in five or six oblique rows; in some specimens these have an olive band near the tip. $F$. carneus, the other British species, has the body and cerata of a pale rose or flesh colour:

The Crowned Eolis (Facelina coromata) is about 1 inch in length, transparent-white tinged with rose, marked on the head, back, and the front of the cerata with opalescent blue and opaque white. The dorsal tentacles are fawn coloured adorned with alternately complete and incomplete olfactory plates - the "crown" of its name. The cerata are grouped in six or seven clusters or curverl rows. This is one of the most likely species to fall in the way of the novice, and it is certainly not one of the least beautiful. It occurs between tide-marks, feeding upon the Beadlet Anemone, on Lucemaria, various sponges, and its own kind. The colour of the cerata tube varies with this food, but ordinarily it is some tint of crimson. There are three other species, of which one, the Dotted Eolis ( $F$. punctata), is figured. The dark flesh-tinted cerata

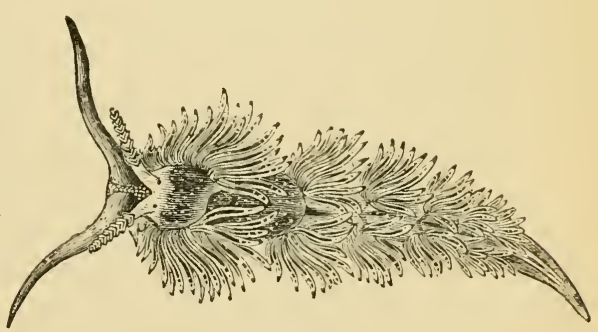

Dotted Eolis are in six or seven large clusters, of which the first and second are separated by a much greater interval 
than the others. The dorsal tentacles bear about two dozen oblique plates, one half of which are imperfect. Both body and cerata are liberally sprinkled with opaque white dots. An allied species, Calma glaucoicles, is said by Hecht (quoted by Cooke ${ }^{1}$ ) to imitate "the ova of certain fishes on which it feeds. Its elongated and depressed form of body, transparent integuments, and silvery grey papillie [cerata] combine to give it a strong resemblance to the spawn of the fish, which is deposited on stones, the roots of Laminaria, etc."

The Noble Eolis (Fiona marina) is long and slender, the tentacles all slender, and the sides of the back irregularly clothed with compressed narrow cerata of transparent buff' with a centre of rich brown and tips of opaque bluish white. The whole creature has a lustrous appearance.

The Crested Eolis (Antiope cristatu) is a deepwater species of a transparent pale yellow tint inclining to buff. The dorsal tentacles are covered with oblique plates which meet behind. The "crest" is found uniting these tentacles, and is arched and lobed. The transparent cerata show a narrow core of brown, and pointed tips of white which gradually changes into ultramarine a little lower. It is $1 \frac{1}{2}$ inches long. The other native species (A. llyalina) is only one-fifth of that size, very transparent, yellowish with red-brown spots and mottlings. The cerata are rugged, and lack the white and blue tips.

The genera Proctonotus and Hero - each represented by a single species - complete the family Eolidiidæ so far as it is represented on our shores.

${ }^{1}$ Cambridge Natural History, vol. iii. p. 74. 
The remaining families are small, and both genera and species few.

The Crimson Hermaa (Hermece bifula) is very slender in proportion to its inch of length, with a row of leaf-like cerata down each side. The body is transparent, tinged with pale yellow, or greenish. The single pair of short tentacles are folded lengthwise, so that they present the appearance of a tube that is split down one side. The cerata are transparent pink, permeated by much-divided branches of the liver, which take on the colour of the food recently eaten. This species and the next appear to be vegetable feeders, and the favourite haunt of the Crimson Hermæa is among the small crimson weeds just below low water. It may commonly be found upon Delesseria, where it is very inconspicuous, for its cerata are just like small shooting fronds of that weed. It has large eyes, and it is apparently very sensitive to changes of light, for a shadow passing over the creature will at once cause it to contract itself, draw in its head and erect its cerata, evidently for the purpose of putting on a fierce aspect. At the same time it ejects a nauseous fluid. The other species is the Green Hermæa (H. dendritica), a much smaller species-about one-third of an inch in length - of pale green colour marked with branching lines of deeper green similar to the reining of a leaf. The slender cerata are in eight rows along each side; transparent, with a sprinkling of opaque white, and with the central vessel green, the contents lobed, so that the cerata appear to be banded crosswise. It feeds upon green weeds such as the delicate Bryopsis plumosa, Codium, Enteromorpha, and Ulva. The 
foot exudes a very adhesive mucus, and it is consequently difficult to dislodge the slug, which appears almost to be part of the plant it feeds upon. It is a remarkable example of the economy of nature when the food serves at once to nourish a creature and to provide it with that protective coloration which renders it invisible to its enemies. In experiments made with this species by Mr. W. Garstang, the slugs refused even to walk over or rest upon red weeds provided for them, no doubt realising by some sense that such a contrast made them too conspicuous.

Alder's Slug (Alderiu moclesta) was discovered nearly sixty years ago by Professor Allman, and dedicated by him to one of the authors of the magnificent "Monograph of the British Nudibranchiate Mollusca." It is remarkable as being almost amphibious. Strictly speaking it is not a Sea-slug, but a salt-marsh slug, as will appear best by a perusal of Professor Allman's account of its discovery near Skibbereen, in County Cork, in a saltmarsh that was only covered by the highest of spring-tides. He says: "The day was bright and warm when I met with this eurious little animal. Many had crept out of the water, and were crawling over the moist fronds of Enteromorplac intestinalis, and seemed to delight in exposing their slimy bodies to the influence of the warm autumnal sun. Others swarmed on the mud in the little shallow pools of the marsh, when their ova were abundantly deposited in the usual gelatinous masses characteristic of the eggrs of the nudibranchiate gasteropods, a fact which is of itself sufficient to prove that this strange semi-marine and even semi-aqueous habit 
was quite natural to our little nudibranch." This slug is about half an inch long, of an oval shape, variably colourer pale yellow, clouded with clusters of small darkgrey spots. The head is small, and the tentacles appear to be represented by mere lobes. The cerata are arranged in six or seven rows alongeach side.

The Green Elysia (Elysice viridis) has its body depressed like that of a leech, but the head is more elevated and

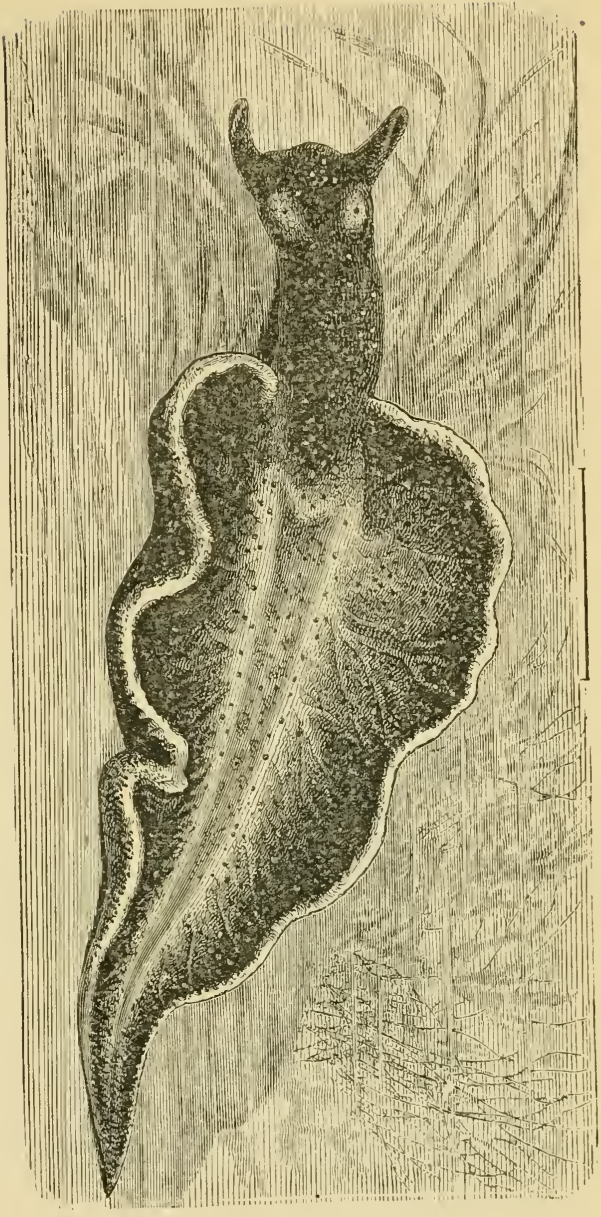

Green Elysia (enlarged)

adorned with a pair of ear-like tentacles in front of the eyes. It is little more than half an inch 
long, and has no cerata; but the sides of the body are expanded into wings in which there are branches of the liver. The foot is narrow, as in Aplysia, in order to fit it for climbing slender stems, and the side expansions are sometimes folded up over the body. Normally this species is greeneither a bright green or dull olive - but in some examples the colour varies to reddish brown. These

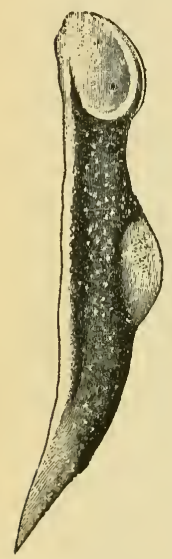

Black

Limapontia darker varieties are found along the shore in shallow water creeping over seaweeds of similar hue.

The Black Limapontia (Limapontica capitutu) is another leech-like slug, and although it is less than a quarter of an inch in length, its dark hue makes it tolerably distinct against the bright green of the finer weeds in the half-tide pools where it is found. The head looks as though it had been cut short in front. The eyes are placed on ridges, and there are no tentacles, neither are there any cerata. There is one other British species, the Flat Limapontia (L. depressu), which is much larger and more depressed.

The Ridged Acteon (Actconia corrugata) is somewhat similar to the Limapontias, but the head is adorned by a pair of conical tentacles, behind which are the eyes, and from which proceed the side ridges indicated in the names.

The Falmouth Sea-slug (Cenia cocksii) is so-called because it was first discovered at Falmouth by Mr. W. P. Cocks, and in selecting names for it Messrs. Alder and Hancock contrived to immortalise both the 


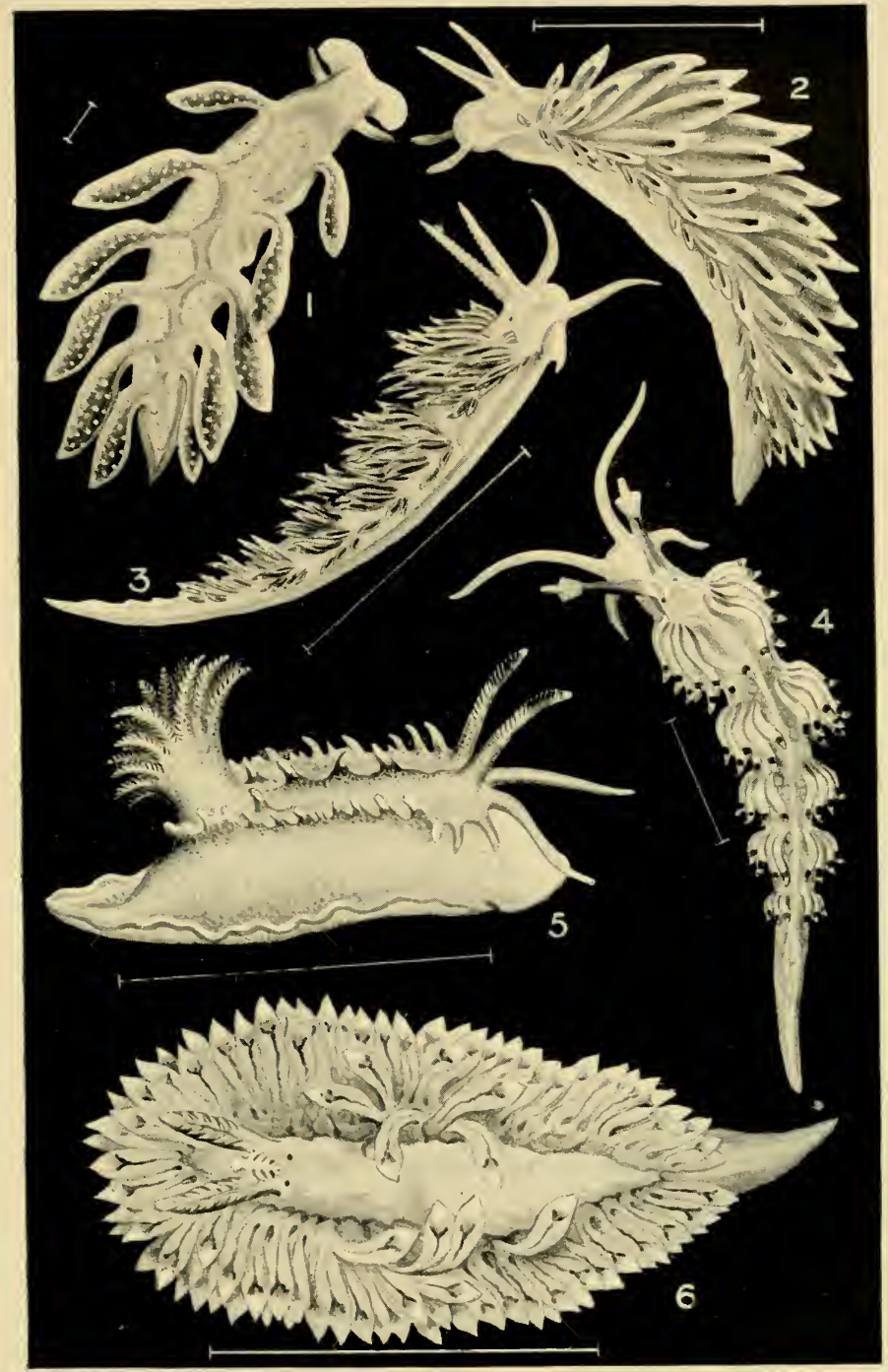

I Eimbleton's Eulis; 2 Three-Coloured Eolis; 3 Red-Gilled Eolis; 4 White Æolis; 5 Venus Slug; 6 Crested Eol.is. 

place (the Cenia of the Romans) and the finder. It is only about a quarter of an inch in length, and is distinguished by an elevated back, a somewhat angular head adorned by a pair of very slender tentacles before the eyes. The back is black, but this gradually fades away on either side until it merges into fawn or yellow.

There is a group of remarkable mollusks scarcely represented in the British area, and which are therefore not of sufficient local importance to have a chapter devoted to them. They are in no sense slugs, but as their natural position appears to be just after the Nudibranchiata we deal with them here. We refer to the Pteropoda, formerly regarded as a Natural Order, but now considered as a sub-order of the Opisthobranchiata. They are Gasteropods in which the side expansions of the foot have been developed into fins, to fit them for a life at the surface of the ocean. On this account they have

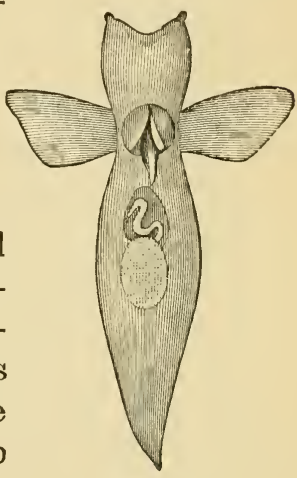

Clione (somewhat enlarged) been called the Butterflies of the Sea, but having regard for their greater activity towards night, it would perhaps be less incorrect to call them Sea Moths. In infancy all are provided with shells, but many dispense with these ere they attain maturity; on the presence or absence of a shell in the adult the primary classification of the group into two sections is based. Those in which the shell, or a covering of cartilage, is always present are known as Thecoso- 
mata; those which in the adult state have neither shell nor mantle constitute the Gymnosomata. They never come near the shore of their own will, for they are purely pelagic, but many come to land nolens volens in storms and are destroyed in thousands. None of them can be said to be truly British, but the remains of three or four species have been taken in sufficient numbers and with such frequency that they must be included in the British list.

Limacina retroversa is one of the shell-bearers. Its body is more or less tinged with purple, and the so-called "wings" of the foot are very large, with a supplementary pair one-third of their size.

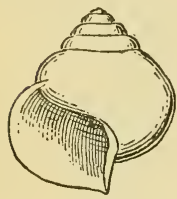

Shell of Limacina The shell is extremely thin and fragile, almost transparent and clear, but with a suggestion of yellow when tenanted by the living mollusk; there is a tiny glassy operculum. It is a common and abundant species, and its empty shell may be found in sand on all our shores where strong currents wash up material from the deeper waters far out. But the living animal has been rarely found in our waters. Forbes found it to the north-west of Skye in 1850; Canon Norman and J. G. Jeffreys took it in Shetland waters in 1861 and 1867 ; and $\mathrm{M}^{\prime}$ Andrew caught several about fifteen miles south of Mizen Head, Ireland. Their position in swimming and floating is reversed-the shell below, the foot expanded above. Their so-called flight is a movement straight up through the water by jerks, effected by depressing the wings. By keeping these organs spread they can remain suspended at the surface or at some distance below it, but on folding 
the lobes they drop to the bottom. A second species $L$. helicoicles, was found dead at the bottom off the west coast of Ireland (lat. $56^{\circ} 44^{\prime} \mathrm{N}$. : long. $12^{\circ} 50^{\prime} \mathrm{W}$.) by the Porcupine Expedition, 1869.

Clio pyramidata has a beautiful triangular shell, of the thinnest crystal, and half an inch in length. It has been dredged to the north-east and north-west of Shetland in water from 60 to 84 fathoms, in one case with the animal in the shell. But in 1869 the Flying Fox off the South of Ireland, found it in abundance at the surface.

The only other species that can urge a slight claim to be regarder as a Britisher is Clione limacina,

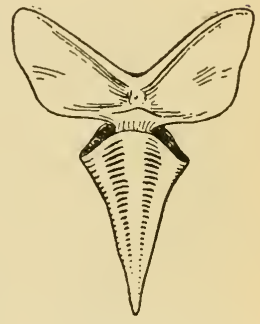

Clio pyramidata which belongs to the shell-less section and has a distinct head. It is an Arctic species, and one of the constituents of the food of whales. Leach captured a living example on the coast of Mull ninety years ago; M.Intosh reported it in considerable numbers at St. Andrews in 1887, and T. Scott took a specimen at Inchkeith in 1889. 


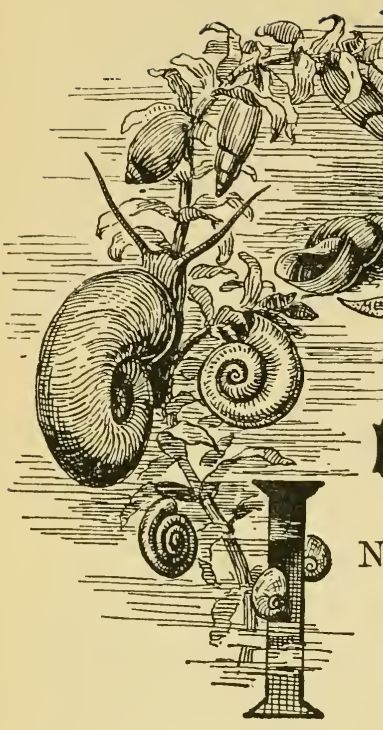

\section{POND-SNAAILS}

$\mathrm{N}$ spite of the title of this chapter we are bound by the natural affinities of the animals to include in it some species that have nothing to do with ponds, one that is an undoubted land-snail, several that belong to the seashore, and one that is somewhat amphibious. But all our pond-snails will be included also, and as these make up the greater part of the chapter its title will probably be forgiven as the most appropriate in the circumstance.

The Least Herald-shell (Caryclium minimum), which is found among moss and dead leaves in woods, will serve to introduce us to the order Pulmonata, though we shall find the characters of the order more visibly manifested in following species. The members of the order are distinguished by the possession of two pairs of tentacles, and by their breathing air by means of a carity 
formed by the union of the front edge of the mantle with the neck of the snail. The sexes are united in each individual; the shell may be developerl or not; and there is no operculum. The order is divided into two sub-orders-Basommatophora, or those that bear their eyes at the base of the upper tentacles; Stylommatophora, or those whose eyes are carried at the tips of the upper tentacles. There are other differences: for the moment we will be content with stating the characters of the first sub-order. The tentacles cannot be retracted, the teeth are in many rows across a radula, there is always a shell and it is always external. The genus Carychium is included in the family Auriculida, whose members have conical shells, and as a rule they increase its roominess not only by adding new matter to the lip, but also by absorbing the internal partitions, and to make up for the want of an operculum they develop the tooth-like processes across the mouth of the shell shown in the figure above. The breathing organ is developed into a true lung, for the air-chamber is lined with delicate vessels through whose tissues the circulating blood can absorb oxygen.

C. minimum has a shell about one-eighth of an inch in length; but in spite of its small size both shell and animal are beautiful. The latter is transparent, with a triangular snout, thick tentacles, and prominent black ejes. The shell is almost spindleshaped, transparent white, glossy, with an ear-shaped mouth obstructed by two strong teeth. The umbilicus is represented by an oblique slit. It is fond of damp places, and must be sought under stones or felled 
timber, among moss, dead leaves, and grass roots. It is pretty generally distributed throughout the United Kingrdom and in the Channel Islands, and is fairly common. According to Moquin-Tandon it can endure prolonged submersion in water, although strictly speaking it is a land-shell, but in all probability its conversion to a terrestrial life is of comparatively recent date.

The Mouse-eared Alexia (Alexia myosotis), as will be seen from the figure of the shell, is very close to Curychium. It is one of a little group that have not yet lost their fondness for salt water, though this species has taken to salt-marshes and mud-flats, where it feeds upon the rotting démis of seaweeds. The shell measures about a third of an inch, and varies from yellow to deep brown in colour; the mouth, which is supMouseeared Alexia posed to resemble a mouse's ear, bears two teeth on the pillar, with often a tubercle beside them and a similar projection from the outer lip. Another species (by some regarded as a variety only), A. denticulatu, lives in rock-crevices and under stones between tide-marks on the open seacoast. This form has a much paler, often white, shell, with a thickened outer lip which is furnished inside with several tubercles, in addition to those on the pillar. The Two-toothed Leuconia (Leuconia bidentatus) is a very similar littoral species, but it is smaller (one quarter of an inch), and of ivory white colour. The outer lip has a thin edge but is thickened within, and the inner lip has two teeth of different size. The smaller tooth is near the base of the pillar and the larger a little above it. 
The Little Ear-shell (Otinc otis) is like a copy in minature of the shell of Velutina (see page 219), but the animal is different. When gliding over the little black lichen that grows abundantly over the littoral rocks, its shell is evidently several sizes too small to shelter it, but when the tide goes out, and the lichen dries up, Otince shrinks and contrives to get efficient shelter. It is thin, and almost transparent, some shade of red-brown tinged with purple. Its measurement is only about one-tenth of an inch; so it requires to be carefully sought.

We are now done with the seashore for a long interval, but we may leave it in the pleasantest manner possible, by way of one of the fresh-water streams that come down the valley and get lost in the sandy beach. Here, on the stones in the bed of the stream, we shall find a tiny limpet-shaped shell closely adhering in defiance of the strong current of fresh water for ever rushing over it. This is the Fresh-water Limpet (Ancylus fluvicatilis), so-called in deference to the shape of the shell regardless of the nature of the mollusk that made it. The resemblance of the shell is to Helcion not Patella, but the animal is widely different from either of these species, and shows near relation to the common Limnæids of our ponds. It has a large head with short cylindrical tentacles, the eyes at their triangular bases. The oval foot is almost as large as the mouth of the shell. The thin

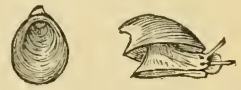

Fresh-water Limpet shell is yellowish grey, devoid of gloss, and covered by a thin epidermis; the spire turned slightly to the right, whilst the animal is twisted to the left. It 
is about a third of an inch in length. The animal feeds upon the minute vegetable growths that cover the stones, and is especially fond of the aquatic moss, Fontinalis antipyretica. It does not restrict itself to the stream, but may often be found on the wet mossy rocks above. The stomach is said often to contain fine particles of sand, which are thought to be taken to aid digestion much as fowls fill their gizzards with gravel. It has been detected in the act of getting a free passage to fresh streams and waters new by clinging to the water-beetle Acilius sulcatus, which uses its wings for a similar purpose. The subjoined figure will give an idea of the character of the teeth in this species. There

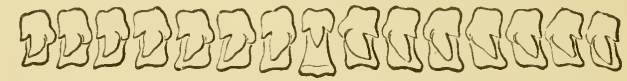

Part of a row of teeth from the radula of Fresh-water Limpet

are 120 rows, and each row contains a central tooth and 37 lateral teeth on each side of it-a total of 9000. The Fresh-water Limpet is generally distributed throughout these islands. Its eggs are deposited in little oval capsules, each containing eight or ten.

The Lake Limpet (A. lacustris) is a somewhat smaller and more local species, with a more oblong shell, the spire of which is distinctly twisted to the left, whilst the animal is turned to the right. It inhabits lakes, ponds, canals, and slow rivers, adhering to the under-side of floating and submerged leaves of water-plants.

The genus Ancylus is included in the family 
Limnæide, but the more typical characters of that family are seen in the genus Limnova, where both animal and shell are twisted to the right. They are familiarly known as Pond-snails, all the species being restricted to still, shallow waters. The animal has a prominent head with short, flattened, triangular tentacles. From the distant position of the sexual organs one individual may be united with two others at the same time, and it is by no means unusual to see a number of Pond-snails so connected in one chain. The character of the teeth on the radula may be gathered from this figure of the middle portion of a single row; there is a small central tooth with 59 laterals on each side, and there are

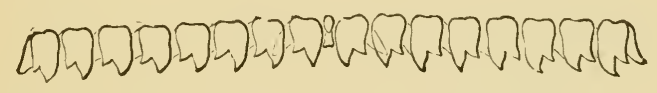

Portion of row of teeth from radula of Great Pond-snail

110 such rows on the radula, making a total of 12,210 .

The Great Pond-snail (L. stagnalis) offers the advantages of being larger than, and readily distinguished from, the other members of the genus, so will serve as a good type. The animal is coloured yellowish grey; its head large and adorned by long tentacles which end in slender points; the broad foot edged with yellow. The yellow-brown or greyish shell is a couple of inches long, and half as broad; thin when compared with marine shells, but tolerably solid for a Pond-snail. It is corered by a thin epidermis, which frequently decays on the older portion of the shell and allows the 
carbonic acid of the pond to attack the lime of the shell material. It is a general feecler, but with a distinct bias in favour of animal matter. It will even attack and kill newts and sticklebacks, whose size and agility might be considered more than sufficient to save them from such a fate. It also destroys the larre of water-beetles in the same way; but the mature Dytiscus retaliates by eating stagnalis. It must be confessed, too, that the Great Pond-

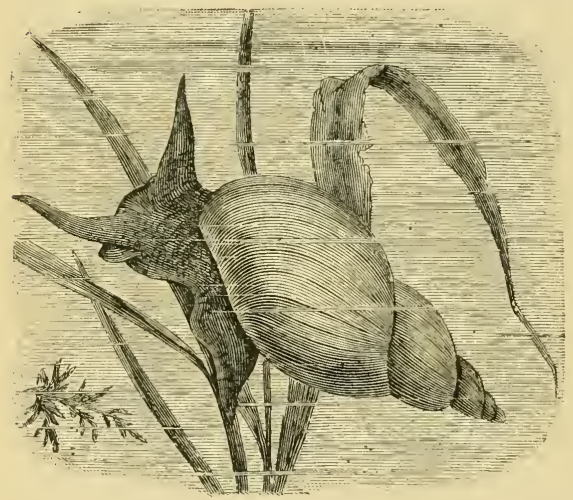

Great Pond-snail snail is, at least occasionally, a cannibal, destroying young individuals of its own kind. Its movements are graceful, whether it be ascending or descending aquatic vegetation or gliding inverted along the surface of the water.

They frequently come to the surface to discharge the effete air in the lung-chamber and take in a fresh supply. Full-sized specimens of the Great Pond-snail need be sought only in large ponds; and it appears to be a well-established fact that the rate of development and the ultimate size attained are in direct proportion to the volume of water in which the individuals have lived. Karl Semper set this point beyond dispute by separating the fry from a single batch 
of eggs, and rearing them in volumes of water varying from 100 to 2000 cubic centimetres, with a full supply of food in each, and all other conditions equal and as natural as possible. At the end of sixty-five days those specimens reared in the maximum amount of water were just three times the length of those in the minimum volume, and the intermediate ones in proportion. Its eggs are deposited in almost cylindrical masses, often curved,

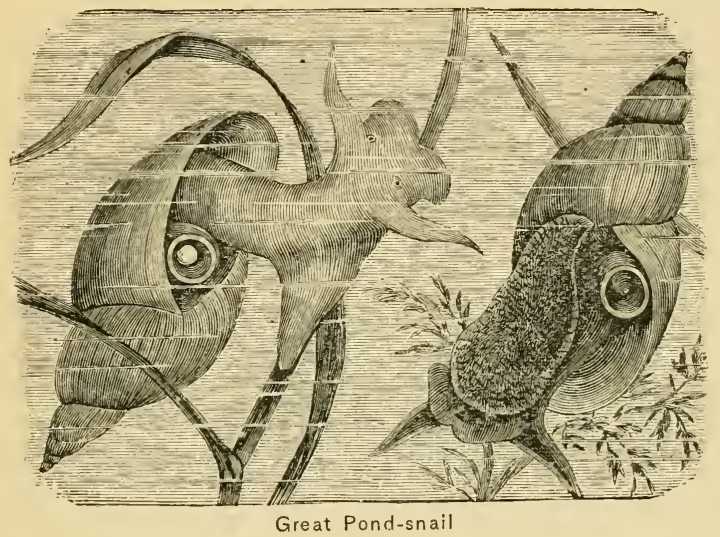

containing from 50 to 120 eggs. Half-grown specimens are much more slender than the adults, the shell nearly transparent, and the mouth contracted. The Great Pond-snail may be found in still or slow waters throughout the country.

The Narsh Limnæa (L. palustris) has a more solid shell, but its body-whorl is not nearly so swollen in proportion, so that the length and breadth measurements are as 5 to 2 . The shell is dull 
yellowish brown in colour, and its oval mouth has a thickened outer lip. It is usually more or less coated with mucl, owing to its life being

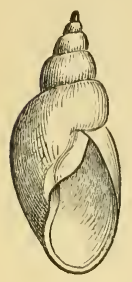

Marsh

Limnæa spent in shallow pools, ditches, and bogs. The animal leads a rather inactive life, and resents disturbance. The shell measures 1 inch.

The Dwarfed Limnæa (L. truncatula) might easily be taken on a superficial view for a young specimen of L. palustris, but the whorls are turreted (that is, somewhat flattened above) and with a nearer approach to glossiness. There is also a distinct umbilical cleft. Its length is half an inch, and its habitat is on the mud beside pools and ditches, where it appears to feed on the low scum-like alye that grow in such situations. We have found it near the base of Cornish cliffs within a foot of highwater mark, and where it must have been constantly splashed by salt water. Fresh water

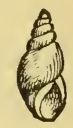

Dwarfed Limnæa trickled through cracks of the limestone and supplied nourishment for a yellowish-green alga apon which truncatulc appeared to feed, and with which most of the shells were coated. Viewed from the human standpoint this species is the most important of the whole order, for could it but be entirely exterminated there would be some hope that Rot, that scourge of the sheep-farmer, could be got rid of. It would be foreign to the purpose of this volume to enter fully into the history of the Liver Fluke (Distoma hepatica) which causes this discased condition of the sheep, from which it is said no less than three million animals perished in this country during the 
winter of $1879-80$; but we may briefly explain that millions of the eggs of this pest are voided with the excrement of diseased sheep. If such an animal is turned out on a marshy pasture there will probably be an abundance of $L$. truncatula among the grass. If not, all those eggs will be wasted. They will hatch, it is true, regardless of the presence or absence of snail-life, but unless the embryos meet with this Limnce within eight hours after hatching, they perish. No other snail-not even another species of Limncea-will serve their purpose, but if truncatule be there the first step in the destruction of a flock of sheep may be said to have been taken. The Distoma that is to fulfil its mission enters the branchial chamber of the mollusk, and there attains a stage of development that fits it for a different life. About midsummer, when the grass has all disappeared from the uplands, the sheep are turned into the marshy bottoms where there is still green feed. About the roots of the grass there are also many truncatulas with their branchial chambers well furnished with Flukes. Sheep are fond of snails; and this would appear to be a fact well considered in the Distoma's plan of campaign. Snails and grass are eaten, and the Flukes, proof against the action of the digestive fluids, find their way to the sheep's liver, and begin to set up that condition of things which the farmer knows as "Rot." Other species of Distoma that cause similar trouble to vertebrates, spend their earlier stages in the bodies of snails. Thus, $D$. endolabum selects L. stagnalis as a wet-nurse, and may pass its second stage in the same species, or may change over to 
the fresh-water shrimp, or to a caddis-worm; finally, however, it gets into the frog. Another species is fatal to bats, but works out its destiny in a manner similar to the progress of $D$. hepatica. First it patronises $L$. stagnalis or Planorbis corneus; its second stage is passed in certain winged insects connected with ponds in early life, and these happen to get snapped up by bats, who thus take at one gulp the bread of life and the seeds of death! Tennyson's well-known line- "Nature, red in tooth and claw," suggestive though it be, is not adequate to express the fulness of the tragerly.

The Smooth Pond-snail (I. glabra) has also some resemblance to a small palustris, but though its length is three-fifths of an inch its brealth is only one-fifth; the shell has therefore a more cylindrical appearance, and is thinner and distinctly glossy. The mouth of the shell is pear-shaped, and at a little distance within strengthened by a broad white rib. There is an umbilical cleft, but it is very minute. The animal is very shy, and seldom ventures from the bottom or sides of its ditch or shallow pool to float along the surface. It is fairly distributed over England, and occurs in a few places in Ireland, Wales, and Scotland, but though plentiful where found at all, it is extremely local.

The two remaining species of Limncece are distinct from the others by reason of their short spires and large mouths. The Ear Pond-snail (L. curicularia) is the larger of these, and its body-whorl is proportionately so enormous that the spire seems merely a little ornament added to the top. The 
animal is yellow or brown with a greenish tinge, dotted with black and white. The tentacles are broad and diverging, and the eyes small. The foot is bordered with yellow. The yellowish shell is semitransparent and glossy, bearing in addition to the distinct lines of growth delicate spiral ridges. The body-whorl accounts for quite five-sixths of the

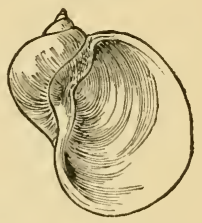

Ear Pond-snail entire shcll. The umbilicus is represented by a slight cleft. It is an inhabitant of stagnant and sluggish waters, where it usually keeps near the bottom and exhibits little activity, only occasionally swimming at the surface. One little characteristic may help the observer to distinguish smaller specimens from some of the varieties of other species. Limnæids usually carry their shells with the spire pointing backwards, but auricularia carries its shell with the spire at right angles with the body and the outer lip well covering the back and head, leaving the tentacles above exposed. The shell is a little more than 1 inch in length, and a little less than 1 inch in breadth. It is quite a local species, and though widely

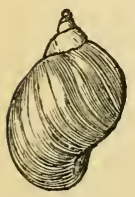

Wandering Pond-snail distributed in England and Wales, its occurrence in Scotland and Ireland is very limited.

The Wandering Pond-snail (L. peregra) is the second of those whose shell is nearly all body-whorl, though here it accounts for only three-fourths of the whole. The animal is yellow-grey tinged with green and black and speckled with whitish and black specks. The 
shell is thin, semi-transparent, yellow-brown, with a large oval mouth. This is the Pond-snail that everybody knows, because it is ubiquitous wherever there is slow or stagnant water. Sometimes it turns up at some distance from the water in damp meadows, and has even been detected climbing willow-trees. Like $L$. stagnalis, the Wandering Snail is liable to great variation, dependent no doubt on the area of the pond, the chemical character and temperature of the water, the quantity and quality of food available. Some of these varieties differ considerably from the type. It is a restless creature when in the water, always on the move, but out of the water, where it spends a good deal of time, it is usually very quiet, being then mainly concerned with the fabrication and hardening of additions to its shell. Like $L$. stagnalis it declines to be restricted in its liet, even practising cannibalism when overcrowded. It may be seen industriously assisting in the dissolution of a superfluous dog that has been consigned to the waters attached to a brick. When drought comes they protect themselves by burial to a depth of several inches in the mud whilst it is still soft. A thick coating of ice on the pond does not stop their activity below, and they may even be frozen in solid ice, apparently, without prejudice to their vitality. It is very prolific, as may be gathered from its abundance, and it is estimated that each individual produces about 1300 eggs in one season. These are deposited in cylindrical masses of clear jelly. The shell in the numerous forms varies from half to one inch in length.

The Glutinous Snail (Amplipeplea glutinosa) is 


\section{1}

$\rightarrow 3$
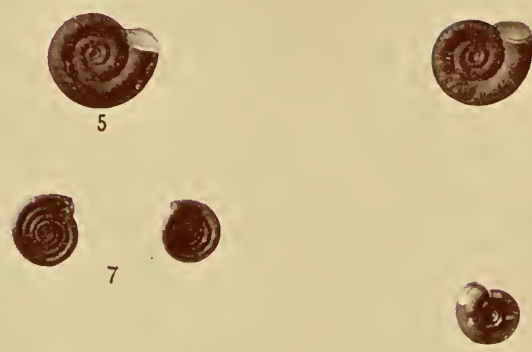

9

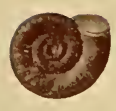

6
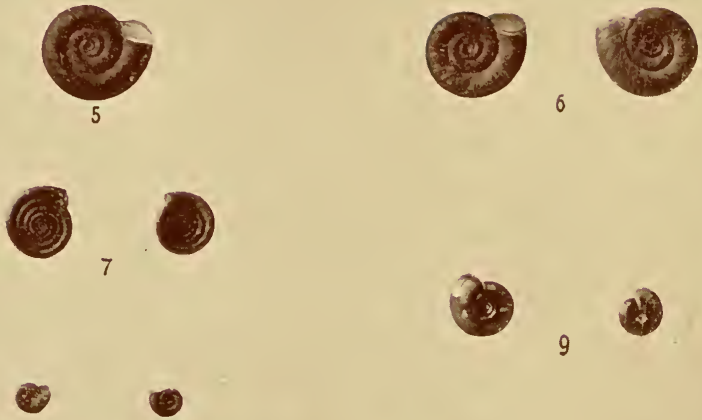

8

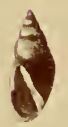

10
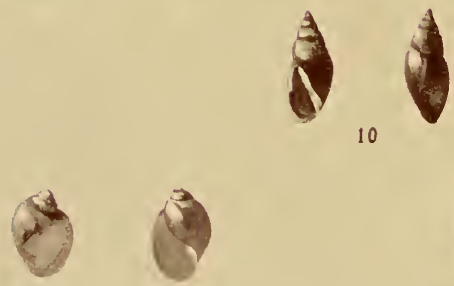

11

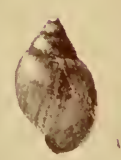

12

I Two-toothed Leuconia ; 2 Nautilus Trumper-snall; 3 Twisted Trumpet-snail.; 4 Shining Trumpet-Snail ; 5 Keeled Trumiet-Snail ; 6 Margined Trumpet-snail.; 7 Round-syired Trumpet-SNaIl ; 8 Glossy Trumpet-SNaIl; 9 Segmentina rineata; I3 Moss Bladder-snail ; il Fountain Blander-snall; 12 Physa acuta. 
separated from the Limnæids because the mantle has a contractile expansion, which is usually turned up until it almost entirely hides the shell. In this condition it presents the appearance of a little dab of glue, whence the name. As one inight expect from our study of certain marine species that cover up their shells in this manner, the globular shell is reducer to the utmost possible thinness, and the spire is exceedingly abbreviated. It is an active mollusk, and has a strange habit of disappearing for long periorls from its known localities, and as suddenly and mysteriously reappearing. Its distribution is very limited, its headquarters being Kent, Surrey, Berks, Bucks, Norfolk, north-east Yorks, Westmoreland, Kings County, and County Down. The Involute Snail (A. involute) is remarkable as being found only in one station, a small tarn on Cromaglaun Mountain, in County Kerry. It resembles a glutinosa, in which, by the growth of the body-whorl and that next to it, the brief spire is almost hidden in a hollow at the top of the shell. Owing to its remote habitat the animal is not well known. The present writer has not seen it alive; but some writers say that it agrees with glutinosa in the mantle expansions enveloping the shell, whilst others declare that the mantle is entirely contained within the shell. It has therefore been variously included as nearly allied to $A$. glutinosa, and as being a unique variety of $L$. peregra! We note that Canon Norman in his Revision of the British Mollusca sets it down as an Amplipeplea, and we therefore retain it as in his list.

The next section of these Pond-snails comprises the Flat-coils (Plunorbis), made familiar by the 
typical species-the Ram's-horn or Trumpet-snail, so frequently introduced in fresh-water aquaria. Here it will be seen by reference to the illustration, that instead of an elevated spire with the whorls one

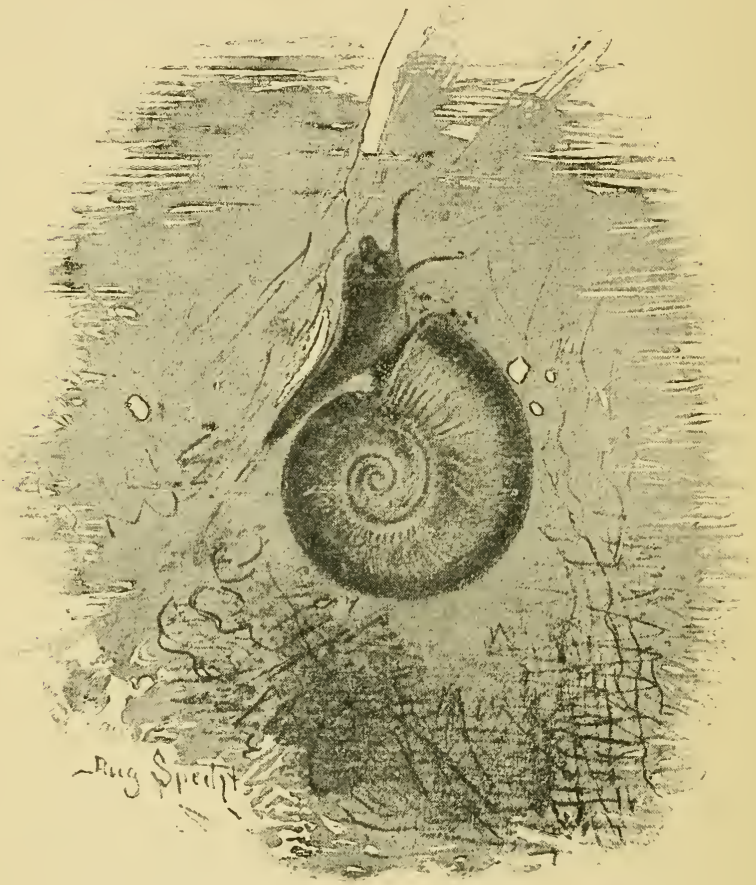

Rains-horn Snail, Planorbis corneus (nat. size)

above the other they are all in the same plane, and that the mouth of the shell is to the left instead of on the right as in Limncea. The spiral is therefore described as dextral, the shell discoidal. The animals 
have a short round foot, a short hearl, and the tentacles instead of being flat and triangular, as in Limncer, are long and slender, with the eyes at their inner bases. They are regetable feeders.

The Ram's-horn ( $P$. comeus), which is the largest known species, has the whorl rounded, the mouth an oblique crescent, almost circular. Its colour is reddish brown approaching to white on the upper surface. It measures about 1 inch across, and the breadth of the body-whorl is about one-third. 'The animal is lark red-brown, approaching black above and paling to grey below. It appears to be absurdly small in proportion to the size of its house, but this enables it to retreat far in when danger threatens, and also when active to carry a large supply of air. When irritated it discharges from a gland in the neck a quantity of red fluid, evidently with the object of making the vicinity unpleasant.

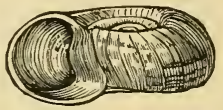

Ram's-horn It is not so prolific as some of the smaller species, and only produces from 60 to $120 \mathrm{eggs}$ during the season. These are laid in shield-shaped masses of firm jelly, each containing from 20 to $40 \mathrm{eggs}$, which hatch in fifteen or sixteen days. The epidermis of young individuals is distinctly downy. Though occurring in many of the English counties, it is a very local species; in Ireland it has been recorded from Limerick.

The Twisted Trumpet-snail (P. contortus) contrasts strongly with the Ram's-horn, for though it agrees with it in having the whorls rounded, it differs so in size that its greatest diameter is only onc-fifth of an inch. In spite of this diminutive size it has no les: 
than eight coils squeezed together. The upper-side is flat, with a depression in the centre, the under-side concave, with a wide and deep umbilicus. The mouth of the shell is crescent-shaped. The animal is not very active, though it is fond of floating at the surface. The egg-capsules of this species only contain from 6 to 8 egres, and the total number of egrgs laid during the season is only about 50 per individual. It is widely distributed throughout the ponds and ditches of Britain, and occurs in the comnties of Limerick and Tipperary, Ireland.

The following four species resemble each other to this extent, that their whorls are numerous, angular, and more or less distinctly keeled. The Round-spired Trumpet (P. spirorlois) is so named because its keel is blunt and but little developed. It is little more than a quarter of an inch across, very thin, one surface concave, the other almost flat; the mouth nearly circular. Umbilicus large and shallow. Found in shallow grassy pools throughout the country. The Whirlpool Trumpet-snail ( $P$. vortex) is very similar, but the shell is larger, thinner, flatter, and

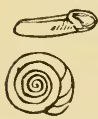

Whirlpool Trumpet more distinctly keeled towards the lower side. The mouth, too, is more oval and angular than round. It is found in similar situations to the last, but is not so plentiful. The Keeled Trumpet-snail (P. carinatus) is a much thicker disk, and measures half an inch across. The prominent keel is at or near the centre of the edge. The mouth is an oblique oval, with a sharp angle above. The flatness of the under-side makes the umbilicus very indistinct. It is nowhere very plentiful, but is more frequent in the 
home and eastern comties. Thence it extends to Hampshire, Somerset, Dorset, and Gloucester; Oxford, Norfolk, Cambridgeshire, Northamptonshire, Worcester, Warwick, and Staff's. It also occurs in Ireland, Scotland, and Wales. The Margined Trumpetsnail (P. umbilicatus), though much like the last named, is larger, thicker, and more plentiful. The whorls are narrower, and the keel instead of being anywhere near the middle is placed at the lower edge, so that it forms a very distinct

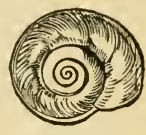

Margined Trumpet margin round the disk viewed from below as in the figure. All these four species are inactive, irritable, and fond of floating on the surface.

The next group of these Trumpet-snails consists of three minute species that agree in their shells having few whorls. Of these the Glossy Trumpet-snail $(P$. glaber) is not so glossy as its name implies, except in contrast with the following species, but it has sometimes even an iridescence. It is little more than one-eighth of an inch across, greyish brown, convex above with a depressed centre, and concave below with a large deep umbilicus; the mouth is almost round. It occurs in ponds and marshes, but is very local, though widely distributed. The White Trumpet-snail ( $P$. culbus. is much like it, but the shell is larger (one-quarter of an inch across), whitish grey in colour, and all pretensions to gloss are destroyed by close-set spiral ridges. The upper-side is convex, the lower concave with a large umbilicus. The mouth is more oval than round. It occurs in similar situations to the last, but is not nearly so local. The strong spiral ridges at once serve to identify it. The 
Nautilus Trumpet-snail ( $P$. nuutileus) is much smaller that $P$. gluber, its shell measuring only onetenth of an inch across. It is a dull brown, shightly concave above, slightly convex beneath, bluntly keeled, and the whorls ridged across, the ridges projecting on the keel "like the rowels of a spur," as Jeffreys has it. The mouth is an oblique oval, and the umbilicus is very large. In spite of its minuteness, its sculpturing makes it a handsome shell. The animal is very inactive; it feeds on decaying waterplants in marshes, ponds, and ditches. A good plan in collecting it is to carefully pull up some rooted aquatic plant and wash its base and roots in a jar of clear water, when-if $P$. nuutileus is present in the pond-a large number of specimens will be found at the bottom.

A species closely allied to $P$. nuutileus was introduced from America, it is believed in cotton-bales, in the year 1869. In that year $\mathrm{Mr}$. Thomas Rogers of Manchester noticerl it in the refuse water from a cotton-mill. It was identified as $P$. dilatutus, an Anerican species about the same size as $P$. nuutileus, but with one whorl less, the under-side swollen, the mouth large and squarish, the outer lip dilated, and the umbilicus small but deep. Since the year of its discovery it has largely increased both in numbers and the area occupied in the Bolton Canal at Pendleton and Gorton. Its naturalisation illustrates how easily even minute and delicate aquatic animals may get carried across thousands of miles of salt water to new homes.

The remaining species of this interesting genus is the Shining Trumpet snail (I'. complanatus), formerly 
regarded as two species by the separation of some well-marked indivirluals as $P$. lineritus. The shell is quoit-shaped, convex above, almost flat beneath, with a central depression on both sides; semi-transparent, highly polished, of a red,lish or yellowish horn colour, and bluntly keeled. The borlywhorl clasps the preceding one so extensively that only about one-third is visible.

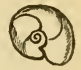

Shinıng Trumpet Mouth heart-shaped, umbilicus small. In the form known as linectus the body-whorl is partially divided inside by four or five transverse plates, which show through the shell as white lines. Some authors separate this species from Planorbis under the name of Segmentince nitidu. It inhabits small pools of stagnant water, where it feeds upon decaying vegetation; the segmented form being more local than the other.

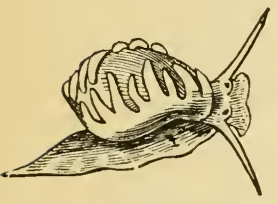

Fountain Bladder-snail

The fresh-water snails are brought to a close with the Bladder-snails (Physa), of which we have two species. They have very thin and highly polished shells, with spires turning from right to left (sinistral). The animal has two long slender tentacles, with eyes at their base. The Fountain Bladdersnail ( $P$. fontinalis) has a shell nearly half an inch long, much like that of a shortspired Limncea except that there is no cpidermis, and the mouth is to its right instead

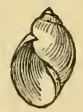

Shell of Fountain Bladder-snail of the left. But the characteristic feature of this species is its mantle, whose sides are expanded so that they turn up and wrap the shell. The borders of these mantle-expansions run into finger-like lobes 
which are shown in our figure. It is a very active little ereature, creeping over the water-plants and skimming the surface of the water from beneath. Its home is chiefly in sluggish streams, brooks, and ditches. The Moss Bladder-suail (P. leypnomin) cannot well be mistaken for its congener, for its longer shell has a very distinct spire, and it

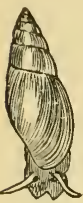

Moss

Bladder-

snail is not even partially hidden by mantle-lobes. It appears to delight in basking in the sun as it glides along the surface of its ditch. It is very unreliable in its haunts. I have sought it where a few lays previously it had been abundant, but not a specimen was to be found. Such sudden appearances and disappearances can only be explained by supposing the mollusk spends much of its time out of water; but some of the stories told of its sudden appearance in districts where it had previously been unknown are in the nature of puzzles. It prefers ditches which dry up in the summer. It is worth noting that so far as at present known this is the most northern of all the Pulmonate mollusks, and has been found living on the peninsula of Taimyr in northern Siberia, where the mean annual temperature is below $10^{\circ} \mathrm{F}$. A larger species, $P$. acuta, appears to have been introdueed to Kew Gardens with West Indian plants, and now it is thoroughly acclimatised in the water-lily tank.

The Bladder-snails have a trick of spinning threads of mucus as they rise to the surface, and by allowing a short length of it to lie on the water so fix it that they can use it repeatedly as a direct way up or down. This mucus thread is not like the byssus of 
the bivalves previously describerl, but simply a secretion from the ordinary slime-gland which most snails possess. The fresh-water snails that have to glicle over deep impalpable mud require to pour out this slime to make a safe track for themselves, just as for quite opposite reasons the land-snail has to use it to make a smooth path over dry or rough substances. Some of these slime-ropes of 1 liysa have measured 14 inches. Most of the threads are spun as the snail ascends, and only rarely (Splecerium for instance) is it spun in the descent. Sometimes they are left for days and used over and over again; at other times the descending snail gathers up the thread as it groes, and probably reassimilates it. Some of the Planorlids and Limnæids spin these threads, and use them in the same manner, but the land-slugs, as we shall see, spin them for different purposes. 


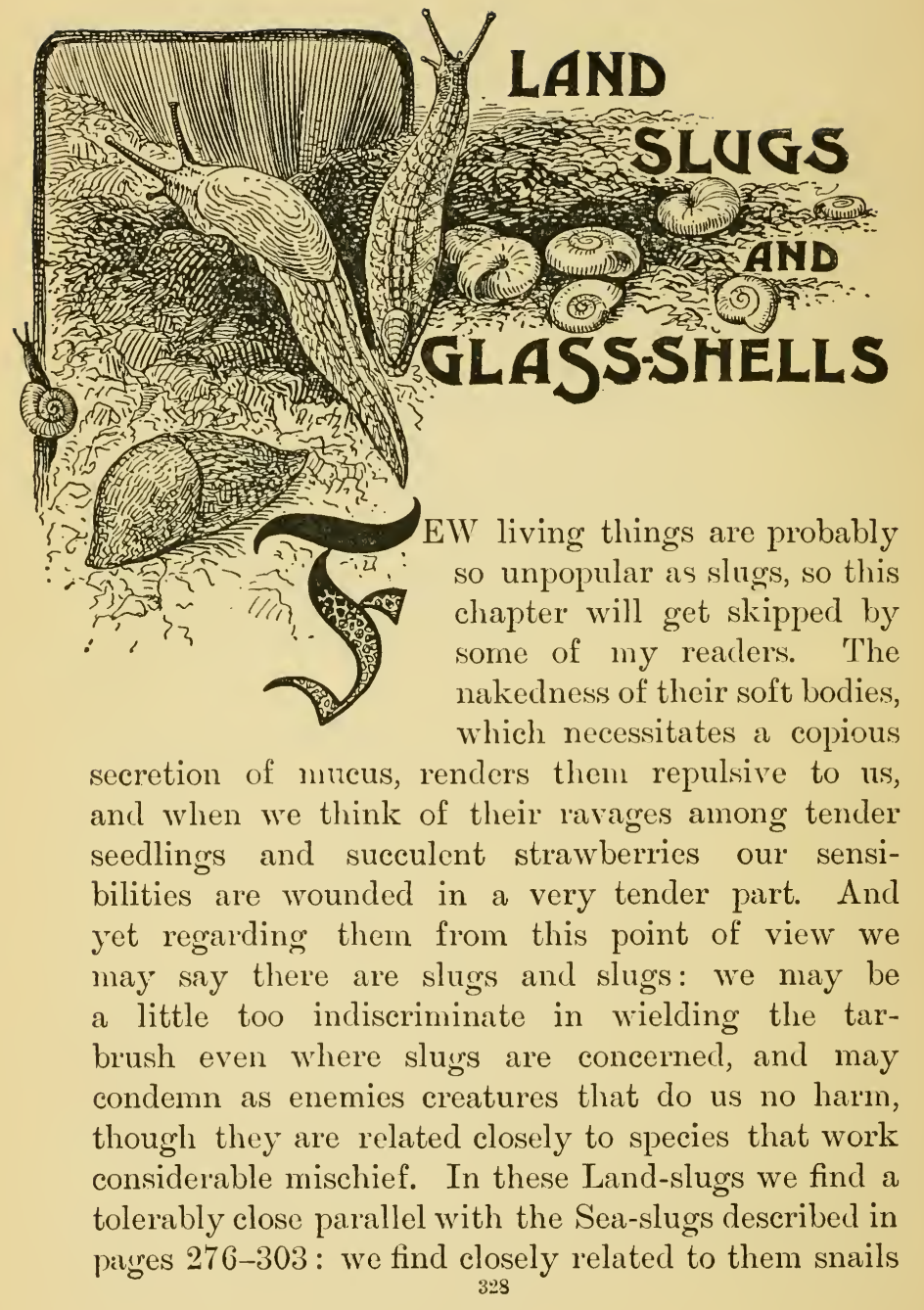


that are covered with very thin shells, in other species the shell is reduced until it is only a small plate acting as a protection to the breathing organs, and then again it has been reduced to a few disconnected grains of shelly material that can serve no defensive purpose. But, strange as it may appear, this last section of the Land-slugs will not be dealt with in this chapter but in the next, their affinities being rather with the Common Garden Snail.

With the slugs we begin our acquaintance with the sub-orler Stylommatophora, the Pulmonates that have two pairs of tentacles which can be completely withdrawn into the head, and that have their eyes placed at the tips of the upper pair of tentacles. The sexual organs (with a few exceptions) have a common opening. The first family of these is the Testacellide, the Shelled Slugs, of which three species are found in this country, but two are believed by some authorities to be only doubtfully indigenous, and one has certainly been introduced within the last century, though now thoroughly naturalised in gardens throughout the country.

The Carnivorous Slug (Testacella halioticlea) is about 3 inches in length, and at once strikes the attention as being of a shape so strongly differing from that of ordinary slugs. In these the broadest, thickest part, containing the principal organs, is towards the forepart of the body, which tapers away behind to a slender tail. All this is reversed in Testacella, whose stoutest part is to the rear, where the shell covers the breathing organ. The animal can elongate itself very considerably in order that it may pass through the burrows of its special prey 
the earthworm. It is covererl lyy a tough smooth skin of yellow-brown, with a slight furrow along each side from the neck to the shell. The foot projects a little along each side. The mouth is not furnished with jaws as in those mollusks that subsist on vegetation, but its radula is covered with long sickle-shaped teeth which can make an impression on the skin of the human hand. Lacking jaws, the carnivorous Slug would appear at first sight to be placed

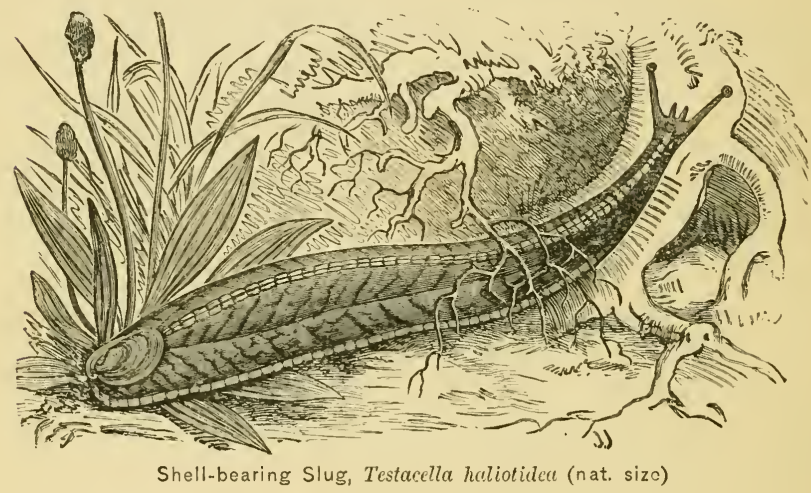

at great disadvantage in securing such active prey as the wriggling earthworm; but it does so by rapidly extruding its pharynx, and transfixing its victim with some of the long teeth of the radula, these organs being then withdrawn and the worm gradually swallowed.

The average gardener objects to the presence of worms in his garden, making his lawn unsightly by their casts, and disturbing the soil in his seed-plots; therefore it might be expected he would encourage 
the efforts of Testacella in keeping down the race. But to the average gardener all slugs are anathema, because all are reputed destroyers of seedlings. It must be admitted on behalf of the gardener that he has little opportunity for discovering the fact that Testucella is doing the work that should commend it to the hater of untidy lawns: for the slug pursues its prey in the underground burrows of the worm, and only visits the upper world at night or when the ground is sodden with moisture. When opposite conditions prevail, and there is a prospect of drought, the Testacella will retire to a depth of about three feet; or if the conditions preclude so remote a retreat it will excrete mucus and fashion it into a tough capsule which hardens and protects the slug from loss of moisture by evaporation. In like manner, early in the autumn, after doing their best to reduce the number of earthworms, they retire into deep ground and appear no more till the spring-time. Slugs and snails, as well as worms, contribute to Testacella's well-being.

Their eggs are not laid in connected heaps, but separately. They measure about one-sixth of an inch across-which is large for a slug-and are enclosed in thick tough skin. Cooke says they are so elastic that they will "if dropped upon any hard surface, rebound several inches, just like an indiarubber ball."

The second species of Testacella is T. scutulum, considered as a variety of $T$. lucliotidec until it was shown that the so-called variety was more plentiful and inore widely distributed than the type. The body is yellowish speckled with brown, and the shell 
is narrower with a longer and more pointed spire. The third species is T. maugei, believed to have been introduced from south-west Europe about 1810-12, in earth about the roots of plants, for according to Fleming it was first discovered by Drummond, the botanical explorer, in Messis. Sweet and Miller's nursery gardens at Bristol in the year 1812. In a paper published ten years later Mr. J. S. Miller expressed the opinion that it had been introduced with foreign plants, probably from Teneriffe. At that date it had greatly increased in rich ground, and in more recent years it began to be discovered in

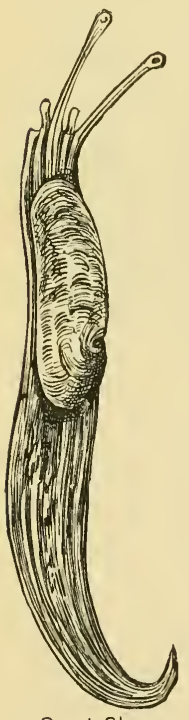

Great Slug remote gardens which had been partially furnished with plants from the Bristol nurseries. It has now obtained a secure hold in eight or nine counties, so that but for existing records it might a few years hence be regarded as indigenous. This species is dark brown, and is otherwise distinguished from its congeners by its smaller head, and larger, more cylindrical, shell.

The Slugs proper constitute the genus Limax, and are represented by eight native species, of which the best known is the Great Grey Slug (L. maximus), which commonly attains a length of 5 or 6 inches. It is by no means restricted to fields and gardens, but has a decided liking for sculleries, dairies, etc., where it can get good food other than that which is commonly thought to delight slugs. It keeps its spotted and streaked yellow-grey body fully 
extended when at rest, or with the "tail " curled round towards the mantle. Close to the tail there is a slight keel; otherwise the back is rounded. The mantle is marked with concentric lines; the upper antennæe are long; and the foot is margined with white. Beneath the mantle is the oblong shell, covering the respiratory cavity whose opening is on the right-

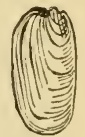

Shell of Great Slug hand border of the mantle towards the back.

All the species in the genus Limax agree generally with the description above: in addition it may be said the reproductive orifice opens at the base of the right upper tentacle, and the mouth is furnisher with a smooth, strongly arched and beaked jaw. They are often seen in little colonies, and they burrow slightly beneath the surface for the purpose of secreting their eggs. Several of them spin threals of mucus by which they suspend themselves from trees, rocks, etc. We have already alluded to the fact that all slugs are not the plant destroyers they are supposed to be. The Great Slug and the Yellow Slug (L. flavus) are said actually to recline all foods containing chlorophyll-the green colouring-matter of most plants. It is therefore highly probable that the gardener who cannot discriminate between the various species is wasting much of his valuable time when he sets out to exterminate slugs. This same L. maximus is fond of all sorts of kitchen garbage that is not green, such as fat, bread, meat scraps, milk, etc. In a passage behind our house in Cornwall we used to keep meat, milk, "buzzas" of spring-water, and so forth, until required for use. The cool slatefloored recess in the wall where stood the water- 
buzzas was a favourite haunt of $L$. maximus, and I was constantly killing them, finding a little later that other individuals of the same species were feeding on the remains. This destruction was necessary on my part, for the slugs, content with the cool niche in the day, would ascend at even to a shelf above and make for the milk-jugs with a view to sipping the cream from them. The family joint for to-morrow's dinner hung from a nail in the wall until I observed a couple of Great Slugs racing up to it. Then I fixed a hook to the roof for the purpose, for though still accessible to these creatures it was more remote.

But what Mr. Cooke ${ }^{1}$ has characterised as " perhaps the most singular instance of a liking for a particular food," came within my experience about a quarter of a century since. In the rear of the publishing house of Messrs. Isbister on Ludgate Hill, London, there was an old house used by them for receiving and storing new books from the binders. During a period of nearly twelve months one or other of the piles of new books was constantly found partially damaged in the morning, though left all right the evening before. There were slime trails on shelves and counters, and many of the book-backs exhibited marks which showed that a slug had been working at their surfaces with his rough tongue for the sake of the colouring matter, the glossy finish, or both. The trouble was laid before me, and a very slight investigation served to satisfy me that the culprit was a slug; but a very long and patient search-assisted by slime-tracks-failed to reveal his hiding-place. I shared the general view of slugs in those days, and ${ }^{1}$ Cambridge Natural History: "Molluses," p. 37. 


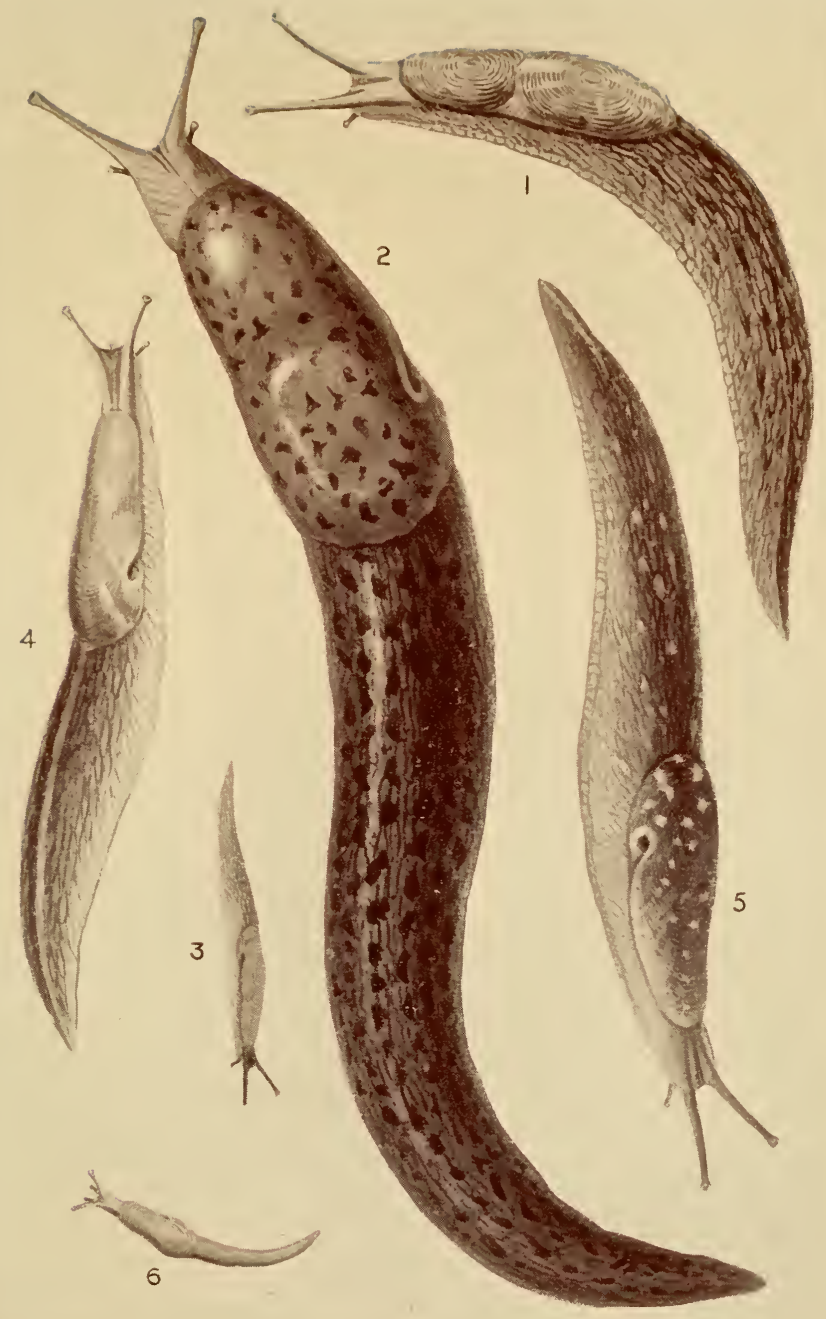

I Great Grey Slug; 2 Limax Cinereoniger; 3 Tender Slug; 4 Tree Slug; 5 Yellow Slug; 6 Shooth Slug. 

directed cabbage and lettuce leaves to be put down in the hope that the slug would stay upon this choice food; but so far as we could determine from an examination of these leaves the slug never went near them. I observed that he had either a feeling for colour or that he found crimson more nourishing, for his depredations were almost confined to cloth of that hue. I gave instructions that if caught the slug was not to be summarily dealt with, but detained until I could see it and fix its specific identity; so one day I received a note to say this molluscan De Wet had been captured. On arriving on the scene I was presented with a chip match-box and told the slug was within. The slug had been within, but had made off again as any sensible slug would have done; and he took care never to be caught again, so his identity could not be established. To-day, however, with a wider knowledge of the ways of slugs, I do not feel a shadow of doubt that it was $L$. maximus turned bibliophile. Had we offered him a mutton cutlet, or even a slice of brearl-and-butter, instead of cabbage leaves, we might have caught him.

The Tree Slug (L. marginutus) might be mistaken for a half-grown individual of $L$. maximus but for the different habitat. Marginatus affects trees (especially beech and walnut) and lichen-covered rocks. Its colour is slaty-grey, with a bias either to blue or green, spotted with yellowish white, and marked along each side by a darker band. Towards the tail the back is keeled, and the foot has a whitish erlge all round." The tentacles are much shorter than in L. maximus; and the thin glossy shell is almost flat. It feeds entirely upon lichens, and when seen 
on a tree its colour and markings are so closely in harmony with its surroundings that it might be regarded as part of the bark. It frequently descends from branch to branch by a threal of slime, and the sexes mite while thus suspended. The Yellow Slug (L. flavus) is not really as yellow as its names indicate, the appearance being largely due to its yellow slime, which is said to stain linen the same colour. But under the slime the animal is seen to be yellowish with black spots, of a shape aud disposition to suggest tesselated work. The head and tentacles - which are short-are bluish. The foot is white, margined with yellow. Like $I_{\text {. }}$ maximus this species has no taste for green-meat. It prefers to haunt cellars, especially if meal, flour, and cream are anywhere handy. In moist woods it spends the hours of daylight at rest under stones, coming out at even and feasting upon any animal remains it can fincl. The Field Slug (L. ayrestis) is a much smaller species

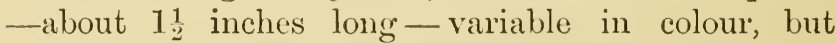
usually some ashy-grey tint mottled with dark brown. The back is keeled near the tail, and the plentiful slime is distinctly white, tenacious, and fatty. It is one of the most destructive slugs we have, viewed from the gardener's standpoint, and is well worthy of the most zealous attentions at his handsand feet! It is not averse to earthworms and insects as food, but its staple diet is tender vegetables, seedlings, and ripening fruit in gardens, and crops of clover, peas, and oats in fields. This is the shug that is taken alive or boiled in milk as a supposed cure for consumption.

The Smooth Slug (L. leveis) is an active, glosisy, 
little dark brown creature, with a paler mantle, and exuding a thin colourless slime. Its length is something between one-half and three-guarters of an inch. It inhabits marshy meatows, but is very local. The Tender Shlug (L. tenellus) is of similar dimensions, but in colon it is almost transparent greenish white, with black head and tentacles. The slime is viscid, and orange coloured. It is a very local species, the only places recorded for it being Shetland and Northumberland.

In all the foregoing species the mantle is wrinkled in concentric lines as described for $L$. maximus; but in the two following the elevations of the mantle take the form of little knobs instear of lines, so that it is said to be shagreened. On this account they are placed in a sub-genus, Ameliu. The Keeled Slug (L. carinatus) is about 21 inches long, of a yellowish or reddish-brown colour speckled with black or dark brown, the back with a prominent keel from mantle to tail of a lighter tint than the ground colour, and usually amber coloured. The oblong mantle has a dark line on either sicle. The foot has a pale margin, and the thick adhesive slime is colourless. This is a common species, and of general distribution. Though it will take earthworms, caterpillars, and its younger relations as a change of diet, it is distinctly a vegretable feeder, and the author of considerable havoc in gardens and fields. The Small Black Slug (L. gugutes) is of similar dimensions, but its colour is variable-black, slaty, red, brown, or even yellowish with darker markings. The head and tentacles slate coloured, and the mantle larger than in L. curinutus, forming two lobes, with 
the respiratory opening more forward than in that species. This also has the prominent keel. The slime is white or pale yellow. When at rest it contracts itself into an almost globular shape. It occurs in hedgerows and gardens, but its distribution is not nearly so wide as that of $L$. curinatus, and is of only local occurrence.

The Pellucid Glass-snail (V'itrina pellucida), which is frequent under mossy logs and stones in damp woods, has special interest for us because of its intermediate position between snails and slugs. The animal may be called a slug, but it has a shell
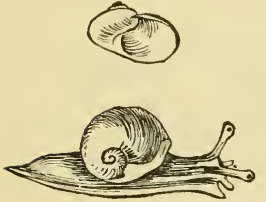

Pellucid Glass-snail and shell (enlarged) ordinarily of just sufficient dimensions to accommodate it within, yet of such exceedingly delicate substance as to be little protection from enemies. Simroth believes that it is the ancestral form from which the Slugs have been evolved by the gradual degener:ation of the shell, and its investment by the mantle. It may also be reasonably supposed that in the opposite direction by the development of the shell in size and solidity, such an ancestral form may have originated the Snails (Helix), the thinshelled Hyalinius marking a stage on the way. Our only native species is very hardy in spite of its delicate covering, and it may more commonly be found in winter crawling over mosses and liverworts than in summer. This hardiness may be partly due to the fact that the eggs are not deposited until autumn, so that the young ones enter upon life at a time when thick-shelled snails have retreated into snug quarters for the winter and have plastered up 
their shell to keep out the cold. As shown in our figure the shell is slightly investerl by the mantle, which has a lobe on the right side, and this is turned up over the shell when the animal is active. Such a habit of shell-investment extended, as we have seen it in many marine species, until the shell is completely hidden, may have brought about the conditions existing in Limax where the shell is reduced to an almost flat plate and is quite hidden away. The Glass-snail has a quaint habit, which is no doubt protective, of giving a vigorous jerk to its tail when alarmed, and so it throws itself off from the twig or stone it may be gliding on and drops among the moss below. It is everywhere plentiful in suitable situations. It appears to be as much carnivorous as herbivorous, sometimes attacking in force a sickly earthworm, and showing a liking for horse-droppings. These traits are shared by the next genus, Hyalinia, in which the shell is sufficiently roomy always to accommodate the entire animal.

Draparnaud's Snail (H.draparnaudi) is the largest of the genus, of which there are ten native species. This one is exceedingly local, and has been found only in Guernsey, Falmouth, Torquay, Bristol, and Isleworth. The shell is about three-quarters of an inch across, glossy, reddish above, whitish beneath. Mouth an oblique oral; umbilicus large. A common species that may be confused with the foregoing is the socalled Cellar Snail (H. celluriı), which scarcely exceeds half an inch across, but it is flatter above, more yellow than red, whilst below it is distinctly white, though sometimes with a greenish tinge. As 
in all the species of the genus, there is an open umbilicus. The animal is slaty-grey in colour, of a shy and retiring nature, and evilsmelling. It will be found under brick rubbish in backyards, in cellars,

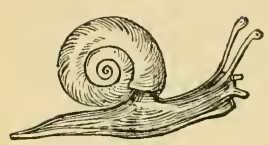

Cellar-snail uncler logs and stones in woods, and in mossy hedgerows everywhere. The Garlic Snail (H.alliaria) is more convex and dirker above, less white beneath, and only a quarter of an inch across. The animal is much darker than $H$. cellaria, and its tentacles are proportionately shorter; but the shell may easily be confused with that of a half-grown Cellar Snail. Jeffreys' test in such a case is to view the two shells sideways, when the last whorl of alliaria will be found to be less deep than in cellaria. It is more local than the last named, and must be sought in more open situations, but hidden under stones. Its name is due to the fact that when irritated it gives off an odour of garlic which varies in intensity. Too much importance must not be attached to this characteristic in arriving at the identity of the species, for several of its congeners have the same peculiarity, though perhaps less markedly. It is, no doubt, a protective endowment, for the odour is not perceptible until the snail is interfered with, and continued irritation appears to lessen its pungency.

The Glossy Glass-snail (H. glabra) is a little larger than the Garlic Snail, whose odour it shares under certain eonditions-as when being killed by the boilingwater method. The animal is bluish grey, with zebra-like stripes in front and mottled behind; the sides marked with a dark line just above the foot. 

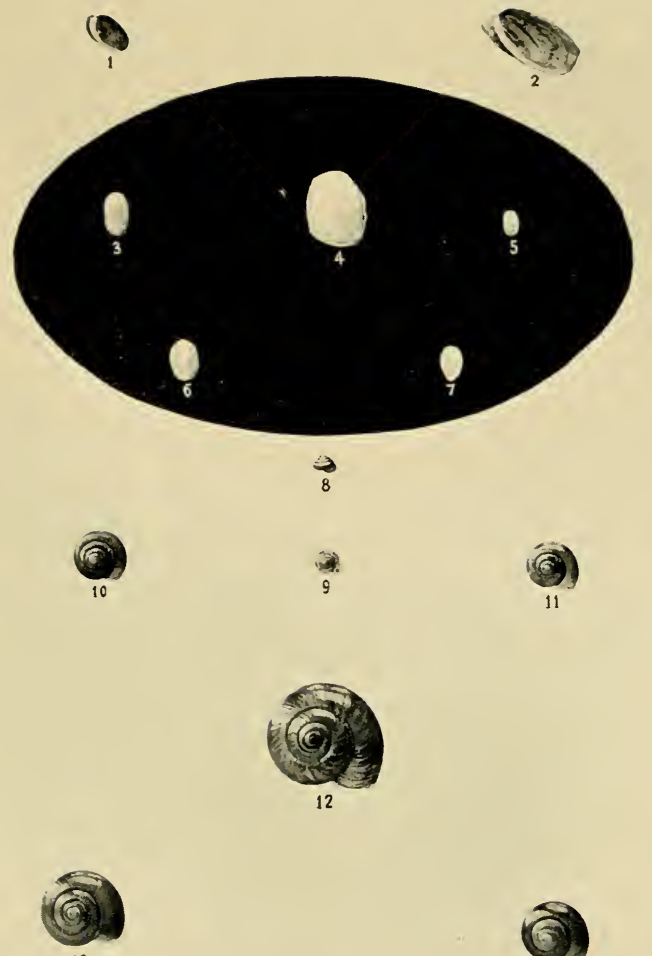

13

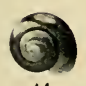

14

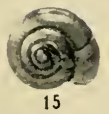

I Carnivorous Slug; 2 Testacella Malgei; 3 Field Slug; 4 Yelloiv Slug; 5 Silooth Sllu; 6 Silall Black Slug; 7 Keelen Sidug; 8 Tawxy Glasssiali, 9 Cristal Sinall; 10 Hollowed Glass-sNall; il Garlic SNail;

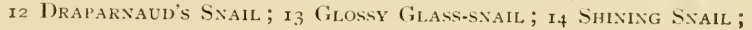
i5 CFllar SNall. 

The shell is rather convex above, less so beneath, dark hom coloured, thin, and exceedingly glossy, clouded with white round the narrow but deep umbilicus. It inhabits woods and fields, but though widely distributed it is quite local. The Smooth Glass-snail ( $H$. nitirlule), though about the same size or slightly larger than the last, is less transparent, and more like the Cellar Snail, but the spire is more raised than in that species, the surface less glossy, the mouth less oblique, and the umbilicus is larger and deeper. It is found under stones, dead leaves and moss, in woods and hedge banks, where it frequently buries itself. The Rayed Glass-snail (H. roticutula) is equally convex above and below, dark brown, thin, very glossy, marked across the whorls by well-defined lines, which give the rayed appearance. The umbilicus is small, but tolerably deep. The shell only measures about one-seventh of an inch across, and may be sought in similar but moister situations than those given for $H$. nitidula.

The Clear Glass-snail (H. purce) is like H. nitidulu, but differs in being much smaller (one-third inch across) and the umbilicus much narrower. It is widely distributed, but somewhat local. It keeps almost entirely buried under dead leaves and moss in woods. The Shining Snail (H. nitida) somewhat resembles $H$. rudiatula, but is larger (one-quarter inch), has a more prominent spire, and the rays are much less distinct. It is also less convex below than above, and is not so thin. It is found at the roots of grass, under stones and among moss in damp places. The Hollowed Glass-snail (H. excaratus) is so-called on account of its wide and deep umbilicus. 
The shell is more convex above than below, dark brown, not very glossy, the whorls crossed by deep lines. It is a local species, occurring chiefly in the south and west of England, its habitat under logs and dead leaves in woods. The Crystal Snail (H. crystallina) is only one-eighth of an inch across, glossy, thin and translucent, with a greenish tinge. It has a very narrow umbilicus. The animal is greyish white, with the upper tentacles deep black. It occurs about decayed stumps, dead leaves and moss, and under stones, in woods and meadows. The Tawny Glass-snail (Conulus fulva) differs from the Hyalinias in having a pyramidal shell, the spire being considerably raised; there is also Tawny a mere depression (with occasional perforaGiass-snail

tion) instead of an umbilicus. The colour is indicated in the names, and the shell is thin and glossy. Its height and its breadth are equal-about one-tenth of an inch. Its habitat is similar to that of 11 . crystallina. This species from the form of its shell makes an easy passage to the snails described in the next chapter.

In another respect two species of Hyalinia show affinity with the genus Helix, that is in the development of what has been termed the "lovedart." The species referred to are $H$. nitida and $H$. excavatu. The instrument consists of a delicate shaft of carbonate of lime, finely-pointed, and contained in a pocket of the female organ, whence it is discharged just prior to the union of two individuals, and embedded in the flesh of its mate. It is only to be found in mature snails, and its office apparently is to excite the sexual instinct. 


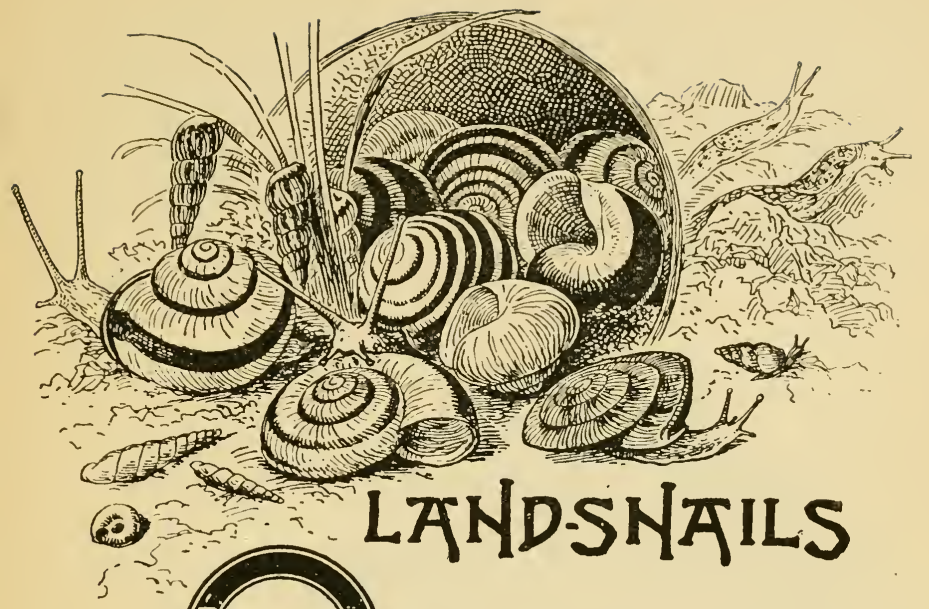

UR introduction to the LandSnails must be made through a few species that may appear to belong to the previous chapter and to have been forgotten when that was written. They are slugs it is true, and until quite recently they were classed with the true slugs of the genus Limax, but of late they have been separated as having closer affinity with snails of the genus Helix - they may, indeed, be said to fall in with the popular and ancient definition of a slug, which says it is a snail that has cast off or not yet developed its shell. The slugs of the genus Arion have not even the debased shell-the mere scale that, hidden by the mantle, protects the respiratory chamber in Limax; in Arion it is represented by a few disconnected granules of shell-matter covered by the hinder part of the mantle. They may be distinguished 
at a glance by noting that the orifice to the respiratory chamber is near the forepart of the mantle instead of to the rear, and the animal has generally a closer resemblance to a snail minus his house. Instead of the mantle being marked with concentric wrinkles it is uniformly shagreened; and the tail is furnished with a slime gland. They appear to be

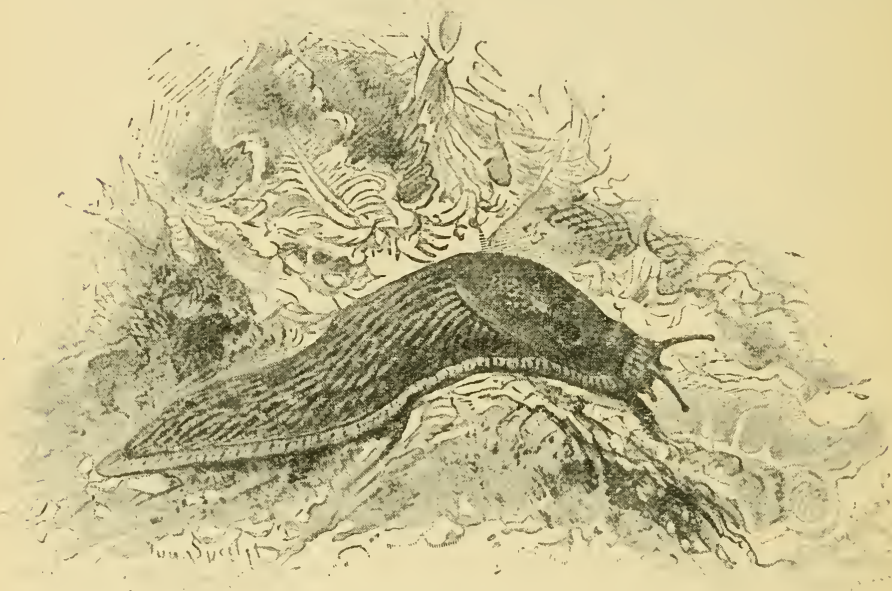

Black Slug

more hardy than the Snails (Helix), and are active for some time after these have gone into hibernation.

The Large Black Slug (A. ater) is a familiar object in all parts of the country, in wood, fielı, hedgerow, and garden alike, in the last named doing great damage through its fondness for fruit --damage which the gardener commonly debits 


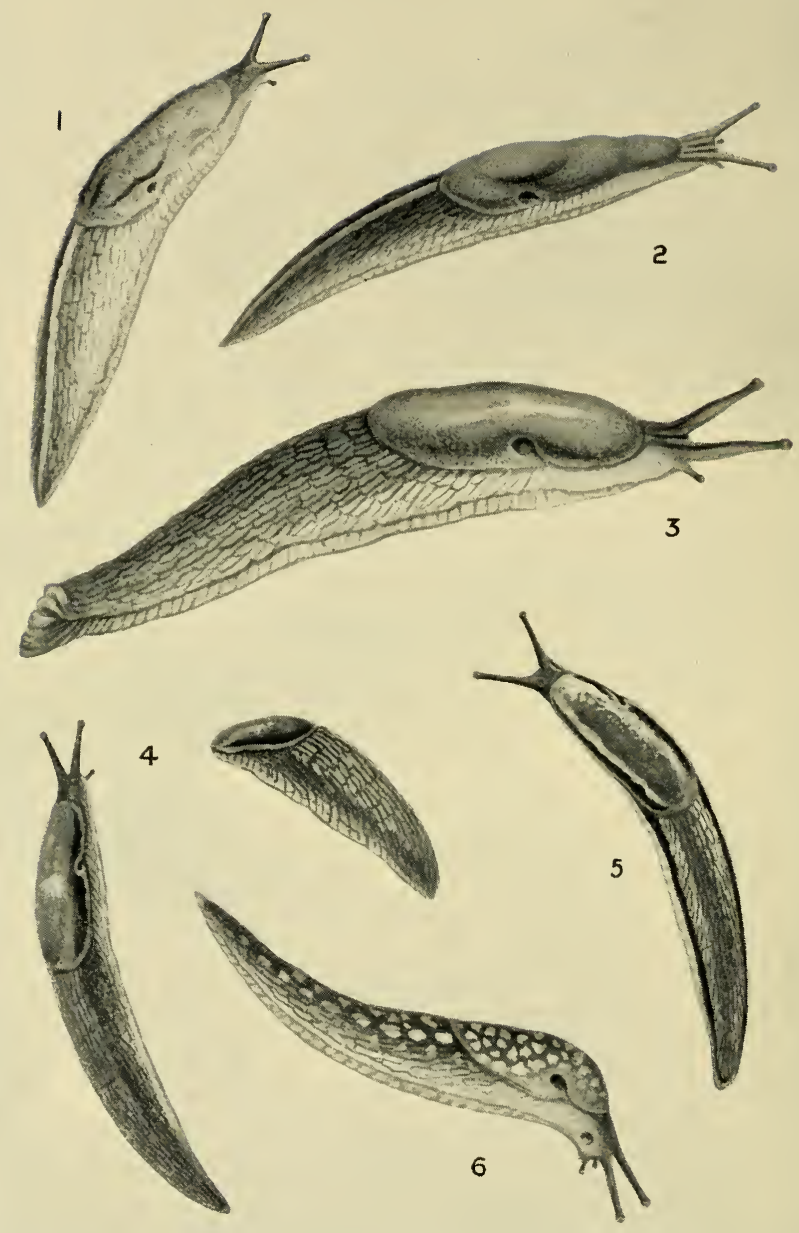

I Keeted Silug; 2 Silall Black Slug; 3 Dusky Slug; 4 Garden Slug; 5 Bourguignat's Slug; 6 Spotted Kerry Slug. 
to the wasp in addition to the share of blame that rightly belongs to the insect. A full-grown Black Slug measures abont 5 inches, and its upper surface is covered with coarse long tubercles. The tentacles are shagreened like the mantle, and their tips are much swollen. In most cases, but not all, the sides of the foot are margined with yellow crossed by dark lines. The Black Slug is by no means always black-it is sometimes white, but more often yellow, red, brown, or black, and there is reason to believe that this variation is protective in character. We have referred to the Black Slug's fondness for fruit, but it must not be supposed it is at all exclusive in respect to diet. Fruit is not always about, so the Black Slug can make a good meal of table vegetables, of wild plants, a dead mouse or bird, earthworms, bread, its own kith and kin, or their slime. It has been known to devour newspaper after two days' fast. The same specimen besides eating the dead bodies of five other slugs, a dead freshwater mussel, some insects, finally ate a little Pear's soap!-though this, Mr. H. Wallis Kew says, it took reluctantly, as a person takes physic, no doubt. It showed the same reluctance respecting the poisonous berries of the Arum, and the leathery leaves of Sea Holly and Polypody, though it readily fed upon the lichens Evernic and Ramalina, and such biting things as the leaves of buttercups. It may often be found on Agarics and Boleti, in which it scoops deep holes, but it may be noted that its evident enjoyment of this class of food is no guarantee that the particular fungus attacked is suitable for human consumption, for the Black Slug will eat the 
peppery and poisonous Emetic Mushroom (Russula emetica). It is a very prolific slug, and during the breeding season-May and June-it lays nearly 500 oval and transparent eggs, which are deposited at the roots of plants, and in other suitable situations, in batches. The shell is represented by a number of roundish or oval granules, which were formerly sought for use in medicine-what has not been used in medicine?-and on this account Férussac gave this species the name of $A$. cmpiricorum, but the name used by Linnæus- $A$. ater-has precedence.

The Dusky Slug (A. sulffuscus) is more cylindrical than the Black Slug, of a reddish-brown colour, marked along the sides with faint black bands. The back is slightly keeled behind, and the foot is grey crossed by black lines. The opening to the lung chamber is almost in the middle of the mantle margin. It inhabits woods and damp places, and attains a length of from $1 \frac{1}{2}$ to $2 \frac{1}{2}$ inches. The Garden Slug (A. hortensis) is about the same size as $A$. sulfuscus, but varying in colour just as $A$. ater does, from which it is distinguished by its relatively more slender proportions and by the back being marked by a dark stripe down the middle and a narrower stripe along each sicle. The mantle is similarly striped. The shelly granules are in this species united into an irregular mass. It is not confined to gardens, but is also common in hedges and woods.

The Spotted Kerry Slug (Geomalacus maculosus) represents a genus generally similar to Arion, but the animal is capable of far greater extension, so that it can pass through very minute apertures; its respiratory orifice is near the front of the mantle, and 
the reproductive opening at the base of the right lower tentacle. The shell is solid, claw-shaped, with concentric lines. All the tentacles are short, and without eyes. There is a large slime-gland at the tail, as in Arion. The upper-side is coarsely tuberculated, black spotted with yellow or white, as well as being sprinkled with minute specks of black and white. The thick brown foot is transversely furrowed and its sides striped; the under surface has a broad clear band with a band of light yellow or grey on either side of it. This mollusk was discovered nearly sixty years since, by Mr. Wm. Andrews, on rocks around Lough Carrough, in County Kerry, and it has never been found many miles away from that locality. The discoverer describes the living slug as a thing of beauty, and Dr. Scharff has more recently pointed out that its colouring is of the protective kind, harmonising so admirably with the lichens that cover the rocks where it is found that the slug does not hesitate to lie extended among them even when exposed to sunshine.

The snail-like slugs are succeeded by the genus Helix, whose nembers are understood more particularly when the word Snail is used. All the species are provided with a shell sufficiently roomy to accommodate the entire animal, but it varies consiclerably in size, shape, colour, and ornamentation. It may be disk-shaped, round, or nearly so, or conical. The lip is frequently strengthened by an internal rib, and there is usually an umbilicus. The animal has a thick mantle which lines the shell, and the head bears a couple of pairs of tentacles, the upper pair carrying the eyes at their tips. Its mouth is 
furnished with an arched and ribbed jaw, and the outer teeth of the well-furnished radula are themselves toothed-that is, their edges are cut up like the edge of a saw.

There is no operculum to close the shell in Helix, but to prevent undue evaporation in summer the mouth of the shell has a film of mucus spread across it, and this rapidly hardening keeps the dry air out and the moisture inside. In winter this epiphragm, as it is called, is again produced, but then consists of many layers, because it has to last much longer and exclude cold. At this period the snails have usually retired to some sheltered corner among dead leaves, or in the crevices of walls, where they can slcep through the inclement season secure against wet and frost, and from which they emerge with the warm spring rains. Their eggs are roundish and enclosed in tough "shells"-in the case of the Roman Snail it is really a shell containing much lime-which are laid in little heaps, often in burrows excavated by the foot of the snail. We have already mentioned the "love darts" of certain species of Zonites, which connect that genus with Helix, in which the possession of these singular instruments is characteristic of about two-thirds of the native species.

Twenty-five British species are inclucled in the genus Helix by the principal systematists, but from time to time others have broken off a few species here and there to make new genera; and quite recently there has been a tendency on the part of some conchologists to respect all these little genera, with the result that the important genus Helix, as most people lnow it, is left with only a few species 
and becomes no more important than Clausilia. In these pages we have kept the genus intact.

The Dwarf Snail (H. pygmecec) is the least of the British species, and one that does not fall into the hands of the collector who has little patience. Horeover, the lens is required for its examination when obtained, to make sure that the specimen is not the young of another species (H. rupestris), which is also very small, but twice the size of pygmea. The Dwarf's shell is circular, flattened from above and below, consisting of four whorls, and measuring onesixteenth of an inch across. It is very thin, light brown, with a silky gloss; the spire but slightly raised, the umbilicus large, and exposing the whole interior of the spire; mouth horseshoe-shaped, without an internal rib. The animal is brown or grey, minutely dotted with black. It chiefly affects woods, where it lurks under stones and dead leaves during the daytime. The knowledge that it is found in a particular wood may be utilised by the collector with limited time, if he will follow Dr. Turton's plan: collect a bagful of moist dead leaves, and on reaching home spread them to dry on an open newspaper; the snails can then be sifted out easily. It is a widely distributed species.

The Rock Snail (H. rupestris), which resembles the last somewhat, attains a diameter of one-seventh of an inch. The shell has five whorls, is of more solid material than that of $H$. pygnece and has a deeper suture-that is, the slight trench separating one whorl from another. It is also less flattened above, of a darker brown, and the whorls are crossed by fine lines. It inhabits the crevices of rocks and walls in 
elevated positions. It agrees with the Dwarf in carrying its shell upright when gliding, though most of the genus carry theirs to one sicle. The eggs are retained until they hatch.

The Rounded Snail (H. rotundata) has a general resemblance to the previous two species, but is much larger, exceeding a quarter of an inch in diameter. The shell is more opaque, coloured a yellow-brown with curved red-brown stripes at regular intervals across each whorl. The whorls are also adorned with numerous transverse ribs, except the first. The periplery or circumference of the shell is bluntly keeled. The mouth is half-moon shaped, and in old specimens is strengthened by a white rib inside. The umbilicus is wide and deep. The animal is very shy. This very common species may be found almost anywhere by turning over stones lying on the earth; it also affects the shelter of loose bark on decayed trees, the moss, leaves, and decayed wood that may be found about old stumps.

The Beautiful Snail (H. pulchella) is another diminutive species, the shell measuring only one-eighth of an inch across, depressed but convex above, of a greyish-white colour, transparent and glossy. It is ornamented with slightly raised curved ridges across the three and a half whorls, which are separated by a rather deep suture. The nearly circular and slightly oblique mouth has a thick and expanded lip. The umbilicus is rather large, and discloses all the interior of the spire. It is a widely distributed species, whose favourite lurking places are under stones and logs, at the roots of grass and among moss.

The Prickly Snail (H. aculeutu), though also small, 

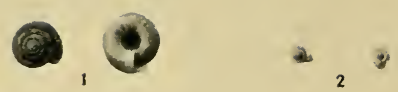

?. 3
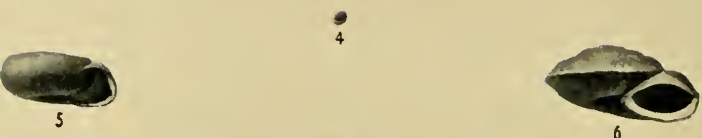

7
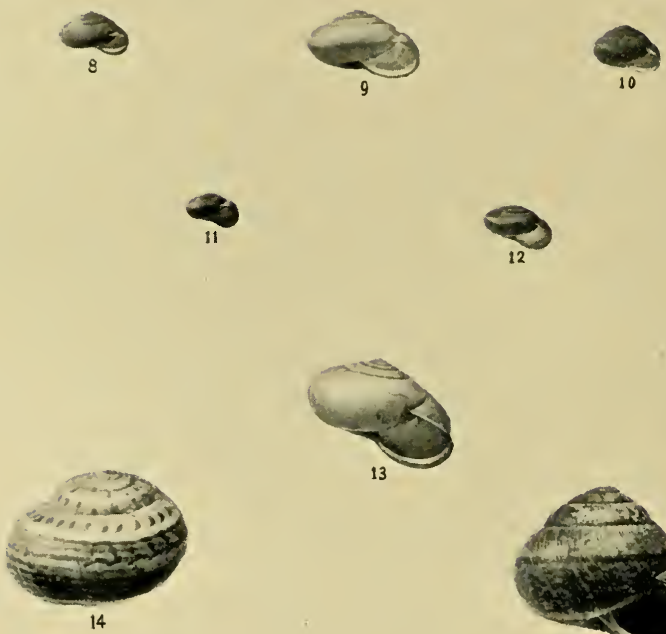

13
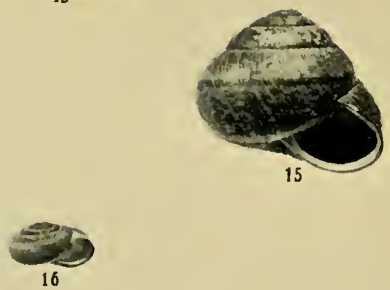

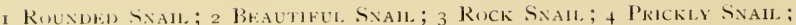

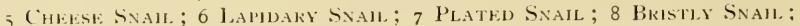

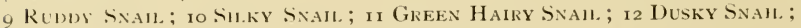

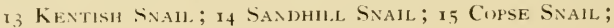

16 Carthusian Sxall. 
is easily distinguished from all its congeners by the shape and ornamentation of its shell. This is conical, the spire raised considerably, of a dull brown hue, and the epidermis forming ridges which in the centre of each whorl are developed into sharp spines. The mouth is thickened by a white rib. The shell is carried erectly when the animal walks. It must be sought about woods, on the dead leaves of beech, alder, and holly, and among scale-mosses (Jungermannic). It is saic to climb trees, but is apparently too knowing to take the trouble to climb down; its method of clescent is to attach itself to a nearly falling leaf and use this as a parachute by which to make the descent. Small snails that attach themselves to dead leaves are, no doubt, often distributed widely from their birthplace by the strong winds of autumn.

The Plated Snail (H. lamellata), of similar proportions to the last named, is less conical and more globose, more tawny, with a satiny lustre. The epidermis is produced into close and regular plaits or folds across the whorls. The half-moon shaped mouth has a thin lip, and the umbilicus is narrow, but very deep. Its habitats are similar to those of the Prickly Snail, but its range is restricted to Scotland, Ireland, and the north of England.

The Cheese Snail (H. obvoluta), so called by Dr. Gray from its resemblance to a flat cheese, is also quite distinct from all other native species. It is $\mathrm{s}$ round coil, flat above, not unlike the Ram's-horn Snail (Planorbis comeus), the spire depressed below the level of the body-whorl, the periphery rounded. It is half an inch in breadth, its colour dull ruddybrown, and the epidermis is thickly covered with 
stiff hairs of the same tint. The mouth is a blunt triangle, the lip thickened and reddish, with an internal protuberance near the periphery. There is a large umbilicus. This mollusk has only been found in a few places in Hampshire and Sussex, and until seventy years ago none of our naturalists were acquainted with British specimens. For years it was thought that it had been introduced from the Continent, and that individuals planted out at Ditcham and Stoner Hill had established colonies at those places. Later it was found to occur on the northern escarpment of the South Downs in Sussex, and in Kew's Dispersul of Shells (1893) Mr. Clement Reid, F.L.S., has shown that all along that range as far east as the river Arun, wherever there are patches of ancient wood the snail may be found. He says: "The species seems to be very particular as to its habitat, it must have calcareous soil and plenty of shade, but the ground must never be sodden. It seems also to be an exceptionally sedentary species, for as far as I could see it was confined to ancient woods, and was never to be found in plantations, even if the trees were a hundred years old. Almost the only place where the necessary conditions are combined is the chalk escarpment, for there we find slopes too steep ever to have been cultivated, and on these, consequently, are preserved many patches of the ancient forest. Nearly all these seattered patches, as far east as the river Arun, are full of $H$. obvoluta. East of the Arun there are few traces of the old forest, and I have not yet come across this snail. . . . Everything seems to show that the creature is a relic of our old woodland fauna, now nearly exterminated 
through the destruction of the forests." Its shell is closed in winter by a very thick white epipluragm.

The Lapidary Snail (H. lapicida), though it has a depressed shell like the Cheese Snail, has the spire distinctly raised and the periphery sharply keeled. The colour is dark ruddy-brown, paling to a dirty yellow in places. The mouth is oval, with a notch corresponding to the keel; the thickened white lip expancled, and forming a complete peristome. The umbilicus is large and deep. The epidermis is very finely granulated, so that through a lens it has the roughness of a fine file. Probably, as Jeffreys suggests, this appearance may have led to the belief current in Linnæus' day, that this snail bored into wood and stone. It was owing to this belief that Limmous called it lapicida or the Lapidary, but though Jeffreys terms this an inappropriate name, it

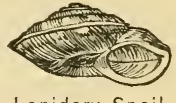
Lapidary Snail is not so when one regards the shape of the shell with its sharp keel, much resembling the polishing wheel of the cutter of precious stones. The Lapidary Snail has only been found in England and Wales, so far as these islands are concerned, and it extends no farther north than Yorks. It is most frequent on soils of a calcareous nature, though by no means restricted to them. It is a very difficult snail to find in dry weather even in places where it is abundant, but after a heavy summer shower it may be found in thousands on trees (especially beech) and palings. It is remarkable how well its form is adapted for concealment in both these situations. When at rest on beech trunks it is the exact counterfeit of the lowknobbed excrescences on the smooth grey bark, and 
along the bottom framing of park palings it as closely resembles the heads of the iron bolts with which the framing is put together.

We have now a little group of snails that may well be considered together, as they agree in the fact that the epidermis is covered with spreading hairs. The first of these is the Bristly Snail (H. hispida), which measures about one-third of an inch across the low-spired shell. This is thin and semi-transparent, yellowish brown, and thickly covered with short, recurved white hairs, which are not easily rubbed off. Sometimes the mouth is furnished with an internal white rib. Umbilicus of moderate width, but deep. This species is common everywhere under stones, logs, and among moss. A variety (concinnc of this species has been regarded by some writers as a distinct species. It differs from the type in being slightly larger, the upper surface of the whorls are less rounded, the colour light ash - grey occasionally streaked with reddish brown, frequently with a white band on the body-whorl, where there is a suspicion of a blunt keel. The hairs are more scattered, and easily detached. Umbilicus rather broad. It is found at the roots of grass in moist places, and under stones and nettles. It approaches in several of these respects to its larger relative, the Ruddy Snail (H. rufescens), which has a nearly opaque shell half an inch broad, of an ash-grey colour suffused with red, and the whorls closely wrinkled. It is bluntly keeled, and there is often a white spiral line on the body-whorl. The umbilicus is fairly large, and deep. Although not well known to others than conchologists, owing to its nocturnal habits, it is very plentiful 
along hergerows, in gardens and woorls. It is partial to beds of strawberry and violet, and in the former may do great damage to fruit without its presence being suspected, the destruction being debited to birds. If a visit be paid to the strawberry bed after a heavy summer shower, a different tale may be told. Thrushes appear to be very fond of this species as a food. In its young state-that is up to the age of four whorls-the shell is covered with hairs, but these are short and readily fall off:

The Silky Snail (H. granulatu) may be mistaken for the Bristly Snail, but though the diameter of the shell is about the same in each, that of the Silky Snail is thinner, and more globular, being more rounded both above and below. The colour too is greyish white, with some approach to glossiness. The thick epidermis is covered with long fine downy hairs which do not fall off. The spire is considerably raised, the umbilicus exceedingly narrow and almost closed. The feel of the shell when handled is quite distinct, and so numerous are the hairs that it may be dropped on hard surfaces with impunity. It is a local species, found on mossy hedgebanks. In Cornwall I found it had a great weakness for the Hart'stongue fern (Scolopendrium vulgare). The Green Hairy Snail (H. revelcte $)$ is of similar proportions to the Silky Snail, but is compressed above. The shell is very thin and semi-transparent (which gramulcte is not), coloured yellowish green, and the four and a half whorls are wrinkled transversely, which gives the very deep suture the appearance of being puckered. The thick epidermis is covered with short white hairs which are easily detached. The 
mouth is never ribbed. The umbilicus is narrow and shallow. Its habitat is on the downs along the coasts of Devon and Cornwall, and in the Channel Islands, where it buries itself deeply in winter and dry weather.

The Dusky Snail (H. fusca) in point of size and shape is much like $H$. revelata, but the shell is yellowish brown and it is not hairy. It is so thin as to be transparent; it is glossy, and the five and a half whorls are strongly wrinkled across. The umbilicus is extremely narrow. Though widely distributed this is a local species, and its habitat is among nettles and dog's-mercury, under the leaves of young alders, and on ferns. It appears to endure a much lower temperature than most of its congener's, and has been found active in winter when the thermometer registered several degrees of frost.

The other members of the genus Helix are all comparatively large. The Kentish Snail (H. cantiana) owes its name to the fact that

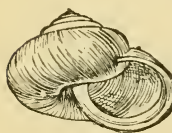

Kentish Snail specimens from Kent were first observed to be different from $H$. rufescens, and it was then thought to be peculiar to that county. Although most plentiful in the south of England its range extends as far north as Northumberland. It has a somewhat globular shell, thin in texture and semi-transparent; the colour yellowish white, tinged with ruddy-brown towards the mouth and on the under-side, often with a narrow white band extending half-way or more round the body-whorl. Adult specimens have a thick white rib just inside the slightly expanded mouth of the shell. The umbilicus is narrow but deep. Young 
examples have the epidermis covered with short hairs which soon fall or get rubbed off:

The Carthusian Snail (H. curthusiana) claims close kinship with the Kentish Snail, but it is smaller, more depressed above, more convex beneath, more solid in structure, less transparent. The colour is yellowish white, tinged with fawn colour, usually with a white spiral band on the body-whorl as in the Kentish Snail. The mouth is strengthened by a white rib, but

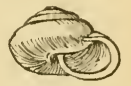

Carthusian Snail it is placed nearer the opening than in the las. species. Umbilicus narrow, and partly concealed by the growth of the lip. It occurs only in hollows of the South Downs in Kent and Sussex.

The Copse Snail (H. arbustorum) has a solid and very globular shell three-quarters of an inch across. Its colour is a pinkish brown splashed and spotted with yellow, and with a darker brown spiral line running just above the middle of the whorls. In many specimens the thin epidermis has largely perished. The mouth is strengthened by a broad white rib at the lip. The small umbilicus is almost hidden by the outer lip. Although its range extends throughout Great Britain, it is distinctly local in its occurrence, and does not appear to inhabit Ireland. Moist and shady woods, especially of alder and willow, and the neighbourhood of streams, are its favourite resorts. It is possible that this species finds abundant moisture a necessity, for Mr. T. Scott has recorded that a specimen kept in a kitchen knew the way to the cold-water tap which it was in the habit of visiting, and apparently enjoyed the water which fell upon it.

The Sandhill Snail(H.pisuna)-whose specific name 
indicates that the original description of it by Petiver was founded on specimens obtained at Pisa, in Italy - measures three-quarters of an inch across its five and a half whorls. The ground colour of the globular shell is yellowish white, over which runs a varying number of spiral brown lines and short oblique streaks. The mouth of the shell describes two-thirds of a circle, and is strengthened by a slight rib. The small umbilicus is partially closed by the expansion of the lip. The animal feeds in this country on Sea Holly (Eryngium maritimum) and thistles, to which it may be found clinging in the daytime in the few places it inhabits. These are in the neighbour-

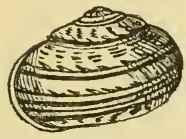

Sandhill Snail hood of Tenby and Manorbeer, in Pembroke; Swansea, where planted by Mr. Jeftreys; St. Ives and Whitsand Bay, in Cornwall; Meath and Dublin Counties in Ireland, and at Jersey and Guernsey. It is only found on sandhills close to the sea, and this fact implies that it may owe its presence in these islands to accidental importation with ballast from the Continent, where it is found far inland, as for example in central France and Spain. In the hot dry weather of summer it buries itself in the sand at the roots of plants. Not only does it skeletonise the plants mentioned-it also has a taste for animal food; the Rev. A. H. Cooke relates how he placed living specimens of this species and the Heath Snail (H. ericetorum) in a box together, but when they were inspected twenty-four hours later, pisana had cleaned out all the shells of ericetorum.

The Banded Snail (H. virgat $\iota$ ) is an exceedingly variable species, a dozen forms being sufficiently 


\section{Land-snails}

distinct to have received varictal names. It is very probable that $H$. pisana, cricetorum, and caperate have been evolved from this species. In the typical form the shell is conical, somewhat globose, and fairly solid, though not quite opaque. The ground colour is white or of a creamy tint. A brown band of varying breadth and tint runs spirally just above the periphery, and below this there may be five or more thinner and less distinct bands which are more or less broken and blurred. The tip of the raised spire is usually brown and shiny. The very regular curves of the mouth describe three-quarters of a circle, and a little way within a rib is formed in adult shells. In many cases the rib is coloured brown, but often it is white. The umbilicus is of moderate width, and deep. Among the varieties is one totally devoid of colour in which the spiral lines are still very evident owing to their being less opaque than the rest of the shell. The Banded Snail is widely distributed in England, Ireland, and Wales, but in Scotland appears to be found only in Ayrshire. It is most abundant along the south coast, especially in Cornwall, on Dartmoor, and along the South Downs. To get an accurate idea of its profusion in these parts it is advisable to walk out on the pastures after heavy summer rain; then one can excuse the local idea that these snails come not from among the herbage but from the heavens, as though they were hailstones. Fences, gates, stones, thistles, and grass stems are so thickly coated with them that one marvels how it is possible for them to find cover or food at other times. These mollusks have long been regarded as the source of the flavour peculiar to Down mutton, but I think 
it is usually considered that they are eaten inadvertently by the sheep in cropping the short grass. I am assured by intelligent Cornish farmers, however, that this is not so: when sheep are turned out to feed on the cliff-pastures they make by preference for those parts near the edge where the "sheepsnails" (H. virgute and $H$. acutc $)$ are most plentiful, and they thrive exceedingly upon them. They do not appear to hibernate. Full-grown specimens measure a little more than half an inch across.

The Heath Snail (H. ericetorum) is like a large Banded Snail that has been depressed until the spire is very little higher than the large body-whorl. White predominates as the ground colour in small specimens, but in large individuals it is chiefly cream or pale buff, only the top of the inner whorls being white; the bands are less numerous and not as deeply coloured. The mouth is more nearly round, and equal to four-fifths of a circle. The internal rib is only developed occasionally; and the umbilicus is very wide. Large specimens measure three-quarters of an inch across. It frequents dry pastures and downs, both inland and maritime, where it may be found about thistles and furze-bushes. It is very shy. Jeffreys describes it as going into hibernation in November, yet I have on several occasions found it in Surrey during mid-winter hanging to dead thistlestems and grasses on the borders of fields whose newly ploughed ridges were frozen hard. It is said to suffer from the attacks of the Devil's Coach-horse Beetle (Ocypus olens), which attacks it with its strong mandibles and eats it. It is widely distributed through the United Kingdom. 
The Wrinkled Snail (H. caperata) may be regarderl as a smaller edition of the Banded Snail in which the spiral lines have got broken up; though in typical specimens the principal band, just above the periphery, is well defined. Its ground tint is not white, but a pale fawn colour, and it is without the gloss of the three previous species. This last character is due to the growth lines across the whorls being here very prominent, as indicated in its names. It is also much depressed, and its umbilicus is relatively larger than that of $H$. virgate. The mouth is the same shape as in that species, and the animal has much the same trick of showing its abundance after rain. It inhabits the same situations as virgate, but is also frequently found in woods, on the trunks of beechtrees. Some forms are as conical as virgata, whilst others are as depressed as ericetorum.

Some of the varieties closely resemble varieties of virgata, but those of caperata can always be distinguished by the wrinkles. The var. ornate is smaller, with broader and darker bands, and the Rev. S. S. Pearce some Jears since, in the Journal of Conchology, explained why this variety is found almost exclusively on downs where sheep are pastured. Occurring with the ordinary mottled form, he argued, orncte was far more conspicuous, and therefore the sheep could avoid them, whereas the less conspicuous mottled forms were eaten, leaving more of the dark form to live and propagate their beneficent variation. Now this reasoning would be satisfactory, but for one thing: it proceeds on the assumption that sheep object to snails and wish to aroid them; whereas, as we have shown in the case 
of virgata, they esteem them as food. It is more likely that the dark colour of the shell may be accompanied by a difference in the flarour of the mollusk which renders them less palatable to the sheep, which have learned to avoid them by means of the colour.

The Pointed Snail (H. acutu), owing to the great height of the spire, resembles a Bulimus. Jeffreys, following Forbes and Hanley, actually included it in that genus; but by general agreement it has since been restored to the position originally assigned to it by Muiller. As will be seen from the figure, its shell is a cylindrical cone a little more than half an

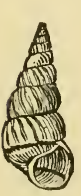

Pointed Snail inch high, of an impure white colour, streaked across the whorls with brown, and one or two spiral bands of dark brown or black-frequently reduced to one, which is restricted to the borly-whorl, and sometimes entirely wanting. The spire tapers regularly, but ends in a blunt tip. The oval mouth has a thin lip, and the narrow umbilicus is almost covered. It inhabits sandhills and grassy downs close to the sea, chiefly in the south and west of England; Wales; islands off the west coast of Scotland, and along the Irish coast. It is exceedingly abundant, and shares the double distinction with virgatc of being a "sheep snail" and being reputed to fall in showers from the clouds. Sheep are exceedingly fond of it, and I have often seen them feeding on dangerous loose edges of cliffs though precisely the same grasses grew on firm ground above, but in the former position this sheepsnail was abundant, and therefore the feed was more desirable. When the air is dry the snail glues the 


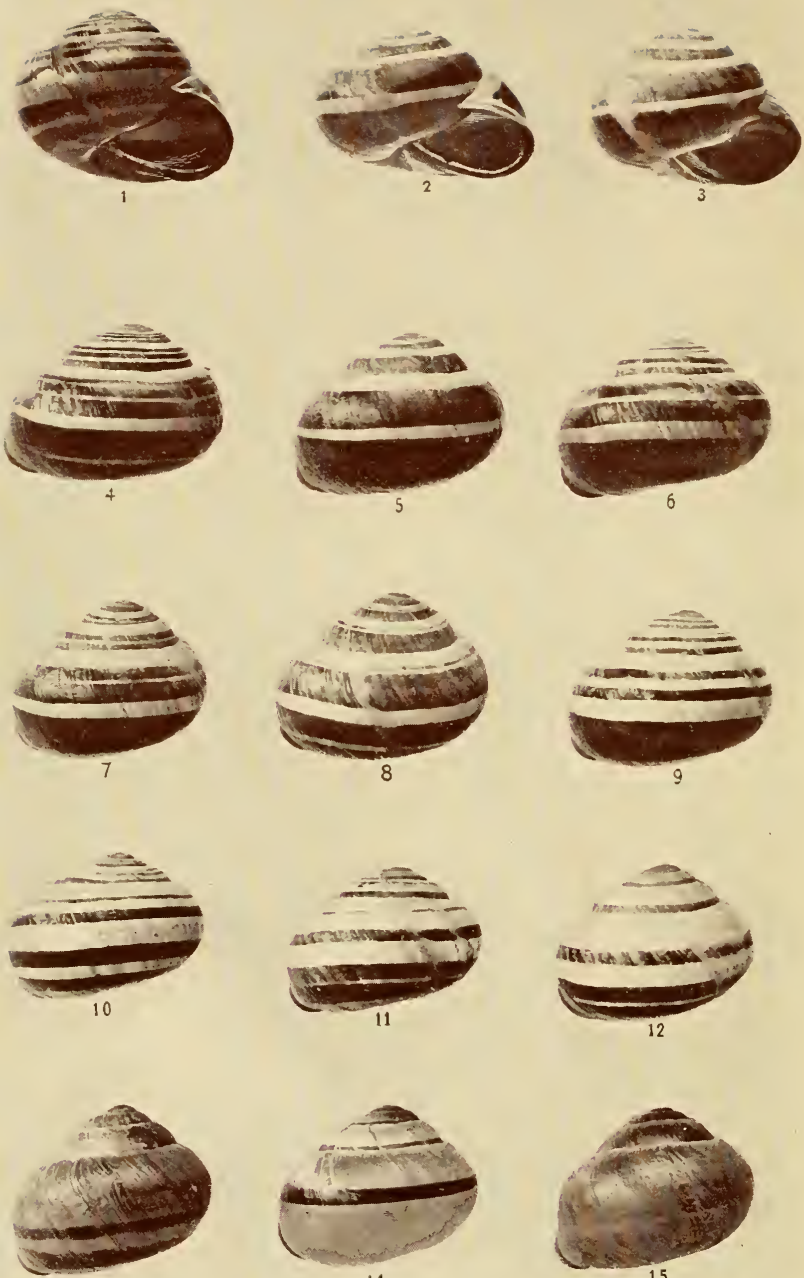

13

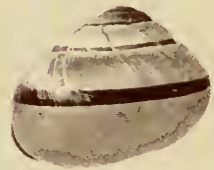

14

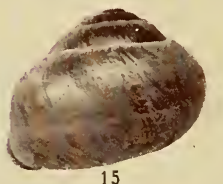

I TO I5 BROWN-LIPPED SNAIL (Helix nemoralis).

SHOWING SOME OF THE VARIATIONS IN COLOUR AND BANDING. 
lip of its shell to a grass stem and retires well inside.

The Brown-lipped Snail (H. nemorclis) is globular, or what would be regarded as the typical form of a snail's shell. Commonly the ground colour is a clear yellow, but it varies from white to pink and sometimes brown. Upon this are laid five cleanly marked brown spiral lines, of which the two broadest are below the periphery, and three narrower ones above. The epidermis is thin and glossy, but in many mature individuals it is more or less dull and perished. There are about five and a half whorls, and full-grown shells measure little short of 1 inch across. The mouth is an irregular crescent in shape, with the brown lip turned slightly outward and strengthened by a dark bar within. There is a narrow umbilicus, which is open until the shell is full-sized, when it is covered over entirely. There is considerable

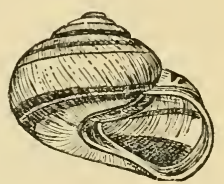

Brown-lipped Snail variation, as we have indicated, in the colouring of this shell, but a much greater amount is seen in the presence, absence, or amalgamation of some or all of the five spiral bands. In some, apart from the dark lip, the shell is quite unicolorous; in others only the central band is present. The three upper and the two lower bands may be united into two broad areas separated by a thin line of yellow and flanked above and below by the lighter tint; in fact nearly every possible permutation may be found in a large number of specimens. This snail is exceedingly abundant in hedgerows throughout the country. It appears to be specially partial to the Stinging Nettle as food and 
shelter, but on dewy evenings and after rain it roams freely over the adjacent hedges. It is the snail whose shelly fragments chiefly surround the thrush's sacrificial stone. It has long been a serious question among conchologists whether this and the form known as H.hortensis are distinct or one, and there are earnest and convinced advocates of each view. We agree with the "lumpers" that the possession of a pale lip and column can scarcely be held a sufficient reason for the separation of two forms that agree so closely in almost every point-especially when they are admittedly the most variable among our land shells in respect of colour and banding. However, for convenience we here treat them separately.

The White-lipped Snail (H. hortensis) agrees with the foregoing, except that it is usually somewhat smaller, with the mouth, rib, and central column pale coloured. It is found in similar situations to the dark-lipped form, but not often with it; and it is less widely distributed, though equally plentiful where it occurs.

The Common Garden Snail (H. aspersa) is far too common to please any gardener. Full-grown individuals measure nearly $1 \frac{1}{2}$ inches across the fivewhorled shell. The epidermis has a little gloss, but this soon passes, and as a rule its appearance is dull and shabby. The ground colour is normally a brownish yellow, over which run five very dark brown bands, but these are always much broken and the yellow appears across them in zigzag streaks. The spire is not much raised, and the tip of it is broad. The lip is white, thickened, and reflected. 

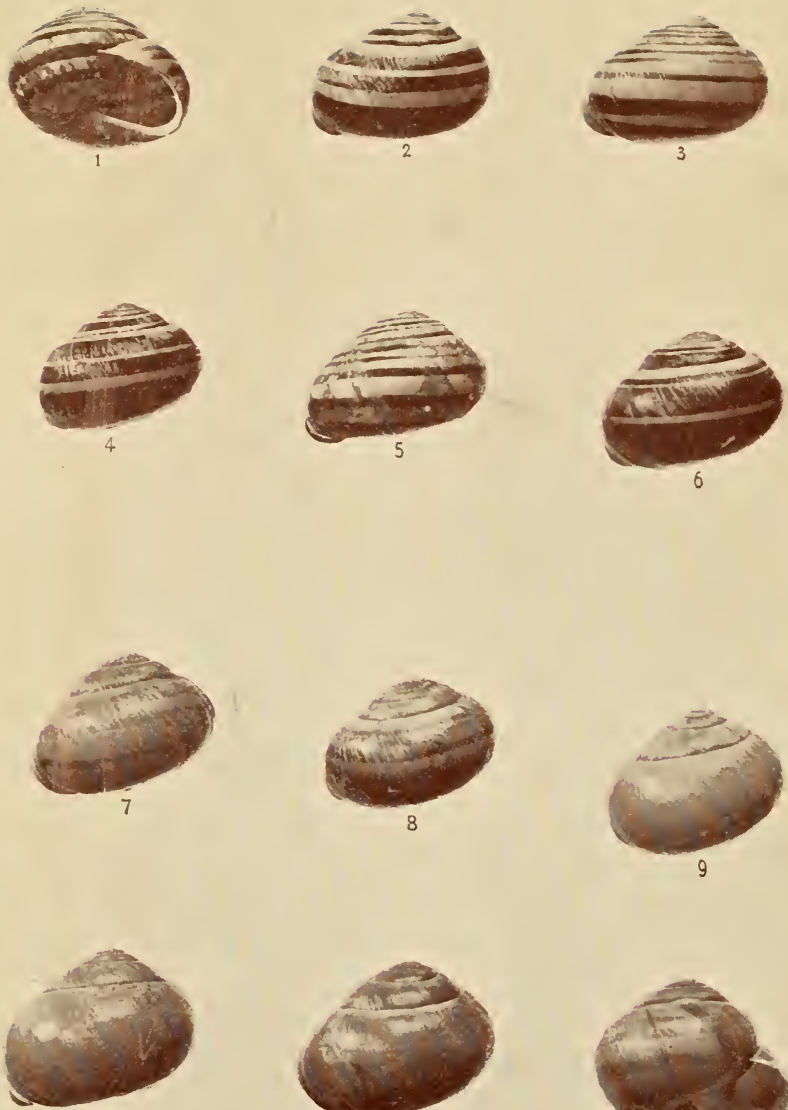

10
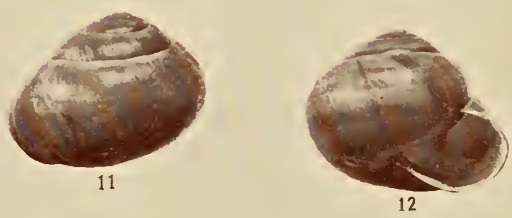

White-Lipped SNail (Helix hortensis)

SHOWING SOME OF THE VARIATIONS IN COLOUR AND BANDING. 

Umbilicus perceptible only in young specimens. The Garden Snail is widely distributed throughont these islands, and in some places is remarkably abundant. Each individual deposits about a hundred eggs, so that, unless the thrushes, blackbirds, and glow-worms come to his aid, the prospects of the cultivator are very bad. They go into hibernation rather early, many clustering together, and attaching the mouth to the shells of their fellows in some snug corner. They have their regular roosting place, from which marked individuals have been noted to emerge on their food-finding expeditions at evening, and returning to the identical spot next morning, much as the limpet does to his pit on the rocks. A few years since I noticed that a Richardia, that stood in a large pot in front of the house, had been much eaten, and a large thick-shelled aspersa was found clinging to the shady side of the pot. Pencilling my initals on his shell I hurled the snail as far as I could. Next morning he was again attached to the pot, though to regain it he had to cross a very broad road and climb a low wall. A second and a third time the same thing happened; but the third time his shell was a good deal damagred; and when, after again hurling him away, he did not return I concluded that the coastguard's foot had come upon him in the dark. Mr. C. Ashford, experimenting in the same way, marked seven asperse with white paint as they lay under a broken flagstone. At ten p.m. three of them had disappeared, but they were back next morning. That night at ten o'clock it was found that five had gone off', but the following morning six out of seven were at home again. The 
eggs are laid in cup-shaped hollows at the roots of grass, etc., and covered with a little earth. The snail becomes full-grown in about twelve months from the time of hatching, and lives about five years. This species appears still to be eaten in the north of England.

The Apple Snail or Roman Snail (H. pomatia) is the largest of our native species. The Garden Snail has usually an untidy vagabondish appearance, but the Apple Snail as constantly looks neat and clean. The ground colour of his shell is a creamy tint, and upon it are from three to five spiral bands usually of pale brown. The surface is not so smooth as in aspersa, the lines of growth being more distinctly raised. There are five whorls, and the mouth is nearly rouncl. The umbilicus is very small. The fact that this species is restricted in range to a few southern English counties, and its local occurrence even there, has caused a wide belief in the legend that it is not indigenous, but is one of those creature-comforts introduced by our Roman conquerors, and left behind as a contribution to the future civilisation of the British barbarians. Others have placed the date of its supposed introduction in the sixteenth century, and more than one individual has been indicated as the philanthropist to whom we are indebted for so fine an item in our molluscan fauna. The Pro-Romanists, however, point to a number of acknowledged sites of Roman camps and villas in whose neighbourhood this snail is found: here, say they, is evidence that the Romans and the snail were fellow colonists. On the other hand, those who put forward the autochthonic claim, point to the fact that there are many important Roman stations-such 

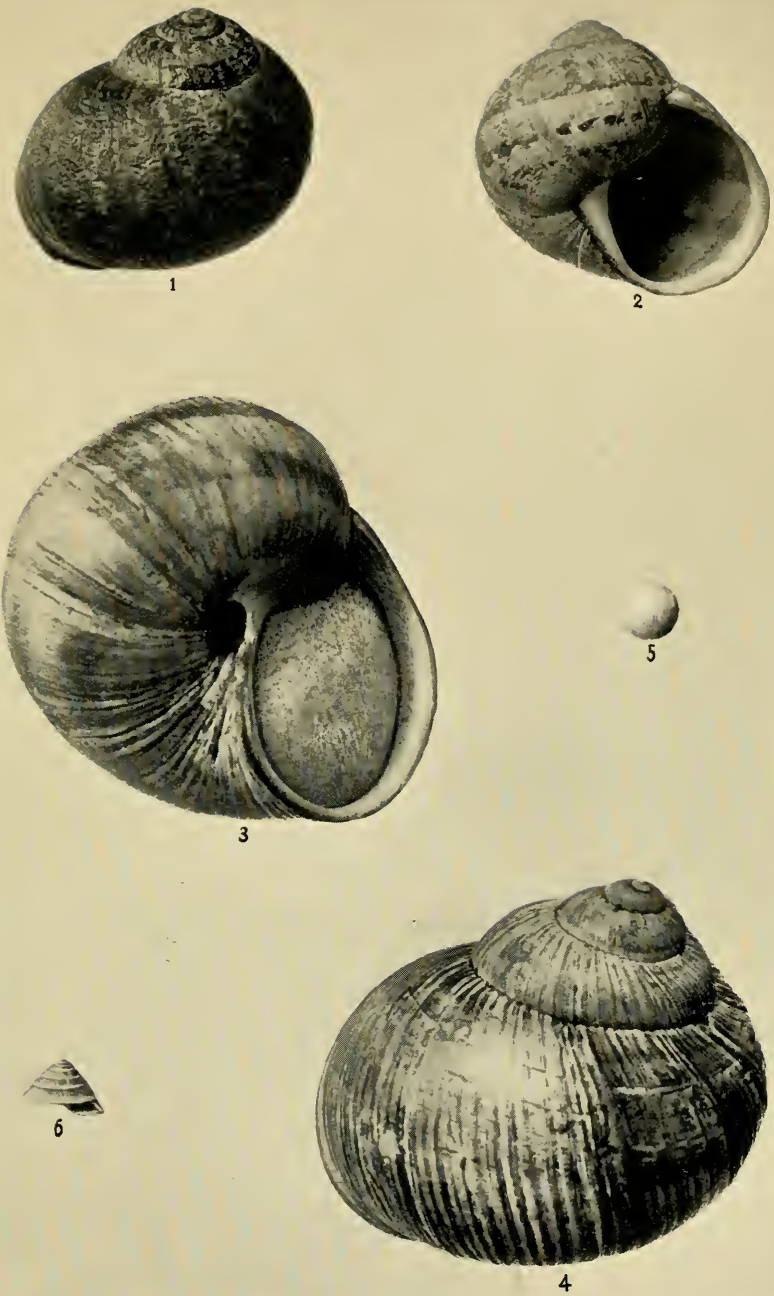

I, 2 Common Garden SNall; 3, 4 Aprle SNail (3 With epiphraga); 5 EgG OF APPli: SNAII; 6 Helix terRestris. 

as York-where there is no restige of the snail, whilst on the chalk ranges of the south it is abundant without the slightest regard to sites of Roman habitations.

There is a general impression that the name Applesnail is reflected in the specific name pomatia, but this is a mistake, the word being taken not from the Latin pomum, an apple, but from the Greek poma, a pot-lid. The reference here is to the solid chalky epiphragm with which it closes the mouth of its shell before hibernation. When the time comes for its winter rest it seeks the shelter of stubs in the copse, and there burrows down through the dead leaves, sometimes a little into the earth beneath them. With its slime it unites some of the leaves to form a roof, and then getting its shell in such a position that the mouth is upward, it constructs the thick epiphragm, and within that again an ordinary filmy epiphragm such as other species make. It is usual with snails to leave a minute aperture in the epiphragm to admit air, but this thick "pot-lid" of pomatic is not perforated; rather is it that the whole structure is porous, as though made of plaster of Paris, which it resembles. About April the mollusk wakes up and pushes aside its doors, coming out with a good appetite to feed on the tender young leaves. In May these snails pair, and in the first half of June they deposit their eggs.

In the year 1854 Mr. E. J. Lowe, F.R.S., communicated to the Royal Society some observations on the growth of land-snails, in which he stated that "most species bury themselves in the ground to increase the dimensions of their shells. H. pomatic and other shells (sic) retreat for that purpose in summer, having their 
heads and the mouths of their shells downwards." Although this statement was quoted by Jeffreys and most subsequent writers, it did not appear to be substantiated by further independent observation, and it always appeared to me to be founded on an error, because the beginning of shell enlargement is a delicate film which has to be hardened by exposure to dry air before the more mineral portions are spread upon it. Such a process seems impossible in the earth. On 9th June 1894, when in company with a party of fellow naturalists on the chalk-hills at Reigate, I felt sure at last that Mr. Lowe's theory was the right one, for I found dozens of $H$. pomatic with their shells partially buried in the chalky soil! Closer investigation, however, revealed the fact that instead of burying themselves for shell enlargement, the snails were excavating holes in which to deposit eggs. A number of snails were actually removed from above holes which they had roofed in, all but a small central aperture. Several of these chambers were opened, the eggs counted and removed. The internal space was equal to the size of the shell, and the contained eggs varied from seventeen to thirty'one ${ }^{1}$ in number. Probably it was the excavation of these pits-effected with the foot I imagine-that Mr. Lowe mistook for the beginning of restivation.

The eggrs of pomatic have a rough-surfaced, deadwhite, chalky shell, which may be blown like the egg of a bird, and will permanently retain its irregular roundish form. They hatch in from twenty to forty days, and the snail-chicks on emergence are as large

${ }^{1}$ Miss F. M. Hele tells me that her captive pomatic have laid as many as serenty eggs. 
as the egg-shell, which they use for their first meal after the manner of caterpillars.

In the Descent of Man, Darwin relates a circumstance that happened to Mr. Lonsilale, in which $H$. pomatic appear's in a new light. A couple of these snails were turned into a small garden butill-provided for their comfort, and one of them was in a sickly condition. Next door was a garden of a better sort, so when the robust snail climbed over the wall into this better land it looked as though friendship was not so strong as self-interest; and yet he had gone but as a pioneer to spy out the land and save his friend needless exertion should it prove to be less suitable than it appeared. About twenty-four hours later the absentee returned, and evidently gave the other a glowing account of the world beyond the wall, for they both started off on the same track and turned their backs on the unsatisfactory enclosure.

A very pretty snail of pyramidal form, with flat base and keeled whorls (H. terrestris), was found in the year 1890 by Mrs. M'Dakin, a few miles out of Dover. There was a colony extending for half a mile along a chalky bank by the roadside, far from houses and gardens. The snails climb tall grasses, like $H$. acuta; and they pass the winter among lumps of chalk, their shells closed by an epiphragm. It is almost certainly not a native, but was probably introduced from the shores of the Mediterranean some few years prior to Mrs. II'Dakin's discovery.

And now we have done not only with the great genus Helix, but with the family Helicide; the family Pupidee claims attention. In this family we shall find the shell of an elongated, more or less cylindrical 
form, the mouth narrowed, and often further reduced by tooth-like growths. The genus Buliminus, which has but two British representatives, agrees generally with Helix, but the tentacles of the animals are shorter, and the character of the lingual teeth is different, the rows being curved towards the margins. The Mountain Bulin (B. montanus) has a semi-transparent shell about two-thirds of an inch long, slightly glossy, and of a pale brown tint. The surface is crossed by delicate spiral and transverse lines, the crossing of which gives the shell the appearance of being minutely shagreened. Mountain Bulin

There are seven and a half whorls, the bodywhorl accounting for one-half the shell. The oval mouth, which has a white lip, is reddish within. It is found on the trunks of ash, beech, and hornbeam, in Somerset, Oxfordshire, Gloucestershire, and Suffolk only. The Lesser Bulin (B. obscurus) is very like it, but smaller - a little more than one-third of an inch long. It is further distinguished from the very similar montanus by being more glossy, the absence of spiral lines preventing the shagreened appearance of its congener; there are only six and a half whorls, the lip is not so thick, the inside of the mouth is white, and the body-whorl is only equal to two-fifths of the whole. It is an inactive creature, sticking on the bark of trees (beech

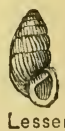
Bulin chiefly), apparently feeding upon the immature mosses and lichens that grow thereon, and disguising itself so that snail-hunting birds may pass it as a bit of dirt or one of the small knots that are so common on beech bark. It does this by covering its shell with slime and dragging it across dirt of various 
kinds, which gets picked up by the slime. The process several times repeated, the shell soon bears no resemblance to itself. The young of $B$. montanus sometimes cover's itself in the same way, as does the young of the next species.

The snails of the genus Pupc are elongated like those of Buliminus, but the spire ends in a short point. The mouth, which is usually horse-shoe shaped, or half-oval, is guarded by teeth or spiral plaits or folds. Some of the animals have the lower pair of tentacles in a rudimentary condition, or they are altogrether wanting; these are sometimes separated to form another genus, Vertigo. There are fourteen native species, and most of these are so minute that we shall not attempt to give distinguishing descriptions of each, but a list of them will be found in the Appendix. They are social in their habits, and where one or two specimens are found a slight search will scon be rewarded by the discovery of others. Old mossy walls with crevices, stone dikes, the loose bark of trees, and among moss, are the favourite resorts of these Chrysalis-snails.

The Large Chrysalis-snail $(P$. secule) is only large by comparison with the others; it is about one-third of an inch in length. There are eight or nine yellow-brown whorls, of which the last four are of pretty equal width. The mouth is largely occupied by eight or nine tooth-like extensions of the thickened lip. It is a local form, found on rocks and in woods in England

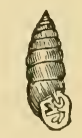

Large Chrysalissnail only, and chiefly in the south. P.cylindracea is the most widely distributed of the genus. It is about one-seventh of an inch long, almost oral in form; the 
almost triangular mouth with a tooth on the pillar and one on the pillar-lip. P. anglica, found no farther south than Herefordshire, measures only one-twelfth of an inch, and has a semicircular mouth protected by seven or eight teeth. P. muscorum is one-seventh of an inch, has a white rib outside the lip, and a small tooth on the pillar. Widely distributed south of Scotland. $P$. edentule, of similar proportions to the last, has a semi-oval mouth without teeth. Generally distributed. P. minutissinuc is similar to the last, but smaller (one-twelfth of an inch), without teeth. Recorded only from the Isle of Wight, south-west Yorkshire, Durham ; Edinburghshire; and Kerry. $P$. clpestris, one-twelfth of an inch, has a semi-oval mouth with four or fire teeth. It occurs only in southwest Yorks, south Northumberland, Westmoreland, and County Londonderry. $\quad P$. lilljeborgi, one-tenth of an inch, globose, mouth semi-oval, with four equidistant teeth, strengthened by a slight rib outside. Found only in County Galway. P. moulinsiana, similar to the last, but nore barrel-shaped, and with a stronger rib outside lip. Found only at Otterbourne, Hants; Hitchin and Rye House, Herts. P. pygmeed, oval, one-tenth of an inch, mouth strengthened by an outer rib which protrudes slightly inside and from which spring two or three of the four or five teeth. Common, and widely distributed. P. substricate, one-twelfth of an inch, mouth somewhat pear-shaped, with from four to six teeth, two or three of which spring from a white rib inside the outer lip. Occurs in Anglesey, Derbyshire, south-west Yorks, Durham; and County Londonderry. $P$. antivertigo, one-twelfth of an inch, mouth half-oval with from six to ten red-brown teeth, and strengthened 
by an external rib. IIoderately common. $P$. pusilla and $P$. angustior differ from all the rest in having sinistral shells, i.e. the mouth opening faces our left side as we look at it. P. pusillu is onefourteenth of an inch, the mouth triangularoval, with six or seven teeth, and a strong antivertigo yellowish-white rib both inside and outside. It is very local, but has been reported from north Devon, Oxfordshire, Notts, Derbyshire, west Yorks, Durham, Northumberland; Ayrshire; and County Londonderry. $P$. angustior is only one-sixteenth of an inch, and proportionately narrower than pusillu; the mouth more triangular and narrow, with four or five teeth, and a rib as in the previous species. It occurs at the roots of grass in wet places, but is very local. Its recorded stations are in Derbyshire, Yorks; Sutherland; County Londonderry, Sligo, Galway west, Cork south.

It is to be presumed that the teeth, which are so important a character of these shells, serve a practical purpose in keeping out minute insect enemies which frequent the same situations.

The Tree Snail (Balea perversa) is the sole British representative of its genus. It is not greatly unlike a Buliminus. The animal is much the same,

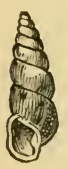
Tree Snail though its teeth and their arrangement on the radula are different. There is a central tooth with 20 laterals on either side in each row, and the number of rows is 130--a total of 5330 . The shell is club-shaped, thin and glossy, coiled to the left as in P.pusilla; yellowish brown in colour. The mouth is somewhat pear-shaped, without teeth, except that occasionally full-grown specimens are found with a small one near the 
centre of the base of the linst whorl but one. The length of the shell is about one-third of an inch. It affects old mossy trees and lichened rocks, hiding under the loose bark of the one, and in crevices of the other so long as the air is dry; but after rain the whole colony walks out upon the surface. It is widely distributed, but local.

The Door-shells (Clausilia) belong to a very extensive genus, nearly a thousand species being known, but in this country represented by four species only. These are spindle-shaped, twisted to the left like Balea, contracted into a throat behind the pear-shaped mouth. Within the mouth are seen two spiral plates, and on turning the shell over these may be traced through the shell some distance into the body-whorl. In some species there are intermediate ridges on the pillar and the outer lip. Within the throat there is a narrow twisted plate of shelly matter, attached to the

Plaited Doorshell pillar by an elastic foot. This plate is the clausilium, which automatically closes the throat when the mollusk withdraws inside, and which is pushed aside when the animal emerges, and so acts as an operculum. The clausilium is obviously a protection from the inroads of beetles of the family Staphylinicle and other small insects, but it is strange that such defence should not be provided until the mollusk has reached maturity. Until the shell is nearly full-grown there is no sign of this device. There is a slight slit-like umbilicus almost hidden by the thickened and expanded lip. They are all herbivorous, and probably at times retain their eggs until hatched. 

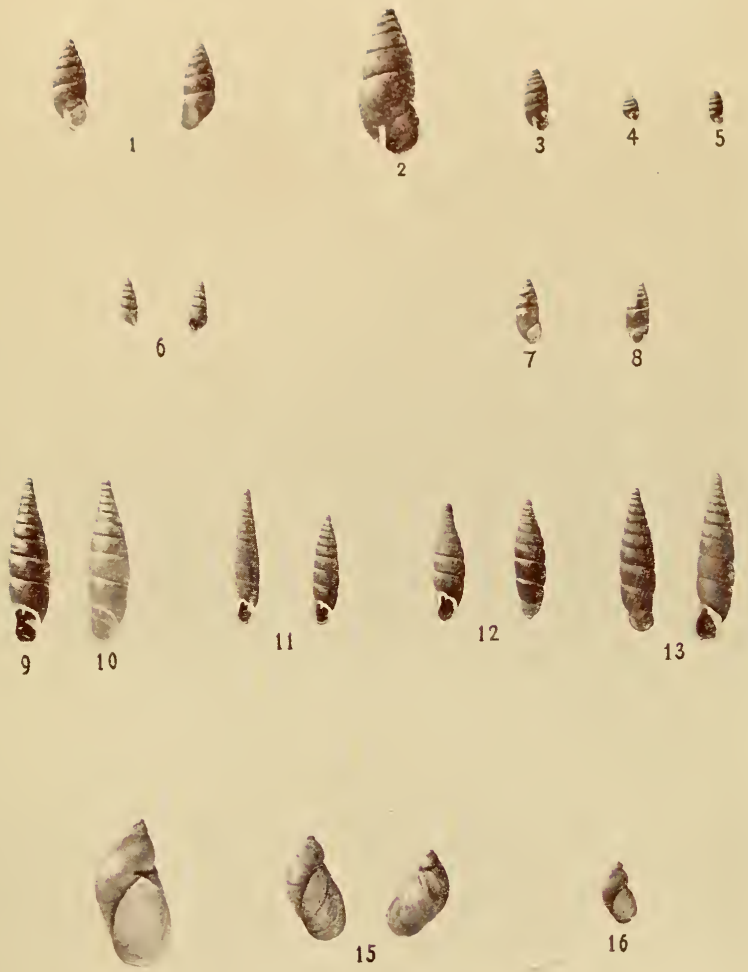

14

I Lesser Bulin ; 2 Mountain Bulin ; 3 Large Chrysal.is-snall. ; 4 Plpa anglica; 5 Pupa muscorum; 6 Tree Snall; 7 Sllppers Moss-snall; 8 Thrlie-Toothed Mloss-SNaIL; 9 PI.AITED DOOR-SHELl AND WhITE Varifty (10); II Two-Toothed

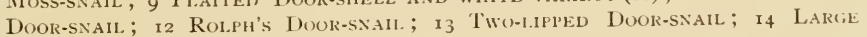

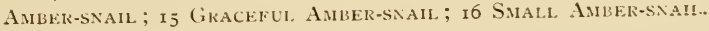



The Plaited Door-shell (C: laminate) is smooth and glossy, semi-transparent, yellow - brown in the upper half deepening to ruddy-brown below. The whorls are more rounded than in the other species, and the teeth in the pillar are stronger. There are three or four plaits or folds within the outer lip, which are visible through the shell. The oblong clausilium has a deep marginal notch near the base. The length of the shell is two-thirds of an inch. Although we must call it a local species it is widely distributed over England and Wales from Northumberland to North Devon and the Channel Islands; it also occurs in Perthshire. It feeds upon mosses and the germinating spores of lichens, etc., which abound on tree-trunks. Ash and beech are its favourite trees, especially beech, whose trunks it ascends at erening, spending the day - except in wet weather - in the angles between the roots. There appears to be a protective value in the shape, size, and tint of their shells, in spring-time, at least, when in their first journeys up the trunk they are more exposed to the scrutiny of birds. At this time the brown envelopes of the beech buds are falling in millions and stick on bark and moss, and as these exactly resemble the laminata shells birds in searching for the latter must have a trying time. In the angles between the roots numbers of these envelopes gather and persist for months; there also under these $C$. laminata will be found gregarious. The eggs are described by BouchardChantereaux as of enormous size when compared with the animal, to be even larger than the mouth of the shell, and to number about a dozen. Deposited in August or September, they hatch in three weeks, and 
the young arrive at full size in two years. I have found the white variety in plenty living in caverns wrought by other creatures in the rotten stump of a felled beech, and fancy the deficiency of colour may be clue to the darkness of their habitat. The greenishwhite shell is certainly more protective amid such surroundings than the ordinary colour would be; and it is not difficult to realise how natural selection would bring about a distinct race of white Clausilias under such conditions.

The Two-lipped Door-shell (C. biplicata) is slightly less in size than $C$. laminata, and instead of being

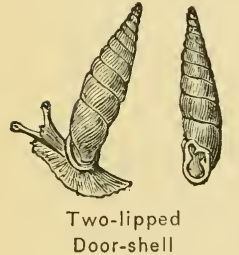
rounded and glossy the whorls are compressed and closely covered by fine but distinct ridges, some of which are half white. It is a duller, more grey-looking shell than that of the glossy laminata, but a further distinction is found in the mouth. In laminate this is contracted above into a narrow channel like the lip of a jug; in biplicuta there is such a lip below as well as above. It is a very rare species, and has only been recorded from the counties of Wilts, London, and Herts. The London localities lie along the Thames between Putney and Hammersmith, but recent municipal "improvements" have at least restricted these. Fifteen or sixteen years ago at Putney I could always put my hand on a few specimens for a conchological friend, but I understand that an embankment of the most solid type has improved away my particular hunting ground and buried the Clausilias. Biplicata spends its days at the roots of willow-trees, and at night ascends the trunks. 
The Two-toothed Door-shell (C. bidentat $\iota)$ is generally similar to the last named, but much smaller (half an inch long) and more slender in proportion. The whorls are covered with ridges in like manner, but these are not so high as in biplicutu. The mouth, too, is similar, though smaller, but the base is rounder, less channelled than in the last. The clausilia of the last species, this, and the next, differ from that of laminate in not being notched. This is a very variable as well as abundant shell. On mossy walls, stone dikes, and the trunks of trees throughout these islands, it may be found in great numbers. Jeffreys expresses a form of astonishment produced by specimens that were partially smooth, and which Dr. Turton and himself once considered to be the Continental C. parvulu. Such examples are common, and if Jeffreys had examined them with a lens he would have discovered that the ridges are almost entirely a matter of epidermis, and that where this has been removed by abrasion in dragging the shell into narrow chinks, or by the radula of a brother, the shell is left nearly smoothagreeing well with his own description of $C$. parvula, "quite smooth with the exception of some very faint transverse lines, which are only observable with a lens."

Rolph's Door-shell ( $C$. rolphi $i)$ is about the same length as $C$. bidentata, but of greater breadth and of thinner material, and covered with a slightly glossy red-brown epidermis which is wrinkled into ridges as in the last species. In many specimens the ridges have almost entirely disappeared, leaving a dull dirty grey surface. There are fewer whorls-nine or ten 
as compared with twelve or thirteen in the other species. The mouth is much the same as in biclentutu. One mark of distinction given by authors is the presence in rolphi of several minute teeth between the folds on the pillar; but this is not reliable, for I have specimens of bidentata with these teeth. The chief differences between the two consist in the more slender proportions of bidentata, the coarser ridges of rolphi, the larger and broader mouth of the latter, and its lighter colour. It occurs among dead leaves and under the bark of trees. It is distinctly local, its distribution in these islands being restricted to the following English counties:-Hants north, Sussex, Kent, Surrey, Berks, Gloster east, and Notts.

The family Stenogyride is represented in this country by two genera and three species of small snails. The animals have the radula teeth arranged as follows: central tooth small and narrow, the lateral teeth much larger, with their ends divided into three points, of which the central is the largest, and the marginal teeth are similar to the laterals, but swollen. The shell is a long dextral spiral with a blunt apex, more or less translucent and shining.

The Slippery Moss-snail (Ferussacia lubrica) well deserves its name, for it is so excessively glossy that it readily slips through the fingers and vanishes among the moss. There are only five whorls of a pale yellow-brown tint, Slippery Moss-snail transparent, the last whorl being equal to half the shell. Mouth nearly oval, the lip thickened within and rounded. It is found among moss and at the roots of grass; also under stones, 


\section{Land-snails}

dead leaves, and decaying wood, in damp and shady situations. So habituated is it to damp that it can endure immersion for several hours, a degree of endurance fostered probably by the occasional flooding of its launts, drowning off those less hardy in this respect. It is generally distributer. Length, a quarter of an inch.

The Three-toothed Moss-snail ( $F$. tridens) is of much the same dimensions as the last, but owing to the seven whorls being individually less rounded its outline is not broken by the sutures. The colour, too, has a suggestion of red in it, which is more evident about the lip. The mouth would be pear-shaped but for three strong teeth arising from the very thick lip. It lives gregariously among moss

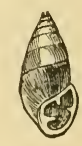

Threetoothed Moss-snail and dead leaves in woods, but it is local, one might almost say rare. Its range extends from Cornwall and Sussex to Northumberland.

The Agate Snail (C'ecilianella acicula), though only about one-fifth of an inch in length, is interesting on
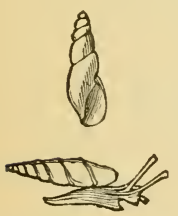

Agate Snail several grounds. It is entirely subterranean in its habits, it is blind, and it is carnivorous, or at least supposed to exist upon animal matter. The animal is white and almost transparent; its shell also is of ivory-whiteness, thin and transparent, with an iridescent gloss. It lives at a depth of from 1 to 3 feet below the surface, and to show preference for the neighbourhood of burying grounds. It never comes to the surface unless turned up by the spade, or thrown out of their burrows by rabbits. As a consequence the search for 
it is attended with some difficulty. It is very local, and does not appear to have been recorded for Wales, Scotland, or Ireland.

The Amber Snails represent the family Succineide, and comprise four native species. The animals are of

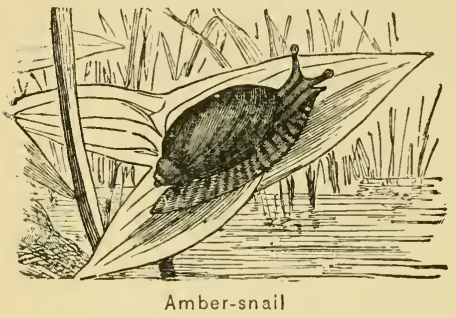
a gelatinous consistency, and are usually a little too big for their shells. There are four tentacles, but the lower pair are very short (in some species wanting). The foot is large and oblong. The characters of the radula are shown in the figure below of the median and lateral teeth. A complete row consists of 65 teeth, and there are 50 rows, or 3250 in all. The shell is very thin, containing little mineral matter, amber coloured, with a short dextral spire, a large body-whorl and mouth. They frequent the margins of lakes, ponds, and ditches, feeding upon the vegetation, and capable of enduring temporary submersion, which is

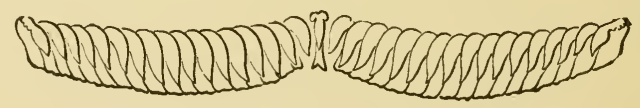

Row of teeth of radula of Succinea putris

probably often of a voluntary character. They may sometimes be seen floating on the surface, shell downwards after the manner of Limnoa and Physa.

The Large Amber Snail (Succinec putris) has a semi-transparent oval shell of three or four whorls, the last being equal to four-fifths of the whole shell, 
with an oval mouth. It is very common on the aërial portions of plants growing in the water. Specimens are sometimes found with the tentacles abnormally distended, a feature that would be sufficient to cause some enthusiastic "splitter" to make a new species of it, dubbing it crussicornis! But this is really

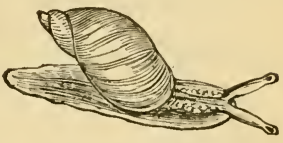

Large Amber Snail a similar case to that mentioned in connection with Limncec truncatula and the Liver Fluke in an earlier chapter. In the present instance it is a fluke that is destructive to birds-Distoma macrostomum. Birds like the blackbird, thrush, and wagtail are very partial to Amber Snails, and the parasite having hereditary knowledge of the fact, gets its young into S. putris, where they push their way into the tentacles and thrive at the snail's expense. But the completion of their life cycle must take place in the body of a vertebrate; so when the Amber Snail is eaten by the bird, the Distoma is in a position to fulfil its destiny. The Graceful Amber Snail (S. elegans) has a darker and more slender shell, with a longer and sharper spire, but it is open to doubt if it is anything more than a

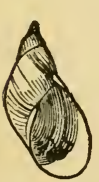

Graceful Amber Snail variety of $S$. putris, with which it is found, and, according to Rimmer, with which it couples. The Small Amber Snail (S. oblonga) has certainly more claim to be considered distinct, for its form is nearer to that of Limncece and its habitat is different. The shell is oblong-oval, rather solid, brownish, and with a proportionately large spire, the body-whorl being equal to only two-thirds of the whole. The mouth is rounder than in the other species. Its length is 
about a quarter of an inch. Instead of frequenting watersides it prefers ditches that are dry, and to retire beneath stones, but it is very restricted in its stations so far as they have been discovered in this country. It has been found in north-east Yorks, in Glamorganshire, in Edinburghshire, and in County Cork.

The last of these land Mollusca that we have to notice is a very remarkable creature, the solitary British representative of the family Onchidiidce. It is a little-known slug, Onclidiella celtica, which is found only on the Cornish and south Devon coasts, where little colonies live so near the sea that, following the ebb and retiring before the flowing tide, the waves break over them without permanently submerging them. The young are provided with a shell, but this is afterwards cast off, and the adult is only covered by a thick warty mantle. In some species some of these warts bear sense-organs or "eye-spots." There is only one pair of tentacles, supporting the eyes. The sexual orifices are widely separate, that of the male under the right tentacle, that of the female at the end of the body. There is no pulmonary chamber as in all the snails and slugs we have been describing, and breathing has to be performed through the skin and the warts on the back. Their food consists of sand-or rather they eat sand in order to digest out the particles of organic matter that have become mixed with it. They are regarded as air-breathing land-mollusks that are reverting to a marine or semi-marine mode of life. 


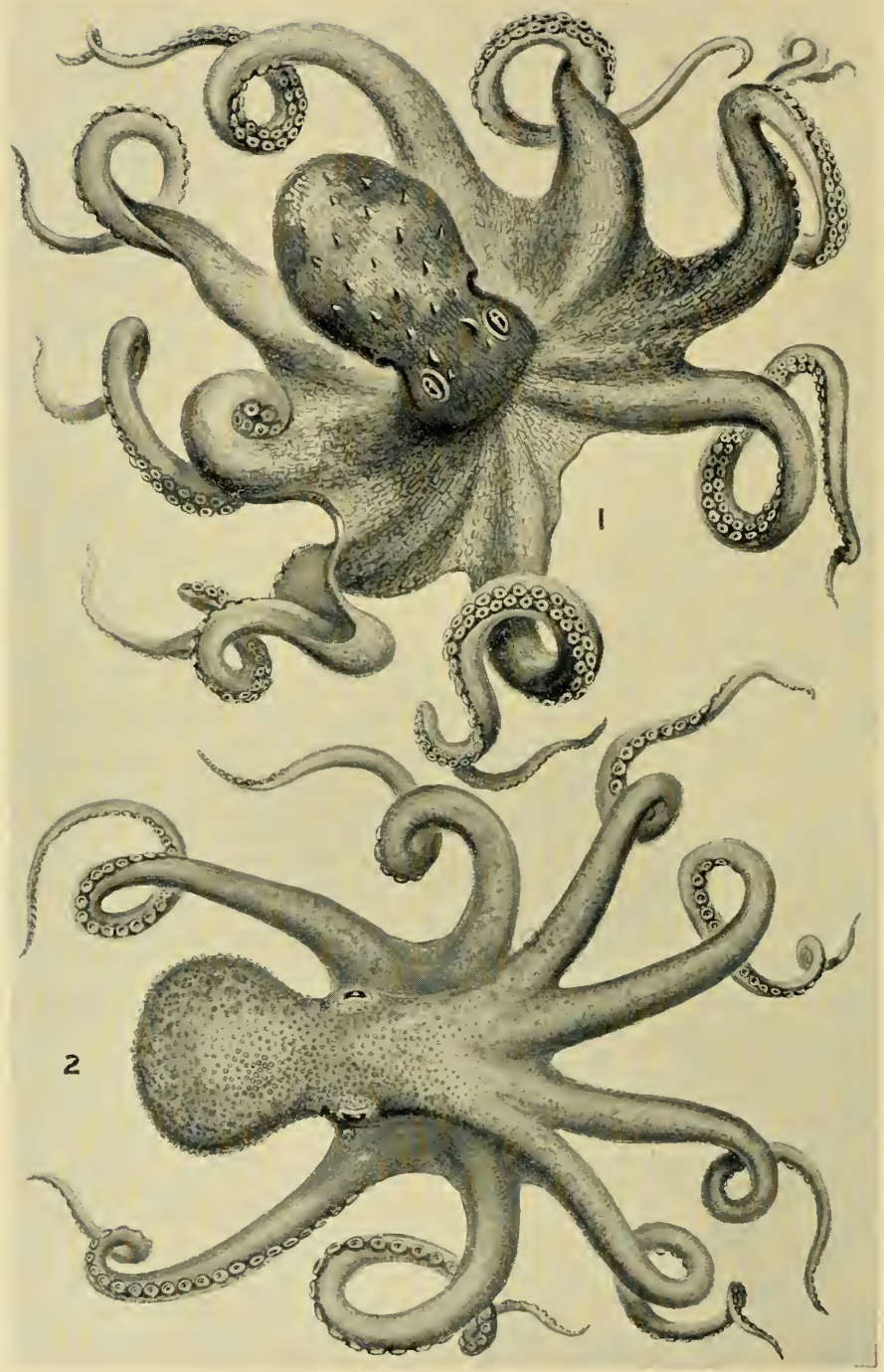

I Comnon Octopus; 2 Curled Octopus. 


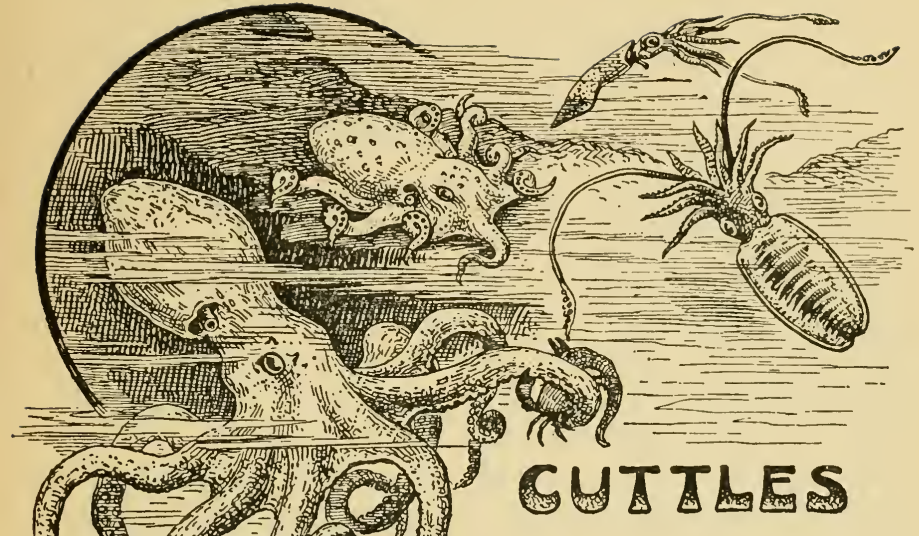

UTTLE-FISHES is the orthodox popular name, but as the compound word implies a creature very different from any mollusk, the less it is used the better. At first sight it is difficult to imagine that the remarkable creatures included in the class Cephalopoda have anything but the most remote relationship to the slugs, snails, and bivalves treated in the foregoing chapters. It is by far the most highly organised class of Mollusca, and there does not appear to be any existing forms helping to bridge over the gulf between it and the other classes. As all the British species belong to the order Dibranchia, our remarks will apply only to them as types of the class. Unlike most mollusks they are symmetrical animals, the right and left sides being equally developed. The shell, variously 
modified, is internal, though the Nautilus of the order Tetrabranchiata possesses an external shell. They have powerful jaws developed into some semblance to a parrot's mandibles, and acting like these. Within these jaws there is a comparatively small radula, the jaws preforming much of the work falling upon this organ among the Gasteropoda. The teeth are not numerous, and they do not exhibit that great diversity of form and size seen in other groups. This is largely due to the fact that the Cephalopods are all carnivorous; and the uniformity of food produces similarity of teeth.

Their bodies are divided-not always distinctlyinto two regions, the head and the trunk. The head is encircled by eight so-called "arms," connected at their bases by a skin. Attention to the embryonic development of Cuttles shows that these arms are analogous to the "foot" in the Gasteropods. At first the mouth is in advance of them, but ultimately they come to encircle it. Beneath the arms are two large eyes, much more highly specialised than in other mollusks but differing in structure from the eyes of vertebrates. There is a transparent cornea, an anterior optic chamber between it and the lens, an iris, a posterior optic chamber, and a retina. These eyes are serviceable not merely for transmitting light sensations to the nervous system as in the snails, but for actual observation, as may be proved by experiment. Owing to the concentration of the chief nerve ganglia into one unbroken mass, we have in the Cuttles the nearest approach to a brain afforded by the Mollusca. The inner face of the arms is 
covered by rows of stalked or sessile suckers of such great clinging power that the arm itself may be torn to pieces before the suckers will leave the surface to which they have been attached. In the sub-order Octopoda these suckers are entirely fleshy, but in the Decapoda they have a horny rim - sometimes toothed. The suckers are disks depressed in the middle, which can be worked piston-fashion. When the margins have been applied to any surface the centre is withdrawn, and a vacuum created which ensures a powerful attachment. One of the arms in the malethe sexes being separate in the Cuttles - undergoes a change, and is charged with

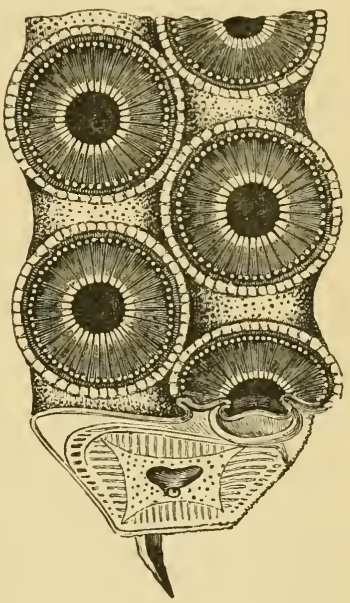

Suckers of Cuttle spermatozoa, but it is never detached as in some exotic species.

The heart consists of two auricles connecting with the two branchiæ which give the name to this order. After the oxygenated blood has been received from these organs into the single ventricle it is distributed fore and aft to the creature's body by the two aortæ and the connected arteries, returning to the branchiæ later by veins. The so-called "funnel" comes out on the lower surface forward. It is the general excretory organ, and connected with it is the inksac. This is divided into two portions, the ink-gland 
in which the ink is produced, and a larger cavity call the ink-reservoir in which a store of diluted ink is kept always ready for use. A long tube connects this with the neck of the funnel, its opening being guarded by a double set of sphincter muscles. When danger threatens a quantity of ink is discharged into the funnel, and the rectum being forcibly emptied the stream carries the ink into the sea and surrounds the mollusk with an aqueous cloud, under cover of which it makes off. The stream of water from the funnel also has the effect of sending the Cuttle quickly backwards through the water.

Another important feature of these mollusks is found in the spots of colouring matter with which the skin is dotted. These pigment-spots are so much under the control of the nervous system that they can be instantly dilated or contracted at the will of the animal. It is by this means that the chameleon-like changes of colour are so rapidly effected, and the creature so harmonised with the hue of its immediate surroundings as to becone practically invisible.

The sub-order Octopoda presents us with the species most familiar to "the man in the street" by reason of its frequent representation pictorially, and by the presence of living examples in our large public aquaria. In the quiescent condition they are very unsightly creatures, the body consisting of a rounded bag, above which stare the great eyes, whilst the long arms coil about it in all directions. We have two species.

The Common Octopus (Octopus vulgaris) is chiefly found along the south coast and in the Channel 
Islands, but it is also recorded from Liverpool, Lamlash Bay, the Firth of Forth, and the Irish coasts. The young are gregarious, but the adult lives a solitary life in some rock cavity of the laminarian zone, the door of which is strewn with the broken shells of the bivalves upon which he chiefly subsists. The arms are connected at their base by a thick web, and the suckers are arranged on them in two rows. There is no shell, though it is indicated by the presence of two small stylets embedded in the mantle. The colour is normally dusky, varying to purplish, yellowish, or grey, and spotted with orange, brown, and purple. The length of the body without the arms is only about 6 inches, but the eight arms measure a couple of feet each. In the male there is a peculiar modification (lectocotylus) of the third arm on the right side. It is much shorter than the others, has very few suckers, and ends in a flat plate which connects with the basal web by a groove in the skin. The spermatozoa are produced in little cylindrical packets (spermatophores), which are probably passed along this groove to the terminal plate. The male of Sepic has been seen to attach similar spermatophores to the female, and it may be presumed that a similar transference takes place in Octopus. In certain genera (Argonauta, Ocythoe, and Tremoctopus) of this sub-order, the specialised arm itself, charged with spermatophores, is detached by the male and left with the female. When the ova are discharged these packets open and their contents fertilise the eggs. These, to the number of several thousands, are attached to a central cord in long cylindrical masses. 
A second species, 0 . arcticus, was captured by trawling in deep water off the south of Ireland in 1889 by Mr. G. C. Bourne.

The genus Eledone, which differs from Octopus in having only one row of suckers, is represented by a single species.

The Curled Octopus (E. cirrosa) is not so repulsive as the common species in appearance, the eyes not being so large and staring, and the arms being more proportioned to the size of the body. The body measures about 6 inches, and the arms are only twice that length. The upper surface is dotted with reddish brown, the under-side is bluish white with larger and more regularly disposed spots. The eyes are orange coloured, with silvery white lids. It is as distinctly a northern species as 0 . vulgaris is a southern form; but as well as being fairly plentiful in deep water off the Scottish coasts, Tenby, North Wales, south-west Ireland, and the Butt of Lewis, it occasionally turns up at Plymouth Sound, Falmouth, and Mount's Bay in the far south.

These are our only eight-armed species. In all the rest the eight arms are supplemented by two others of a different shape, having a different origin, and called tentacles. Cuttles of this character form the sub-order Decapoda. Their sides are developerl into fins, the margin of the mantle "buttons" to the base of the funnel, and there is an internal shell. The tentacular arms are three or four times the length of the ordinary arms, their ends with flat expansions which alone bear the suckers. One member of this sub-order, Spirula peronii, abounds on the Atlantic coast, and its delicate shell, which is 
chambered like that of the nautilus, is brought across the ocean by the Gulf Stream and afterwards drifted by currents to our southern and western shores; but the living animal has not been so transported, and in its native waters the animal is "scarcely ever seen. Our knowledge of it is by no means reliable, because

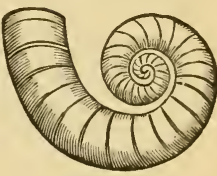

Spirula peronii only damaged specimens of the mollusk have been

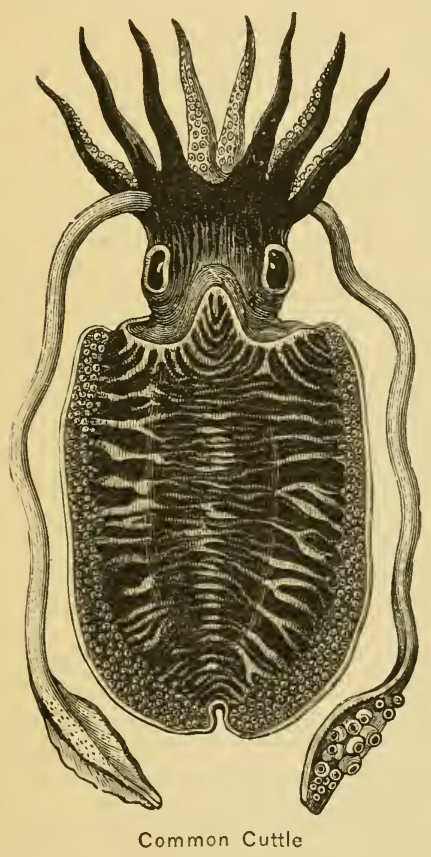
found. We give a figure of the shell for the purpose of identification.

The family Sepiide possess an internal shell which is well known as "Cuttle - bone," being largely used by bird fanciers for their pets to peck at, and formerly much in request for making "pounce," now superseded by blottingpaper.

The Common Cuttle (Sepia officinalis), whose shell is a common object on many shores all round these islands, has been well-known from antiquity. The ancients used its ink for writing and painting, and its shell in medicine as an antacid. The animal is not by any means a familiar sight, and 
there is little doubt that we owe the abundance of well-cleaned shells cast up on our rocks and beaches to the steady efforts of the conger and other large fishes to keep down the numbers of Cuttles. Its form is well represented in the preceding figure. Its broad brown back is striped with white, zebra fashion,

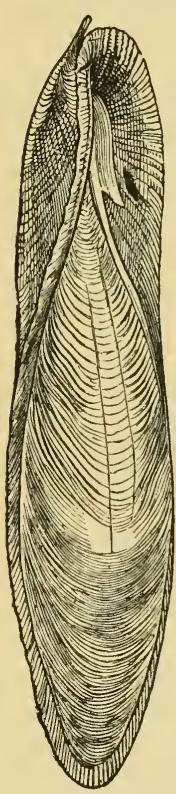

Shell of Sepia and dotted with purple and white. The margins form thin narrow fins. The arms are short, but the tentacles are very long, the expansions at the tip covered with unequal suckers. When not in use the two tentacles are entirely withdrawn into pockets in the hear. The suckers, as in all the Decapods, are stalked, and have horny rings. Those on the arms are in four rows, and are pretty regular in size. The head is much narrower than the body, and the prominent eyes are black. Its length is about a foot, without the tentacles. The shell or "bone" is about threequarters of the animal's length, of a broad lance-shape, with a border of cartilage, and almost filled with thin overlapping plates of a soft porous shellmatter, which is exceedingly buoyant, and which may be powdered by the finger-nail. Among the maritime population in Cornwall the name is Cuddle, and this no doubt is the correct form of a word having a common origin with our modern verb cuddle, and referring to the embracing action of the arms.

$S$. rupellaria is a much smaller species (3 inches 
long), of a greyish-pink colour spotted with purplebrown. The suckers are in two rows on some arms and in three rows on others. The shell is more lanceshaped and slender, $2 \frac{1}{2}$ inches long; its convex side of a rosy flesh tint. The complete mollusk was taken by Laughrin at Polperro in Cornwall, and the shells have been cast up in Oxwich Bay near Swansea, on the coast of Northumberland, at Mawgan Porth, Cornwall, in Guernsey, and at Magilligan, County Derry. S. elegans has a shell about 4 inches long, somewhat similar in colour, etc., to the last mentioned.

The eggs of the Sepics are large and black, with beaked ends, attached by flexible stalks until they resemble bunches of grapes. These are attached to large weeds in the laminarian zone, where the parent lives upon fishes and crabs. These eggs, thrown up on the beach after a storm, may be hatched in a vessel of sea-water.

The remaining families have the shell reduced to a gladius of thin horn, commonly called the pen. In the family Sepiolide the fins are enlarged and spring from the back, the tentacles are retractile into pockets as in Sepia, and

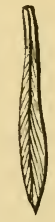

Pen of

Little

Cuttle the two central upper arms in the male are hectocotylised. The pen is half the length of the body.

The Little Cuttle (Sepiola atlantica) is common in shallow water on all our coasts, and is frequently taken when shrimping. It is a smooth flesh-colourerl creature, less than 2 inches in length. In the male the tentacles are twice the length of the animal, less the arms; but in the female they are little longer than the arms. The late P. H. Gosse recorded its 
curious habit of burying itself in the sand, pouring out a stream of water from its funnel and directing it upon one spot so that the light grains would be

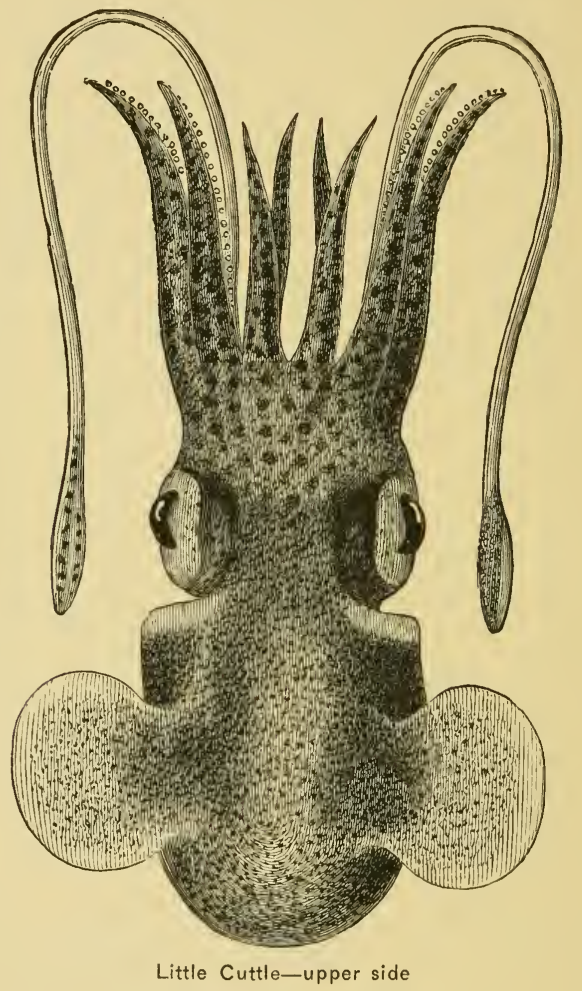

blown out until a hole was formed sufficiently large to accommodate it. Where small stones mingle with the sand, however, the creature knows that its current has not sufficient power to lift these, so it proceeds 
to move them by means of its suckers. A second species, $S$. scandica, has been taken in the dredge off Little Cumbrae, Firth of Clyde, in 50 fathoms; at the mouth of Loch Fyne in 48 fathoms.

Ross' Cuttle (Rossia macrosoma) differs but little from Sepiola, except that the mantle above instead of being connected to the neck by a broad band, as in Sepiola, has a free margin all round. The fins are relatively smaller. The entire length exclusive of the tentacles is from $2 \frac{1}{2}$ to 3 inches, and the "pen" about $1 \frac{1}{2}$ inches. Jeffreys described it as "rare or not often met with," but since his day the trawl has been more largely used in the deep waters off our shores; so that Canon Norman, who has done much exploring work of this sort, can now say, "the use of the trawl has shown it to be far from uncommon in 40 to 90 fathoms in the Clyde District, and off the west of Scotland." It is also recorded from the Minch; off the coast of Wexford; off the Butt of Lewis (40 fathoms), Dublin Bay, Plymouth Sound, and the Isle of Wight. R. glaucopis, a smaller species, has been taken in from 60 to 100 fathoms, off the north of Shetland, and the Outer Haaf, Shetland. A third species, $R$. sublevis, was obtained in one of the trawling expeditions of the Flying Fox, off the south of Ireland in 250 fathoms of water.

In the family Loliginida, the bocly is longer, the tentacles only partially retractile, the pen as long as the animal's back, pointed like a quill-pen in front, and strengthened by a keel along the lower side.

The Common Squid (Loligo forbesii) is the largest of our common Cuttles. Exclusive of the tentacles, 
adult examples measure about 2 feet in length. The body is cylindrical, tapering to a blunt point behind, and furnished with two large triangular fins which are united behind. The arms bear two

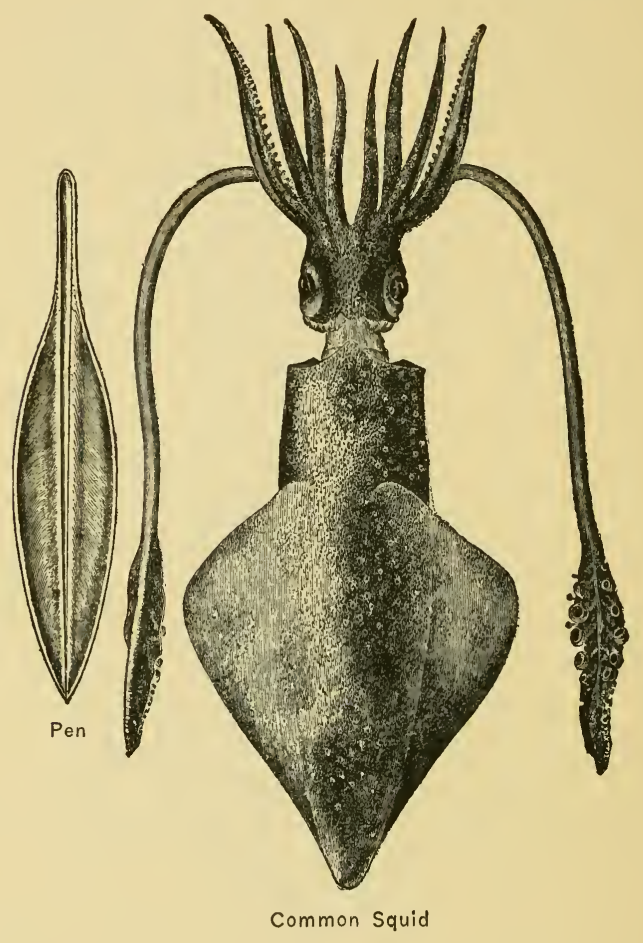

irregular rows of suckers; the expanded tips of the tentacles have four rows. The fourth left arm of the male has the tip hectocotylised. When freshly extracted from the mantle-where it lies without muscular attachment-the long pen (15 to 18 inches) 
is quite transparent, but as it dries it becomes less so, and shrinks. Squids appear in shoals, swimming on the surface of the sea, whether smooth or rough, and in the brightest sunshine. They feed upon fishes, and the fishes are only too eager to reciprocate. The somewhat gelatinous flesh makes a splendid bait for sea-fishing. The professional fishermen fish for Squid to use for baiting their boulters. The Squid is a wary and an active quarry, and some skill and adroitness is required to capture him, for he does not make the mistake of taking a baited hook as a fish does. The modus operandi for catching a Squid is quite different from that where a little bit of the captured Squid is used to entrap a fish. The fisherman securely fastens a pilchard to a strong line, and throws this out from his boat. Near at hand he has a light gaff, made by splicing a number of mackerel hooks to the end of a bamboo rod in such manner that the barbed tips are all turned outward, but pointing towards his hand. The Squid's sense of smell soon attracts him to the pilchard, which he clings to with his suckers and tears with his beak. Now the fisher hauls in his line very gently so as not to alarm the Squid, until at length he is within striking distance. Then when the Cuttle is in the right position he is firmly gaffed in the hinder part of his body and held with his head away. There is a tremendous spouting of water and ink from the funnel, the Squid making effort by this means to escape. When he is for a time exhausted he is taken on board. An inexperienced assistant essaying to catch his first Squid will almost certainly gaff it and haul in head first, with the result that his face and 
clothes are well covered with the jet-black ink, which has a painful burning effect on the skin, as well as being difficult to wash off. On a coast where this species is very plentiful, and where the "bones" of Sepia are abundant along the beaches, I have never seen a pen of the Squid so cast up. The explanation appears to be that when conger and other fishes bolt the Sepia they are unable to digest its shell, which is afterwards vomited in a clean condition. The "pen" of Loligo under similar conditions appears to be digested and so is got rid of altogether. The eggs of this species are deposited in long gelatinous sheaths, each containing many ova. These egg-cases are united to form large masses known as "sea-mops," which float loosely in the sea. Bohadsch estimated one of these mops to contain 40,000 eggs. The Common Squid occurs on all our coasts.

Two other species are included in the British fauna: $L$. marmorce - with much broader fins situated farther back-taken off Youghal, Ireland; and $L$. medica, found at Jersey, Plymouth, Tenby, and Lamlash Bay. These are both small species, measuring only 4 or 5 inches, excluding the tentacles. All the Loligos can swim forwards by using their fins, as well as dart backwards by expelling water from the funnel.

In the family Ommastreplictee the animal is of similar shape to Loligo, but the fins are only half the length and placed right at the end of the body. The rows of suckers on the arms vary in number, and the arms have a more voluminous web for swimming. The attachment of the mantle-margin to the neck is more elaborate than in preceding 
species. The pen is very narrow and bears a hollow cone at its hinder end.

The Flying Squid (Ommastreples sagittatus), or Sea Arrow of sailors, gets its name from the shape and position of the fins. If the animal be viewed with the arms towards us and the fins away, its form is seen to be that of a thick arrow with barbed point; and as the seamen see these hurl themselves from mid-ocean to the vessel's deck they come like flying arrows, point first. This species is about 15 inches long, and has been taken at Shetland, St. Andrews, the Firth of Forth, and Durham. $O$. eblance has been taken at Plymouth, Belfast, and in Dublin Bay; and a third species, 0 . coincleti, is recorded from the Firth of Forth and Eastbourne. The Flying Squids occur in schools, and are of great importance in connection with the Newfoundland cod fishery, forming as they do the principal bait used in that industry. They also form inportant items in the bills of fare of whales, dolphins, and some of the larger oceanic birds.

To the same family belongs the genus Architeuthis, containing the largest species of Cuttles known to us - the creatures that have often been still further enlarged by the sensational writer, acting on the principle of "to him that hath shall be given." More than once some giants of this tribe have shown themselves in the vicinity of these islands, so that we are able to claim $A$. monachus as sometimes British. More than two hundred years ago a gigantic Cephalopod was cast ashore at Dingle, County Kerry, whose length was 19 feet. Its tentacles were 11 feet, but they had been mutilated, so that their 
original length must have been greater. The arms were of the thickness of a man's leg, and varied from 6 to 8 feet long, bearing two rows of toothed suckers. The entire animal is said to have been as large as a big horse, and its beak like an eagle's but broader. Mr. Verrill, who has an intimate acquaintance with the large American species of this genus thinks there is no reason to suppose it was other than $A$. monachus.

This was not the only visit paid to our islands by this species, for Jeffreys has told us how "the mutilated carcase of a huge Cephalopod, perhaps belonging to Steenstrup's species [A. monachus], was stranded in 1860 or 1861 between Hillswick and Scalloway, on the west of Shetland. From a communication received by Professor Allman it appears that the tentacles were 16 feet long, the pedal arms about half that length, and the mantle-sac 7 feet; the mantle was terminated by fins; one of the suckers examined by Professor Allman was threequarters of an inch in diameter."

A more recent example was met with on the northwest of Boffin Island, Connemara, on the 26th of April 1875, when a floating mass surrounded by gulls was observed to seaward and thought to be a wreck. A canvas boat (curragh) was put off to it, but to the astonishment of the crew it was found to be an enormous cuttle-fish, lying still as if basking in the sun. They paddled up cautiously, and succeeded in lopping off an arm before the creature became alarmed. It then rushed out to sea at a tremendous pace, but the canvas boat followed, and by hard pulling for five miles the crew came up to 


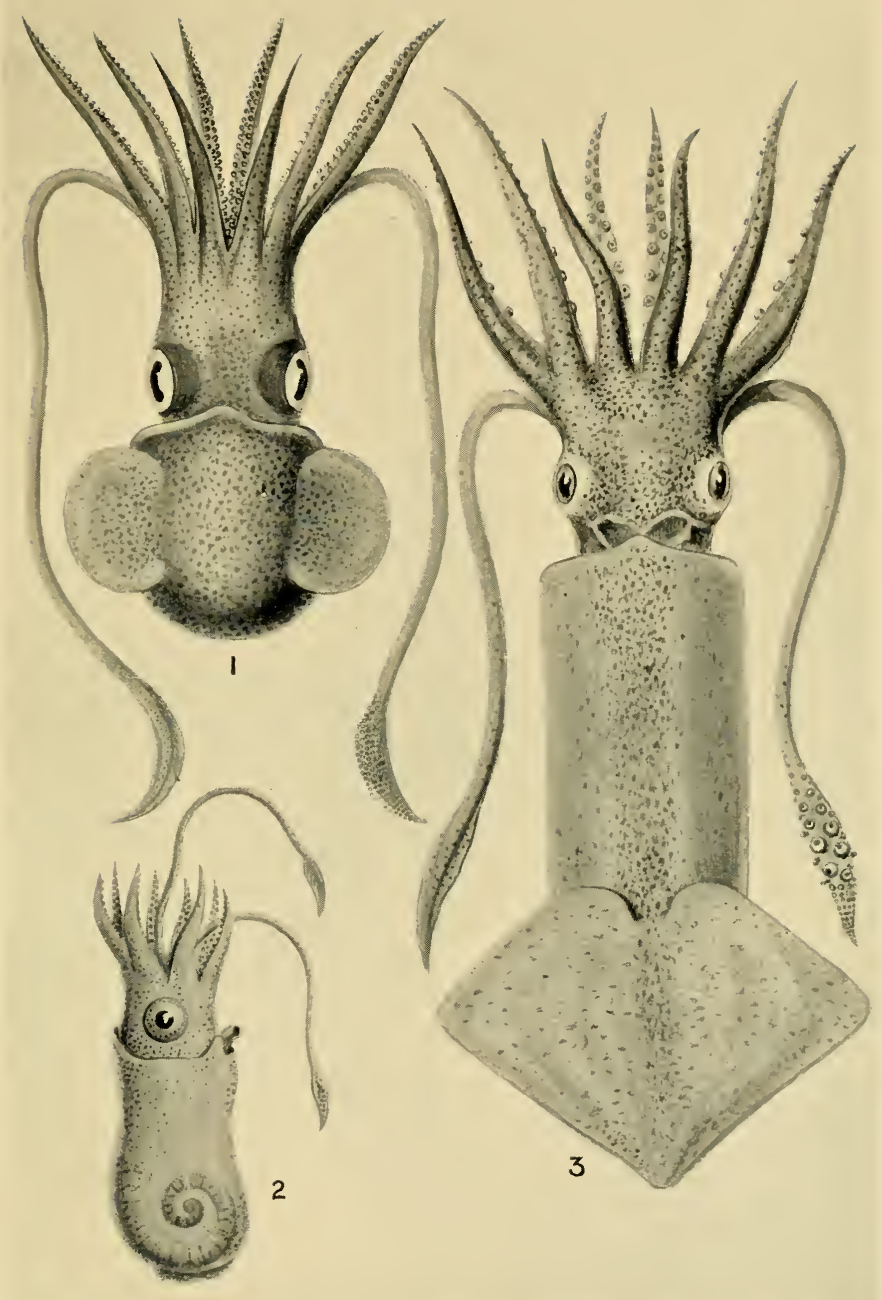

I Rossla MACRosoMA; 2 SPIRULA PERONII (FIGURED AS THOUGH TRANSPARENT TO SHOW POSITION of SHELL); 3 FiriNG SQQUID. 

the cuttle, and severed its head and another arm. The borly sank, and the head and eyes were unfortunately lost. From a detailed description given by Mr. A. G. Nore in the Annals and Magarine of Natural History we glean these particulars: The arms were 8 feet in length with a circumference of 15 inches round the base; the tentacles 30 feet long, of which the club was probably over three feet when fresh, for its present preserved and shrunken length is 2 feet 9 inches. The centre of this club had two rows of 14 large stalked suckers nearly 1 inch across, and outside these on either side was a row of alternating suckers to the same number, but only half the dimensions. There was also a cluster of still smaller suckers in transverse rows at the base of the club. The half-inch suckers were furnished with bony rings having their edge cut into about 28 teeth all pointing inwards; and it is believed that the 1 -inch suckers had been of similar character, but their rings had been removed or had fallen out before they were examined. The long slender stalk of the tentacle also bore a few suckers at intervals along the inner surface, as customary in this genus. The beak had a strong broad tooth above the middle of the edge of the inner mandible, and a much narrower notch on the outer mandible.

In addition to the foregoing species, two oceanic Cuttles have been taken in British waters, but of course have little claim to be considered anything but chance visitors. Onychoteuthis banksii, which is very general in the Atlantic, Indian, and Pacific Oceans, was captured at Banff in 1853, and two dead specimens of Taonius hyperboreus were found in 26 
1869 by the Porcupine Expedition, floating at the surface, 140 miles to the north-west of Ireland.

From the brief descriptions we have given of the Cephalopods that occur on our coasts, it will be seen that there is considerable difference in the characters of the shell. Lankester considers that these differences may indicate successive stages in the development of the shell. The probable course of such development can only be appreciated by a comparative study of the shells of all the genera, exotic as well as native, fossil as well as recent; but taking the Chambered Nautilus (Nautilus pompilius.) as one end of the series, we can see in the shell of Spirula its degradation. No longer able to contain the animal, it has become almost entirely enveloped in folds of the mantle. "These folds gradually concresce to form a definite shell-sac, by the walls of which are secreted additional laminæ of calcareous shellsubstance. These laminæ invest the original shell, which gradually (Spirulirostra, Belosepia) loses the spiral form and becomes straight, eventually disappearing, while the calcareous laminæ alone remain (Sepia). These in their turn disappear, leaving only the plate or 'pen' upon which they were deposited (Loligo), which itself also, with the shell-sac, finally disappears, surviving only in the early stages of Octopus." 


\section{A P P E N D I X}

\section{A CLASSIFIED LIST OF BRITISH MOLLUSKS}

\section{MOLLUSCA}

CLASS I. -CEPHALOPODA. ORDER DIBRANCHIATA; SUB-ORDER OCTOPODA.

FAM. OCTOPID无. OCTOPCS VULGARIS, LAMK. o. ARCTICUs, Plosch.

FAM. ELEDONIDAE.

ELEDONE CIRROSA (LAMK.). SUB-ORDER DECAPODA.

\section{FAM. SPIRULIDA.}

SPIRULA PERONII, LAMK.

\section{FAM. SEPIID Æ.}

SEPIA OFFICINALIS, L.

S. RUPELLARIA, D'OrB.

S. ELEGANS, D'ORB.

S. BISERIALIS, DE MONT.

FAM. SEPIOLID $Æ$.

SEPIOLA SCANDICA, STEENST.

S. ATLANTICA, D'ORB. ROSSIA MACROSOMA (CHIAJE).

R. GLAUCOPIS, LOVÉN.

R. SUBLEVIS, VERR.

FAM. LOLIGINID王.

I.OLIGO FORBESII, STEENST.

L. MARMOR.F, VÉRANY.

I. MEDIA (I.).

FAM. OMMASTREPHID压.

OMMASTREPHES FBLANE, (I;ALL).

o. COINDETI (VÉRANY). o. SAGITTATUS (LAMK.). ARCHITEUTHIS MONAr'HTS, STEENST.

FAM. ONYCHOTEUTHIDAE.

ONYCHOTEUTHIS BANKSII, (LEACH).

FAM. CRANCHIID瓜.

TAONIU'S HYPERTORET', STEENST.

CLASS II.-GASTEROPODA. ORDER AMPHINEURA;

SUB - ORDER POLYPLACOPHORA.

FAM. MOPALOIDA.

CHITON FASCICTLARIS, L.

C. DISCREPANS, BROWN.

C. HANLEYI, BEAN $=$ DIBILIS, GRAY.

C. CANCELLATUS, SOW.

C. CINEREUS, L.

C. ALIUS, $\mathbf{L}$.

C. MARGIXATUS, PFNY.

c. RUBEI, LOWE.

C. LEVIS, MTROS.

(. MARMOREUS, FAFR

C. SCABRIDUS, JEFF.

SUB-ORDER APLACOPHORA.

FAM. NEOMENIID压.

NEOMENIA CARINATA, TCLLBERG. 
FAM. NEOMENIIDE-continued. RHOPALOMENIA AGLAOPHENIE, KOW. \& MAR. MYZOMENIA BANYULENSIS, PRUYOT.

FAM. CHATODERMATID在.

CHETODERMA NITIDULUM, LOVÉN.

ORDER PROSOBRANCHIATA ; SUB-ORDER DIOTOCARDIA.

FAM. ACM ÆID死.

ACMÆA TESTUDINAIIS, MÜLL.

A. VIRGINEA, MULL.

\section{FAM. LEPETID尼.}

LEPETA FULVA, MÜLL.

L. CECA, MÜLL.

PROPILIDIUM ANCYLOIDES, FOIRBES.

FAM. PATELLID死.

PATELLA VULGATA, L. HELCION PELLUCIDUM (L.).

FAM. FISSURELLID压.

FISSURELLA GRECA (L.). PUNCTURELLA NOACHINA, L. EMARGINULA FISSURA, L. F. ROSEA, BELL. E. CRASSA, SOW.

\section{FAM. HALIOTID㞋.}

HALIOTIS TUBERCULATUS, L.

FAM. PLEUROTOMARIID压. SCISSURELLA CRISPATA, FLEM.

\section{FAM. CYCLOSTREMATID王.}

CYCLOSTREMA MILLEPUNCTATUM, FRIELE.

C. NITENS, PHIL.

c. SERPULOIDES, MONT. MÖLLERIA LEVIGATA, JEFF. M. COSTULATA, MÖLL.

FAM. TROCHID死.

circulus striatus, PHIL. = TROCHUS DUMINYI. TROCHUS HELICINUS, FABI. T. OLIVACEUS, BROWN.
T. GRENLANDICUS, CHEM.

T. CINCTUS, PHIL.

T. MAGUS, L.

T. TUMIDUS, MONT.

T. CINERARIUS, L.

'T. UMBILICATUS, MONT.

T. LINEATUS (D. C.).

T. MONTACUTI, WOOD.

T. STRIATUS, L.

T. EXASPERATUS, PENN.

T. MILIARIS, BROC.

T. GRANULATUS, BORN.

T. ZIZYPHINUS, L.

T. OCCIDENTALIS, MIGH.

FAM. TURBINID王.

PHASIANELla PUllus (L.).

FAM. NERITID仺.

NERITINA FLUVIATILIS (L.).

SUB-ORDER MONOTOCARDIA.

\section{FAM. IANTHINID正.}

IANTHINA ROTUNDATA, LEACH.

I. COMMUNIS, LAMK.

FAM. SCALARIID王.

SCALARIA TURTONE (TURT.).

S. COMNUNIS, IAMK.

S. Clathratula (ADAMS).

S. TREVELYANA, LEACH.

S. PSEUDOSCALARIS, BROC. ACLIS SUPRANITIDA, S. WOOD.

A. ASCARIS, TURTON.

A. WALLEII, JEFF.

PHERUSA GULSONE, CLK.

CIONISCUS UNICUS, MONT.

FAM. NATICID王.

NATICA ISLANDICA, BEAN.

న. GRENLANDICA, BECK.

x. SORDIDA, PHIL。

N. CATENA (D. C.).

N. GLAUCINA, L.

N. MoNTACUTI, Forbes.

N. AFFINIS, GMEL.

FAM. LAMELLARIID无.

MARSENIA PERSPICUA, L. VELUTINA LEVIGATA (PENN.). 


\section{A Classified List of British Mollusks 403}

FAM. TRICHOTROPID压.

TRICHOTIOPIS BOREALIS.

FAM. CAPULID正.

CAPUIUS IIUNGARICUS (L.). CREPIDULA FORNICATLS.

c. UNGUIFORMIS, LANK. CALYPTREA CHINENSIS, L.

FAM. HOMALOGYRID压.

HOMALOGYRA ATOMUS (PHIL.).

H. HOTA (FOR. \& HAX.).

FAM. LITTORINID尼.

LITTORINA OBTESATA (L.).

l. NERITOIDES, I.

L. RUDIS, MATON.

1. LITTOREA (L.).

LACUNA CRASSIOR, MONT.

L. DIVARICATA (FAB.).

I. PUTEOLUS (TURT.).

L. PALlidUla (D. C.)

FAM. CYCLOSTOMATIDE.

CYCLOSTOMA ELEGANS (MÜLL.).

FAM. TRUNCATELLIDE.

TRUYCATELLA SUPCYLINDRICA, L.

FAM. ACICULID尼.

ACICULA LINEATA (DRAP.).

FAM. RISSOID压.

IISSOA STRIATCLA, MONT.

R. LACTEA, МICH.

R. CANCEllatA, DA C.

R. CALATHUS, F. \& H.

R. RETICLLATA, MONT.

R. CIMICOIDES, FORBES.

R. JEFFREYSI, WALL.

R. PUNCTU RA, MONT.

R. ABYSSICOLA, FOIB.

R. COstulata, ALD.

R. ZETLANDICA, MONT.

R. COSTATA, AD.

r. PARYA, DA C.

R. IXCONSPICUA, ALD.

r. ALBELLA, LOV.

i. MEMBRANACEA, AD.

R. VIOLACEA, DESI.

R. GUERINI, RÉCL.
R. STRIATA, AD.

R. PHOXIMA, ALI).

R. VITREA, MONT.

R. PLLCHERIIA, JEFF.

R. FVL(III)A, AI).

R. OBTUSA, CANT.

r. SEMISTIRATA, MONT.

R. TIIFANCIATA, AI).

BARLEEIA IUUIBA, MONT.

FAM. HYDROBIIDE.

HYDLOBIA ULYE, PENN.

II. VENTROSA, MONT.

II. SIMILIS.

I. JENKINSII, SMITH.

DITHYNIA TENTACULATA, L.

B. LEACHII, SHEP.

FAM. ASSIMINEID压.

ASSIMINEA GRAYANA, LEACII.

FAM. SKENEID正.

SKENEA PLANORBIS (FABI.).

FAM. JEFFREYSIIDA.

JEFFREYSIA DIAPHAYA

(ALD.).

J. OPALINA, JEFF.

J. GLOBULARIS, JEFF.

FAM. ADEORBIDE.

ADEORBIS SUICARINATUS

(MONT.).

A. Unisulcatus, chaster.

FAM. VIVIPARIDE.

VIVIPARA VIVIPARA, L.

I. CONTECTA, MILL.

FAM. VALVATIDE.

rALTATA PISCINALIS

(MÜLL.).

v. CIISTATA, MÜLL.

\section{FAM. CERITHIIDA.}

TRIFORIS PERVERSA (L.).

CERITHIUM PHOCERUM, JEFF.

BITTILM RETIC'LATUM

(DA C.).

I.OVENELLA METULA

(LOVÉN).

CERITHIOP'SIS TUBERCU -

LARIS (MONT.). 
FAM. CERITHIID仺-continued.

C. BARLEEI, JEFF.

c. CONGATENATA, CONTI.

(i) PULCHELLA, JEFF.

i. METAXE (CHIAJE).

C. COSTUlatA (MÖLLER).

FAM. TURRITELLIDA.

TURRITELLA COMNUNIS, liIsso.

FAM. CCECID压.

CCEUM TRACHEA, L. C. GLABLUM (MONT.).

FAM. CHENOPODID压.

('HENOP'US PES-PELECANI, L. c. SERRESIANUS, MICH.

FAM. CYPR乎ID死.

OVULA PATULA (PENN.). CYPLEA EUROPEA, MONT. ERATO LEYIS (HON.).

\section{FAM. CASSIDID瓜.}

CASSIDARIA RUGTSA (L.). c. ECHINOPHORA, L.

FAM. TRITONID在.

TRITON NODIFER, LAMK. 'T. CUTACEUS (L.).

FAM. ATLANTID压.

A'TLANTA SP.

\section{FAM. EULIMID瓜.}

EULIMA POLITA, L.

E. INTERMEDL, CANT.

E. PHILIPPII, WEINK.

E. EPHAMILLA, WATS.

l. SUBULATA, DON.

E. BILINEATA, ALD.

E. CURVA, MONTS.

E. PETITIAIA, BRUS.

E. PERMINIMA, JEFF.

E. MONTEROSATI, DE BOTRr: STILIFER TURTONI, BROI).

\section{FAM. PYRAMIDELLIDÆ.}

ODOSTOMIA MINIMA, JEFF.

o. NIVOSA, MONT.

o. TIUTCATULA, JEFF.

O. ILAVULA, LOVÉN.

o. LUKISI, JEFF.
O. DELICATA, MONTE.

o. PALLIDA, MON'T.

o. CONOIDEA, BROCCHI.

o. UMBILICAIIS, MALM.

o. ACUTA, JEFF.

o. CoxsPICCA, ALD.

O. UNIDEXTATA, MONT.

O. TURRITA, HANLEY.

o. PLICATA, MONT.

o. INSCULPTA, MONT.

O. OBLONGCLA, MARSII.

o. DIAPHANA, JEFF.

O. WARRENI, THOMPS.

o. OBLIQUA, ALDER.

O. DOLIOLIFOHMIS, JEFF.

o. DECUSSATA, MONT.

TURBONILLA CLATHIATA, JEFF.

'T. INDISTINCTA, MONT.

T. INTERSTINCTA, MONT.

T. SPIRALIS, MONT.

T. EXIMIA, JEFF.

T. FENESTRATA, FORBES.

T. FXCAVATA, PHILIPPI.

T. SCALARIS, PHILIPII.

T. RUFA, PHILIP'I.

'T. MULTILIIATA, MONTEROS.

T. VERTICALIS, MARSII.

T. LACTEA, L.

T. PUSILLA, PHILIP'P.

T. INSOVATA, MONTEIOS.

T. DELICATA, MONTEROS.

EULIMELLA SCILLE, SCACCHI.

E. COMPACTILIS, JEFF.

E. ACICULA, PHILIPPI.

F. VENTRICOSA, FORBES.

k. NITIDISSIMA, MONT.

E. FALLAX, MONTEHOS.

\section{FAM. MURICID死.}

TROPHON MURCATUS (MONT.).

T. BARVICENSIS, JOHNST.

T. TRUNCATUS (sTRÖM.).

T. CARINATUS, JEEF. OCINEBIRA ERINACEA (LINN.). O. ACICULATA (LAMK.). PURIUIA LAPILLU'S (L.). 


\section{A Classified List of British Mollusks 405}

FAM. COLUMBELLID尼.

COLUMBELLA IIALIETI, JEFF.

\section{FAM. NASSID㞋.}

N.ASS.I RFTICLLATA (L.). N. INCRASSATA (NTRÖM.). N. P'I'GMEA, LAMK.

\section{FAM. BUCCINID压.}

CHRYSODONUS ANTIQUA (L.).

C. DEsPECTA (L.).

c. TURTONI (BEAN)

c. NORVEGICA (CHEMN.).

C. ISLANDICUS (CHEMX.).

C. GRACILIS (DA C.).

c. TURGIDULUS (FRIELE).

c. PROPINQUUS (ALDER).

C. JEFFREYSIANUS (FIS('HER).

c. ATTEXUATUS (JEFF.).

C. EBUR ( $\mathrm{MÖlCH.}$ ).

C. FUSIFORMIS (BRODERIP). LIOMESUS DALEI (J. SOW.).

L. STRIATUS (JEFF.). BUCCINUM UNDATUM, L.

B. HUMPHREYSIANUM, BEXNETT.

DONOVANIA MINIMA(MONT.).

\section{FAM. FASCIOLARIIDE.}

THOSCHELIA TERNICIENSIS (KING).

FAM. CONIDEE.

DIILLIA SEMICOLON (s. WOOD).

SPIROTROPIS CAPINATA (PHILIPI).

TYPHLOMANGILIA NIYALIS (LOVÉX).

HEDIOPLEU RA SEPTANGULARIS (MONT.).

BELA PYRAMIDALIS (STRÖM.).

B. CANCELLATA (MIGH.), VAR. DECLIVIS (LOVENA).

B. CINEREA (MÖLL.).

13. TREVELYANA (TURTON).

B. TENUICONTATA (M. SARS.).

B. OVALIS, FIIELE.
B. BICARINATA (COUTHOUY).

13. EXARATA (MÖLL).

B. TURRICULA (NONT.),

1. RUFA (MONT.).

MANGILIA STRIOLATA

(SCACUII).

M. ATTENUATA (MONT.).

M. Costata (nox.).

M. RUGLLOSA (PHILIPII).

M. IBACHYSTONA (PIILII'I).

M. NEBULA (MONT.).

M. PACKARDI, YERIILL.

M. NANA (LOVÉN).

M. ANCEPS (EICIIW.).

M. GIRACILIS (MONT.).

CLATHURELLA LINEARIS

(MONT.).

C. RETICULATA (IENIER).

c. PURPUREA (MONT.).

C. LEUFROYI (MICH.).

\section{FAM. CANCELLARID丑.}

ADMETE VIRIDULA (FABR.).

ORDER OPISTHOBRANCHIATA ;

SUB-ORDER TECTIBRANCHIATA.

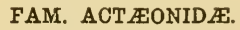

ACTEON TORNATILIS, L.

A. EXILIS, JEFF.

FAM. TORNATINIDE.

TORNATINA OBTUSA (MONT.).

T. MAMMILATA (PHILIPPI).

T. TIUNCATULA (BIUG.).

T. TMBILICATA (MONT.).

T. NITIDULA, LOVÉx.

T. OVATA (JEFF.).

VOLVULA ACUMINATA

(BURG.).

\section{FAM. SCAPHANDRID死,}

SCAPHANDER LIGNAIIUS(L.). S. PUNCTOSTRLATLS (Migh.). CYLICHNA CYLINDRACEA

(PENT.).

C. NITIDULA (LOV.).

C. ALBA (BROWN).

AMPHISPHYRA HYALINA

(TURTON). 
FAM. SCAPHANDRID王-continued.

A. EXPANSA (JEFF.).

A. VENTROSA (JEFF.).

A. GLOBOSA (LOVÉN).

CRYPTAXIS CREBRIPUNCTA-

TUS, JEFF.

FAM. BULLID压.

BULLA UTRICULUS, BROCCHI. B. SEMILEVIS, SEGUENZA. HAMINEA HYDATIS (L.). ACERA BULLATA, MÜLL.

FAM. PHILINID正.

PHILINE APERTA (L.).

P. NITIDA, JEFF.

P. SCABRA (MÜLL.).

P. CATENA (MONT.).

P. ANGUIATA, JEFF.

P. QUADRATA (s. WOON).

P. PUNCTATA (CLARK).

P. PRUINOSA (CLARK).

COLPODASPIS PUSILLA, M. SARS.

\section{FAM. APLYSIIDÆE.}

APLYSIA DEPILANS, I. A. PUNCTATA, CUT.

FAM. PLEUROBRANCHIDE. PLEUROBRANCHUS MEMBRANACEUS (MONT.). P. PLUMULA (MONT.).

FAM. RUNCINID王.

RUNCINA CORONATA

(QUATTE.).

\section{SUB-ORDER ASCOGLOSSA.}

\section{FAM. HERM㞋ID死.}

HERAFEA BIFIDA (MONT.). II. DENDRITICA, A. \& H. ALDERIA MODESTA (LOTÉN).

\section{FAM ELYSIID瓜.}

ELYSIA VIRIDIN (MONT.).

\section{FAM. LIMAPONTIID五.}

LIMAPONTIA CAPITATA (MÜLL.).

L. DEPRESSA, A. \& II.
ACTAONIA CORRUGATA, A. \& $\mathrm{H}$.

CENIA COCKSI, A. \& H. BEIGHIA CARULESCENS, LAURILL.

SUB-ORDER NUDIBRANCHIATA.

\section{FAM. ÆOLIDIID压.}

EOLIS PAPILLOSA (L.). Æ. GLAUCA, A. \& H.

E. ALDERI, COCKS.

E. SANGUINEA, NORM. CUTHONA NANA, A. \& H. C. AURANTIACA (A. \& H.). CRATENA VIRIDIS (FORBES).

C. AMENA (A. \& H.).

C. OLIVACEA, A. \& H.

c. PUStulata (A. \& H.).

C. GLOTTENSIS (A. \& II.).

C. ARENICOLA (FORBES).

C. CONCINNA (A. \& H.).

c. PEACHII (A. \& H.).

c. STIPATA (A. \& H.).

C. ANGULATA (A. \& H.).

c. INORNATA (A. \& H.).

c. COUCHII (COCKs).

c. Nonthumbrica (A. \& H.). TERGIPES DESPECT'US

(JOHNST.).

EMBLETONIA PULCHRA,

A. \& $\mathrm{H}$.

F. MINUTA (FOI. \& GOOD.).

F. PALLIDA, A. \& II.

AMPHORINA CERULEA

(MONT.).

A. PURPURASCENS (FLEM.).

A. HOLIOS (HERDM.).

GALVINA EXIGUA, A. \& H.

G. TRICOLOR, FOR.

G. PICTA, A. \& H.

(x. FARRANI, A. \& II.

(4. ADELAIDE (W. THOMPS.)

G. VITTATA, A. \& H.

G. CINGULATA, A. \& II.

CORXPHELLA RUFIBRANCHI-

ALIS (JOHNST.).

¿. GRACILIS, A. \& H. 


\section{Classified List of British Mollusks 407}

FAM. AOLIDIIDE-continuet.

r. SMARAGDiNA, A. \& II.

c. I.ANDSBURGII, $\lambda$. \& il.

c. PliLCUIH, A. \& H.

C. LINEATA (LOVÉN).

FAVORIXUS ALBUS, A. \& 11.

F. ('AliNEU', A. \& H.

FACELINA DRUMMONDII (W. THONPS.).

F. CORONATA (FORBES).

F. I'UNCTATA, A. \& H.

F. ELEGANS, A. \& H.

CALMA GLAUCOIDES, A. \&. H. FIONA MARINA (FORSK.). ANTIOPA CRISTATA ('HIAJE). A. HYALINA, A. \& H. P'ROCTONOTU'S MUCRONIFER, A. \& H.

HERO FOLIIOSA, LOVÉx.

\section{FAM. LOMANOTID蚱.}

LONANOTL'S MARMORATUS, A. \& $\mathrm{H}$.

I. FLAYIDUS, A. \& H.

L. PORTLANDICT'S, W. THOMPS.

L. HANCOCKI, NORM.

\section{FAM. DOTONID死.}

DOTO FRAGILIS (FORIES).

D. PENATIFIDA (MONT.).

1). CORONATA (GMELIN).

D. CUSPIDATA, A. \& II.

\section{FAM. DENDRONOTIDAE.}

DENDIONOTL'S FRONDOSUS (ASCAN.).

\section{FAM. SCYLLÆID尼.}

SCYLLAA PELACICA, L.

\section{FAM, PLEUROPHYLLIDIIDA.}

PLELTOPHYLLIDIA LOVÉNI, BERGH.

\section{FAM. TRITONIID压.}

TRITONIA HOMRERGI, CUV.

T. ALBA, A. \& H.

T. PLEBEIA, JOHNST.

T. LINEATA, A. \& H.
FAM. DORIDID死.

DORIS TUBEICULATA, CLV.

1). FIAMMLA, A. \& H.

1). MACULATA, GALS.

1). JแนกรTUхI, A. \& II.

1). TESTUHINARI, HISSO.

1). ZETLAXHI( $A, A . \& 11$.

1). MILLEGIANA, A. \& H.

1). REPANDA, A. \& II.

1). COCCINEA, A. \& II.

\section{FAM. POLYCERIDAE.}

EGIRUS PUNCTILUCENS

(1'Oris.).

TRIOPA CLAVIRERA (MÜLL.). ('RIMOLA PAPILLATA, A. \& II. THECACERA PENXIGEIA

(MONT.).

T. VIRESCENS, A. \& H.

T. CAPITATA, A. \& H.

POLYCERA QUADIILINEATA (MÜLL.).

P. LESSOXII, I'ORI.

\section{FAM. GONIODORID死.}

ACANTHODORIS PILOSA

$$
\text { (MÜLL.). }
$$

A. SLBQTADRATA, A. \& H.

LAMELLIDORIS ASPERA,

A. \& $\mathrm{H}$.

I. MURICATA (MÜLI.).

I. ULIDIANA (THOMPS.).

L. DIAPHANA, A. \& H.

L. BILAMELLATA (L.).

I. DEPRESSA, A. \& H.

L. INCONSPICTA, A. \& II.

I. PUSILLA, A. \& II.

L. SPARSA, A. \& H.

L. OBLONGA, A. \& H.

L. PIOXIMA, A. \& 11 .

L. LOVÉXI, A. \& H.

GONIODORIS NODOSA(MONT.).

G. CASTANEA, A. \& H.

IDALINA ELEGANS (LAMK.).

I. LEACHII, A. \& H.

I. INEQUALIS (FORBES).

I. ASPEISA, A. \& H.

I. QUADRICORNIS (MONT.).

I. PULCHELLA (A. \& II.).

AXCULA CRISTATA (ALUER.). 
SUB-ORDER PTEROPODA.

\section{FAM. LIMACINID尼.}

LIMACINA IETROVERSA (FLEM.).

FAM. CAVOLINID王.

CLIO PYRAMIDATA, L.

FAM. CLIONID死.

CLIONA LIMACINA, PHIPI'S. ORDER PULMONATA; SUB-ORDER BASOMMATOPHORA.

FAM. AURICULID压.

CARYCHIUM MINIMUM, MÜLL.

AIEXIA MYOSOTIS (DRAP.). A. DENTICULATA (MONT.). LELCONIA IIDENTATA (MONT.).

ГAM. OTINID㞋.

OTINA OTIS (TURTON).

FAM. LIMN AID正.

ANCYLUS FLUVIATILIS, MÜLL.

A. LACUSTRIS (L.).

I.IMYAA STAFNALIS (L.).

L. PALUSTRIS (MÜLL.).

L. TRUNCATUIA (MÜLL.).

L. GLABRA (MÜLL.).

L. AURICULARIA (L.).

L. PEREGRA (MÜLL.).

AMIHIPEPLEA GLUTINOSA (MÜLL.).

A. INVOLUTA, THOMPS. PLANORBIS CORNELS (L.).

P. Costolitus (L.).

P. CARINATUS, MÜLI.

P. IMBILICATUS, MÜLL. = COMPLANATUS, JEFF.

P. VORTEX (L.).

P. SPIRORBIS (L.).

[P. DILATATUS, GOULD.]

P. GLABER, JEFF.

P. ALISU, MÜLL.

P. NAUTILEUS (I.).

P. COMPLANATUS (L.) = NITIDIS, GRAY. SEGMENTINA NITIDA (MÜLL.) =PL. LINEATUS, WALK.
FAM. PHYSID EE.

PHYSA FONTINALIS (L.).

I. HYPNORUN, L.

SUB-ORDER STYLOMMATO-

\section{PHORA.}

\section{FAM. TESTACELLID王.}

'TESTACELLA HALIO'TIUEA, DRAP.

T. SCUTULUM, SOW.

T. MAUGLI, FERUSS.

\section{FAM. LIMACID无.}

LIMAX MAXIMUS, L.

L. CINEREO-NIGER, WOLF.

[L. TENELLUS, NILSS.]

L. MARGINATUS, MÜLL. = AIBORUM, J. $\mathrm{CH}$.

L. FLAVUS, I.

L. AGRISTIS, I.

L. LEVIS, MÜLI.

L. CARINATES, RISSO. = MARGINATUS, DRAT.

L. GAGATES, DRAP. VITIRINA PELLUCIDA(MÜLL.) CONULUS FULVA (MÜLL.). HYALINIA CRYSTALLINA (MÜLL.).

H. NITIDA (MÜLL.).

H. EXCAVATA (BEAN.).

H. P'RA (ALDER).

[II. PETRONELLA (CHAII'.).]

II. IAADIATULA (ALDER).

H. GLABRA (STUDER).

II. ALLIAIRA (MÜLL.).

H. CELLAIIA (MÜLL.).

H. DRAPARNAUDI (BICK).

H. NITIDULA (DRAP.).

FAM. HELICID王.

ARION ATER (L.).

A. SUBFUSCUS, DRAP.

A. IxTERMEDIUS, NORM.

A. HORTENSIS (FERUSS.).

A. CIRCUMSCRIPTUS, JOHNST.

GEOMALACLS MACULOSUS, AI.L.M.

HELIX PYGMEA, DRAP.

H. ROTUNDATA, MÜLL.

II. RUPESTIIN, STUDER. 


\section{A Classified List of British Mollusks 409}

FAM. HELICIDAE-continued.

H. PULCHELLA, MÜLL.

H. ACULEATA, MÜLL.

H. LAMELIATA, JEFF.

If. OBVOLLTA, MÜLL.

II. LAIICIIA, L。

II. HISPIDA, L.

II. RUFESCENS, PEXN.

Ji. GRANULATA, ALDER = SERICEA, MÜLL.

II. REVELATA, FERUSS.

H. FLSCA, MONT.

H. CANTIANA, MONT.

H. CAITHUSIANA, MÜLL.

H. ARELSTORTA, L.

H. PISANA, MÜLL.

H. VILGATA, DA C.

H. EIICETORUM, MÜLL.

H. CAIERATA, MONT.

[H. TERRESTRIS, PENN.]

H. AC'UTA, MÜLL.

I. NEMORALIS, MÜLL.

II. HORTENSIS, MÜLL.

H. ASPERSA, MÜLL.

H. POMATIA, L.

FAM. PUPID压.

BULIMINUS MONTANUS, DIAP.

B. OBSCURUS (MÜLL.).

IUPA CYLINDRACEA, DA ', = UMBILICATA, DRAI'.

I. ANGLICA (FERUSS.) = IINGENS, JEFF.

P. SECALE, DRAP.

P. MUSCORUM, MÜLL. =MARGINATA, DRAP.

P. EDENTULA, DRAP.

P. MINUTISSIMA, HARTM.

P. ALPESTRIS, ALDER.

P. LILLJEBORGI, WEST. = TERTIGO MOULINSIANA, JEFF.

P. MOULINSIANA, DUPUY.

P. PYGMEA, DRAP.

P. SUBSTRIATA, JEFF.

P. ANTIVERTIGO, DRAP.

I. PUSILLA, MÜLL.

I. ANGUSTIOR, JEFF.

D.ALEA PERVERSA (L.).
CLAL'SILIA LAMINATA (MONT.).

r. IIILLICATA (MONT.).

c. BIDENTATA, STRËN. = megona (DRAl.).

C. ROLPHI (GIAY).

\section{FAM. STENOGYRIDAE.}

FERUSSACIA JUBIRICA (MÜLL.).

F. TRIDENS (PULT.).

CECILIANELLA ACICULA (MÜLL.).

[STENUGYIA GOODALLI

(MÜLL.).]

FAM. SUCCINEID㞋.

SUCCINEA PUTRIS (L.).

S. ELEGANS, RISSO.

S. STAGNALIS, GASSIES.

s. OBLONGA, DRAP.

FAM. ONCHIDID瓜.

ONCHIDIELLA CELTICA (CLV.).

CLASS III.-SCAPHOPODA.

DENTALIUM ENTALIS, L. D. TARENTINUM, L. SIPHODEXTALIUN LOFOTEXSE, G. O. SARS.

‥ AFFINA, SARS.

CLASS IV.-PELECYPODA.

ORDER PROTOBRANCHIATA.

FAM. NUCULIDAE.

NUCULA NUCLEUS, L.

N. SULCATA, LROWx.

I. TENUIS, JEFF.

N. NITIDA, SOW.

LEDA PYGMÆA, MÜNST.

L. MINUTA, MÜLL.

L. PERNLLA, MÜLL.

L. TENLIS, PHIL.

ORDER FILOBRANCHIATA; SUB-ORDER ANOMIACEA.

\section{FAM. ANOMIID㞋.}

ANOMIA EPHIPPIUM, I.

A. PATElliformis, L. 
SUB-ORDER ARCACEA.

\section{FAM. ARCAD王.}

ARCA TETRAGONA, POLI.

A. PECTUNCULOIDES, SCAC'.

A. LACTEA, L.

A. OBLIQUA, PHIL.

A. NODULOSA, NÜLL.

PECTUNCULUS GLYCIMERIS, I.

LIMOPSIS AULITA, BROC: SUB-ORDER MYTILACEA.

FAM. MYTILID A.

MYTILUS EDULIS, L.

MODIOLA MODIOLUS, L.

M. BARBATUS, L.

M. ADRIATICA, LAMK.

M. PHASEOLINUS, PHIL.

C'RENELLA IRHOMBEA, LEIK.

C. DECUSSATA, MONT.

MODIOLAIIA MARMORATA

(FORBES).

M. costulata (risso).

M. DISCORS, L.

M. NIGRA, GRAY

ORDER PSEUDOLAMELLT-

BRANCHIATA.

FAM. AVICULIDE.

AVICULA HIRUNDO, L

JINNA RUDIS, I.

FAM. OSTREID死.

OSTREA EDULIS, L.

\section{FAM. PECTINID尼.}

PECTEY PUSIO, L.

P. VARIUS, L.

P. ARATUS, GMEL.

P. OPERCULARIS, L.

P. PES-LCTHE, I.

P. TIGRINUS, MÜLL.

P. INCOMPAIABILIS, RISSO.

P. STRIATUS, MÜLI.

P. SIMILIS, LASK.

P. MAXIMUS, L.

P. VITREIS, r'H.

FAM. LIMID王.

LIMA ELLIPTICA, JEFF.

L. SUBAURICULATA (MONT.).

L. LOSCOMBII, SOW.

L. HIANS, GMEL.
ORDER EULAMELLIBRANCHIATA ;

SUB-ORDER SUBMYTILACEA.

\section{FAM. ASTARTID在.}

ASTARTE SULCATA, D. C.

A. COMPRESSA, L.

A. TRIANGULARIS (MONT.).

A. CRENATA, GRAY.

FAM. CYPRINID死.

CYPRINA ISLANDICA, L. ISOCARDIA COR, L.

FAM. UNIONID王.

UNIO MARGARITIFER (L.).

U. PICTORUM (L.).

U. TUMIDUS, PHIJ.

ANODONTA ANATINA (L.).

A. CYGNEA (L.).

FAM. DRIESSENSIID $Æ$.

DRIESSENSIA POLYMORPHA, PALL.

FAM. LUCINID互.

LUCINA BOREALIS (L.).

L. SPINIFERA, MONT.

LORIPES LACTEUS, L.

I. COMMUTATUS, PHII.

L. DIVARICATUS, L.

AXINUS FERRUGINOSU, FORBES.

A. FLEXUOSUS, MONT.

A. CROULINENSIS, JEFF.

A. CYCLADIUS, WoOD.

A. CUMYARIUS, M. SARS.

DIPLODONTA ROTUNDATA, MONT.

MONTACUTA SUBSTIIATA

(MONT.).

M. BIDENTATA (MONT.).

M. FERRUGINOSA (MONT.).

M. DAWSONI, JEFF.

M. 'TUMIDULA, JEFF.

M. DONACINA, WOOD.

SCINTILLA EDDYSTONIA, MAISH.

FAM. ERYCINID王.

KELLIA SUBORBICULARIS (MONT.).

K. MINUTA (FABR.).

LASEA RUBRA (MONT.). 


\section{A Classified List of British Mollusks 4 I I}

FAM. ERYCINIDA-continued.

LEPTON SQUAMOSUM, MONT.

L. NITIDUM, CLARK.

L. SULCATLLXM, JEFF.

L. CLARKIF, CLARK.

L. SYKESI, CHASTEL.

FAM. GALEOMMID屟.

FAL EOMMA TLLTONI, ENS. ZOOL. JOURN.

FAM. CYRENID㞋.

SPHERIUM CORNELM (L.).

S. RIVICOLA (LEACH).

s. PALLIDUM, GRAY.

s. LACUSTRE (MÜLL.).

PISIDIUM AMNICUM (MÜLL.).

P. FONTINALE (DRAT.).

P. PUSILLUM (GMELIN).

P. NITIDUM, JEN.

P. MILIUM, HELD.

SUB-ORDER TELLINACEA.

FAM. TELLINIDAE.

TELLINA BALAUSTINA, L.

T. CRASSA (I'ENX.).

T. BALTHICA, L.

T. TENUIS, D. C.

T. FABULA, G1RON.

T. SERRATA, BROC.

T. SQUALIDA, PULT.

T. DONACINA, L.

T. PLSILLA, PH.

GASTRANA FRAGILIS (L.).

FAM. SCROBICULARIID压.

SCROBICCLARIA PRISMATICA (MONT.).

S. NITIDA, MC̈LL.

S. LONGICALLUS, SCAC.

SYNDOSMYA ALBA, S. WOOD.

S. PIPERATA (GMEL.).

S. TENUIS, MONT.

\section{FAM. DONACID王.}

DONAX VITTATUS (D. C.).

D. POLITUS, POLI.

D. TRUNCULUS, L.

ERVILEA CASTANEA, MON'T.

\section{FAM. MACTRID正.}

MACTRA SOLIDA, L.

M. ELLIPTICA, BRO.

M. SUBTRUNCATA, D. C.
M. STLLTORUM, I.

M. GLACCA, BORN.

SUB-ORDER VENERACEA.

\section{FAM. VENERID咂.}

('IRCE MINIMA (MONT.).

JUSINIA EXOLETA, I.

1). LUPINA, L.

VENUS CHIONE, I.

V. FASCIATA (I) (C).

V. CASINA, L.

v. VEIRUCos $\mathrm{A}$, L.

Y. OVATA, PENN.

V. GALLINA, L.

[1. MERCENARIA, I..]

LUCINOPSIS UNDATA (PEXN.).

TAPES AUREUS, GMEL.

T. VIRGINEUS, L.

T. PULlASTRA, L.

T. DECUSSATA, L.

VENERUPIS IRUS (L.).

\section{FAM. PETRICOLID在.}

[PETRICOLA LITHOPHAGA, RETZ.

P. PIIOLADIFORMIS, LAMK.].

SUB-ORDER CARDIACEA.

FAM. CARDIID压.

CARDILM ACULEATCM, L.

C. ECHINATUM, L.

c. TUBERCULATUM, L.

C. PAIILLOSL M, POLI.

c. EXIGUUM, GMEL.

c. FASCIATUM, MONT.

c. NODOSUM, TURTON.

c. EDULE, L.

c. MixinuM, PHIL.

c. NORYEGICUN, SPENG.

SUB-ORDER MYACEA.

\section{FAM. PSAMMOBIID压.}

PSAMMOBIA TELLINELLA, LMK.

1. COSTULATA, TURT.

I. FERRÖENSIS, CH.

P. VESPERTINA, CH.

FAM. MYID平.

MYA ARENARIA, I.

M. TRUXCATA, L.

M. BINGHAMI (TURT.). 
FAM. MYID㤅-continued.

CORBULA GIBBA, OLIVI. NEÆRA ABBREVIATA, FORB. N. COSTELLATA, DESH. N. CUSPIDATA, OLIVI. PANOPEA PLICATA, MONT. LUTRARIA ELLIPTICA, LAMK.

L. OBLONGA, CH.

FAM. SOLENID死.

SOLECURTUS SCOPULA, TURT. S. ANTIQUATUS, PULT. CERATISOLEN LEGUMEN (L.) SOLEN PELLUCIDUS, PENN.

s. ENSIS, L.

S. SILIQUA, L.

S. VAGINA, I.

FAM. GLYCIMERID王.

SAXICAVA RUGOSA, L.

S. ARCTICA, L.

S. NORVEGICA, SPENG.

FAM. GASTROCH ENID王.

GASTROCHANA DUBIA, PENX. SUB-ORDER PHOLADACEA.

FAM. PHOLADID王.

PHOLAS DACTYLUS, L. P. CANDIDA, L.
P. PARVA, PENN.

P. CRISPATA, L.

PHOLADIDEA PAPYRACEA TURT.

XYLOPHAGA DORSALIS, TURT.

FAM. TEREDINID㞋.

TEREDO NORVEGICA, SPENG.

T. NAVALIS L.

T. PEDICELLATA.

T. MEGOTARA, HAN.

SUB-ORDER ANATINACEA.

FAM. PANDORID丑.

PANDORA INEQUIVALVIS, L.

FAM. LYONSIID王.

LYONSIA NORVEGICA, CHEM.

FAM. ANATINID庄.

THRACIA PRETENUIS (PULT.).

T. PAPYRACEA (POLI.).

T. PUBESCENS, PULT.

T. CONVEXA, WOOD.

T. DISTORTA (MONT.).

ORDER SEPTIBRANCHIATA.

FAM. POROMYID死.

POROMYA GRANULATA, NYST.

* * A List of the Classes, Orders, Families, and Species of the British Mollusea in conformity with this Appendix, but specially printed on one side of the paper only, for use as Labels for the Cabinet, is issued by the Publishers. Price One Shilling net. 


\section{N D E X \\ TO POPULAR NAMES}

ACtæon-SHELLS, 270.

Agate Snail, 379.

Alder's Slug, 300.

Alexia-shells, 308.

Amber Snails, 380.

Ark-shells, 64 .

Artemis-shells, 129.

Astarte-shells, 93.

Auger-shell, 240.

BASKET-SHELLS, 150.

Belted-shell, 234 .

Bladder-snails, 325.

Blind-shell, 240.

Breathing, 44.

Bubble-shells, 271.

Bulin Snails, 370 .

Bushy-backed Slug, 288.

"Butterflies of the Sea," 303.

Bithynia Snails, 233.

CANOE-SHELL, 272.

Carnivorous Slugs, 329.

Carpet-shells, 135.

Chink-shells, 225.

Chrysalis Snails, 371 .

Circe-shell, 129.

Cockles, 139; Fresh-water, 107.

Coin-shells, 103.

Conelets, 265.

Cowry, 245.

Crenella-shells, 73 .

Cuttles, 29, 389.

Cyprina-shell, 95 .

DOG-COCKLE, 65.

Dog-whelks, 257.
Door-shells, 374.

Double-tooth, 99.

EAR-SHells, 196, 309.

Elephant's-tusk, 180.

Eyes, 51.

Falmouth Slug, 302.

Fan Mussel, 77.

Feeding, 40.

File-shells, 87.

Flask-shells, 162.

Flat-coils, 319.

Fresh-water Cockles, 107.

Fresh-water Limpets, 309.

Fresh-water Mussels, 26, 114.

Furrow-shells, 122.

GAPERs, 148.

Garden Snail, 22, 364.

Glass Snails, 338.

Glutinous Snail, 318.

Gulf weed Slug, -287.

HATCHET-SHELLS, 98.

Hearing, 53.

Heart-Cockle, 96.

Herald-shells, 306.

Horn-shells, 238.

Horse Mussel, 70.

Hungarian Cap, 220.

KELLY-SHELLS, 101.

LAND-SLUGS, 328.

Land-snails, 347.

Lantern-shells, 175 .

Leda-shells, 59.

Limpets, 186, 220. 
Lobe-shell, 27.5.

Lucina-shells, 97 .

MAIL-SHELLS, 180.

Marbled Slug, 290.

Margin-shell, 243.

Montagu-shells, 99.

Moss Snails, 378.

Mussels, 27, 67.

NECKLACE-SHELL', 215 .

Nut-shells, 56 .

Octopus, 386.

Orb-shells, 108.

Ormer, 196.

Otter-shells, 152.

Oyster, 78.

PANDORA-SHELLS, 173.

Pearl Mussels, 111.

Pea-shells, 109.

Pelican's-foot, 241.

Periwinkle, 222.

Pheasant-shell, 207.

Pildocks, 163.

Poached Egg, 244.

Point-shell, 230.

Pond-snails, 311.

Purple, 254.

Pyramid-shells, 250.

RAZOR-SHELLS, 155 .

River Snails, 235.

Rock-borers, 138, 160.

Rock Venus, 137.

Round-mouth, 228.

SAddLe Oyster, 61.

Scallops, 81.

Sea Hare, 276.

Sea Lemons, 281.
Sea-nymphs, 289.

Sea-slugs, 276.

Sentinel-shells, 233.

Shell-bearing Slugs, 329.

Shell-forms, 32.

"Shillifillies," 238.

Ship-worms, 170.

skye Gaper, 177.

Slit-shell, 197.

Slugs, 328, 344 .

Smell, Sense of, 54 .

Spindle-shells, 252, 259.

Spire-shells, 231.

Squids, 393.

Sting-winkles, 253.

Sumset-shells, 145.

Swan Mussel, 26, 114.

Tellins, 119.

Tooth-ribbon, 42.

Top-shells, 200.

Touch, Sense of, 55.

Tree Snail, 373.

Triton-slugs, 286.

Trough-shells, 125.

Trumpet-snails, 319 .

URChIN SNAIL, 250.

VALVE-SHELLS, 236.

Velvet-shell, 219.

Venus-shell, 128, 130.

Violet-snail, 210.

WEASEL-EYE, 106.

Wedge-shells, 124.

Wentletraps, 212.

Whelks, 259, 261.

Wing-shell, 91.

Winkles, 222.

Zebra Mussel, 116. 

Whatas

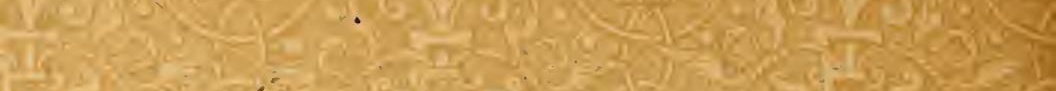

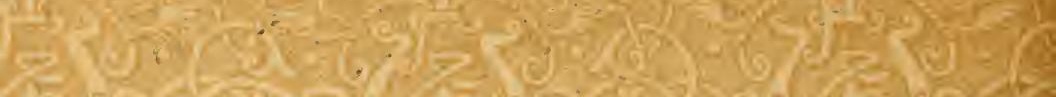

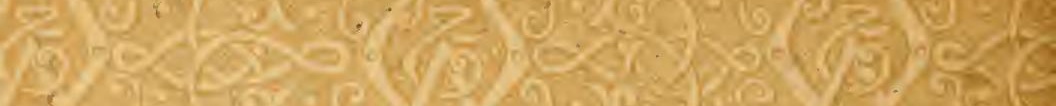

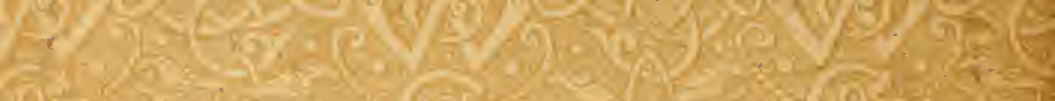

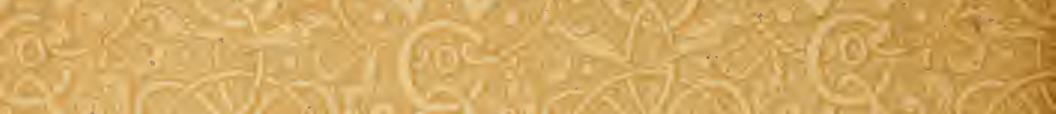

C.j

B

08

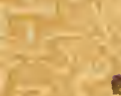

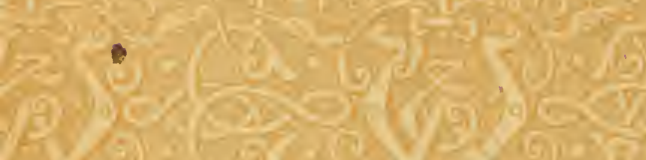

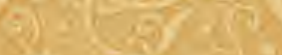

bxis

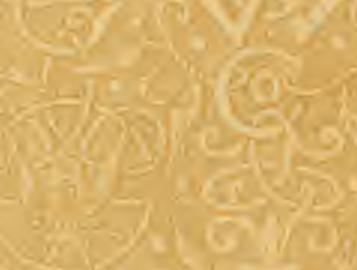

The

$3 x$

a.

S60.6)

政

tes? $\frac{1850}{280}=$

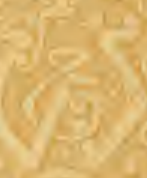

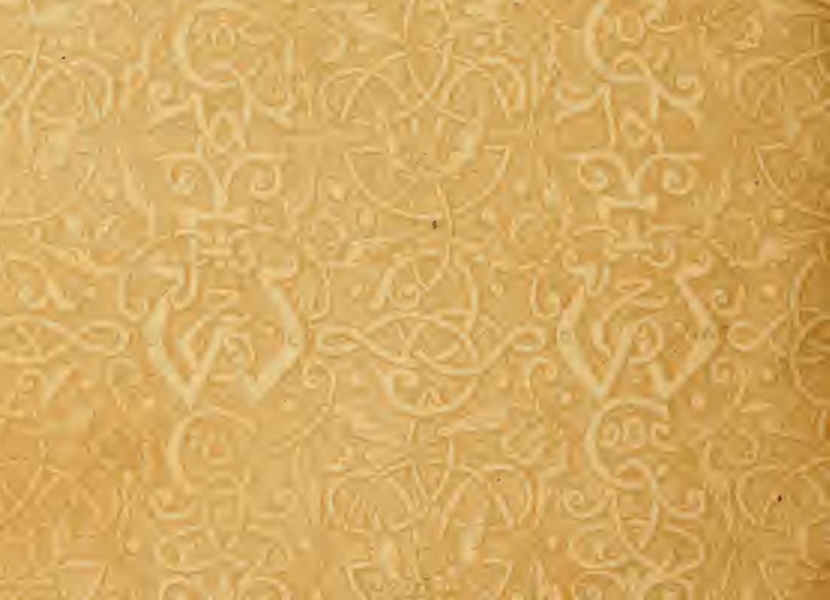

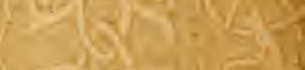

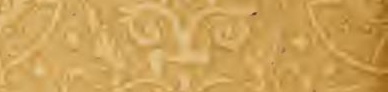
B)ing

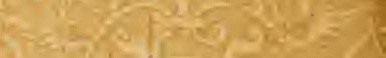

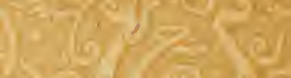
ajoly

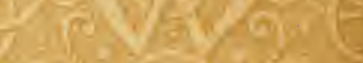

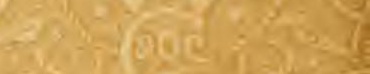
$80 y^{2}$ $6 y$ 8

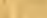

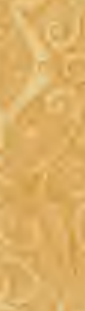

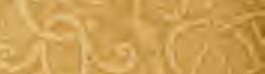

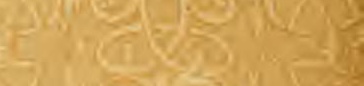

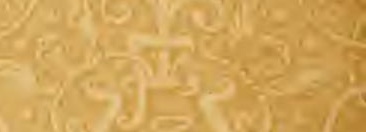
$\operatorname{lin}^{2}=8$ ex. 然

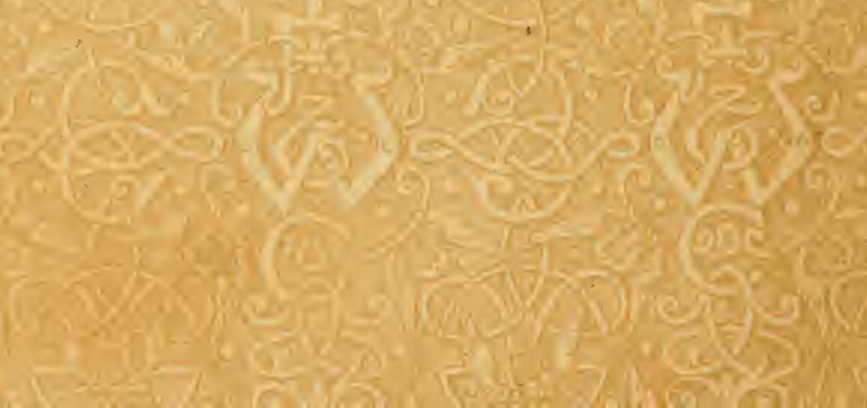


